\title{
Finding Sanctuary: The Occupational Choice of Animal Shelter Work
}

\author{
Anne O’Connor
}

In partial fulfilment of the requirements for the Degree of Doctor of Philosophy National University of Ireland, Maynooth

Department of Sociology

October 2016

Supervisor: Professor Seán O’Riain 


\section{Dedication}

In memory of my mother Eileen, (1930-2007), whose greatest wish, not an uncommon one for her generation, was that I should marry a Doctor. I wish you could know what I did instead, mo chuísle, mo chroí.

This thesis is also dedicated to animal shelter workers everywhere, past, present and future. 


\section{Declaration}

This is to clarify that this thesis is the original work of Anne O'Connor. The author is solely responsible for the content. Neither the thesis nor the original work contained therein has previously been submitted for a higher degree.

\section{Anne O’Connor}

$18 / 02 / 2017$ 


\begin{abstract}
This qualitative study examines the reasons why animal shelter workers choose this occupation, and why they remain, despite the sorrows and travails inherent in this work. This thesis makes an original contribution to knowledge in three domains. While the Human-Animal Studies (HAS) literature explains shelter entry as counterhegemonic and based on loving animals, my data provides evidence that these antecedents to occupational choice are insufficient. Instead, I find that my respondents' occupational choice is processual; multiple pathways, false starts, and changes in the life course combine to precede entry. Rich insights into the role of process in occupational choice exist in the gendering literature. However, although it is a gendered occupation, shelter work does not appear to be simply a culturally, gender-based choice. I have found evidence of similar processes leading to this choice amongst both male and female respondents, although the few males in my sample (which is reflective of shelter work more broadly) suggests that further research on this point would be valuable.
\end{abstract}

Second, the HAS literature on staying in shelter work focuses on emotion management strategies. While coping strategies are indubitably necessary in order to persist, to this insight I add a moral economy lens and the notion of sanctuary to explain why my respondents stay in this occupation. My respondents feel their occupation is part of a project of wider significance, and they are supported by some members of the public in this belief, by the 'moral economy of the crowd'. My respondents have found an alternative experience of the economy, one which is not isolated from, but embedded in their values and moral rationalities. Shelter work also offers sanctuary from the market economy and in animal care.

Third, I make an empirical contribution by producing unique data on shelter work in the Republic of Ireland, based on two years of ethnographic observations in seven shelters and one veterinary surgery, 24 semi-structured interviews, and an analysis of shelter social media. This study advances sociological theory in the area of occupational choice and promotes a re-visioning of the meaning and purposes of work under conditions of $21^{\text {st }}$ century capitalism. The findings in these pages also bring us a small step closer to understanding our complex, messy, and contradictory relationships with other animals 


\section{CONTENTS}

Declaration............................................................... i

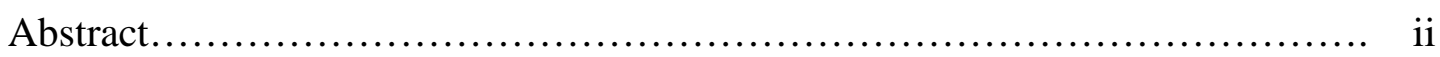

List of Figures and Tables............................................ viii

List of Abbreviations.................................................... ix

Acknowledgements................................................. $\mathrm{x}$

\section{Chapter 1 Introduction: The Occupational Paradox of Shelter Work}

1.0. Introduction and Background to this Study.............................. 2

1.1. Beyond Calling: Understanding the Choice of Shelter Work............ 5

1.2. Study Aims and Research Questions............................... 12

1.3. Methodological and Epistemological Approach...................... 13

1.3.1. Research Settings.......................................... 14

1.4. Conclusion and Chapter Overview................................ 15

\section{Chapter 2 Literature Review}

2.0. Introduction......................................................... 19

2.1. Occupational Choice........................................... 19

2.2. Human-Animal Studies (HAS)............................... 30

2.2.1. The Rising Significance of HAS in Sociology................... 31

2.2.2. Benefits of Animals to Humans: Animals in a Therapeutic........ 36 Context

2.2.3. Attitudes to Animals........................................ 39

2.2.4. Working with the Animal 'Other' $\ldots \ldots \ldots \ldots \ldots \ldots \ldots \ldots \ldots \ldots \ldots . \ldots 2$

2.3. Shelter Work: Calling or Moral Choice? ............................ 48

2.3.1. Moral Economy $\ldots \ldots \ldots \ldots \ldots \ldots \ldots \ldots \ldots \ldots \ldots \ldots \ldots \ldots \ldots \ldots, 51$ 
2.4. Sanctuary and Postmodernity

\section{Chapter 3 Methodology}

3.0. Introduction..................................................... 60

3.1. Preparation for Field Research and Learning from Conceptual Error..... 60

3.2. Ethical Review Process............................................ 62

3.3. Sampling Methodology......................................... 64

3.3.1. Research Settings....................................... 69

3.4. Data Collection: Interviews...................................... 71

3.5. Participant Profiles............................................ 77

3.6. Data Collection: Participant Observation.......................... 85

3.7. Approach to Data Analysis.................................... 88

3.7.1. Ethnography as Methodological Approach to Analysis............. 90

3.8. Social Media Analysis............................................. 98

3.9. Chapter Summary ............................................... 99

\section{Chapter 4 Organisational Field}

4.0. Introduction............................................... 102

4.1. The Legislative Platform: The -Animal Welfare Act 2013........... 103

4.1.1. Control of Horses Act 1996.............................. 106

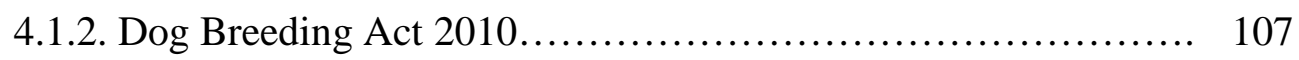

4.2. The Department of Agriculture, Food and the Marine (DAFM)..........108

4.3. ISPCA and the Pound System....................................109

4.3.1. Dog Pound Controversy: The Case of ACS.................. 112

4.3.2. DSPCA............................................... 116 
4.3.3. Other SPCAs

4.4. Dogs Trust

4.5. Other Shelters

4.6. RSPCA Guidelines.

4.7. Shelter Social Media Self-Presentation and Fundraising Activities 123

4.8. The Labour Market: Central Statistics Office........................... 125

4.8.1. Barriers and Enablements to Occupational Choice............... 125

4.9. A Day in the Life of a Shelter Worker........................... 126

4.10. Chapter Summary........................................... 130

\section{Chapter 5 Pathways to Entry: Making Sense of the World}

5.0. Introduction.................................................... 132

5.1. Choice Within the Organisational Field of Shelter Work ............. 134

5.2. The Dog that did not Bark: Calling................................. 135

5.3. Antecedents of the Occupational Choice of Shelter Work.............. 136

5.3.1. Early Experience with Animals and in Rural Settings............ 141

5.3.2. Social and Demographic Characteristics as Determinants........ 142

5.3.3. Gender, Class and Care Work............................... 144

5.3.4. The Influence of a Significant Other.......................... 148

5.3.5. Negative Influence of Significant Others or.................... 149 Socio-Cultural Milieu

5.4. Pathways to Occupational Entry.................................. 156

5.4.1. A Sudden Change in the Life Course.......................... 156

5.4.2. Alienation from Alternative Workplaces Leading to the.......... 158 'Moral Choice'

5.4.3. Unintended Choices: Epiphanic or Serendipitous Experience...... 164

5.4.4. Becoming a Volunteer..................................... 166 


\section{Chapter 6 Shelter Work: Part of the "Moral Economy of the Crowd"?}

6.0. Introduction......................................................... 170

6.1. Sorrows.................................................... 174

6.1.1. Broader Societal Institutionalised Cruelty towards Animals...... 175

6.1.2. Non-normalised Cruelty or Neglect Cases..................... 178

6.1.3. Euthanasia of Shelter Animals............................... 181

6.2. Travails................................................... 183

6.2.1. Dealing with the Public: Direct Interaction..................... 183

6.2.2. Dealing with Staff and with Other Shelters................... 186

6.2.3. Financial Strains and Constraints............................ 187

6.2.4. Lack of Personal Time and Money.............................. 188

6.2.5. Injury or Zoonotic Diseases................................ 189

6.2.6. Reconciling Contradictory Positions towards Animals........... 190

6.3. Consolations..................................................... 193

6.3.1. Moral Economy: Helping Animals, Helping People............. 194

6.3.2. Helping Animals......................................... 194

6.3.3. Helping People............................................ 195

6.3.4. Public Recognition...................................... 197

6.3.5. Public Help.......................................... 197

6.4. Joys: Animals, Moral Economy, Sanctuary....................... 198

6.4.1. HAR Rewards: for the Love of Animals...................... 198

6.4.2. Animal Shelter Work: Moral Work? ......................... 200

6.5. Facebook Thematic Analysis on Sorrows, Travails, Consolations....... 205 and Joys

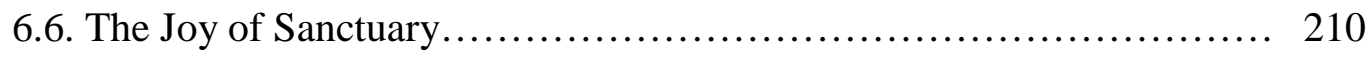


Chapter 7 Concluding Words on Shelter Work: The Best Job in the World?

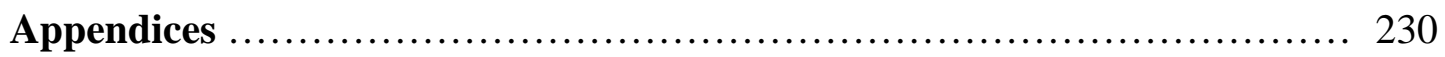

Appendix A...................................................... 231

Appendix B............................................................. 232

Appendix C.............................................................. 233

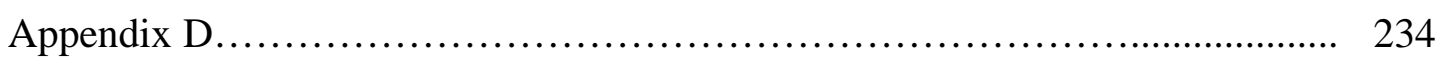

Appendix E....................................................... 235

Appendix F..................................................... 236

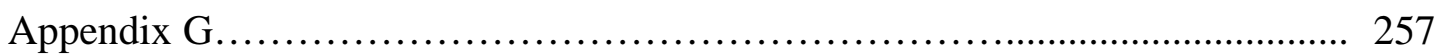

Appendix H........................................................... 258

Bibliography........................................................ 264 


\section{List of Tables and Figures}

Table 3.1. Research Settings............................................. 70

Figure 3.1. Information Sheet for Interview Participants..................... 74

Figure 4.1. Inspectorate Area Map.......................................... 110

Table 4.1. Official Pound Statistics $2004-2015 \ldots \ldots \ldots \ldots \ldots \ldots \ldots \ldots \ldots \ldots \ldots \ldots \ldots \ldots \ldots$

Table 4.2. Official Pound Statistics (Greyhounds) 2010-2015.................. 115

Table 5.1. Loving Animals.......................................... 138

Table 5.2. Pathways to Entry....................................... 152

Figure 5.1. Do You Know Why Your Dog is Happier than You?......................... 163

Table 6.1. Dialectical Tensions in Shelter Work............................. 174

Figure 6.2. "Who Rescued Who?”.................................... 210 


\section{List of Abbreviations}

AAT: Animal-Assisted Therapy

ACS: Animal Collection Services

AHSG: Animal/Human Study Group

ANT: Actor-Network theory

DAFM: Department of Agriculture, Food and the Marine

DSPCA: Dublin Society for the Prevention of Cruelty to Animals

HAI: Human-Animal Interaction

HAR: Human-Animal Relations

HAS: Human-Animal Studies

ISAZ: International Society for Anthrozoology

ISPCA: Irish Society for the Prevention of Cruelty to Animals

PTS: Put to Sleep

QC: Quality Control

SNA: Special Needs Assistant

TNR: Trap, Neuter, Release

UCD: University College Dublin

VPI: Vocational Preference Inventory 


\section{Acknowledgements}

Special thanks to Professor Arnie Arluke, whose ground-breaking work set me on this path, and who was extraordinarily generous with advice from outset to completion. I am grateful to Dr. John Cullen for his enthusiasm for this study at its embryonic stage, and for never once making me feel stupid at a time when I knew more or less nothing. Thanks to Paul Geraghty for finding the apposite Beston quotation and for much else besides.

I would like to thank Dr. Rebecca King-O'Riain for her superb organisational and teaching skills, and for opening the perspective-altering world of Sociology to me. Thanks to Dr. Brian Conway for insightful reading suggestions early in my study. Thanks to Dr. Eamon Slater for encouraging me to actually go into the field, rather than reading about it, as is my wont. Deep thanks to my supervisor, Professor Seán O'Riain, for his erudition and kindness. I count myself extremely fortunate for having studied under his tuition, and I will be grateful for his expert guidance all my life.

Thanks also to Dr. Peter Murray from whose comments my draft greatly benefitted. Thanks to Professor Mary Corcoran for her perspicacious comments on my draft, and for putting me at ease during my viva voce examination. Thanks to my External Examiner, Dr. Rhoda Wilkie, for her commendably close reading and helpful remarks.

Thanks to my Head of Department, Mr. Martin Meagher for his support, and for kindly accommodating my study-related leaves of absence from work. I also thank the Institute of Technology Carlow for financial support with my tuition fees, and all my kind colleagues, especially Gina Noonan, Dara McHugh, Claus Derenda, Annette Holden and Caroline French who put up with me breaking the office photocopier with reliable regularity. Thanks also to Ann Marie Byrne in Reprographics, who always retained her cheerful good humour, despite the tasks I invariably brought with me.

I thank my sister Maura O’Connor for her financial and emotional support, uncle Tommy Doyle, Auntie Kathleen Doyle and all the Doyle clan, most of all Terry, and all my friends, especially Alison Hearne, Dr. PJ White, Elinor Mountain, Grá O’Connor, Ella Lovett, Maeve O’Shaughnessy, Dee O’Connor, Jane Barry, Annette Murphy, the late and much-missed Michael Massey, Dr. Mike Watts and Fran Watts and others for all their love and support despite my relative absence from their lives during my study.

Finally, thanks to Dr. Karl Woods, my great love, for his unconditional intellectual, emotional, technical and financial support, and for being able to make me laugh if the roof blew off. What 'a big lucky' we had baby. 
Chapter 1 


\section{Chapter 1 Introduction: The Occupational Paradox of Shelter Work}

For the animal shall not be measured by man. In a world older and more complete than ours, they move finished and complete, gifted with the extension of the senses we have lost or never attained, living by voices we shall never hear. They are not brethren, they are not underlings; they are other nations, caught with ourselves in the net of life and time, fellow prisoners of the splendour and travail of the earth (Beston, 1928: 19).

\subsection{Introduction and Background to this Study}

This study took root with a misapprehension under which I laboured for some time. I have volunteered for many years at various animal shelters, both in a fundraising capacity, and as a dog-walker. In 2007, I 'rescued' a stray pitbull-lurcher crossbreed and brought him to a local Dog Pound; the sign above the door states that the organisation is a 'Dog Shelter'. He was a large but severely undernourished dog who was affectionate and gentle. When I called the Pound to inquire about him the following day, I learned that he had been 'put to sleep' as he was deemed unsuitable for re-homing. At that time I did not realise that dogs were routinely euthanized in the Pound system in Ireland. Nor was I aware that large, black dogs are frequently euthanized as they are not popular with the dog-adopting public. My published poem 'Hammerhead' (see Appendix A) was a reflection on that experience, and more broadly on our contradictory and ambivalent relationships with other animals.

In the same year, I adopted one of my own dogs from the same Pound and increased my volunteering activities at a local dog shelter. My thinking about shelter work was already - albeit unknowingly - beginning to take a form into which the 'melted metal' (Bauman, 2014: 2) of my empirical data would later be poured. As an occasional volunteer, I could drop in and out, and scale back on my contribution at particularly busy times at work. Further, volunteers are not usually asked to do tasks such as cleaning kennels and an offer to do so is - and was - usually politely declined. I became increasingly intrigued by shelter workers and dedicated volunteers. 
The question arose in my mind as to why people would choose to work in animal shelters. What shared frame of reference drives people to intertwine their work lives with the lives of abandoned animals? ${ }^{1}$ These jobs do not pay well - even for 'handsoff' CEOs in larger shelters, salaries are substantially less than in the private sector (Interviews, 2014) - they do not confer status, they are often physically demanding. They exemplify the notion of "dirty work", the term invoked by Hughes (1958) to describe occupations that include disgusting or degrading elements (pus, faeces, urine, and sometimes euthanasia in the case of shelter work).

Is it that people who choose to enter shelter work do so simply out of a deeply held passion or love for animals? Certainly, even a cursory reading of social media sites used by animal shelters themselves would appear to confirm such a proposition: here love is a frequent justification for action as well as a vocabulary in common use. But then how can one reconcile such affective sentiments with the ineluctable decision to euthanize animals? In 2014, 2,986 dogs were euthanized in Pounds in the Republic of Ireland or $20 \%$ of the dogs seized or surrendered (Department of the Environment, 2015). Although the Irish euthanasia rate is significantly higher when compared to our closest neighbours ${ }^{2}$, it was even higher in the previous decade. In 2004, 68\% of stray dogs were 'destroyed' (the term used until that year) in Irish Pounds (Department of the Environment, 2015).

I am drawn to people who work on behalf of stray or abused animals. My particular sympathies are transparent and I do not consider it intellectually desirable to hide

\footnotetext{
${ }^{1}$ I am sensitive to the nomenclature 'nonhuman animals'. Terminology is important because the way we speak about animals is "inseparable from the way we think about them" (Dunlayer, quoted in Wilkie, 2010: 124). Indeed, Shapiro (quoted in De Mello, 2012: 15) observes that the term 'humans and animals' is analogous to the term 'carrots and vegetables'. For the sake of simplicity, I employ the term 'animals' to denote nonhuman animals throughout this dissertation. Likewise I substitute 'shelter' for 'animal shelter'.

${ }^{2}$ There are no similar local authority statistics for Scotland. However, Dogs Trust commission an annual survey of local authority dog wardens and environmental health officers, in order to determine what happens to stray dogs in the UK (Dogs Trust Summary Report, 2014). In 2014, an estimated 3\% of dogs were put to sleep in Scottish Pounds (Dogs Trust Summary Report, 2014). This is a striking difference, given that Scotland is of comparable size and population to Ireland. $7 \%$ of dogs were put to sleep in Pounds across the UK in the same year. The UK figures represent a $90 \%$ response rate but all figures were grossed up to represent $100 \%$ of authorities (Dogs Trust Summary Report, 2014).
} 
them. It was this and my curiosity about the apparent contradictions or tensions inherent in the role that led me to embark upon this study. Shelter work offers much to capture the imagination, not least the blurring of ontological lines between humans and other animals to which one bears witness in that environment. In the shelters I observed how the human-animal hierarchy, elsewhere taken for granted, melts away, and how moral dignity is afforded to the animals. Shelter work falls outside the individualistic, neoliberal ${ }^{3}$ paradigm - of course career individualism predates neoliberal ideology - of what constitutes career 'success' and one cannot easily account for its selection as an occupation through Rational Choice Theory. ${ }^{4}$ Becker's (2016) Human Capital Theory, which points to the inseparability of people from their knowledge, skills, and values is arguably more apt for my shelter respondents.

In 2012, anecdotal reports given to me by shelter staff in my early forays into the field suggested that their work was a passion. The Irish Veterinary Nurses' Association (IVNA, 2011) website describes working in animal care as a devotion. 'Passion' and 'devotion' are quasi-religious terms which suggest a zeal that was reminiscent of a 'calling'. So it was that in the initial stages of my research I became increasingly certain that 'calling' was the answer to the questions my encounters with shelter workers had raised in my mind. Although the literature on work callings revealed a polyglot of definitions (Wrznesiewski, 1997; Dobrow, 2007; Bunderson and Thomson, 2009; Duffy et al, 2011) the commonalities that exist (otherorientation, a deontological sense that one 'must' do the work, a wish to serve the common good) seemed to have resonance for shelter workers. However, as my study progressed, it gradually became clear to me that this was the greatest misapprehension under which I was labouring.

While there are Weberian elements to this occupational choice, experiencing a 'calling' to animal care was rejected by almost all of my respondents. Even where

\footnotetext{
${ }^{3}$ In using the term 'neoliberal' here, I refer to a prevailing economic and political ideology which dictates that the best way to maximise efficiency and economic growth in society is to give primacy to the free market in human affairs, with minimal State invention.

${ }^{4}$ Most of my respondents had held better-paid jobs and so, in conventional terms at least, shelter work represented a downward mobility.
} 
the vocational aspect of the job was acknowledged, this was retrospectively constructed and not an antecedent to occupational choice. I expected otherwise for reasons I explain in the next section. That said, my labours were not entirely in vain; in discovering that my belief in 'callings' as a basis for the occupational choice of shelter work was a misapprehension, I was eventually able to frame a formal research question that reflected the actual trajectory of my research and, consequently, to challenge some preconceived ideas, my own included, about why people might choose such a career. What I discovered was found in interactive dialogue with my participants as well as through my own ethnographic observations, and my interpretations thereof.

\subsection{Beyond Calling: Understanding the Choice of Shelter Work}

The current study is situated in the interstices of three bodies of literature: HumanAnimal Studies (HAS), occupational choice theory, and moral economy. Clearly, a study of shelter work is deeply connected to the broader HAS domain of intellectual inquiry, and within that literature, to the literature pertaining to working with animals. My initial sense of wonder that people would freely choose such an onerous, low-paid, emotionally demanding job, places the study in the field of occupational choice theory. During my first, informal forays in the field in 2012, I was struck by how often people told me that they 'felt good' about themselves as a result of their work, that they felt their work 'matters', and makes 'the world a better place for animals'. Secondly, they often compared their work favourably with other jobs (in factories, offices, in the Irish Civil Service) they had held. In my mind, these informal conversations began to recall Polanyi’s (1957) warnings about the dangers of commodifying land and labour, as well as Thompson's (1971) seminal essay on the "moral economy of the crowd".

In the rest of this section I give a brief overview of the scope and sweep of the HAS, occupational choice, and moral economy literature. This literature is reviewed in

depth in Chapter 2. My three central research questions arising out of this literature are then laid out.

Though the activities of shelter workers are invisible to many members of the public, shelters are part of society and should be understood within a sociological 
framework. Abandonment or abuse of companion animals is a societal problem, dealt with by shelter workers, with wider support. The failure of some members of the public to neuter their companion animals, as well as backyard 'puppy farming' (ISPCA, 2015) in Ireland constitute societal problems which largely fall to shelter and Pound workers. Shelter workers' stories thus tell us something about society, and about ourselves, as Arluke and Sanders (1996: 4) observe. The HAS literature matters for this study because of the specific nature of human-animal relations, which may influence occupational choice. Zelizer's (2012) concept of relational work also highlights the often-overlooked role of emotions in economic exchange, as an alternative to rational action theory in economic sociology.

However, HAS is not a thriving research domain in Ireland. To the best of my knowledge, at the time of writing, there is only one other doctoral student undertaking research in this area, and her thesis is on Equine-Assisted Therapy.

Despite Bryant's (1979) evocative appeal to Sociology to consider the "zoological connection", the role of animals in society has seemed a theme Sociology has been reluctant to embrace. I find this sociologically curious, given that animals have been enmeshed in the social since human society first emerged. Various reasons for this absence have been advanced by Shapiro and De Mello (2010) such as the inherent conservatism of the Academy, dearth of funding opportunities for HAS research in the Social Sciences, and perhaps an indicator of our deeply ambivalent attitudes towards other animals. 'Some we love, some we hate, some we eat', as Herzog's (2011) eponymous book frames the issue.

Nonetheless, in recent decades a growing number of sociologists and psychologists have produced many fascinating explorations of human-animal relations (Arluke and Sanders, 1996; Alger and Alger, 2003; Harbolt, 2003; Irvine, 2004; Taylor, 2007; Wilkie, 2010; Herzog, 2011; Pachirat, 2011; Hamilton and Taylor, 2013). Three important strands in the HAS literature are: the importance of HAS for sociology in advancing social theory, the psychosocial benefits of animals for humans, and working with animals.

In this thesis I draw a distinction between antecedents that predispose people to care about animals and those that lead my respondents to care for animals in the 
quotidian reality of the shelter. I critique the very notion of choice. Many of the former antecedents are present in my own life course. I grew up near a farm and spent many happy summers of my childhood and early teens in social contexts that involved the company of farm and companion animals - kittens and cats, dogs, calves, peacocks - a context that was similar to what Arluke and Rolfe (2013) have termed a "peaceable kingdom". As a child, my favourite books featured animals. These included: Anna Sewell's Black Beauty, Alf Wight's stories under the pseudonym James Herriot, and Orwell's Animal Farm (though its political message was entirely lost upon my ten-year-old self, I felt huge empathy for the plight of the workhorse Boxer, who was so cruelly exploited by the 'more equal' pigs). Pallota (2008) finds evidence that children sometimes resist the massive power of socialisation regarding dominant norms of consumption. I resisted eating meat from the age of about ten, though I did not become vegetarian (more accurately pescatarian, as I document in Chapter 6, and which I am now reviewing, as I explain in the conclusion to this thesis) until I left home to pursue Third-Level studies. Yet despite experiencing similar antecedents to those given in HAS literature as an explanation - if antecedents are mentioned at all - for the occupational choice of shelter work, I have never considered entering a zoocentric occupation. Similarly, I will demonstrate how, for my respondents, early exposure to animals ignited caring about animals, but does not explain caring for animals in work. Such exposure formed part of the recipe for entry to the occupation, but not the whole.

My data suggest that 'loving animals' is not all that is happening in this occupational choice. The specific nature of human-animal relations influences my shelter respondents' decision to remain in this occupation. However, I find that a complex interplay of processes combine to lead my respondents to the world of the shelter, a world most of them claim they can now never imagine leaving. Although Harbolt (2003) does advance having experienced institutional or interpersonal oppression as a reason for entry, and Taylor (2007) counter-hegemony on the part of the shelter workers, my data does not reflect these themes as being critical. Instead, alienation from alternative experiences of the market economy, the shelter as moral alternative, and as sanctuary emerged as three of the central reasons for entry and staying. 
The discursive landscape of the career paradigm has recently been extended to include study into work callings (Wrzesniewski, 1997; Dobrow, 2007; Bunderson and Thomson, 2009) which tends to conceptualise callings as an expression of the deepest self in work (Bellah et al 1995; Novak, 1996; Bunderson and Thomson, 2009) or as a transcendent summons that holds other-oriented values (Duffy et al 2011) or more prosaically, a subjective orientation towards a particular goal (Hall and Chandler, 2005). Although there are commonalities in the prevalent definition of callings, there remains confusion about what the concept means in the contemporary workplace.

Wrzesniewski's much-cited (1997) article is a signal contribution to the literature on callings and constitutes perhaps the clearest categorization of job, career, and calling. For Wrzesniewski (1997), a job orientation is characterised by a focus on financial rewards or necessity, a career is geared towards personal advancement. A calling however, encapsulates the enjoyment of socially useful work (Wrzesniewsk, 1997). Elangovan et al (2010) go somewhat further. These scholars argue that the person with a calling feels that they must do something about it, and tend to define themselves by what they do. Of this deontological viewpoint, Crawford (2009: 201) observes: "Obligation to others is the claim made on us by various systems of universal ethics. It has a dreary quality to it, like a summons for jury duty [..] By contrast, solidarity with others is a positive attraction, akin to love”.

Berg and Grant (2010) also define the contours of a calling with reference to the common good. They further point out that the religious connotations of callings have complicated efforts to arrive at a single secular definition (Berg and Grant, 2010). Of course, as Fromm (1997: 110) highlights: "religion does not necessarily have to be concerned with a God but can apply to any group-based system of thought and action that offers an individual a frame of orientation and an object of devotion" (Fromm,1997: 110). Bunderson and Thomson's (2009) and Baran et al (2012) study of zookeepers and shelter workers encouraged me in my early theoretical assumption that my respondents would report feeling their work was a vocation. Bunderson and Thomson (2009) found evidence that zookeepers experience their work as a calling in a deontological, or in what Bunderson and Thomson describe as a 'duty-bound' way. Although Baran et al (2012) do not explicitly refer to a calling, the "silent 
shouldering” of the burdens of shelter work also speaks to this concept. Some of my workers may have come to understand their work as a calling, once they were doing the work, but my processual analysis allows us to see a different process at work.

As I extrapolate in Chapters 5 and 6, in the main my respondents did not enter or stay in shelter work for this reason. At least they do not report feeling 'called' as an original impetus to entry, nor do most feel their work is enjoyable because socially useful, as Wrzesniewski (1997) predicts. Instead a host of other factors such as alienation from former workplaces and serendipitous experiences paved the way to shelter work for my participants. Nonetheless, the literature on callings - in particular Dobrow's (2007) and Conklin's (2010) respective work on musicians and ecoworkers, as I will discuss in Chapter 5 - retains some explanatory power for their career choices.

So how are we to understand shelter work? How do we make sense of it within the economic and political context of a larger (state and world) order that frequently relegates animals to moral insignificance? I next turned to the occupational choice literature for answers.

The early occupational choice literature has tended to focus on factors such as parental influence or limiting social and economic factors (Blau et al, 1956), an individual's psychological traits (Holland, 1973), or the sequence of roles a person plays over the span of a lifetime (Super, 1980). As noted in the introduction, occupational choice theory has largely been subsumed into the gendering literature which contains a wealth of insights into how preferences arise, not out of thin air, but through formative cultural and social influences (Nussbaum, 2000). 'Feminine' qualities such as empathy and nurturing are argued by Crompton (2006: 256) to be disadvantageous in 'masculine' organisational contexts. While shelter work is feminized, my data does not 'fit' the thesis that gender is the principle, or even a centrally important factor in my respondents’ occupational choice. Certainly, gender is important, but it is not the only point of vantage. My female respondents report having disliked 'masculine' work in capitalist organisations, but so too do my male respondents. 
18 out of my 24 respondents are female (one respondent is a male veterinary surgeon, and one a female Special Needs Assistant for children on the autistic spectrum, and with other physical and mental disabilities), which suggests that this occupational choice is gendered. Four out of the six male respondents are, or had been CEOs of their respective organisations, which does of course reflect themes about gender-based occupational choices (Pilgeram, 2007; Irvine, 2010; Lupton, 2000). Nonetheless, gender is not my primary focus in this thesis, in fact, my data challenges the assumption that women work - or volunteer, as almost all of my respondents did prior to occupational entry - in shelters because of restricted cultural or gender-based choices. Most of my female workers are enabled to do their job because of familial or partner support, or simply because they are not very concerned with pecuniary rewards. My few male respondents have other enablements, such as retirement and financial security, or as in the case of Colm, who is a 26 year old zoologist, say that they are equally not motivated by money (see Participant Profiles, Chapter 3).

Moreover, the gendering literature, including Irvine’s (2010) article on veterinary surgeons, often assumes that women have to either preserve hegemonic masculinity in male-dominated occupations or 'settle' for 'feminine' occupations (Crompton, 2006). Far from feeling oppressed or repressed, my respondents, male and female, are enabled by various circumstances (see Chapter 5) to do work that they love, rather than work they actively disliked. In that sense, quite 'conventional' gendering has allowed my respondents an escape from the 'career trap' arising out of a need to maintain high mortgage repayments or accumulate branded consumer goods. These findings are broadly compatible with some feminist analyses (Crompton, 2006). I do find the emphasis on 'choice' and 'processes' in the gendering literature very valuable in my analysis of the repertoires within which my respondents choices were enabled or constrained, and of the processes of occupational entry and staying.

Even if shelter work is not a 'calling' that does not mean that it is an entirely rational, amoral choice. In fact, I argue that the whole process occurs within a 'moral economy' of human-animal and human-human relations. It was my respondents who led me to the moral economy literature. Their comments on "meaningless" jobs they had previously held in "cooped-up” offices, which they 
contrasted unfavourably with shelter work, were striking. At an early stage of analytical work, I used the term 'disenchanted' or 'disillusioned' to describe my participants' feelings about former workplaces. However, I came to the conclusion that these were inaccurate terms, as they were not 'enchanted' or full of 'illusions' in the first place. I thus employed the term 'alienation', in the sense that my respondents' stories describe feeling alienated from the work that they did, from the activity, and from the structures determined by those organisations. Polanyi (1957: 262) reminds us that people are agentic and resist the corrosive effects of market logic. Polanyi (1957) maintains that the concept of economic rationality is specific to a particular place and time, and that people act less out of a desire to possess material things, than out of a desire to safeguard their social relationships (Polanyi, 1957: 46) an argument taken up by Engster (2006). My respondents have found an alternative experience of being in the economy, in which they flourish (Bolton et al 2012), despite the many sorrows and travails this work entails. The conventional, neoclassical definition of the economy employed by academic and professional economists divorces it from both culture and from other areas of social life. The substantive definition is broader in its application; the economy is not disembedded from other areas of social life such as kinship or values (Polanyi, 1957). My respondents are socially motivated to act in the interests of animals, rather than out of supposedly rational, economic self-interest. They are united in a common cause; saving animals. I was also cognizant of the picturesque rural settings of all but one of the shelters. In this way, shelters resemble the harmonious ${ }^{5}$, pre-modern Gemeinschafte. This is arguably a romantic idea, but it is a thesis my data upholds.

The importance of the wider public support for shelter work (see Chapter 4, Animal Collection Services case study) is evident on the social media sites that shelter organisations use, and in the workers' personal accounts. This recalls Thompson's (1971) arguments about the "moral economy of the crowd" and the notion of legitimacy. By legitimation, Thompson (1971) is referring to people's defence of traditional rights or customs against the inexorable logic of the market. In Chapter 4, I outline a recent controversy about the proposed transfer of the running of a Dog

\footnotetext{
${ }^{5}$ Though intra-shelter harmony does not necessarily prevail, as I document in Chapter 6.
} 
Pound from a non-profit, welfare organisation to a private, profit-making organisation. This controversy exemplifies Thompson's (1971) thesis because it shows how significant collective understandings and actions can be when it comes to resisting commodification of social realms traditionally seen as outside the logic of market imperatives, in this case the rescue and care of companion animals.

Seven of my 22 shelter respondents are volunteers and therefore unpaid, although most receive benefits in kind, such as the private use of a SPCA vehicle.

A prolonged engagement with these three domains led me to formulate three central research questions. This I did in light of the lack of empirical data on, and theoretical understandings of shelter work in Ireland.

\subsection{Study Aims and Research Questions}

The overarching aim of this study is to make a contribution to what Wilkie (2015) terms "animalising social life", to further unveil the human/animal distinction as being neither clear nor immutable, a phenomenon Bourke (2011: 9) calls the “Möbius strip”. The Möbius strip, named after the $19^{\text {th }}$ century mathematician, is a rectangular strip of paper, twisted at one end by 180 degrees, and glued to the other end. So there is "no beginning or end, no single point of entry or exit" (Bourke, 2011: 10). True, animals’ worlds are ordered instinctually and olfactorily. We call the shots, but animals share the world with us. Therefore, I too challenge the anthropocentric assumption that 'the social' equates to the human.

Specifically, my study aims to make a contribution empirically by producing data about the work lives of shelter workers in Ireland. My study expands our theoretical knowledge of Occupational Choice theory by adding a processual dimension to the reasons for entry, and by distinguishing between entry and staying as two separate processes. I add to our knowledge of HAS by adopting a moral economy perspective to the reasons for staying in this work, and by using the overarching concept of sanctuary as an explanatory device, as I describe in depth in Chapter 2.

There are three core research questions:

1. How are the choices of ostensibly 'bad' - in term of pay, status, working conditions - jobs to be understood? 
2. What is specific to Human-Animal Work in the choice to enter and remain in shelter occupations?

3. How are choices structured through repertoires of choice, the entry process, and the process of staying?

I now turn to a brief discussion of how I attempted to answer these questions.

\subsection{Methodological and Epistemological Approach}

I adopted an ethnographic approach, informed by a symbolic interactionist paradigm. From this perspective, social structures are deemed to be the product of intersubjectively determined meaning, and always under symbolic construction. Symbolic Interactionism (Blumer, 1969) has three central premises: first, people act toward things on the basis of the meaning that 'thing' (in this case an animal) has for them; second, this meaning is derived in social interaction with one's fellows; third, these meanings are mediated through a series of interpretative processes. Blumer (1969) advocates getting close to the area of study and digging deep. Many humananimal interaction (HAI) studies (Arluke and Sanders, 1996; Sanders, 2003; Taylor, 2007) adopt an interactionist approach.

My study participants were observed in their work settings, in interaction with the animals in their care. I believed participant observation was particularly important in order to study shelter work, where the ethnos is not restricted to the human. I attempted to make sense of the phenomena observed in terms of the meaning the participants bring to them. I also tried not to impute motives to my respondents, rather to honour their own words. I understand the production of knowledge to be an inter-subjective, relational process between researcher and researched, and the resultant knowledge to be partial and situated.

Hamilton and Taylor (2012) argue that ethnography is ideal for the purposes of studying HAI. I employed three methods of ethnographic data production: participant observation, semi-structured interviews with 24 participants (22 shelter workers/volunteers, one veterinary surgeon, and one Special Needs Assistant (SNA) for children with a wide range of physical and mental disabilities) and analysis of Shelter Social Media. Of the 22 shelter workers, six were male and 16 female. 
I took field notes immediately after each field visit, in order to preserve the immediacy of the encounter. I felt that scribbling notes in their presence would have been off-putting for my participants, and might therefore have changed their behaviour in some way.

Finally, I analysed properties of contemporary social media of the shelters for their ideological content. Social media is of crucial importance to all the shelters in this study, both as a means of producing and reproducing their view of animals as being of moral import, as well as a tool to elicit public support, to build and draw upon the moral economy of the crowd. This support can take the form of adopting or fostering animals, fundraising, or making donations. Mumby (1988: 110) observes that where narrativity is present in any account of reality, we can be sure that a "moralizing impulse” is present too. Shelter social media postings abound with such narratives, as I will demonstrate in Chapter 6 (see also Appendix F).

This triangulation of methods (participant observation, interviews, and social media analysis) attempts to paint a more complete picture of the phenomena under investigation. The research settings are outlined in the next section.

\subsubsection{Research Settings}

I studied empirical situations beyond shelters. Participants were drawn, using a snowball sampling method, from seven shelters, one Dog Pound, and one veterinary surgery. Large and small shelters (which represent the dominant modes of animal welfare organisation in Ireland) are included. I explain my sampling methodology in detail in Chapter 3. I was also alert to human-animal interaction (HAI) during my daily walks with my own dogs, and to people's dietary choices (on social media, for example). When the context changes, the construct of the 'animal' changes. My own private Facebook page is a study in contradiction. I have vegan friends who regularly 'post' images of animal suffering under conditions of industrial farming, together with pleas for clemency: 'Vegan, because I have no rights over anybody else's body'. As I lived and worked in Hamburg in the early 1990s, my German friends often post photographs of open air barbeques in their gardens, accompanied by captions such as, “lecker!” (tasty). 
I elected to interview respondents from a wide range of settings, in order to extrapolate my findings across a range of species. Some of the shelters take in mainly cats, or dogs, or donkeys, while others care for many species. All of the shelters in this study care predominantly for one species however. I immersed myself most in shelters A (no holding facilities) E, a large all-species shelter, and $\mathrm{H}$, a mainly dog-shelter. I chose these settings partly because of geographical proximity (I lecture fulltime, so time was a constraint in this study) but also I had long involvement with Shelter $\mathrm{A}$ as a volunteer, and because shelters $\mathrm{E}$ and $\mathrm{H}$ deal with a very high number of cruelty and abandonment cat and dog cases, up to 60 and 120 respectively at any one time. I hoped to enrich my findings through the resultant insights into the difficulties faced by this cohort of workers.

I participated in the daily work activities in all of the settings. I walked dogs, cleaned cat litter trays when allowed to do so, fed donkeys, and undertook volunteer orientation training in one organisation. I was given permission to 'sit in on' veterinary client consultations at one surgery. Access was not entirely unproblematic however, and I endured some setbacks during the research process as I explain in Chapter 3.

\subsection{Conclusion and Chapter Overview}

In this chapter I have introduced the analytical framework which guided this study. I explained how my deep interest in animal shelter work began and developed over time. I gave an overview of some of the relevant literature from which my research questions eventually emerged. I have laid out what I hoped to achieve in this study, and how. The processual nature of the occupational choice of shelter work and the moral rationalities which help my respondents bear its sorrows and interpret its joys are under-scrutinised in the HAS literature.

This study makes a contribution to our knowledge of the pathways to entry to animal shelter work, which turned out to be a far more winding, processual road than merely a direct consequence of loving animals. I also add moral economy and sanctuary as conceptual frameworks through which to view the apparent anomaly of why people enter and stay in this occupation. I argue that sanctuary is a concept within the 
overall framework of moral economy. The empirical contribution lies in the production of unique data about shelter work in Ireland.

My findings represent a diachronically situated albeit partial vantage point; the situations depicted are not fixed or immutable. The analysis is processual, but it represents particular historical moments in the changing lives and career trajectories of my participants. Feedback in post-interview conversations with my participants suggests that the themes of moral economy and sanctuary identified do indeed have explanatory power for their own sense of their work lives. They agree that their work is more meaningful than previous jobs they have held, and that they would not want to return to work in the private for-profit sector.

The remaining chapters are an attempt to map those themes and are organised as follows: Chapter 2 contextualises the study in the relevant HAS, Occupational Choice, and Moral Economy literatures. I locate my study at the intersect between the HAS and occupational choice literatures, and I identify gaps in that scholarship. The literature on moral economy is discussed as a powerful conceptual framework through which to grasp my respondents' choices. The Weberian notion of a work 'calling', though largely discounted by my participants, I will show, still carries some explanatory weight for their actions. I develop a framework to analyse these choice processes emphasising repertoires of choices, processes of entry and staying, and the moral economy within which these take place.

Chapter 3 shifts the focus to present the epistemological and methodological frameworks guiding my research design. This study was guided by a Weberian focus on individuals and understanding (Verstehen). I also explain the rationale behind my research design and data production methods.

Chapter 4 describes how the organisational field of animal care structures the repertoire of choices within which the choice of shelter work is mediated. This chapter examines the institutional settings that shape the shelter work options. Even where an individual sets up her own shelter, she does so within existing structures in the organisational field. A typical day in the world of the shelter is described; its rituals, routines and processes, as is a recent case exemplar of my moral economy argument in the shape of ACS' opposed involvement in the running of a Pound. 
In Chapter 5, I analyse the labour market process and the occupational choice to enter shelter work. This choice is a result of a complex interplay of factors and pathways. These comprise less a list of 'ingredients' for entry but rather a 'recipe'. I thus add a processual dimension to occupational entry theory. I demonstrate that the overwhelming majority of my respondents did not 'always know' they would work in a shelter. Instead, false starts, experiences of alternative forms of being in the economy, and changes in the life course characterise this choice.

Chapter 6 presents my findings on the sorrows, travails and also consolations and joys of shelter work. I analyse the dialectical tension between my respondents' values - as they define these - and the broader contexts within which they carry out their work. This chapter focuses on the reasons why my respondents remain, and on how they constitute and reconstitute their work as important enough to merit dedicating their working lives to the service of unwanted animals. I add a moral economy lens to make sense of my respondents' endurance in their work. Shelter workers stay in this occupation, I find, not for economic reasons, but because they construct their work as a moral experience of the economy and because they find sanctuary there.

In the concluding chapter, I summarize my study's findings, contributions, and its limitations. I consider the extent to which, in interaction with the empirical material, I have answered the questions detailed in this chapter. I then integrate my findings into the wider HAS and Occupational Choice literature. I attempt to make clear my contribution to a revisioning of the embedded hegemony which assumes human dominion over animals. I then draw out the implications of this study for HAS and more broadly, social theory, and I suggest future avenues for research. 
Chapter 2 


\section{Chapter 2 Review of the Literature}

For us, however, the richest metaphors are those that attribute the difficulties in writing to the complexity of literature work; persuading (selected arms) of an octopus into a jar (Kamler and Thomson, 2014: 36).

\subsection{Introduction}

This study aims to contribute to our knowledge of occupational choice, HAS, and of the world of the shelter. This intersection of topics engages this research with three strands of literature. First, the occupational choice literature is scrutinised, in an effort to shed light on the pathways and processes by which people are conceived to choose occupations. Second, I examine the field of HAS within sociology, specifically that literature which pertains to working with animals. The third strand of literature reviews potential theoretical lenses through which the paradox of shelter work - high employee commitment despite the difficult quotidian reality - might be understood. Polanyi's (1957) and Thompson's (1971) theories of moral economy seem to have particular resonance for my findings on why my respondents persevere in their frequently unglamorous and physically and emotionally demanding jobs. The concatenation of these strands signposts the avenues for this study.

\subsection{Occupational Choice}

Industrialised societies have moved from the assumption that young people would inherit their family's occupation in favour of an expectation that they would instead choose their own preferred path, Savickas (2007) observes.

Over 50 years earlier, the conceptual paper by Blau et al (1956) posed the question as to why people enter different occupations. They suggest four main approaches to answering this question. I include this comprehensive paper on occupational choice though the theme of occupational choice has largely been subsumed into the gendered occupational literature over time. Another current research strand suggests that parental influence is still a factor in occupational choice (Oren et al, 2013). With regard to attitudes to animals, Arluke and Sanders (1996) concur: "Much like other cultural phenomena - love of country, or the success ethic, the meanings of animals 
may be passed from generation to generation” (Arluke and Sanders, 1996: 9). The early occupational choice literature (Blau et al, 1956; Blau and Duncan, 1967) neglected to focus on processual factors, that is, how particular contexts constrain or enable the choices individuals and categories of people make over time and how those choices can change through time. The gendering literature, on the other hand, does offer rich insights into general processes of occupational choice; into how choice is structured and shaped by cultural expectations of the self and others, and how occupations themselves have cultural meaning (Crompton, 2006; Cahusac and Kanji, 2014 ; Irvine, 2010). However, despite its full acknowledgement of process and culture, journals such as Gender and Society or Gender, Work and Organization very seldom carry articles on animal-related work, with exceptions (Irvine, 2010; Peek et al, 1996), instead tending to focus on themes such as how far occupational choice is actually 'free' for women or to what extent it is constrained by social, cultural, or familial influences, as well as on the gendered nature of occupations themselves (Piligram, 2007; Lupton, 2000; Cahusac and Kanji, 2014).

In Blau et al's (1956) conceptualisation, first, an individual's psychological traits drive her towards certain vocational choices, a theoretical stance later taken up by John Holland (1973) when he developed a Vocational Preference Inventory (VPI) and suggested that personality types should be congruent with chosen occupations, in order to maximise job satisfaction and minimise turnover. Holland's theory centres around a six-category typology: Realist, Investigative, Artistic, Social, Enterprising, Conventional (RIASEC). He places each of the six RIASEC types on a nodal point of a hexagon. According to Holland (1973) the likelihood of individuals persisting in their career can be predicted by their level of congruence. For example, the Realistic person prefers activities that entail the ordered manipulation of objects, tools, machines and is not academically inclined. Congruent occupations are farmer, mechanic or tree surgeon (Holland, 1973).

The genetic inheritances and environmental influences of an Investigative person lead to a preference for activities that entail the systematic study of physical, biological or cultural phenomena. Science, mathematics, journalism are congruent occupations, according to Holland (1973). The Artistic type enjoys ambiguous, free, unregimented activities such as drama, language, music or writing. Diametrically 
opposite to the Artistic 'type' is the Conventional person who prefers routine, systematized activities such as accountancy.

The Social type's heredity and experiences lead to a preference for activities that help, cure or enlighten others. The sixth type identified by Holland (1973) is the Enterprising person who is predisposed to use enterprising competencies to solve problems at work and in other situations. The hypothesis is that people match their personality type to the occupational type, and there are various similarities between the types. For example, a physics professor who enjoys teaching creatively would be classified as Investigative, Social, Artistic (ISA). Shelter workers are intriguing, as they appear to exhibit Social, Artistic and Realist tendencies; they want to help the animals in their care, they report disliking systematized workplaces and enjoying how different every day is because they never know what animals will be admitted. Induitably, shelter work also requires a practical, 'Realist' bent; cleaning out stables, kennels or crates entails physical labour. The Realist and Artistic types are at opposite sides of the octagon; according to Holland (1973) these are opposing personality types. Managers in the animal shelters in which I conducted ethnographic research display Social and Enterprising tendencies; they want to help animals and yet they need to be enterprising to garner public donations and influence policymakers on animal welfare. Leaders of global social movements (for example, Amnesty International, Greenpeace, World Wildlife Fund) are presumably also social and enterprising. An occupational realisation of the imperative to care about some larger cause would seem to co-exist with the goal of influencing policy-makers for this cohort, which is arguably true of many occupations, and which could be a general critique of Holland's (1973) theory. In any case, I do not find 'personality' very useful in my interpretations of my participants’ occupational choice.

Second, Blau et al (1956) allude to the social and economic structures which enable or constrain these psychological processes. The social structure's significance for occupational choice is twofold, according to these scholars. On the one hand, it affects the personality development of the choosers; on the other, it dictates the socioeconomic conditions in which the selection takes place. Contextual variables are subject to change; the values that guide a person's aspirations may have developed over a period of prosperity, but she may have to find a way to make a 
living in recession. This socio-structural approach will be examined more deeply in Chapter 4, in which I lay out the complex animal shelter organisational field in the Republic of Ireland, which dictates the gamut of occupational choices in this sphere. Blau et al (1956) focused on socio-economic triggers for occupational choice and did not place as much emphasis on culture as would be contemporaneously usual. The large number of stray horses and dogs in the Republic of Ireland is linked to sociocultural issues. The Irish agro-rural heritage may also play out in the processual choice of shelter work, as many of my participants come from rural backgrounds.

Third, changes in the wage structure and other economic factors (an influx of students to engineering courses, for example, if sectoral wages are high) make certain occupational choices more appealing (Blau et al 1956). Economic theories tend to view people as rational utility-maximisers who choose occupations to maximise net income (human-capital theory) though utility theory includes nonpecuniary factors also. Many of my shelter respondents are from working-class backgrounds and thus arguably do not have the same career expectations placed upon them as their middle class peers. Further, most shelter workers are female. Arguably, most men do not have the same opportunity to do 'menial' care work as society places expectations of success on them. Structurally, even if men wanted to do this work, they may be disinclined because of the 'success' expectations placed upon them. Almost all of my female respondents have supportive partners and/or families who enable them to continue in this low-paid occupation. Three out of the six male shelter respondents are, or had been, CEO of their respective organisations. In one case, this was a voluntary position, however. My veterinary surgeon treats a lot of shelter animals in his practice. Jon is in possession of a private inheritance and was not subject to financial pressures and Colm proclaims himself unmotivated by money (see participant profiles, Chapter 5).

The fourth rationale discussed by these scholars is social stratification; parental social status affects the occupational opportunities of their children. As to the relative influence of these various determinants, Blau and al (1956) contend that this can only be found through empirical research. The paper goes on to propose a conceptual framework which would have to be combined with empirical research in 
order to develop theory, by finding relationships between antecedent factors and the relationships between them (Blau et al 1956).

Blau et al (1957) treat occupational choice as a one-off choice, or at very least, underplayed the processual element. I argue here that occupational choice is not a singular choice but a process that extends over many years. There are many crossroads in the life course at which people make choices which narrow the range of future alternatives. Savickas (2007) refers to this phenomenon as the developmental paradigm because it focuses on changes within an individual across time, rather than on differences between individuals. The first phase in the decisional process is orientation, or the awareness of the need to make an occupational choice in the future. Orientation is followed by exploration, to enable the individual to make an occupational choice based on self-knowledge and occupational information. This phase is followed by implementation of the specified choice by entering training for it or by undertaking a trial position in the field (Savickas, 2007). Qualifications influence the decision of selectors (and prior experience as a volunteer has been a pathway to shelter work for most of my study participants, see Chapter 5) but so do other factors. People may 'choose' occupations but may not be successful in their application, so recruitment and selection must be taken into account in order to explain why people end up in different occupations. The fourth and final stage is stabilization, during which new occupational choices are unnecessary until the process is recycled (Savickas, 2007). Wuthnow (2003: 255-265) notes the emergence of prolonged uncertainty about work in North America and the rise of temporary positions, which has become known (euphemistically, according to Wuthnow) as "outsourcing”. Allied to the trend is the shift from work as a single, lifetime career to having multiple careers during one’s lifetime (Wuthnow, 2003).

From a sociological point of view, the life course, including 'linked lives' may shed further light of the choice of shelter work. The life course perspective seeks to understand the continuities as well as the vagaries in the paths of individual lives (Hutchinson, 2011). Apart from the temporal dimensions of human behaviour, personal characteristics and the environment in which the person lives also count (Hutchinson, 2011: 8). The life course is not a linear path, it contains twists and turns along with continuities. Of course, there is interplay between human lives; family 
connections and other linkages to people also contribute to an understanding of people's choices and the life course perspective emphasises this interdependence. Hutchinson (2011: 15) also notes that life events may produce changes in life's trajectory, either closing or opening doors. The life course perspective does not neglect human agency; people are not cultural dupes and can exert influence to shape their lives, and construct their own career paths within systems of opportunities and constraints. The social constructionist paradigm which guides the current study takes the perspective that social reality is created in social interactions to create common understandings and so I draw upon the notions of the life course and linked lives. I pay particular attention to my participants' accounts of changes in their lives that precipitated occupational entry, and to their stories of significant others who helped to shape their attitudes to animals (Interviews, 2014).

The organisational field in which such opportunities and constraints exist for shelter workers is examined in chapter 4 . The choice to do shelter work is not usually made early in life, rather the choice to enter is one life transition as part of a larger life trajectory embedded in a particular historical point in time. The recession which began in late 2007 is one of the factors which played a part in some of my respondents' choices to enter shelter work, for example. For others, the choice was prompted by a change in perspective and represented a choice towards financial downward mobility. Of course, as Becker (1963) and Goffman (1959) remind us, unusual or 'deviant' choices have no inherent deviance, they become deviant (or psychiatrically 'sick') only when they are labelled as such. Turner and McMahon (2011) find census evidence to suggest that there is an increase in the proportion of women in low-skilled occupations in the Irish labour market, with the exception of public sector employment. They point to the dearth of childcare supports and being a lone parent as significant barriers to female participation in the Irish labour market (Turner and McMahon, 2011). Though all of the current study's participants are still in the field, general conversations the author has had with veterinary nurses over the last five years indicate that the long, unpredictable hours and low-pay in this occupational sector make it difficult to combine with having young children.

Shelters often select employees from a pool of former volunteers. People may 'toy' with the idea for several years before 'choosing' shelter work. Unlike undertaking an 
accountancy qualification or studying medicine, shelter work is rarely chosen at the age of 17 or 18; people 'fall into' the occupation at various stages. There are two pertinent choices at play: the choice to enter shelter work, and perhaps most importantly, the choice to stay. Archer (2007) observes that as active agents, people develop and define their ultimate concerns over time: "those internal goods that they care about most” (Archer, 2007: 7). As Gergen (2009: 144) observes, organisations and sense-making are cut from the same cloth. People intersubjectively determine what they are doing and why, otherwise there is no organization. Or as Bogdan and Taylor (1989: 291) put it: "What others are depends on our relationships with them and what we choose to make of them”. According to Blumer (1969) all communication is symbolic and based upon interaction and meaning. His three core assumptions address meaning, language and thought. People act towards people and things, theorises Blumer (1969), according to the meanings they give to those people and things. Second, language gives humans a means by which to negotiate meaning through symbols and identify meaning in speech acts with others, a definition later extended by HAS scholars to include nonhuman animals (Arluke and Sanders, 1996; Alger and Alger, 1997; Taylor, 2007). Third, thought modifies each individual's point of view (Blumer, 1969). Symbolic interactionism and sense-making are fruitful additions to the literature on occupational choice. The metaphors, symbols and meanings which abound in the animal shelter world will be examined in chapters 5 and 6 in order to shed light on the processes governing occupational choice and persistence in this field.

Gender must also be considered as being inextricably linked to this occupational choice; shelter work is overwhelmingly feminized. Of my 22 shelter participants 16 are female. Crompton (2006: 253) suggests that the reason women are underrepresented in higher-level jobs stems from the “ideology of domesticity”, which still allocates most caring work to women. Further, nursing, and care work in general tends to be not as well paid as "men's work". Although women may indeed have a preference for caring occupations, Crompton (2006) cites Nussbaum's (2000) argument that preferences do not arise out of thin air but may be shaped by habit, low expectations and disadvantaged background conditions. Crompton (2006) also draws on Ferguson's 1984 article which claims that 'feminine' qualities such as 
empathy and nurturing ability were disadvantageous in 'masculine' organisational contexts, where qualities of rationality and hierarchy are valued (Crompton, 2006: 256). Empathy and nurturing are a prerequisite of choosing shelter work, and are in evidence in all of my shelter participants' treatment of the animals in their care. Scheper-Hughes (1992: 401) argues persuasively that theories proposing universal ‘womanly scripts’ such as Carol Gilligan's (1982) womanly ethos are both culture and history bound. Mother love, according to Scheper-Hughes (1992: 401) corresponds with the rise of the modern, bourgeois, nuclear family and with the enormous decline in infant mortality. She goes on to question the very paradigm of an essentialist ‘feminine’ psychology (Scheper-Hughes, 1992: 403).

Midgeley (ISAZ conference, 2011, personal communication) contends that it is not anti-feminist to suppose that women probably do have a superior capacity for nurturing and empathy than do men. I contend that the more pertinent question may be whether such care work is sufficiently rewarded or garners sufficient respect under conditions of advanced capitalism. Palmer and Eveline (2012) argue that employers sometimes sustain an opposition between care as love-centred and work as money-centred; as care work is 'natural' for women, it does not merit higher pay, which recalls Bunderson and Thomson's (2009) finding that zookeepers cared so deeply about their animal charges as to leave themselves vulnerable to managerial exploitation. West and Zimmerman (1987) present gender as a powerful ideological tool used to construct and reproduce distinction between genders. "Doing gender", these scholars contend, occurs on individual, interactional, and institutional levels and results in the naturalisation of attributes associated with each sex. However, in late modernity, some men can actively chose non-traditional occupations (Hancock, 2012) and all but one (Colm) of the male shelter workers (including both highly-paid CEOs) in the current study came to this occupation later in life.

Husso and Hirvonen (2012) find evidence that women face competing expectations. On one hand, they are expected to be engaged in emotion work. On the other, they must perform tasks efficiently. There is thus a dialectical tension between their habitus and the field of care work (see Chapter 6, telephone conversation with Jean, 2015) As we shall also see in Chapter 4, shelter work requires mental and physical strength, and yet frequently requires emotion work. 
Another aspect not taken into account by Blau et al (1956) is the moral economy and the agentic choices which people can and do make, either partially as a result of epiphanic or serendipitous experiences, or as a result of a growing awareness of where their interests and animals' needs coincide in the case of my participants; people view working with animals as a different experience of the economy (see also Sayer, 1984, on 'moral' sociology). This latter aspect appears to have explanatory power for my participants' occupational choice. Savickas (2007) notes that newer models in occupational choice under postmodernity have taken the "narrative turn" focusing on careers from a constructionist perspective. Interpretive processes, social interaction, and meaning-making are at the heart of the constructionist approach adopted in the current study.

In this vein, Conklin's artful 2012 phenomenological study of nine environmental workers may also furnish some clues about the choice of shelter work. Four themes emerged as shapers of the occupational choice of environmental work; first, the introduction to 'nature' at an early age, and the significance of childhood experience as the foundation on which a lifelong passion would build, second, career development in terms of pursuit of the participants' interests, or through a "lens of love” and containing serendipitous elements (Conklin, 2012). Third, society and others, specifically like-minded individuals are identified as precursors to a calling (as in Dobrow's 2007 study of musicians). The fourth leitmotif was an urgent imperative; the study participants felt called to do something they believed was urgently necessary in the world (Conklin, 2012). Although for Conklin's (2012) participants the 'love' refers to love of nature in the abstract, rather than to sentient beings, his findings have resonance for my cohort of shelter workers. In a similar way, my respondents all report early experience with animals, a wish to do 'meaningful' work and a dislike of clerical and other occupations, and a strong urge to be 'a voice for the voiceless'. For most of my respondents, this occupational choice was a dawning realisation, rather than a dasmascene moment of clarity. In all cases, the foundations for this later occupational choice were already in place.

Hirschler’s (2011) aptly entitled purposive, snowball sample study ('Hirsch’ means 'deer' in German) of the reasons for becoming vegan found evidence of a epiphanic or 'catalytic' experience which led many of the participants to adopt a vegan diet and 
lifestyle. One participant gives the following stark reminiscence of a childhood chicken dinner, as he realised: "It's a pile of bones. Everybody is gnawing on bones" (Hirschler, 2011). Of course it cannot be assumed that animal shelter workers are predominantly vegan or vegetarian (45\% of animal activists were not vegetarian, according to Herzog and Golden's 2009 study (quoted in De Mello, 2012: 413). Only three out of 24 of my participants are vegetarian or vegan (one vegetarian and two vegans). Nonetheless, there are affinities in terms of shelter workers' apparent empathy with animal suffering, and desire to alleviate that suffering through proactivity; "ethics up close and personal” in the words of one of Hirschler's (2011) participants. What is really interesting is how my respondents reconcile their work with not being vegetarian, as holds true for the majority. This important theme will be revisited in chapter 6 and process and meaning-making will be examined in relation to occupational choice theory. Choice, in this instance, is as much or more about choosing to stay as to enter the field; indeed these choices involve different processes as will be laid out in chapters 5 and 6 .

The choice to enter is often a reaction to the structural weaknesses of alternative workplaces. Harvey (1995) and Lipietz (1993) argue that with the Fordist mode of regulation, the state oversaw a social contract that allowed productivity gains in industry to be matched by increased consumer demand, higher wages for workers, job security and a far-reaching welfare state. Tenure and 'jobs for life' are no longer the 'normal' desirable mode of existence in the post-Fordist order however (Lipietz, 1993: 11). Most of my respondents experienced alternative workplaces as competitive, less meaningful, and in some cases "brutal” or "mind-numbing”.

Once working in a shelter, as will be shown, these jobs present many challenges. The low-pay structures, physically strenuous work, and emotional challenges of dealing with abused animals make it difficult, from an etic perspective, to comprehend why people remain. Every respondent reports feeling happier and more fulfilled in shelter work than in previous workplaces, despite these challenges. To the occupational choice literature, I will add the notion of meaning-making. By taking a social constructionist perspective, I will endeavour to unpack the meanings shelter workers attribute to their work, as these occupations are not those for which the occupational choice literature was developed. While symbolic interactionism is a common 
theoretical framework for HAS scholars (Alger and Alger, 1997; Arluke and Sanders, 1996; Taylor, 2007) and the post-Meadian perspective has been persuasively argued by Arluke and Sanders (1996), Myers (2003), Wilkie and McKinnon (2013) and others, occupational choice theory could be extended by using symbolic interactionism to unpack the processes of choices which intersubjectively emerge, sediment and are subject to change over time. Choices are not made as we please of course, but are subject to socio-structural constraints. There are barriers to fulfilling any occupational choice, from the organization itself or from people outside of work. Aspects of modern (Irish) society of course constrain or enable the emergence of people's work choices in relation to animals also. Occupational choice is envisioned here as a process which unfolds via epiphanies, alienation from alternative workplaces, linked lives, and other phenomena. Seven of my 22 shelter workers are volunteers and do not receive a wage for their productive efforts, although some receive benefits in kind.

In their quantitative study in the UK, Lim and Laurence (2015) find that a decline in volunteering since the 2008 recession has more to do with community factors such as reduced levels of trust and engagement than with personal experiences of economic hardship. Dobbins et al (2014) critique human capital approaches to unemployment, and their influence on maintaining neo-liberal policy. These scholars track workers' responses to redundancy after the closure of their employer, Anglesey Aluminum, (AA) in North Wales. They find that ex-AA workers faced a paradox of being skilled but surplus to labour market requirements. Even for those workers who retrained there were not enough quality job opportunities. Dobbins et al (2014) describe the workers' plight as being part of a labour 'precariat' and find that the workers had little choice but to 'make do and mend'.

Nesbit (2012) finds evidence that people's motivations to volunteer change over the life course. She finds that being a parent decreases the likelihood of a person volunteering and the hours spent in volunteer work (Nesbit 2012). Most of my respondents are either childless or their children are adults as we shall see in Chapter 5. 
Meier and Stutzer's (2008) empirical study demonstrates that volunteers in East Germany are more satisfied with their life than non-volunteers. These scholars conclude that helping others is a pathway to well-being (Meier and Stutzer, 2008). Volunteer work, these authors conclude, is intrinsically rewarding.

My framework in the current study moves from 'choice' to 'process' and I draw on a series of building blocks in order to analyse that process. In Chapter 4 I analyse the repertoires of choices available in the organisational field of shelter work. I find that occupational entry and staying are different processes, and that choice for my respondents is a journey through different occupations, rather than cognitive. I demonstrate that the key concepts of meaning-making (moral economy), linked lives and gendering form part of the processes of entry and staying.

Although it has become commonplace for sociologists to examine (see Zelizer, 2012) relational work - which emphasizes the continuously negotiated and meaningful interpersonal relations constituting economic activity - and interactive service work (Casaca, 2012), work involving interaction with, and service for animals is distinct in several ways. My respondents tell me that there are specificities involved in animal shelter work (almost of my participants have held service, office, or factory jobs) such as the 'non-judgemental' way of being of other animals, the relationships with these animals which do not depend on dress, appearance or status, and the moral aspects of work focused on helping the 'truly voiceless and helpless' (Interviews, 2014). There is a rich, albeit nascent, Human-Animal-Studies literature and the next section examines some of the emphases therein.

\subsection{Human-Animal-Studies (HAS)}

It is more than 150 years since Darwin called into question the champions of human uniqueness and unveiled the human/animal distinction as being one where the boundaries are neither clear nor immutable; a phenomenon Bourke (2011: 9) calls the "Möbius Strip". Darwin undermined human-animal dichotomies in the name of gradual continuism (quoted in Calarco, 2008). In recent decades HAS emerged in the intellectual landscape of philosophy (Singer, 1975; Regan, 1983). However, Weber (1947:104) much earlier acknowledged the possibility that animals could play a role in sociological analysis and Bryant recently (1979) evocatively urged the 
sociological community to consider the "zoological connection”. Various arguments have been advanced for the importance of HAS for sociology. For example, Arluke (1993) points out that research findings are critical to make what is often an emotionally charged debate about the proper use of animals more reasoned and informed. Stevens (2012) argues that extending the social to the more-than-human world could offer new views on the social. Sanders and Arluke (1993) observe that HAS research promises to expand sociological understanding of key issues such as how identities are assigned to others when these 'others' are ostensibly unable to employ conventional symbols of communication.

Four of the main emphases in the HAS literature are: arguments for its inclusion as a theme in sociology, the psychosocial benefits of animals for humans, human attitudes to animals and working with animals.

\subsubsection{The Rising Significance of HAS in Sociology}

The promise of HAS for sociology focuses on the central role which animals play in human culture. In the last century Weber acknowledged that animals could play a role in sociological analysis: "It would be theoretically possible to formulate a sociology of the relations of men to animals, both domestic and wild” (Weber, 1947: 104). Given the prevalence of animals - both utilitarian and affectional - in human society, and given the development of animal protection as a social movement, it seems bizarre not to examine the human-nonhuman relationship sociologically. Yet despite their importance as companions, as commodities, in animal-oriented occupations, sociology has been slow to grant the issue of human-animal interaction status. Clifton Bryant (1979) argued that sociologists have been remiss in their reluctance to address the zoological component in human interaction and related social systems. Since Bryant's evocative 1979 urge to sociology to consider the 'zoological connection', this anthropocentric stance is rapidly beginning to change and increasingly, it is deemed appropriate for sociology to examine animals within the context of human environments and social systems (Arluke and Rolfe, 2013; Hamilton and Taylor, 2013; Jerolmack, 2013;Wilkie, 2010; Irvine, 2007; Taylor, 2007; Tovey, 2003; Arluke and Sanders, 1996). 
Humans have always been enmeshed in social relations with animals, after all, and today the growing number of sociologists who acknowledge the nonhuman animal as an important site of intellectual inquiry has yielded many fascinating explorations of deeply constitutive human-animal relation studies. Indeed, Shapiro and DeMello's useful article (2010) notes that the HAS field has exploded over the past 20 years, mirrored in the proliferation of new books, journals, conferences, organisation, college programs, and listservs relating to the field. Including Anthrozoös and Society and Animals, there are now over a dozen journals covering HAS issues. The British Sociological Association founded an Animals and Human Studies Group (AHSG) in 2006, of which I am a member, and Animals and Society is a section of the American Sociological Association. The Animal and Society’s Institute website lists over 300 courses in human-animal studies. Nast (2006) observes that a concern with human-animal relations has expanded signifcantly in the last few years, leading to their reconceptualization. Other trends in HAS scholarship Shapiro and DeMello (2010) identify include animal-assisted therapy (AAT), the human-animal bond, also known as anthrozoology, and Critical Animal Studies which employs an ideological critique of current animal-related institutions. Trans-Species psychology applies findings from human psychology to the understanding of other species.

Tovey (2003) too alludes to the paradox between the increasing intellectual and social interest in the 'animal question' and their comparative invisibility in social science texts. She points out that nature, in the form of domestic animals, has been “dragged into society” for many aeons, despite their relative invisibility in mainstream social science texts. If domestic animals are to be thought of as a part of nature, this scholar contends, then we have to reconceptualise our understanding of HAR to include communicative relations (Tovey, 2003). Arguably, human-animal relationships in shelters challenge and contest the notion of 'communication'. Tovey (2003) argues that it makes more sense to consider animals as part of 'society' rather than as of 'nature'. Late modern society is alienating for both human and non-human animals, after all. Much like industrial workers, food animals have been subjected to social divisions of labour. They lose most of their agency to exercise choice over what they eat, whom to choose as a mate, how to rear their young (Tovey, 2003). 
She further criticises the primary portrayal of animals as 'species' or 'biodiversity' in environmental sociology texts, rather than as individual animals with unique experiences and subjectivity (Tovey, 2003). It is clear from my ethnographic study that my respondents have relationships with individual animals who are 'given' names, rather than with species. While individual respondents sometimes expressed a particular love for one species (dogs, cats or equines) more typically they lived with several species.

Cerulo (2009) commends the recent questioning of the anthropomorphic stance in sociological analysis. She acknowledges that nonhumans were previously ignored in studies of social interaction on the theoretical grounds proposed by Parsons, Goffman, Mead and others, namely, that animals lacked the mindedness required for symbolic interaction. She then presents new theoretical approaches, for example Actor-Network theory (ANT), that concede a role for nonhumans in social interaction. In ANT, an actant is any entity, animate or inanimate, that can make things happen within the actor-network. Studies guided by these theories have found that nonhumans (not just animals, but also objects) actively engage human emotions. For example, ANT questions 'clean' attributions of specific capacities of specific things; anything, whether human, non-human, or abiotic, can be an actant. Animals, too, can take their place in Latour's 'parliament of things' (Latour, 1993:142). Cerulo (2009) concludes that nonhuman animals are not beyond sociology's purview, indeed that they demand our sociological attention. She makes a compelling case for the inclusion of nonhuman entities into our analytical framework: "Only then can our analysis of the social remain comprehensive and alive” (Cerulo, 2009). Sanders (1999) also observes that this area of research is pertinent to sociological understanding of key issues such as how 'mind' is constituted in social interaction, and how identities are assigned to others when these 'others' are allegedly unable to employ conventional symbols. Of course, non-human and human animals have different capabilities and potentialities, but so too do people. In chapter 6, I will endeavour to show how much they can nonetheless matter, each to each. 
The interactionist perspective, which informs the current study, allows for social interaction as a way to 'make' meaning. Sanders (1993) and others (Alger and Alger, 1999; Arluke and Sanders, 1996; Irvine, 2007) have documented how people frequently treat animals as minded interactants, and how humans and animals can read one another's gestures. As somebody who lives with dogs and formerly cats, I am almost certain that they can negotiate social order; my cat used to sit by her food bowl and mew constantly when she was hungry, my dogs drop tennis balls at my feet. It is difficult to construe such behaviours as anything other but imbued with meaning and as attempts to compel me to act. These actions go beyond the notion of human-to-animal 'simple' care; they constitute interspecies symbolic interaction, as I will contend in chapter 6. Wilkie and McKinnon (2013) concur. These scholars argue that Mead's Mind, Self and Society has largely featured as a negative classic in HAS, because of its generally interpreted (see Blumer, 1969) lingual quality. Wilkie and McKinnon (2013) do not accept that Mead asserted human exceptionalism (unlike Alger and Alger, 1997, who do). Rather they argue that Mead's thought is more nuanced and ambivalent on the question of whether society is distinctively human (Wilkie and McKinnon, 2013). Mead views society and social interaction as more than human, they contend, citing his references to birds taking up the call of other birds (Wilkie and McKinnon, 2013).

Jerolmack (2013) also calls for integrating human-animal interaction into the sociological canon. His study of human interactions with pigeons offers surprising insights into city life, community, and politics (Jerolmack, 2013). Jerolmack (2013) finds evidence that keeping pigeons enables humans to mould how they are perceived by others, and that pigeon ownership can conjure up feelings of attachment to a social group. Jerolmack (2013) unveils contradictory ways in which pigeons figure in how people experience urban space. For those who feed them, pigeons provide opportunities for interaction and enhance people's enjoyment of the park in Manhattan where Jerolmack (2013) conducted some of his observations. For those who deplored the presence of the pigeons, Jerolmack (2013) notes that the birds threaten cleanliness and order in a public space. Many working-class men keep pigeons, Jerolmack (2013) finds, in order to give them a sense of constancy in an ever-changing neighbourhood in Brooklyn. Rather than finding solace with the 
'natural world', Jerolmack (2013) contends that the pigeon-keepers use the birds as resources to compete for status and to augment the flyers' connection to other people.

From a historical perspective, Bourke (2011) notes that the distinction between 'human' and 'animal' is constantly re-constructed and policed with precision. The value system which acknowledges the domination of a particular understanding of 'the human' over the rest of sentient life are what create society and social life, according to this scholar. Bourke (2011) points out that the negative health consequences of eating animals do not just include the numerous environmental effects, including high emissions of greenhouse gases, and soil erosion. The costs to animals are “incalculable”, she adds (Bourke, 2011: 298).

Irvine (2007) also argues that sociological study of animals is warranted because our treatment of animals is connected with numerous mainstream issues. Much of the HAS theoretical framework is psychological (attachment theory, biophilia) but the current study looks at HAS through a sociological lens. There are wider and broader sociocultural reasons why my participants choose and remain in this organisational field. Taylor (2007) observes that: "Nonhuman animals are a part of our social life and deserve attention and consideration of human-animal relationships may also contribute to advancements in social theory and are therefore important to sociology” (Taylor, 2007). Wilkie (2010) has even called for the 'animalisation' of sociology. In a similar vein, Philo and Wilbert (2000) argue for the need for a new animal geography within cultural and social geography, a geography concerned with understanding how animals are situated within the everyday spaces of human activities. Any social science which fails to pay at least some attention to HAR, to their differential constitution and implications, is arguably deficient, these scholars contend (Philo and Wilbert, 2000).

Shelter work could be deemed to be a kind of interactive service work (Casaca, 2012) but unlike call centre or supermarket checkout workers, shelter workers are not subject to surveillance or regulation in their encounters with the animals in their care. Nor are shelter workers required to engage in 'front stage' (Goffman, 1957) behaviour with the animals - although sometimes they must with members of the 
public - and many participants reported the relief they felt in being able to be 'completely themselves' in dealing with the animals. Formerly neglected animals 'act back' with love when they are shown love, according to my participants, and this renders the work worthwhile and meaningful. Further, as the shelter workers deem their co-workers to be 'good people', and as career progression is not often possible in the conventional sense, there is a cultural levelling evident in the shelter environment. Even in larger shelters, this is true of care-workers.

In sum, sociology is ideally positioned for investigation into human-animal interaction, as sociology seeks to understand the relationship between private experience and wider society. Much of the literature in HAS journals such as Society and Animals and Anthrozoös focuses on the psychosocial benefits of animals to humans, to which theme I now turn.

\subsubsection{Benefits of Animals to Humans: Animals in a Therapeutic Context}

The complex and nuanced bond between human and nonhuman animals has been shown to enhance human quality of life. In 2006 there were an estimated 640, 620 dog owning households and 215,542 cat owning households in Ireland (Downes et al, 2011). Many quantitative studies, often funded by pet-food multinationals, focus on animal-assisted therapy, animals in a therapeutic context, in prisons, hospitals, schools or simply the benefits of living with companion animals (Barlow et al, 2012; Gee et al, 2012; Pedersen et al, 2012). Qualitative studies on human-animal relations sometimes also take psychosocial benefits as their focus. For example, Irvine's (2013) study presents compelling findings that companion animals bolster the sense of self-worth of homeless individuals, one of the most vulnerable segments of society.

There has been a rise in the popularity of animal-assisted therapy (Shapiro and DeMello, 2010) courses and these curricula focus primarily on the benefits that the human-animal bond provides to humans. For example, dogs have been increasingly employed to assist in elder care, critical care, and in prisons (Nast, 2006).

Research on the benefits of pet ownership has recently flourished and many such studies are published in the journal Anthrozoös and are usually hypothethicodeductive and funded by petfood multinational corporations (MNCs). For example, 
the International Society of Anthrozoology (ISAZ) 2011 conference in Cambridge, which I attended, was funded by Waltham Mars and most of the presentations at this conference were based on quantitative studies which used biomarkers to demonstrate the benefits of living with companion animals. The natural science dimension is important to the further development of HAS, if it is to become a player in the policy arena according to Shapiro and DeMello (2010). Other published studies include Sugawara et al (2012) which finds evidence of lower stress responses in participants in the presence of pet dogs. This finding is supported by Schoeberl et al (2012); dog owners who considered their pets to be 'meaningful companions' showed lower morning cortisol values. Handlin et al (2012) find a higher oxytocin level in owners to be associated with greater frequency in kissing their dogs.

There are ethnographic studies which reach similar conclusions: Sanders (2003) concludes that relationships with companion animals are "constant rather than contingent, the animal's response to his or her companion does not depend on the latter's appearance, age, economic fortunes, abilities, or the other vagaries that, for good or ill, constrain human-to-human relationships” (Sanders, 2003). The literary academic and poet Mark Doty would appear to concur when he remarks of dogs: "They are the pattern of fidelity - Fido! - the very template of enduring loyalty, of love without the prospect of abandonment"' (Doty, 2008: 33). Of course some animal workers work with (and say they love) animals that could, and probably would, eat them, given the opportunity (Bunderson and Thomson, 2009).

Such positive psychosocial effects are not restricted to companion animals. Pedersen et al (2012) investigated the potential of nature and the natural environment to improve or promote health and mental well-being using interventions at farms. Their findings suggest that farm animal-assisted intervention could be a useful supplement to more conventional mental health care interventions. Pedersen et al (2012) use the concept of "Green Care"- a diversity of interventions at farms where nature and the natural environment are used to promote health and well-being of humans. A significant decline in depression and a significant increase in self-efficacy were seen in the intervention group ( $\mathrm{n}=29$ ) (Pedersen et al 2012). 
On a broader societal scale than those one-to-one effects, Wood et al (2007) find evidence that companion animals exert a positive 'ripple effect' on neighbourhood interactions and sense of community. In both qualitative and quantitative research undertaken, these scholars find pet ownership to be positively associated with social interactions in the community, perceptions of neighbourhood friendliness, and favour exchanges. In other words, there is evidence that there exists a nexus between pet-keeping and community flourishing (Wood et al 2007). I witness this socially lubricating effect whenever I walk my own dogs. In this instance, civil inattention (Goffman, 1959) is not the norm. Conversations with other walkers commonly take place, to an extent that would be extremely unusual in the absence of our dogs.

Irvine’s 2013 narrative study of homeless people is intriguing because the focus is on how pets encouraged a sense of responsibility in 'non-generative adults'. Following Erikson (1950) Irvine (2013) defines generativity as a wish to leave a positive legacy in the world. Her study reveals that the reward for the homeless and marginal participants was the unconditional love provided by the animals. The attributions made by the homeless participants were weighty; the animal companions were reported to be 'life changing' and in some cases 'life saving'. As dependent others, Irvine (2013) concludes, animals reward the fulfilment of responsibility. As 'silent witnesses', they help to keep the homeless respondents from engaging in risky behaviour. Irvine (2013) conveys both the individual and social dimensions of the personal narratives of her respondents; she argues that the subjective element does not limit the participant accounts to the idiosyncratic because these accounts are socially embedded in a specific historical point in time (Irvine, 2013).

The benefits of animals for the elderly are outlined by the surgeon Gawande (2014) in his bestselling memoir, Being Mortal: Illness, Medicine, and What Matters in the End. When animals (cats, dogs, parakeets) were introduced into one nursing home in the US the effect on residents was irrefutable: "They (the residents) began to wake up and come to life". People who had previously been withdrawn and nonambulatory started asking to walk the dogs, and adopted and named all the parakeets. The benefits were quantifiable; drug costs fell to 38 percent of the comparison facility and deaths fell by 15 percent (Gawande, 2014: 123). 
A 15,000 year old bond has yielded a deeper understanding between humans and dogs than between humans and any other animal (Harari, 2014: 46). When one considers that for animal shelter workers all of these psychosocial benefits are part and parcel of their working lives, the choice to remain in this field seems somewhat easier to apprehend.

\subsubsection{Attitudes to Animals}

Since the publication of Peter Singer's (1995) and Tom Regan's (1983) seminal books on animal rights theory, there would appear to have been a shift in people's attitudes toward animals, or at least toward some species. Books about companion animals regularly feature on bestseller lists (Marley and Me, A Street Cat Named $\mathrm{Bob}$ ) and TV channels such as 'Animal Planet' have become increasingly popular (Nast, 2006).

Despite the widespread evidence that animals have positive psychosocial effects on humans, our attitudes to other animals are nonetheless characterised by tensions and contradictory elements, as Yi Fu Tuan's influential (1984) work on the dominance and affection in our relationships with companion animals reveals. He argues that the dog calls forth the best that we are capable of, while on the other hand, also calling forth the "temptation to exercise power in a wilful and arbitrary, even perverse manner” (Tuan, 1984: 102). The accumulated bias of the entire Western tradition, as noted by Wilkie (2010) has resulted in an instrumental attitude to nature, and a systematic commodification of animals, reflected in the terminology 'food animal' or 'productive animal'. Arluke and Sanders (1996) coined the term 'sociozoologic scale' to refer to the varying and arbitrary attitudes towards different species. Stevens (2012) also observes that charismatic megafauna (dolphins, polar bears) tend to elicit more sympathy from humans than 'less media-friendly' species such as wasps. In most contexts, rats are viewed as vermin. However, the rats used to detect landmines in Tanzania are hailed as 'hero-rats' (Apopo, 2014). Cook (2015) argues that the relation of humans to other animals is a matter of pressing environmental, social, economic and philosophical concern. Cook (2015) contrasts the discursive representation of animals by analysing two interviews which exemplify diametrically 
opposed views: a spokesperson for the Vegan Society in the UK and a spokesperson for the Countryside Alliance, a pro-hunting pressure group (Cook, 2015).

Hudson (2011) contends that neither animal rights nor philosophical discourses provide an adequate critique of the system of capitalism that exercises a structural violence towards both humans in particular and the planetary environment in general. She views non-human animals as occupying a liminal place where this violence erupts. The lives of pigs on factory farms is described in similarly stark terms by Scully (2002: 29) "genetically designed by machines...themselves treated as machines from 'birth' to 'bacon'”.

Attitudes to other animals remain a gendered sphere. Herzog (2007) and Neumann (2011) write of the feminisation of animal workers and the gendered nature of attitudes to animals. Herzog (2007) finds that women's behaviours and attitudes toward animals are, on average, more positive than men's. It is thus unsurprising that women outnumber men in animal protectionism, and are more likely to adopt vegetarian or quasi-vegetarian diets for moral reasons. In the mid-1960s, there were fewer than 300 female veterinary surgeons in the US. By 2002, nearly $85 \%$ of $1^{\text {st }}$ year vets were female (Herzog, 2007), a situation mirrored in Ireland (Joyce 2012, personal communication). Herzog (2007) suggests that the picture is more complex than simplistic genetic dichotomies, however. Instead, he argues, a "host of postnatal environmental and cultural influences” are involved. Interestingly, he finds that while women tend to express more concern for individual animals, men are often more concerned with species and habitat restoration (Herzog, 2007). This could be framed as a care versus politics paradigm.

Neumann (2010) developed a profile of the typical animal welfare volunteers (n: 426) as 'female, White, pet-owning, heterosexual, employed, childless, married or partnered, democrat-leaning, 40-59, with an income between 50,000 and 99,000 US dollars, and Protestant. Apart from religious affiliation, this is a description of me. Of course, the typical picture of a volunteer is not necessarily the same as that of a shelter worker. Typically, shelter workers in my study emanate from a lower social 'class' than do I, have less formal education, and earn substantially less. But there is an ethical dimension to this work, beyond all these considerations. 
A theory of ethics that is not reliant on rationality but instead draws on "qualities associated with women such as empathy, caring and love” (De Mello, 2012: 391) is a guiding angle of vision for the present study, despite its somewhat essentialist premise. My four 'nitty-gritty' (hands-on with the animals) male shelter participants are equally predisposed to care for animals; care is not uniquely feminine. Gilligan (1982) charged traditional moral approaches with male bias and argued that the "voice of care" is a legitimate alternative to the "justice perspective". She characterised the difference as one of theme rather than of gender (Gilligan, 1982). The question of what moves people to consider the ethics of their dealings with other species is interesting. Engster (2006) argues that humans owe animals moral sympathy and should assume moral duties to care for animals when we make them dependent upon us for their basic well-being. The reasoning behind Engster's (2006) argument is that we sympathize with animals based upon our recognition of the similarity of their needs to our own. Second, Engster (2006) posits, we assume a duty to help animals when we make them dependent upon us to achieve their needs. This author notes that the factory farming system is morally indefensible from the standpoint of care ethics (Engster, 2006).

Adams and Donovan (2007) expand on Adams' (1990) analysis of the sexual politics of meat to maintain that a feminist care tradition offers a preferable basis for animal ethics than rights theory, given the latter's tendency to extend rights to animals based on 'human' traits, and given its abstraction. The feminist care ethic ontology, these scholars argue, acknowledges love and empathy as bases for human-animal connections (Adams and Donovan, 2007). My respondents' thinking is akin to the feminist care ethic, as it is characterised by love and empathy.

One phenomenon whereby this love for animals can tip over into the extraordinary is hoarding behaviour. Individuals who hoard amass scores of animals in often filthy, cluttered conditions, but often claim to love them and though some hoarders are diagnosed with mental illnesses, others are thought to have a "blind spot" that prevents them from seeing the negative consequences of their good intentions (Arluke, 2006: 91). Sadly, for hoarders animals are usually their primary or sole connection to others (Arluke, 2006: 114). Some shelter work could be viewed as an 
ethical form of hoarding; it permits the worker to be surrounded with more animals than would normally be feasible in the home environment.

Animal welfare activism is arguably an antisystemic movement; the ideological cleavage between humans and nonhumans does not appear to prevent animal shelter workers from experiencing kinship with other species. Contrary to Heidegger's contention (cited in Calarco, 2008), animals would not appear to be held to be weltarm - poor in world - by those who care for them. Arluke (2003) studied how pro-animal inclinations in children come to be shaped. Themes associated with “super-nurturance” included: acknowledging the importance of animals, describing oneself as an 'animal person', viewing animals as helpers, and willingness to assume responsibility for animals (Arluke, 2003). In other words, a complex array of sociopsychological factors combine to contribute to animal super-nurturing in children (Arluke, 2003). In their quantitative study of over 4000 Ohio residents conducted in 2002, Kendall et al (2006) also find that childhood experience has the greatest effect on attitudes to animals. Pallotta (2007) finds evidence that children can sometimes resist the massive power of socialisation regarding the consumption of animals. In addition to engaging in resistance to eating animals, some children are predisposed to feel empathy for the suffering of animals. Pallotta (2007) finds that this predisposition to be a variant of the trait empathy but specifically animal-oriented. She conducted open-ended interviews with 30 vegan animal activists, and finds that these childhood experiences and predispositions set the stage for later activism (Pallotta, 2007).

Animal shelter work appears to be an occupational realisation of our sense of compassion in our dealings with animals, and it is to the literature on working with animals that I turn in the next section.

\subsubsection{Working with the Animal 'Other'}

Humans have worked with animals since the Neolithic Revolution and many recent texts have focused on such work, running the spectrum from the slaughterhouse to the animal sanctuary (Pachirat, 2011; Arluke and Sanders, 1996; Taylor, 2007; Harbolt, 2003) have attracted recent research interest. Illuminating as these studies of 
shelters are, rarely are the reasons for occupational entry considered beyond the selfevident: workers have grown up with animals and love animals (Sanders, 2010). Occupational choice is rarely viewed through the HAS lens of scholarship; it appears to be deemed almost a self-evident outcome of shelter workers' regard for animals (Arluke and Sanders, 1996; Taylor, 2007; Herzog and Golden, 2009).

Animal-related occupations comprise farming, slaughter-work, zoo-keeping, veterinary surgery, veterinary nursing, and shelter work. Within the shelter, there are various occupations: canine carer, fundraiser, manager inter alia. In larger organisations, Marketing and PR staff are commonly employed. In smaller organisations these roles are carried out by the care staff, often outside of working hours.

Pachirat (2011) undertook a covert ethnography in an unnamed US slaughterhouse, and he illuminates how a politics of "sequestration and surveillance" exist in symbiosis as mechanisms of power in contemporary society. Through the use of rigidity and separation of tasks, the facility is able to kill a cow every twelve seconds without anyone being 'accountable' for the work. The contemporary slaughterhouse, he concludes, is "a place that is no-place”, physically hidden from sight in a "zone of confinement” (Pachirat, 2011). Wilkie’s (2010) Livestock/Deadstock examines the relationships humans have with 'food' animals while they are still alive.

Wilkie’s 2010 award-winning ethnographic study of livestock workers reveals the ambiguities and complexities of human-animal relationships in farming. As farm animals are sentient beings and commodities at the same time, this complexity is unremarkable. Wilkie (2010) finds that people experience different emotions towards animals depending on such factors as the type and scale of hobby or commercial production, and the stage of the production process. She notes that the recent legal reclassification of livestock as 'sentient beings' somewhat destabilizes their hitherto taken-for-granted tool-like status, thereby potentially undermining the workers' emotional distance from stock. A further development that renders the humanlivestock interactional order increasingly unstable is that future recruits (as a result of the skills gap) are less likely to come from a farming background (Wilkie, 2010). 
Other ethnographies have instead focused on animal shelter work (Taylor, 2007; Alger and Alger, 2003; Harbolt, 2003; Arluke and Sanders, 1996).

Alger and Alger's (2003) study of the social world of a cat shelter applies symbolic interaction to the study of cat interaction with humans and with other cats. The symbolic interactionist sociological perspective treats humans as active constructs of their social world; humans do not act solely on the basis of norms and other external constraints. Instead human actors receive and evaluate a social stimulus filtered through their own goals and prior experiences as well as in terms of dominant social norms (Alger and Alger, 2003). The actor's subjective viewpoint is thus a factor that must figure in any explanation of how, in response to a stimulus, people define the situation, select a course of action, and act. Alger and Alger (2003) conclude that the shelter workers view the cats as capable of thought, in possession of distinct personalities, and able to reciprocate emotion. The cats appear to view the shelter workers in a similar vein (Alger and Alger, 2003).

In her feminist ethnographic study of a dog shelter, Harbolt (2003) draws a parallel between shelter workers' experience of interpersonal or institutional oppression and the decision to enter the occupational field. This author also infers the decision to be an attempt to control their social environments (Harbolt, 2003). Her acknowledgement that people are drawn to shelter work out of more than simply a desire to help animals is interesting, for scant attention is paid elsewhere in the HAS literature to the reasons for occupational entry, or to the reasons why people stay, despite the emotionally and physically "dirty" work inherent in the world of the shelter. The animals do not judge you (Interviews, 2014) and so control of emotional expression common in other relational work (Casaca, 2012) is unnecessary for my participants in their dealings with the animals in their care. Harbolt (2003) posits that shelter workers make this occupational choice as a result of having experienced institutional or interpersonal oppression. For a subset of four of my respondents, natal or social influences were indeed negative and helped to ignite a backlash which resulted in those respondents caring about animals, but none linked this to the eventual occupational choice. I will endeavour to demonstrate the plethora of dialectical tensions inherent in shelter work in Chapter 6. 
Nik Taylor (2007) writes about shelters from the perspective of intersubjectivity and explicates how animals are constructed as possessing personhood in these organisations. Ethnographic data over three years was produced to establish how workers construct the identity of the animals under their care. The coping techniques she identifies include naming the animals, a priori assumption of personality (“Grover hates cats, don’t you boy”) and being 'in it’ for the animals (Taylor, 2007). Like Alger and Alger (2003) she notes that if we act towards animals at any given time as though they are minded interactants, then, for the purposes of that interaction, they are (Taylor, 2007). Taylor (2007) argues that shelter work is counterhegemonic, and as my respondents are not co-opted into the mainstream market economy, my data has resonance with her findings. Nonetheless, as I will demonstrate, other processes and multiple pathways lead my respondents to shelter work. These include: changes in the life course, cumulative epiphanies (Denzin, 1989) alienation from alternative workplaces and serendipitous events. There are structural bases for the choice of shelter work, as we shall see. There is a link to interactive service work (Casaca, 2012) in the sense that my shelter workers are actively engaged in human-animal interaction every day of their working lives. Unlike Casaca's (2012) call centre agents and supermarket checkout operators however, my shelter workers do not have to regulate their genuine feelings in dealing with the animals. The world of the shelter is far removed from what Casaca (2012) calls a 'big brother' environment. As I explain in Chapter 6, direct encounters with some members of the public do constitute part of the travails of this occupation. Nonetheless, the rewards of helping animals, and the concomitant human-animal relationship rewards bring tremendous joy to my participants (Interviews, 2014 and participant observation).

Arluke and Sanders (1996) also write penetratingly on the institutional self of shelter workers, the conflicts and complexities of their work which often entails euthanasia of healthy animals. Their conflicts are emblematic of the wider social context, these scholars contend. Coping strategies adopted by shelter employees included adopting mascot animals, blaming the animal surrenderers, and resolving cognitive dissonance caused by euthanasia by saying it is infinitely better than to have them confined in cages for months. In a later work, Arluke (2006) further examines this “caring- 
killing paradox" for shelter workers, and concludes that it is difficult for shelter workers to feel authentic in their work if they must perform euthanasia. Killing animals, unless they are suffering, is an anti-thethical position for workers who define themselves by their concern for the welfare of animals (Arluke, 2006: 119). Arluke points to the tensions inevitable between "open-admission" shelters and "nokill” shelters. The former tend to accuse the latter of neglecting the bigger picture and "warehousing" animals. Their "no-kill" counterparts tend to point to the inauthentic identity of "open-admission” workers (Arluke, 2006). In their earlier study, Arluke and Sanders' (1996: 84) find that shelter workers must develop coping strategies in order to deal with the complex feelings to which involvement in euthanasia activities gives rise. Attachment and empathy are used as coping devices, for example, by giving the dog a 'good death' (Arluke and Sanders, 1996:84). Certainly, the sorrows and travails of shelter work (dealing with the public, bearing witness to animal cruelty and abandonment, having to euthanize some animals) must be managed in order to persist in this work. None of my shelters euthanize animals, unless the animal is too ill or aggressive to rehome. There is no fixed roster of coping strategies to deal with the saddening aspects of this work for my respondents but the fact that successfully rehoming animals 'makes it all worthwhile' is commonly reported. The lows are very low, but the highs are sometimes very high and make recompense. Further, most of my respondents tell of their low expectations that penalties for animal neglect will be adequately imposed, or that the public at large will all decide to spay and neuter their companion animals. For the most part, instead they reluctantly accept these difficulties without harbouring high hopes for dramatic improvement and seem attached to the heroic strain in their work against the odds (Interviews, 2014). Shelter work is a narrative of resilience. My data also demonstrates evidence of a further striking reason why my respondents stay - they view their work as an alternative experience of the economy, and as a moral one. Not only does their work make them feel good about themselves, and part of a "project of wider significance” (Giordan, 2007), they are also supported by the wider opinion of members of the community; the "moral economy of the crowd" (Thompson, 1971). I thus contribute further layers to the question of staying; shelter work as moral economy and as sanctuary. I argue that moral economy is the caraspace that protects and sustains their efforts; the easier path is not necessarily the better one, if you think 
of yourself as a 'good' person, as the majority of my respondents have come to do. Even with regard to the animals who cannot be saved, the effort to save them is part of the 'rightness' by which my respondents measure the general rightness of their lives - comments in the vein of 'at least he knew a loving hand, someone who cared', were made by all of my respondents.

Apart from the Pound which has a designated weekly 'Put to Sleep' (PTS) day (Tuesday), all the shelters in the current study claim to operate a "no-kill” policy . In the official literature of one rescue organisation appears the statement: "We never put down a healthy dog”. Of course, one must ask what constitutes physical or mental health and who makes this often capricious decision, and on what bases? Further, when full to capacity, shelters sometimes have no choice but to bring dogs to the local pound. The issue of euthanasia is thus complex and multi-layered and resists simple dichotomies. Reeve and Rogelberg (2005) provide unsurprising evidence that euthanasia related work is negatively correlated with employee wellbeing independent of its relation with generalised work stress. Specifically, these authors find that individuals involved in euthanasia activities experience more physiological complaints, substance abuse, work stress and less job satisfaction, than do workers not involved in euthanasia activities (Reeve and Rogelberg, 2008). Euthanasia is one of the major dilemmas in shelter work (even my "no-kill” shelters deal with euthanasia of sick and injured animals) but as will be shown, there are others. For example, dealing with the unreasonable expectations of the public is commonly cited as a downside of the work. Shelters depend upon the donations of members of the public to continue their work. Further, shelters rely on members of the public to foster, adopt, to volunteer. In chapters 5 and 6 , a social constructionist perspective will be used to try to unpack and lay bare these dialectical tensions.

I turn next to the guiding questions of this study. Why do people choose shelter work, and why do they stay in this occupation? Shelter work stands outside the neoliberal prescriptive paradigm, where profit carries the day. Of course, this is true of other types of 'care work' beyond animal care. Animal care work is perhaps distinctive in that it can be physically dangerous, pays less than most alternative care jobs, and extends our moral compass to include other species. England (2005) identifies five theoretical frameworks in which to organise care work: The 
devaluation perspective, public good, 'prisoner of love', commodification of emotion and the 'love and money' paradigm. The devaluation perspective argues that care work is poorly remunerated because it is seen as 'women's work'. The public good framework points to the broader societal benefits of care work while the 'prisoner of love' theory emphasises that the intrinsic motives of care workers allow exploitation (see also Bunderson and Thomson, 2009).

The commodification of emotion framework focuses on the emotional harm to workers when they have to sell services that use an intimate part of themselves. Finally, ‘love and money’ argues against the dichotomous view in which markets are seen as anti-thethical to true care (England, 2005). The first four of these frameworks have resonance for shelter workers. The pull of caring for the animal 'other', undercut by the countervailing tug of the 'reality' of the hegemony of the marketplace is an anomaly. Of course, this is true of other forms of care work. The only non-animal worker among my respondents is a Special Needs Assistant (SNA) for children with a wide range of physical and mental disabilities, including profoundly autistic children. This is demanding work as some of the children can be violent. Like the shelter respondents, she describes her job as rewarding because the children are so vulnerable. The challenges (she has been physically assaulted several times) appear to be worn as a "badge of honour” (Sanders, 2010), just as the shelter workers nonchalantly tell of receiving bites or scratches.

Some potentially fruitful theoretical lenses through which to view the particular case of shelter work are discussed in the next section.

\subsection{Shelter Work: Calling or Moral Choice?}

Mizzoni (2004) argues that as an economic system, capitalism views work in purely economic terms; the economic approach is based on the behavioural model of homo economicus, the model of a 'rational utility maximiser'. He cites how Csikszentmihalyi (1990) describes how economic rationality has become so successful that we have come to take for granted that the measure of any human effort is to be measured in pecuniary terms. For example, if the market puts a high price tag on certain occupations then they must be 'good', and low-wage occupations must then be 'bad' (Csikszentmihalyi, 1990). 
According to Mizzoni (2004) if we look beyond an economic model of the nature of work, and draw on non-economic traditions, then our toil may become part of something larger than private. Clearly, shelter work is unlikely to be motivated by pecuniary considerations, and it falls outside the traditional neoliberal paradigm. So how is this occupational choice to be understood? My early theoretical presupposition was that shelter work would be constructed as a vocation by my respondents. Wrzesniewski et al (1997) distinguish between job, career and calling orientations to work. The governing rubric of Wrzniewski's much-cited 1997 article on work callings is categorization: she emphasizes the import of the distinction between a job, a career and a calling. A job orientation is defined as a focus on financial rewards or necessity, a career is geared towards personal advancement, and for a calling the focus is on doing fulfilling, socially useful work (Wrzesniewski et al 1997). Strikingly, in a later book chapter Wrzesniewski (2002) describes how many people turned towards what they perceived as more meaningful work in the aftershock of the 9/11 terrorist attacks in the US. It would seem that what counted as 'successful' prior to those calamitous events, was, for some individuals, chimerical in their wake. Giordan (2007) suggests that perceiving life in terms of a vocation means lifting it out of the banality of a simple succession of random events and giving them the added value of a harmonious framework, part of a "wider project of significance” (Giordan, 2007). The majority of my respondents did not see their original choice to enter shelter work as a 'calling'; synchronicities or changes in life circumstances, as well as disaffection with alternative workplaces constituted more significant pathways to entry. Nonetheless, my respondents all describe shelter work as 'work that matters' or 'makes a difference'. Further, it is difficult to reconcile my ethnographic findings with the notion of shelter work as 'just a job' or as offering opportunities for advancement. There is evidence that for some of my respondents, their occupational choice may be retrospectively contructed in symbolic interaction as a calling, though they do not use this term.

Therefore, theoretical insights from the vocational literature have been retained. For example, Dobrow's 2007 longitudinal study of musicians conceptualised a calling as comprised of 7 core elements: passion, identity, urgency, longevity, sense of meaning, engulfing conscience, and specific to self-esteem. None of these factors 
emerged as principal antecedents to the choice of shelter work in the current study. Nor do these elements appear to constitute the primary reasons for staying in the shelter. Shades of all of Dobrow's (2007) themes are evident in my participants' narratives however. Calling would thus appear to form part of the processual nature of this occupational choice.

Two recent studies linked the concept of 'calling' to animal work. Bunderson and Thomson (2009) invoke the Calvinistic origins of work calling in their study of zookeepers. They found that calling for zookeepers resembled the classical origins: they work for 'a cause bigger than me', not just for pay (on average 26,000 US dollars) or status (dirty work) but for ideological reasons: the preservation of biodiversity, and socio-emotional reasons. One of Bunderson and Thomson's (2009) respondent's humorous anecdotes is included in their paper; a nun taking a group of school students around the zoo indicated to him, saying: "See the kind of job you get if you don’t finish your education!” Bunderson and Thomson (2009) note the irony, given that most zookeepers in the US have a college degree. There are powerful implications inherent in the ability to see humour in one's occupation being publically demeaned; these workers will make sacrifices that other workers will not and have a strong sense of meaning in their work. However, the 'calling' orientation comes with costs attached, according to Bunderson and Thomson (2009); zookeepers hold their organisations to a higher standard, and they are open to exploitation by management because the zookeepers perceive their work in deontological terms. The word passion derives from the Latin 'passio' for suffering, and Bunderson and Thomson (2009) focus on the "dark sides” of possessing a calling.

There are echoes here of Frankl's (1959) invocation of Nietzsche's observation that he who knows the 'why' can bear almost any 'how'. Baran et al (2012) also refer to the flipside of animal work, in their study on shelter workers in the US when they speak to the 'silent shouldering' of the burden of this occupation. There are few other studies on the difficulties of shelter work.

Clinton Sanders (2010) calls much of the work veterinary technicians (the North American equivalent of veterinary nurses) do 'dirty work' in that it often involves dealing with blood, pus, and urine. In addition, he observes, it is emotionally 'dirty 
work'; it often invokes emotions such as grief or anger, though these may be borne as a badge of honour by some veterinary technicians (Sanders, 2010). Higgins (2010) observes that without interest, we would only experience the world, in William James' famous phrase, as a "booming, buzzing confusion”. Occupations are one of our main purposive organising factors, he argues, and determine what sort of world we live in (Higgins, 2010). It is striking how all of my study participants compare shelter work favourably to other jobs they have held in the for-profit sector. Obviously, my respondents have chosen to remain in shelter work, so selection bias is a limitation of any conclusions drawn in these pages. However, the Ariadne's thread of 'the best job' or 'the only job' runs through my interviews and on-site observations, and strongly suggests that my shelter respondents, the two male CEOs Mike and Des included, see their work in moral terms, if not explicitly as a vocation. The veterinarian works pro bono, and allows shelters to run up large bills, which are seldom entirely paid in full, and so vets like him also form part of the moral economy - they are not just operating commercial practices. The next section reviews the literature on the moral economy.

\subsubsection{Moral Economy}

Polanyi's illuminating 1957 work traces how English thinkers responded to the destabilizing effects of early industrialization by developing the theory of market liberalism: society should be subordinated to self-regulating markets, a belief which became the organizing principle for the world economy. Polanyi (1957) argues that market liberalism spawned an inevitable set of concerted efforts to protect society from the market. The second "great transformation" - the rise of fascism was directly related to the rise of market liberalism. Polanyi has important things to say about the dangers of market liberalism, and of commodifying nature. This study finds theoretical inspiration from Polanyi’s arguments. Polanyi (1957) emphasizes that the entire tradition of modern economic thought rests on the concept of the economy as an "interlocking system of markets that automatically adjusts supply and demand through the mechanism of price” (Polanyi, 1957:xxiii). Before the nineteenth century, he insists, the human economy was always embedded in society. The term “embeddedness" expresses the notion that the economy is not separate from, as in economic theory, but interwoven with politics, religion, and social networks. The 
control of the economic system by the market is therefore of enormous significance to the whole organization of society because it suggests that society should be organised as an adjunct to the market. Further it requires human beings and the natural environment to be commodified. Land, labour, and money should not be considered commodities because they were not originally produced to be sold on a market. But people are agentic and they resist. Institutions are "embodiments of human meaning and purpose” (Polanyi, 1957: 262). As will be shown in chapters 5 and 6, Polanyi's influential argument has deep resonance in explicating the decision to enter shelter work, and the decision to stay, despite the many sorrows and difficulties this work entails. My shelter participants rely on the moral economy which is embedded in sentiment about animals and is inherently not market-oriented, although I have also documented marketised interactions with animals. Though situated in a particular historical point in time, my respondents can find an alternative experience of being in the economy, one in which "human flourishing" (Bolton and Laaser, 2013) is possible. While it should not be over-idealised, I contend that shelter work is closer to a pre-modern Gemeinschaft than to a Gesellschaft (Bolton and Laaser, 2013). Shelter work is deeply embedded in society and meets human (and animal) needs, and is viewed by incumbents as a moral space which is connected to their values, aspirations, and mores. Like Becker's (196: 147163) 'moral entrepreneurs' who take the initiative to generate a 'moral enterprise', my respondents are not simply trying to prevent animal owners from doing what they have constructed in symbolic interaction as the wrong thing. Rather they are trying to forge a better life for companion animals. All respondents compared shelter work favourably with other jobs they had held in offices, the Civil Service, factories (Interviews, 2014).

Bolton et al (2012) offer the conceptual lens of moral economy as an ethical framework through which to assess Human Resource Management (HRM) practice. Their focus is on temporary workers and they argue that a moral economy lens views employment as a "relationship rooted in a web of social dependencies, and considers that 'thick' relations produce valuable ethical surpluses that represent mutuality and human flourishing” (Bolton et al 2012). This perspective reminds us that 
employment is both economic and social; human wellbeing is the most central purpose of social and economic life.

Jacobson and Lindblom (2013) instead theoretically link activists' motivation to Durkheim's sociology of morality. Durkheim identifies the building-blocks that constitute the moral order of society as ideals and norms, where the former denote what is desirable but not yet implemented. Norms are rules of conduct which are legislatively or socially sanctioned. According to Durkheim, ideals are imbued with prestige because they belong to the "sphere of the sacred" (Jacobson and Lindblom, 2013). These scholars draw on Durkheim's sociology of morality to argue that activists' ideals are vested with prestige because they belong to the "sphere of the sacred” (Jacobsson and Lindblom, 2013). There are shades of this notion to be found in my participants' accounts but I also find evidence that my respondents choose shelter work as an 'escape' from alternative employment which they found meaningless or divorced from their values and lifestyle preferences. My shelter workers' shared values and norms about 'justice' for animals helped me to interpret their actions in terms of the moral economy. The non-human interaction provides the possibility of sanctuary from human only workplaces, and as a buffer from regimented workplaces, as I will demonstrate in Chapter 6. My respondents' productive efforts are the means to social, not economic ends.

Hamilton and Taylor (2012) also make the important observation that the rewards in the animal shelter are not pecuniary, but rather reach into the more symbolic and ethical domains of value creation.

Work, as Terkel reminds us, is "about a search for daily meaning as well as for daily bread, for recognition as well as cash, for astonishment rather than torpor, in short for a sort of life, rather than a Monday through Friday sort of dying” (Terkel, 1972: xi). Of course, shelter workers must earn money in order to survive. Two of my shelter respondents are highly paid CEOs. The 20 'care-workers' are either volunteers with alternative sources of income (running a cattery, teaching Animal Ethics, in receipt of unemployment assistance, drawing a pension, financially assisted by a partner who is engaged in more lucrative work,) or workers earning a 
very low income (15 respondents) which some supplement with dog-grooming on their days 'off' (Interviews, 2014).

Facebook 'posts' of many shelters suggests that this work is seen as meaningful: 'We no longer wearily face the working day. We are making a difference' (Appendix F). The shelter may be the place where Bell and Taylor's 'work-joy dichotomy' disappears (Bell and Taylor, 2004).

Shelter work is a bastion of female activity, and most of my respondents were either victims of the 2008 credit bubble and subsequent financial crisis, or they simply found their jobs (in factories, the Civil service, in IT) meaningless, empty and alienating. In most organisations, the construct of work tends to retain its "capitalist garb” (Dawson, 2005).

By situating the employment relationship within a wider social and cultural context, a moral economy framework makes it possible to better apprehend the apparent contradictions inherent in shelter work. Interspecies connectivity provides an opportunity for my participants to flourish and to feel that their work matters to wider society.

Sayer (2007) agrees that economic processes, even capitalist ones, are socially embedded in various ways. The economic cannot therefore not be understood without reference to the social and the cultural. Capitalism depends upon non-market forms of division of labour as well as on market ones, Sayer (2007) argues. Moral economy is the study of how economic activities of all kinds are influenced and structured by moral dispositions and norms, and so is highly relevant to my study participants' work lives. I seek here to add moral economy to a processual perspective on the occupational choice of shelter work. Shelter work is a dialectical process whereby the workers are constantly shaped by and shaping the meaning of their co-constructed environment. Chapters 5 and 6 try to develop a processual moral economy theory of occupational choice, bearing in mind that my respondents' accounts are partial, synchronic, and therefore partially untrue, or at least subject to change.

My participants frequently state that shelter work is the 'right way' of being in the world, and despite its travails and dark sides, they appear to find this work conducive 
to well-being. The processes and pathways by which this choice is made and sustained are examined in chapters 5 and 6. As my respondents tell it, the sanctuary is not only bestowed upon the animals; this work appears to offer shelter workers a kind of sanctuary as well. Shelter workers experience social cohesion, human-animal bonding and work consistent with their moral values; a gamut of phenomena that add richness to human life.

\subsection{Sanctuary and Postmodernity}

We have seen that companion animals act as 'life-changers' for the homeless people in Irvine's 2012 study. Could their work constitute a kind of sanctuary for shelter workers themselves?

Many Facebook remarks on shelter websites suggest that possibility; for example, a 2014 'follower' post on my respondent Agata's website remarks: “Told you it was sanctuary. The contents of the Ark are next”. This remark refers to the large menagerie of animals kept in Agata's home, and she too describes her rural home as 'her' sanctuary.

Franklin et al (2001) hold that postmodern conditions have wrought fundamental changes to social and cultural life, and that trends in human-animal relations can be linked with the broader trends of post-modernization. Franklin et al draw on Inglehart's (1997) earlier theory of postmaterialism and criticise its focus on sociopolitical changes to the exclusion of shifts in human-nonhuman relations. Franklin et al (2001) argue that companionate human-animal relations meet the emotional lacunae which were once met by enduring human relationships. Franklin et al's 2001 conceptual article is centred on the rise of the animal rights movement, and not on animal care workers, however the thesis clearly has resonance for the latter cohort. The 'fragmented and fugitive' nature of labour markets, communities, and family relations create an emotional space which companion animals might fill. 'Are domestic animals a kind of hearth?' echoes Mark Doty (2008: 38).

Work has changed in the postmodern context (Harvey, 1995). Work is much less secure, entails fewer benefits, is more 'market' driven, and therefore more alienating. For Harvey (1995) neo-liberalism is the ideological mode of regulation in this context. This conceptualisation would seem to have some potential explanatory 
power for the incentive for my respondents to seek sanctuary in shelter work. The fact that most of my respondents began as volunteers in shelters, or are still volunteers who rely on family members or partners or unemployment benefits to subsidise their wish to help animals is also important. Drawing on Lipietz (1993) volunteering might have been relevant in this context also. In the post-Fordist economy, argues Lipietz (1993); more and more of the potential working population become superfluous to its needs and 'choose' 'half-jobs' in the voluntary sector (Lipietz, 1993). My participants do not view their work as 'half a job' however, rather as the most important work they have ever done.

In a similar vein, on the pet question, Nast (2006) argues that post-industrialism is characterized by conditions conducive to pet-love; smaller families arising out of deindustrialization, longer lifespans, and 'boundaryless careers'. Such conditions, she points out, produce a "plethora of human alienations, such as loneliness and aloneness, and an erosion of long-term place-based communities” (Nast, 2006: 304). In Nast's (2006) conceptualisation, post-industrial isolations have made pets into "screens onto which all sorts of human needs, desires, and investments can be and are being projected”. Nast (2006) focuses on how post-industrial alienations have been wedded to pet-mediated modalities of domination, affection, (see also Tuan, 1984) love, family, and community in our century. She points out the paradoxical rise of animal rights discourses in the light of modernity's violence between humans.

All but one of the shelters in the current study are situated in rural locations. In the case of the exception, the CEO respondent returns home to rural Ireland every weekend. The 'closeness to nature' afforded by these occupations is rated highly by all respondents, and they frequently favourably contrast their working lives to office work in capitalist organisations. The sanctuary they experience appears to operate on three different levels. First, the interpersonal relationships with co-workers, and the interspecies relationships are described in familial terms. As speech does not form the bedrock of our relationship with animals (at least, not in terms of two-way communication) for shelter workers, the interspecies relationships are defined by mutual sensitivity and alertness (participant observation). Second, the settings of the shelters are rural and picturesque and removed from the urban space, by which I mean that there appears to be a kind of sanctuary to be found in 'nature'. Third, the 
work seems to represent sanctuary from alternative employment. In light of LipsWiersma's (2002) view that employees' current experience of work includes a "lack of trust and being treated as expendable in the process of maximum profits" the impetus for some towards a search for sanctuary is unsurprising.

The term sanctuary here requires some explanation. Like any word, this one has a history of use and meaning. Historically, the term sanctuary referred to physical places, geographic locations, such as churches, where individuals could seek refuge from legal or state sanction (Branchi, 2010). Understandably, people commonly see shelters as providing sanctuary to animals, from cruelty, abandonment and suffering. In fact, some shelters even call themselves 'sanctuaries' (for example, The Donkey Sanctuary, Ireland). However, I am using the term in a wider, quasi-metaphorical sense to help explain how shelter work offers a refuge for the workers themselves. This refuge or sanctuary can also be conceived as a 'place', but in the sociological rather than simply geographic sense of the word. Here, the place of sanctuary that shelter work offers to its participants is encapsulated in both the nature of social relations it entails as well as the geography and time in which those relations are situated. I use sanctuary as a device to reflect how my respondents have a different experience of the economy through their occupation. From this perspective, I conceive of sanctuary not only as a refuge or escape from the mainstream labour market where my respondents had less happy experiences, but also as a site of resistance to the pressures of market relations. In this sense, sanctuary is not merely inherent in the physical place of the shelter, but is also exemplified in the fact that my participants can sport tattoos and body piercings, and be accepted by their colleagues and the animals in their care and can challenge the commodification of their charges and their own labour in a way that would rarely be accepted in the mainstream labour market. Thus, this concept of sanctuary here operates on two levels: sanctuary from the standard market economy, and in the moral economy of shelter work. The theme of sanctuary is revisited in more depth in chapters 5 and 6.

\subsection{Chapter Summary}

This chapter reviewed the literature on occupational choice, HAS, and moral economy. Despite the many insights furnished by all these studies, the sociological 
bases and processes driving people to deem animal shelter work a choice-worthy occupation have tended to be overlooked. Further, the extant literature on the 'dark sides' of such occupations is scant, with notable exceptions (Arluke and Sanders, 1996; Bunderson and Thomson, 2009; Baran et al 2012), also the reasons why shelter workers stay are seldom articulated in the HAS literature. These lacunae were the trigger for the pages that follow.

My goal is to contribute to an understanding of why people make the onerous 'choice' of shelter work, and to what is specific to human-animal work in this choice. Thirdly, I aim to uncover how choices are structured. The framework which organised my analysis has three parts: repertoires of choice, occupational entry, and staying.

The contemporary organisational field structuring the occupational choice of shelter work forms the basis for the chapter four. Chapter 4 also examines the origins of animal welfare organisations in the Republic of Ireland as well as the regulatory and legislative environment governing animal welfare. The organisational structuring of animal care into jobs explicates the contexts that people are moving through, before and during occupational entry.

Chapter 5 examines the various reasons why people make the choice to enter shelter work, which is often a choice 'against' other occupations. The 'real' choice may be the choice to remain in these occupations, the theme of chapter 6. Shelter work is somewhat of a Faustian pact, with rich rewards but at the cost of being subject to immense pressures and contradictions. Meaning-making processes and the moral aspects of the occupation will be unpacked, as will the social value of saving animal lives and the responsibilities which the few carry for the many animals who depend upon them.

In the next chapter, I introduce the epistemological underpinnings of this study, and explain the methods I used to try to understand the people who mind abandoned animals in that liminal space before these animals find a permanent home, or do not. 
Chapter 3 


\section{Chapter 3 Methodology}

The essential vocation of interpretive anthropology is not to answer our deepest questions, but to make available to us answers that others, guarding other sheep in other valleys, have given, and thus to include them in the consultable record of what man has said (Geertz, quoted in Arluke and Sanders, 1996: 9).

\subsection{Introduction}

This chapter introduces the research methodology used for this study and how it has guided my data collection, subsequent analysis and development of theory. I discuss how I prepared for fieldwork, the intricacies of the ethical approval process, my sampling methodology, access issues, data collection and my approach to analysis. I also introduce my participants.

\subsection{Preparation for Field Research and Learning from Conceptual Error}

Shelter work as a 'calling' (Bunderson and Thomson, 2009; Baran et al 2012) initially seemed a fruitful avenue to pursue but was not borne out. Very few people said they 'always knew' that they would work in a shelter, nor that this choice was borne out of sense of duty, much less out of a 'transcendental summons' (Bunderson and Thomson, 2009). I was therefore forced to rethink my vocational theoretical presupposition. Fieldwork took much longer to complete than I had anticipated. Participants were sometimes unavailable at short notice due to unforeseen events, some participants were happy to talk to me informally but seemed reluctant to be audio-taped as they re-scheduled interviews many times. Prior to conducting formal interviews, I engaged in 24 months of preparatory work.

I undertook several informal visits prior to interviewing: to a veterinary nursing (many VNs work in shelters) conference, to local animal shelters, to undertake volunteer orientation training in a Dublin shelter. I acted as principal volunteer fundraiser for a local branch of the SPCA from 2008-2011. I have also volunteered as an occasional dog-walker for a different local shelter from 2010 to the present. I walk my own two dogs every day and as observed above, am often struck by the socially lubricating effect of the presence of companion dogs; dog-walkers frequently engage in conversation, often about their dogs' antics, in a way that people walking alone do 
not. All of these prior experiences indubitably sensitised me to issues which are relevant to the world of the shelter.

I received further training in Qualitative Methods at the two-week Essex Summer School in Qualitative Research in July 2013. The course included delivered lectures, a presentation of candidates' participant observations, conducting and transcribing an interview as well as documentary analysis and MAXQDA training and a final examination.

I also attended Martyn Hammersley's Ethnography Seminar, at Dublin City University in May 2014 and completed modules GSS1 and GSS2 in 2013 at NUIM, as part of the structured $\mathrm{PhD}$ programme. A qualitative approach was appropriate for the current study because of my concern to make sense of the meanings the workers themselves bring to their work. Denzin and Lincoln (2000) offer the following definition of qualitative research:

Qualitative research consists of a set of interpretive, material practices that make the world visible. Those practices turn the world into a series of representations, including fieldnotes, interviews, conversations, photographs, recordings and memos to the self. At this level, qualitative research involves an interpretive, naturalistic approach to the world. Qualitative researchers study things in their natural setting, attempting to make sense of, or interpret, phenomena in terms of the meanings people bring to them (Denzin and Lincoln, 2000: 2).

Ritchie and Lewis (2003:7) note how strongly Dilthey's notion of 'Verstehen', or understanding people’s lived experiences influenced Max Weber. For Weber, however, the researcher must understand the "meaning of social actions within the context of the material conditions in which people live” (Ritchie and Lewis, 2003: 7). The current study adopts an interpretivist approach which seeks to understand the psychological, social and cultural factors that shaped my participants' choices and lives.

I had an abstract based on this study published at the BSA conference, April 2014, and presented a paper at a roundtable at that conference. My abstract was accepted for the 'Family and Relationships' stream, which I found interesting. I described my motivation for the study, methodology and settings, and initial findings from the ten interviews I had conducted. At that early stage, I conceptualised my findings in 
terms of antecedents, rewards, dark sides and coping strategies (Appendix G). As my research progressed, I refined those early categories into sorrows, travails, consolations and joys of shelter work. These new categories seemed more representative of the spectrum of experience which my shelter respondents described. My research settings also expanded over time, as I describe in section 3.3.1. below.

\subsection{Ethical Review Process}

The ethical dimensions of research demand careful attention, and prior to data collection, I sought ethical approval in the Summer of 2013 from the Social Research Ethics Sub-Committee at NUI Maynooth. This was an onerous task which required writing a detailed submission, and making several amendments and clarifications as required by the panel. Nonetheless, it was valuable as I was compelled to think in detail about my research design and methodology at an embryonic stage in my study. At this stage I envisaged that 20 interviews would be conducted, and participant observation carried out in four research settings. Ultimately, this was to become 24 interviews and seven shelter settings (plus a veterinary surgery and a Dog Pound). For example, I had to reflect on whether this study might pose any risks for my participants, or repercussions beyond the research context. I submitted that I did not anticipate risks to my participants. However, anyone participating in research, where the researcher is 'empowered' to gather and interpret information could be said to be vulnerable.

Shelter work is 'emotion work' and it was possible that participants might become distressed when describing animal abuse cases, for example. I explained that participants' wellbeing would, at all times, take precedence over the aims of this study. Should any participant become distressed, I would acknowledge this distress and the interview would only be continued if consent was given. In the event, some interviewees did become distressed during interview (as on more than one occasion did I) but nobody wished to stop or discontinue the interview. With regards to the possibility of details about bullying or other deviant organisational practices emerging, I was prepared to offer advice as to help available, and to have contact 
details to hand. I believed that I would be able to draw upon my over twenty years lecturing experience should any such situation arise, which thankfully it did not.

Nor did I anticipate any possibility of risks to the animals posed through this study. As I planned to be involved in walking, grooming and feeding animals during participant observation, my hope was that my research would have some small positive outcomes for the animals who would also be under study, albeit unknowingly. No information was withheld about the research procedure or purposes. Deception was neither necessary, nor justified. My intention was, and is, to offer to make a summary of the research findings available to participants, as well as the transcript of their own interview.

In order to preserve the confidentiality and anonymity of data, transcripts were to be stored on a password-protected PC, and in a locked filing cabinet to which only I had access. The data were anonymised; no data generated referred to the shelters or participants by name and code names were assigned to all participants. Shelter/veterinary surgery locations were not identifiable as all identifying features were removed from the transcripts. I propose to retain the data for five years after the study and analysis, keeping the key codes connecting subjects' data to their identity in a separate locked filing cabinet from the transcripts. Participant consent will be renegotiated if the data is subsequently used in other outputs resulting from this study

I scripted and had 80 information sheets (Figure 3.1.) printed. I also designed a Consent Form for Participants (Appendix B). Both of these documents were designed to clearly communicate the intent of this study in an informal way. The information sheet was intended for the personal information of would-be participants, to review at their leisure in order to assist in their decision whether to participate.

As everything participants told me in the course of the research was confidential, data were anonymised, and my PC password protected, I did not envisage any negative repercussions arising for my participants. The protection of the safety and integrity of participants is a core research concern, but so too is respecting their agency and autonomy. In the next section, I lay out my sampling methods. 


\subsection{Sampling Methodology}

I used a theoretical sampling method; I selected participants according to my criteria of interest. Recruitment of potential participants in the first instance involved making contact with the owner/manager/CEO of the various shelters across six counties: Dublin, Carlow, Kilkenny, Wicklow, Wexford, and Tipperary. As I needed to make several field visits to each setting, and as I work fulltime, shelters in the West of Ireland were precluded from the study, although I have Facebook 'friends' in the latter shelter cohort, so some shelters in other geographical locations are included for the purposes of social media analysis in Chapter 6. Formal interviews were conducted between January and December 2014 and this allowed me to see the shelters and to hear participants' accounts over different seasons which was useful. Animal shelter work is particularly challenging in the post-Christmas period for dogs, for example, and in the summer months for cats. The sample of 24 respondents was spread over urban and rural locations in the East of Ireland. Participants varied in age from 20 to 67 and were from diverse socio-economic and ethnic backgrounds. I developed a participant profile for each respondent (see Chapter 3). The female:male ratio of 4:1 (for shelter care-workers) is broadly in line with other shelters not included in this study (3:1 in the Irish Horse Welfare Trust, for example).

I spent most time in Organisation A (which has no holding facilities), Shelter E (a large SPCA), and Shelter $\mathrm{H}$ (a large mainly dog-shelter). Of the 24 interview participants, 20 are 'nitty-gritty' level shelter workers, of which 16 are female and four male, which reflects the gendered nature of shelter work. Obviously, more than four male respondents would be desirable in order to reach theoretical saturation. The two highly-paid CEOs are not as hands-on with the animals, although both are animal-lovers, and both gave similar reasons for entry and staying to my other respondents.However, for the four male shelter workers in my sample (deviant cases), entry and staying were described in similar terms to those of my female respondents. Further interviews with male workers - although this would perforce skew the male/female ratio typical of shelter work - would be necessary in order to establish whether there are other categories of male workers not reflected in my data. 
I interviewed a veterinary surgeon (John) who has almost 40 years of experience in practice, and has dealt with hundreds of shelter workers and 'their' animals over that time. Further, as he treats shelter animals on a pro-bono basis, allowing shelters to run up large bills which are rarely settled in full (Interviews, 2014), I contend that his work goes beyond the commercial and enters a moral economy realm. For these two reasons, his insights were invaluable to this study.

I also interviewed a SNA in order to gain further insights into low-paid care work. Her comments led me to the insight that the care ethic is part of the moral economy of the shelter. I contend that these interviews (and participant observation in the case of the veterinary surgeon) add richness to my findings. When I write about "my respondents" in the following pages, I refer to my 22 shelter respondents, unless otherwise stated.

My Pound employee could be deemed to be a special case. Like my shelter respondents, she works with animals every day. However, as a Local Authority employee she operates within different structural conditions to my workers in small shelters. In the latter case, shelters could close should funding cease. Nor do shelter workers have pensions or tenure. For these reasons, the question arose in my mind as to whether a Pound could be considered a 'shelter', and whether I should include this worker due to her different institutional setting. I made the decision to include her interview as she gave the same reasons for entry and staying as my other respondents, they perceive her to be doing the 'same' work as they do, and I regard her work as part of the moral economy.

A snowball sampling technique was used; my contacts in one shelter vouchsafed for me or acted as a "sponsor" for other research sites. My research sites were selected to reflect different animal species (cat mainly, dog mainly, across species shelters, and a veterinary surgery which engages in pro bono work). The research sites were also selected on the basis of geographical location; my time and resources are limited so research sites within a reasonable distance of Carlow/Kilkenny were preferred. There was thus a selection bias towards geographically convenient counties, and towards people who wanted to participate in the research, but this is common to most qualitative research study. Further, this study did not set out to produce statistically 
generalizable laws, but rather to gain a deeper understanding of the participants' lived experience of shelter work. In other words I aimed to generalize about the categories at work in the process entry and staying in shelter work. By reference to previous research (Arluke and Sanders, 1996; Harbolt, 2003; Taylor, 2007) I argue that my inferences go beyond my participants' experiences, and fit into the broader phenomenon of shelter work. Further, my conclusions are generalizable in the sense that they are generalizable in the context of moral economy. I therefore expect the shelter workers I studied to be similar in important respects to workers in other shelters.

Gaining access, as Ritchie and Lewis (2003: 62) observe, requires patience and sensitivity. Following Ritchie and Lewis (2003: 62) I tried to be sensitive to issues of hierarchy, and as soon as this was possible, I provided clear and unambiguous information about the aims and purposes of this study, and about how its findings would be reported (See Information Sheet, Figure 3.1.). Of course, as Miles and Huberman (2014: 295) point out, I could only talk to people who wished to be interviewed, which in itself signals something particularistic: "Anthropologists have often warned of fieldworkers' tendency to rely too much on articulate, insightful, attractive and intellectually responsive participants, such people often turn out to be the local elite” (Miles and Huberman, 2014: 295). Further, my presence was noncontinuous, and I had to infer what was happening when I was not there, which is a common pitfall in terms of representativeness (Miles and Huberman, 2014: 299). Aware of this pitfall, I spread my participants across seven shelters, included volunteers or part-time, less 'elite' participants and an outlier respondent (Interview with Joan, $25^{\text {th }}$ February 2014). The problems I encountered with access were both institutional and individual. In the case of shelter E, I had attended volunteering training orientation, I had made five field visits, and obtained informal interview consent from several male and female workers. A retirement and change of CEO in this organisation in 2012 meant that my access was effectively rescinded. I gathered this when, after initial inquiries about the nature of my study (which was difficult to furnish at such an embryonic stage), he failed to respond to further email correspondence. Ultimately, the only formal interview I conducted with respect to 
this organisation was with the retired CEO and it was illuminating (Interviews, 2014).

The other participants' awareness that I was a $\mathrm{PhD}$ candidate initially appeared to increase wariness and reticence for some. This probably initially affected how I was seen and what I was told. However, my interactions were facilitated by the information sheet for respondents, my longstanding familiarity with dogs and cats, and the animals' positive response to my presence. The shared space of empathy and recognition for animals my participants and I share helped me gain their trust. My gender was perhaps also of advantage; shelters are predominantly female environments, and dogs who have been ill-treated are generally more at ease in the company of women. All of these factors helped me to build rapport with participants, human and non-human, more quickly than may otherwise have been the case.

Gaining access to the Pound was considerably more difficult because Pounds (often correctly) perceive themselves to be negatively viewed by no-kill shelters, and by some members of the public. I explained that most of my interviews were completed but that I would love to include the Pound's perspective on working with animals. I also explained that I understood the importance of the Pound's role, and that euthanasia is inevitable given the dearth of good homes for unwanted dogs in Ireland. This is true; I do not endorse the idea of life at any cost. There are four employees: two dog wardens, and two canine carers. The carer whom I met was interested in being interviewed - which I scheduled quickly, before she changed her mind - but the other carer was not, as was the case for both dog wardens. This was disappointing but I did not expect to get access at all so I was pleased. This respondent told me that "work shadowing" was out of the question. I do not know how she arrived at using this term, or its provenance, as it certainly does not appear on my information sheets. I surmise that Pounds may be warier than "no-kill" shelters of outsiders, particularly those outsiders with a research agenda. The Pound is a really interesting setting. The sign on the building says "Dog Shelter" and two white vans parked in front of the building say "Dog Control Unit".

There were two other individual instances of difficulty with access. At a conference in 2012, I spoke at length with two female former VNs who had left shelter work for 
positions as pharmaceutical representatives at a large petfood manufacturer. Just as nurses are commonly employed as pharmaceutical representatives because of their medical knowledge, so too are VNS. They explained that the arrival of their children had rendered shelter work too difficult, due to its low pay structure, and unpredictable hours. If an injured animal is admitted at 5pm, they explained, it is not possible to leave. This fact is incompatible with child care arrangements. Neither woman particularly liked their new careers but despite missing shelter work, both felt they had had no choice but to leave which represents a different outcome of the same generic process I describe in this thesis. After successfully obtaining ethical approval from NUIM in October 2013, I emailed these two potential respondents who had left the field with whom I had had informal conversations at a conference. One email 'bounced back' and the other went unanswered. I surmise that the length of time that had elapsed may be a contributory factor, or it is possible that these women simply did not want to go on record about their experience of leaving the field. It proved very hard to find participants willing to be interviewed on record about their decision to leave animal shelter work. As Archer (2007: 22) reminds us: "We modify our goals in terms of their contextual feasibility". Another reason one VN who formerly worked in a large Dublin-based shelter informally gave for leaving was the change in shelter management. The new CEO sought to "run the shelter as a business", and did not care about the animals, in her view. She returned to a position as a VN in private practice. In the context of moral economy, it would seem that when the market logic encroached on her sense of her work with animals she felt uncomfortable and left. If this is the case, this instance of leaving the field does not contradict my theoretical conclusions, rather it is consistent with them.

As my ethnographic focus was on people who have stayed in the field, it represents only part of the picture and not the whole. Negative cases could have afforded me the opportunity to modify my theoretical explanations. Research on why people leave would be a fruitful area to explore, as entry, staying, leaving could be deemed to be a natural history of a career (Arluke, 2016, personal communication). In the next section I lay out my research settings. 


\subsubsection{Research Settings}

The Irish animal welfare/rescue landscape is rather complex. There are Pounds (seven of which are run by the SPCA at the time of writing in 2016), county SPCA rescue organisations (some of which have holding facilities, some of which do not), and privately run shelters (usually with charitable status, and usually lightly regulated). In addition, since 2009 the UK-based Dogs Trust, a large organisation which is commercially very successful (the $12^{\text {th }}$ largest charity in the UK) has set up operations in Finglas, Dublin. Like the shelters, it takes dogs from the Pound system, as within this system, dogs have 5 'stray days' after which they can legally be euthanized. The situation in regard to the euthanasia of dogs in Irish Pounds has improved (though the figure is still much higher than our neighbouring Scotland, a country of comparable size and population which euthanized about 500 dogs in 2013). In the Republic of Ireland, in recent years: 21, 357 dogs were euthanized in pounds in 2002 (a figure which represents 81\% of all dogs 'seized' or 'surrendered') and that number dropped to 1,824 dogs in 2015 (Department of Environment, 2016).

Participant observation began informally in the summer of 2012 when I volunteered weekly at a dog sanctuary in Co. - and attended volunteer orientation and volunteered as a dog-walker at an all-animal sanctuary in Co. -. The findings presented here are drawn from interviews conducted with 24 respondents drawn from seven organisations in six counties: Dublin, Kilkenny, Carlow, Wicklow, Wexford and Tipperary. These descriptions mirror the respondents' definitions of their organizations, rather than the researcher's, and were selected to span different animal species for theoretical comparative purposes. I wanted to try to grasp whether the socially constructed meanings of animals differ across species. I observed that they vary but do not differ substantially. Rescued pigs, lambs (even for nonvegetarian respondents), donkeys, horses, dogs, cats, cockerels, are all considered to be unique individuals with biographies by my cohort, and are all imbued, arguably sometimes anthropomorphically, with unique personality traits. 


\section{Table 3.1. Research Settings}

\begin{tabular}{|l|l|l|l|}
\hline & Organisation & Interviewees & Field Visits \\
\hline A & All-species rescue & A1, A4, A20 & Approx. 20, inc. meetings \\
\hline B & All-species shelter & B2, B3, B6, B18 & 5 kennel cleaning and cat feeding \\
\hline C & Dog-only shelter & C5 & 2 \\
\hline D & All-species shelter & D7, D8, D9 & 3 \\
\hline E & All-species shelter & E10 & 5 , inc. volunteer orientation \\
\hline F & Donkey sanctuary & F11 & 2 \\
\hline G & Veterinary surgery & G12 & 5 \\
\hline H & Dog-only shelter & $\mathrm{H} 13-17, \mathrm{H} 19, \mathrm{H} 21, \mathrm{H} 24$ & Approx. 20, dog walking \\
\hline I & Dog pound & $\mathrm{I} 23$ & 0 \\
\hline
\end{tabular}

Although the nature of the work varies according to species (cats do not need to be walked, dogs do, for example) a typical day at an all species (mainly dog) shelter looks something like this:

Cleaning takes up a large part of the shelter worker's day. The shelter worker cleans the kennels and crates and feeds the animals. This entails several hours of cleaning faeces, disinfecting areas, washing feeding bowls, and checking animals for signs of illness. This is clearly not glamorous work. Animals are fed, bathed if necessary, and in the case of dogs, walked. The shelter worker also deals with members of the public who either wish to surrender unwanted animals or adopt an animal. Other daily activities include taking sick or new animals to the veterinary surgeon to be given a health check or spayed or neutered. Sometimes, for badly injured animals, this involves comforting the animal while the veterinary surgeon administers a lethal injection of sodium pentobarbital.

Fundraising and maintaining a presence on social media are usually done in the evenings. At any time, on any given day, there can be a crisis: abandoned puppies found in a plastic bag, two of whom were already dead, 30 semi-feral cats to be removed from a hoarding situation where there were dead kittens in the toilet bowl, a dying sulky horse whose front legs were severed are but recent examples of crises in three of my settings. The daily life of the shelter worker is examined in more detail in Chapter 4. Below I describe how I collected my data. 


\subsection{Data Collection: Interviews}

The time required to complete ethnographic research post fieldwork was longer than the hundreds of hours I spent in shelters, observing, volunteering, and having informal conversations with the shelter staff. I immersed myself in my subjects' work-worlds to the extent that this was possible given my fulltime lecturing commitments. Physical source data consisted of approximately 20 hours of MP3 audio recordings of interviews, ethnographic field notes, and personal journal entries. I transcribed the recordings verbatim into an individual Microsoft Word document for each participant, and stored these in separate box files for each shelter. The process of listening and transcribing notes was recursive, iterative and labourintensive; I replayed and listened to the audio recordings multiple times in order to try to grasp the context and meaning of the dialogues. The more I listened to my participants' cumulative accounts, omissions and silences, the better I 'heard' what they were telling me.

Once ethical approval was granted in October 2013 I then had 80 copies of my information sheet (Figure 3.1.) designed and printed, and I commenced the formal participant observation process and the interviewing of participants. I then finalised my interview consent form (Appendix B) which included a statement that consent was without prejudice to participants' legal and ethical rights, and that withdrawal from the study was possible at any time. The information sheet documented the contribution that participants would make to our knowledge of the positive and negative aspects of working with animals in shelters. It explained that I was doing this study in my capacity as a $\mathrm{PhD}$ candidate in Sociology, and not as an animal advocate. I felt it important not to mislead my participants in any way, as some shelter workers had informally expressed the hope that my study might lead to increased public awareness or funding. The information sheet did however document that it was my hope that publications and data resulting from this study might help to highlight the importance of animal care work in Ireland.

Conklin's (2012) phenomenological study on calling focused on 9 eco-workers. Sanders' (2010) ethnography of veterinary technicians in the US produced data from 
participant observation and interviews with 22 respondents. Alger and Alger's (1999) ethnographic study took place in one cat shelter as did Taylor's (2007) study of a dog shelter. Pachirat's illuminating (2011) political ethnography was conducted in one (unnamed) US slaughterhouse. Following all of those studies, I believed that 24 interviews (22 with shelter workers) and 24 months of participation observation would be sufficient to illuminate my research areas of interest.

In the case of the current study, saturation was deemed to have been reached after approximately 12 interviews and further interviews were useful in order to lend support to early findings and to strengthen my emerging conceptual framework. Nothing further was learned after about 12 interviews, apart from the insight that a care worker for teenagers with profound physical and mental disabilities spoke of her work in a very similar way to my shelter workers. She too felt her work 'mattered' and that these children 'have so little and appreciate you so much' (Interview with Holly, $4^{\text {th }}$ October, 2014). A moral career choice in both instances, it would appear, although of course further interviews with SNAs would be required to draw significant inferences. In 2014, at the time of interview, Helena was undecided whether to study nursing or veterinary nursing in her native Sweden. I followed up with Helena in February 2016. She is studying nursing in Stockholm but she continues to volunteer in her mother's dog shelter (Participant Profiles, Chapter 3). Jean's experience in caring for adults with disabilities is contrasted to caring for animals in Chapter 5. She found the former much more stressful partly because of the regimented nature of the privatised nursing home where she worked.

As observed above, I believe that my previous volunteering experience enhanced communication, mitigated my 'outsider' status somewhat, and facilitated the establishment of a rapport with the participants. Kleinman (1984) adopts the view that her shared identities with the respondents (as woman, dorm-dweller, student) aided the development of trust. I adopted a reflexive stance in interpreting the data, and the participants were consulted on whether the interpretation reflects their lived experience. Following Emerson et al (2011) I documented my own activities, circumstances, and emotional responses throughout, and in this way I believe I came to understand my respondents' work more deeply than any other approach would have afforded. 
I had to clarify to my participants how long each interview was envisaged to last and put this information on the consent form (Appendix B). This was difficult to say as I suspected that some participants would be more voluble and expansive than others, which turned out to be the case. As parameters I estimated between 1 and 2 hours. Most interviews took between 45 minutes and one hour, but I conducted second phone interviews with some participants, and had several informal conversations with many participants thereafter.

Recruitment was done by asking shelter managers to display the information sheet (Figure 3.1 below) on noticeboards or distribute to staff members. 
Fig. 3.1. Information Sheet for Participants

\section{Information Sheet for}

Interview Participants

Minding Animals: a study of the motivations, attitudes and work lives of animal shelter workers and VNs.

What is the study about?

This study is focused on human-animal interaction. It seeks to understand why people choose to work in animal care. These jobs are physically demanding, and demanding in terms of the unsocial hours worked. The study aims to shed light on what drives shelter employees and VNs, and on the ways in which you find your work meaningful, despite its challenges. The study is timely because although research on humananimal interaction is a rapidly growing area in the US, Australia, the UK, and in Austria, very little research has been done in Ireland on this important theme.

What are the inclusion criteria for study participants?

Are you a veterinary nurse or do you work in animal care in a veterinary surgery or in an animal shelter? Have you got 3 or more years experience in this field? If so, then you are ideally suited to participate in this study.

My contact details are:

Anne.OConnor.2013@nuim.ie and 0851545635
What will participation involve?

It will involve my observing the daily work routines and duties in your workplace, and observing how you and others interact with the animals in your care. I will be happy to help with all those duties on those occasions, dates and times for which would be agreed in advance. Probably one week will be sufficient, and those 7 days will not be in a row.

If you are one of the participants you will be asked to take part in an interview. This interview will involve you reflecting on your working life and your attitudes to animals. During the interview my role is to listen. I will ask some 'open ended' questions which you are free to answer however you wish. There are no right or wrong answers. It is your experience and views about your work with animals that $\mathrm{I}$ am seeking to understand.

Many thanks for taking time to read this leaflet and for considering taking part in this important study.

If you think you might be happy to talk about your work, I would be delighted to hear from you 


\section{How often and for how long will What if I change my mind I be interviewed? \\ The interview will last from 1-3 hours. I will and want to opt out partway through?}

audio record all interviews as it would not be possible for me to remember or take accurate notes of everything you have to say. One interview will probably be sufficient but 1 would be grateful if you would allow me to seek clarification on some of your answers at a later stage, if necessary. The interview will take place at a time and place convenient for you. If you decide to take part I will phone you and arrange where and when to meet. If you incur any travel costs I will of course reimburse these.

\section{What will happen to the information once collected?}

After I spend time in your workplace, I will make notes on the routines, the processes, the interaction with animals I observed in order to help me begin to better understand your work.

Once the interview is over I will transcribe the information on the recording onto paper so I can read it and begin the process of looking for common themes among participants' experience of working with animals.

The tape recordings and any transcripts will be kept in a locked, secure filing cabinet. Any information held on a computer will be protected by password access. At no stage will your name or that of your organisation appear on the interview transcript. Each participant will be given a code number and pseudonym. I am the only person who will know to whom the number corresponds and I will divulge this to no-one. Everything you say in interview is completely confidential. The

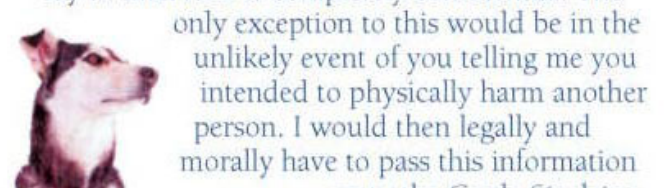

Participation in this study is entirely voluntary and you are free to drop out of the study at any time. You can do so by letting me know at interview or by phone or email later.

\section{Will I benefit directly from the study ?}

The field of human-animal studies is a new field of study. Relatively little is known about human-animal interaction at work, or about the positive and negative aspects of working with animals. Large-scale survey data can be extremely useful for some types of research. However, such surveys arguably do not get to the 'heart of things'-they often tell us 'what' but now 'why'. You telling your story of how you became involved in animal care work, and what it means to you will make a valuable contribution to new knowledge. I am doing this study in my capacity as a Sociology $\mathrm{PhD}$ student, and not as an animal advocate. However, I would hope that publications and data resulting from the study may help to highlight the importance of animal care work in Ireland.

\section{Are there any risks involved ?}

Because of the very strict confidentiality around this study I cannot foresee any risk to you. The needs and wishes of the participants will take precedence over the needs of the study at all times.

\section{Is the study being funded?}

I am in full-time employment as a lecturer in the Institute of Technology, Carlow and therefore a part-time student at NUI Maynooth. My employer reimburses my academic fees at the end of each year. Apart from fee reimbursement, I am funding this study myself. on to the Garda Síochána.

Many thanks for taking time to read this leaflet and

My contact details are:

Anne.OConnor.2013@nuim.ie and 0851545635 for considering taking part in this important study.

If you think you might be happy to talk about your work, I would be delighted to hear from you 
Should any participant have become distressed during an interview, I would have acknowledged that distress and if necessary stopped the interview. The former case did not arise, and though several participants became upset when recounting cruelty cases they had experienced, no participant wished to terminate the interview. Every study participant was treated sensitively and with due consideration and respect at all times. This study depended upon the participants giving me access to bear witness to their work lives, and I was very cognisant of, and grateful for their cooperation.

Webb and Webb (quoted in Ritchie and Lewis, 2003: 138) describe the interview as "conversation with a purpose". I aimed to take a non-hierarchical approach in interviewing and I shared information about my own feelings on issues where I judged that this might be conducive to putting my participants at ease.

I tried to explore fully, as advocated by Ritchie and Lewis (2003:141), all the “factors underpinning my participants’ comments: reasons, feelings, opinions and beliefs”. Of course, some respondents (for example, Jean or Jon) were more thorough in their responses than others. Some respondents were too busy to wish to talk to me for long, and others preferred to talk to me informally, when the voice recorder was turned off. To boot, some of my early interviews were somewhat marred by my failure to probe in sufficient depth the reasons for answers. This failure became apparent to me on reading my early interview transcripts and I learned to seek deeper explanations in subsequent interviews.

Schutz (quoted in Hammersley and Atkinson, 1995: 229) points out that people can only grasp the meanings of their actions in retrospect, and that much social action operates at a subconscious level, "leaving no memory traces”. Therefore, Hammersley and Atkinson (1995: 229) conclude, we cannot assume that participants are consciously aware of the decision rules they use, or even that they can recognise them when somebody else documents them. While writing this thesis, I consulted with several participants (Jean, Nick, Agata and others) with whom I had formed close relationships. I explained the notions of moral economy and sanctuary in nonacademic terms (as apart from Agata, my respondents are not well-versed in the conventions of academic discourse). These respondents recognised the relevance of these interpretations to their own lives. 
24 formal interviews, and two (several informal conversations took place but those two were important because they were with individuals who had left shelter work) informal conversations were carried out and the findings in chapters 5 and 6 are based on those interviews and on participant observation carried out over a 24-month period. My interviews were semi-structured, and I was happy when my participants went 'off on tangents', and talked about those phenomena or experiences that were of particular importance to them. In interviewing, personal disclosure was used in an attempt to equalise and humanise the research relationship; I openly discussed my views on animal welfare with the participants. My participants - veterinary surgeon and SNA included - are animal advocates and I include myself in their group. My shelter participants' concerns and conversation were strikingly focused on the animals at almost all times. For most interviews, the interviewees' own companion animals (and/or shelter animals) were present, and always during participant observation. I formed the strong impression that the presence of the animals facilitated the interview process, both for my participants and myself as interviewer. The presence of a purring cat, or a donkey loudly demanding more carrots, or a dog's head resting on the 'interviewer's' lap were all conducive to a more relaxed interview situation than would have been the case in the absence of those factors. I surmise that the presence of the animals revealed the distinctive perspectives of us all, participants and researcher. Participant observation was very important as what people do around animals is as, if not more telling, than what they say. In the next section I introduce the Dramatis Personae of this study.

\subsection{Participant Profiles}

\section{Participant Profiles}

All names are pseudonyms and location identifiers have been removed.

\section{Participant \#1, Nick, Male, Age: 62, childless}

Location: The participant's workplace.

Date: January $14^{\text {th }} 2014,10$ am. Weather: cold, cloudy.

Nick is 62 years old, married, childless, and he has been involved in animal rescue for nearly 20 years. He took early retirement from his job as a maintenance engineer 
because of a back injury. He grew up around farm animals because his grandparents had a small farm in - .He always loved animals and felt bad when, as a teenager, he had to take the pigs to the slaughterhouse. He fell into shelter work by chance when he went to a meeting with his wife and saw that the rescue organisation needed to be run more "like a business". He is now chairperson. He believes his work helps people too especially children, because “animals don't come with batteries, they're alive”.

\section{Participant \#2, Jean, Female, Age: 54, two grown-up children}

Location: The participant's living room in front of an open fire.

Date: $4^{\text {th }}$ February 2014, 12 noon. Weather: cool, cloudy.

Jean is a youthful looking 54 and has worked in animal rescue in for almost 20 years since she gave her number to people collecting food for stray animals and it "grew from there”. She grew up on a small farm where she always had her 'own' lamb and pig. As soon as they were born they were 'hers'. She is a grandmother and has two grown up children. She loves and understands cats and rescuing cats brings her enormous joy, despite the personal sacrifices this entails. She was "burned out" in her former job as a nursing assistant. She believes her work helps the elderly, by adopting out pets to older people. The dog or cat is "the other little heartbeat in the house”.

\section{Participant \#3, Emma, Female, Age: 26, no children}

Location: The participant's partner's living room.

Date: $5^{\text {th }}$ February, 2014, 2pm. Weather: mild, rainy.

Emma is 26 and lives with her partner. She has no children, though her partner does. She got involved in animal rescue three years ago after she lost her job and was devastated and "looking for a way to be useful". She saw a sign for the shelter in the vets. She grew up with dogs and cats and loves both, as well as donkeys and goats. The second she walked in the door of the rescue shelter she felt "in the fold". She loves her volunteer work, despite sometimes looking like "Edward Scissorshands" after catching feral cats for neutering purposes.

\section{Participant\#4, Lisa, Age: 46 , female, childless.}

Location: The participant's kitchen. Her three dogs and a cat are present.

Date: $11^{\text {th }}$ February 2014, 2pm Weather: bright, sunny.

Lisa is 46 years old and volunteers for her local animal rescue organisation. She also runs a cattery, a decision she made on the suggestion of a friend after she became disillusioned with her "mind-numbing” civil service job. She loves cats and dogs and 
keeps her own chickens, whom she names. She lives in an idyllic rural location with a large garden and a goldfish pond. Chickens, cats and dogs all intermingle on the lawn.

\section{Participant \#5, Mike, Age: 46, male, one teenage child}

Location: The participant's work office

Date: $18^{\text {th }}$ February, 2014, 2pm

Mike is 46 and retired from - then took a career break from - and wanted something useful to do. He always loved dogs so applied for the job as CEO of a rescue organisation. His family all earn more than him but he think his work matters more than "the dollar". He commutes home to a rural area in rural Ireland every weekend. His family member was a vet and kept show-jumping horses and Mike also loved dogs as a child.

\section{Participant \#6, Joan, Age: 37, female, 4 school-age children}

Location: The participant's home, in a cosy front room

Date: $25^{\text {th }}$ February, 2014, 2pm. Weather: bright but cold

Joan is 37 and has 4 children. She works in the home. After losing 8 stone in weight she wanted to "do something that matters" and when a local rescue helped her with neutering her stray cats, she resolved to help the charity. She wanted to be "more than somebody's mother". She does the accounts, and no hands on work. She grew up with dogs and cats and sees herself primarily as a "cat person”. Her home is located in a rural area and there are several gravestones for deceased cats in her garden. She believes that there must "be a beacon over her house only cats can see”.

Participants \#7 and \#8, Fran, Female, Age: 63, two grown-up children and Tommy, Male Age: 62.

Location: The sitting room of the participants' home in the sanctuary grounds.

Date: $4^{\text {th }}$ March 2014, 2pm. Weather: Bright and sunny.

Fran's partner is 62 and they have two grown up children and now grandchildren. They became involved in animal shelter work after moving to Ireland. The impetus was coming upon a man about to throw a puppy in the river. They took the puppy home and it "all started from there". Their all-species shelter is high in the hills and in a picturesque location. They consider it a "corner of paradise". When they moved to Ireland in 1990, they quickly realised that the animal welfare situation was "so bad" that they "had to do something about it".

Participant \# 9, Fiona, Female, Age: 34, childless 
Location: The sitting room of the house in the research setting grounds.

Date: $4^{\text {th }}$ March 2014, 3.30pm. Weather: Bright and sunny.

Fiona "always knew" she wanted to work in animal care but "wasn't clever enough to be a vet". She completed a one-year course in Animal Care, and then got a fulltime job at the shelter, where she had previously volunteered. She loves working outdoors and couldn't do any other job. She never wants to have children.

\section{Participant \#10, Des, Male, Age: 67, 3 adopted, grown up children.}

Location: Respondent's home,

Date: $15^{\text {th }}$ April 2014, 2pm. Weather: sunny, mild.

Des is retired and aged 67. He has two grown up children, and two grandchildren he loves. He lives with his wife in and has a lovely conservatory which is designed to "let the garden inside". He was a - and retired at 55 when he got tired of "them getting greedier every time you renewed your contract”. Then he volunteered at the shelter and became CEO within 2 years. He loves his cat and has several formerly loved cats buried beneath gravestones in his garden. He is a very articulate man who uses poetic language to describe his former work in animal rescue. For example he describes animals as kin: "We are all a chain of creatures on this earth".

Respondent's wife had made scones and respondent makes us a pot of tea, china is laid on on kitchen table and I feel very welcome.

\section{Participant \#11, Suzanne, Female, Age: 33 years, childless.}

\section{Location: Restaurant}

Date: June $4^{\text {th }} 2014$, 2pm. Weather: rain with sunny spells.

The participant is in her early thirties. She is open and expansive in her answers. She comes from a wealthy background and had horses as a child and does now. She describes herself as "animal crazy". Though she studied Journalism, she disliked how "nosy you had to be" and when a friend of hers suggested she run a donkey sanctuary with his financial backing she didn't have to think twice. She has been a dietary vegetarian since childhood.

\section{Participant \# 12, Male, John, Age: 64, grown-up children}

Location: The participant's Veterinary Surgery

Date: $28^{\text {th }}$ June $2014,9.30$ am. Weather: sunny, warm.

The participant John is in his early sixties and has practised as a vet for almost 40 years. He became interested in studying veterinary medicine as a child on the farm 
where he grew up. He was amazed that vets could "tell what was wrong" with animals. He believes that the increasing feminization of his profession is down to women being more drawn to the caring professions. He deals with a lot of shelter workers and in his view they do it because they feel they are filling a gap that needs to be filled, and that it provides them with purpose.

\section{Participant \#13, Katja, Female, Age: 25, childless.}

Location: Animal shelter, in onsite mobile home

Date: $4^{\text {th }}$ July 2014, 11.45. Weather: rainy with bright spells.

Katja is female, blond and has several ear piercings. She is from the Czech Republic. People are crazy about dogs in the Czech Republic she says. She used to volunteer for the shelter where she is currently employed. She studied languages and translation studies at University but she never worked in the area as it "wasn't her thing”. She came to Ireland to be with her boyfriend and she intends to stay in shelter work in the future. She feels it is an important way to spend her time.

The respondent's own dog is a large Staffordshire Pitbull terrier and sits beside me on the couch during the interview, licking my ears from time to time. Katja's partner is Irish and very supportive of her work.

\section{Participant \# 14, Jen, Female, Age: 54, childless and widowed.}

Location: Animal shelter, in participant's home

Date: $4^{\text {th }}$ July 2014, 12.45 . Weather: rainy, with sunny spells.

Jen set up the shelter in the late nineties at a time when she was unemployed after losing her job in - and was volunteering at another shelter. Her mother asked why she didn't just set up her own. So she did. She finds the lack of personal time difficult, and also dealing with the public but she would do this job for no pay, as would many of her staff. She loves dogs for the "unconditional love" they give you and she also loves donkeys who "bond with you like dogs do".

\section{Participant \#15, Sally, Female, Age: 30, childless and partnered.}

Location: Animal shelter, in an onsite mobile home

Date: $4^{\text {th }}$ July 2014, 13.30. Weather: rainy, with sunny spells.

Sally is female, aged 30 and has volunteered/worked in the shelter since she was 13 years old. Though she has spent a year in Australia doing other jobs she could never see herself doing any other work now. She has won a charity employee award and her family were very proud of her. Cruelty cases are the hardest part of the job and successfully re-homing animals the best. She becomes quite emotional when giving an account of a pitbull who was beaten half to death with a hammer. He was 
subsequently put to sleep by the Pound, as he was deemed "too dangerous" to rehome. She thinks we "blame the wrong end of the lead".

Participant \#16, Jon, Male, Age: 45, childless and divorced.

Location: Animal shelter, in an onsite mobile home

Date: $4^{\text {th }}$ July 2014, 14.30. Weather: rainy, with sunny spells.

Jon is aged 45. His former networking and IT specialist job bored him and he hated the "brutal" corporate world. He always loved dogs and never forgave his mother for taking away his beloved dog when he was a child. His greyhound is his "best friend" and the only close family member Jon says he has. He was married once for a short time and has no children. He loves the Irish landscape.

\section{Participant \#17, Helena, Female, Age: 20, childless.}

Location: Animal shelter, in an onsite mobile home

Date: $4^{\text {th }}$ July 2014, 16.00. Weather: rainy, with sunny spells.

Helena, is Swedish, tall with short blond hair, and tattooed. She is on work experience in the shelter for the Summer of 2014. She doesn't yet know what she will study in College but probably veterinary nursing or general nursing. Animals have no voice and so it matters to help them, in her view. Her mother runs the Swedish equivalent of the Irish shelter and she loves dogs. She points out the animal cruelty is much more likely to be prosecuted in Sweden and that greyhounds are seen as pets in her home country, rather than "racing machines". (Helena is currently studying nursing in her native Sweden, April 2016).

\section{Participant \#18, Maria, Female, Age: 23, childless.}

Location: Animal shelter - a light airy conservatory with the sound of dogs barking outside, and an irate cat attempting to gain entry from the cattery in the next room.

Date: $9^{\text {th }}$ July 2014, 12.15. Weather: sunny and warm.

Maria is originally from Dublin. She has recently been diagnosed as being on the Aspergers spectrum. She looks reminiscent of the actress Audrey Hepburn and has a mouth-piercing. She has been volunteering for 5 years in the shelter, and has lived there for a year in the past. She grew up in what she describes as a "rough area" of Dublin and always felt different to other children. She witnessed animal cruelty as a child and resolved that when she was "big enough" she would save animals. She loves cats and keeps two pet rats and tarantulas. She explains that she probably couldn't talk to me without the cats present. She is open and fluent in her answers to questions but maintains very little eye contact with me. 


\section{Participant \#19, Molly, Female, Age: 28, childless.}

Location: Animal shelter

Date: $22^{\text {nd }}$ July 2014, 2pm. Weather: strong sunshine.

Molly believes in God but not in religious organisations. She "always knew" she would work in animal care and grew up around all species of animal. Her grandfather was a farmer and he was "an animal person”. When he retired he turned his land into a preserve. She studied animal grooming and farm management. She loves her work at the shelter although they cannot afford to employ her fulltime so she signs on and off the dole. She says she "makes it work" and there's no other job that would bring her "so much joy". The noise of dogs barking in the background meant that I had to listen to the audio-recording several times in order to transcribe.

\section{Participant \# 20, Agata, Female, Age: 43, childless.}

Date: 22 August 2014, 19.00, Skype interview

Agata is Italian and used to volunteer for her local animal rescue organisation. She now lives with cats, dogs, chinchillas, the latter of which she rescues from pet-shops, and chickens. She grew up in the North of Italy and even as a child felt the slaughter of turkeys she witnessed was not right. She is a $\mathrm{PhD}$ student and a strict vegan.

\section{Participant \#21, Maura, Female, Age: 39, two school-age children.}

Location: Animal shelter

Date: October $7^{\text {th }}, 2014,2.30 \mathrm{pm}$. Weather: sunny and warm.

Maura is British and used to work as in Quality Assurance in a factory. She found the work "soul-destroying", and hated "wearing hair-nets and a white coat and being indoors all the time". Further, the nature of shift-work was difficult to combine with raising two children. So eight years ago she applied for a job at the shelter and now she has a flexible working week, and loves her work, even if the money was better in the QA job. She grew up with animals on her parents' smallholding. She is a dietary vegan.

\section{Participant \# 22, Holly, Female, Age: 42, 3 teenage children.}

Location: Respondent's kitchen

Date: $4^{\text {th }}$ October 2014, 20.00 Weather: Mild.

Holly works as a Special Needs Assistant for children on the autistic spectrum. She studied journalism but it "wasn't for me". So she did a FETAC level 5 course in Community and Healthcare. Then she sought and obtained employment in a school for children with special needs. She loves the work; "you feel appreciated by these 
children who have so little, more than by your own children, who have so much". Despite the physically difficult nature of the work (some of the teenagers wear nappies, others can be violent) Holly says she loves her work. Holly also loves her dog, and has a framed photo of her recently deceased cat displayed in the kitchen.

Participant \# 23, Anna Pound Employee, female, age: 32, no children.

Location: Pound foyer

Date: November $28^{\text {th }}, 2014,15.00$ Weather: mild.

Anna is 31 years old and had worked in the Council Pound for several years. She had many previous jobs, and describes herself as a "Jack of all trades and a master of none”. She loves all animals and has three rescue dogs herself, including an Argentinian Dogo. She loves her job but expresses relief that she rarely has to assist in euthanasia as the PTS day is her day off.

Participant \# 24, Colm, male, age: 26 , no children.

Location: Animal shelter

Date: $2^{\text {th }}$ October 2015, noon Weather: Mild.

Colm is a 26 year old zoologist. He finished his degree but disliked the "academic side" of zoology and wanted to work "hands-on" with animals. He began as a volunteer at the shelter and loves his job. He reports how he "can't wait” to get to work on Monday morning to see "who has come in" over the weekend. 


\subsection{Data Collection: Participant Observation}

Three or more visits were made to most sites, and several to shelters A, E, and $H$, in order to glean insights into human-animal exchange, work practices, processes and interpretative mechanisms. I spent the whole working day at each site (with the exception of the Pound), every time, talking informally to employees, and helping with the animals. This participant observation was supported by data produced from interviews and documentary analysis. These site visits were not consecutive, rather spaced over a period of 12 months in rotation, in order to try to establish if there are temporal differences in patterns in shelter work. I was largely limited to Easter and Summer breaks, as only then was I on leave from work. However, weekend observations were carried out at other times, and were incorporated into the observations. I made every effort to ensure that work quality of the participants was not hindered by my presence. The animals probably benefitted from my presence, as with each visit I brought food or treats (for example, dog chews) and I walked dogs and fed animals on every field visit.

During formal participant observation in term-time, I spent an average of two days per month in different shelters, usually either Saturdays or Sundays. I spent years as a volunteer in organisation A which does not have holding facilities but devotes itself to rescuing injured or stray animals who are then rehoused in other shelters, pounds or with foster carers. I spent most of my on-site time in shelters $\mathrm{E}$ and $\mathrm{H}$ both because of their proximity and because of the large numbers of cats and dogs, up to 120 at a time, sheltered there. Watching these workers interact with animals in situ helped me to understand the largely ineffable aesthetic experiences that result from the relationship with animals; neither interview nor survey can capture this stuff beyond words (Lock and Strong, 2010). Field notes were taken to attempt to inscribe the 'inchoate understandings and insights' of the researcher (Emerson et al 2001:14). I kept a journal as a personal repository of my emotions, doubts, and developing thought throughout the study. These auto/ethnographic accounts are included where these can enhance the arguments, for example where my own reactions to events alerted me to something important. For example, in one shelter I was introduced to 
an ex-security dog, a Ridgeback-Rottweiler cross. It was explained to me that this dog was not rehomeable as he had been trained to attack. My participant told me this dog's kennel was never locked because some people try to steal dogs from shelters for fighting purposes. "If they want to steal dogs, I invite them in here to him". I wrote about this incident in my personal journal afterwards, as I was quite shaken by the participant's readiness to cause harm to potential intruders, although I felt the participant's attitude was understandable in the light of the cruelty to which he bears witness.

On another occasion, I noted my envy of the participants' daily routine helping animals in a natural setting, doing what I and they perceive to be deeply 'moral' work.

As a third example, I identified strongly with some participants' accounts of alienating and meaningless jobs they had previously held in the corporate world. Before completing my MA in Languages, my Primary Degree was in International Business and prior to entering academia, I held jobs in Sales and Advertising in the UK and in Germany. I related to my participants accounts of 'brutal' or 'meaningless' jobs to Weber's 'iron cage’.

By experiencing the phenomena first hand, including the visual, auditory, tactile and olfactory experience of the shelters, I gained a more in-depth understanding of the complex processes at work. Following Robson (2002: 320) I took notes on the settings, the people, and the events that were taking place. These included the following (Robson, 2002: 320):

Space Layout of the physical setting and outdoor spaces

Actors Relevant details of the people involved

Activities The various activities of the actors

Objects Physical elements, artefacts

Acts $\quad$ Specific individual actions

Events Meetings etc. 
Time

The sequence of events

Goals What actors seem to be attempting to accomplish

Feelings Emotions in particular contexts

I gave attention to the indigenous meanings and concerns of my participants, as Emerson et al recommend (2011: 15).

Further, I participated in the activities of the shelter settings: I walked dogs, like the shelter workers I got a tetanus booster vaccination, I cleaned cat litter trays, talked with potential animal adopters, fed donkeys, attended veterinary-client consultations and undertook volunteer orientation training. Blumer (1969) advocates taking the role of the other whose behaviour one seeks to understand. In that sense, the humananimal relationship rewards and negative aspects related as though self-evident by my participants have become more familiar to me, for I too have been their recipient. Although the fact that I was known by my participants to be working as a lecturer, and to be a $\mathrm{PhD}$ student was a mitigating factor against establishing rapport initially. For example one participant remarked; "Why would you be interested in what $I$ say?” This distance was largely overcome in the process of repeated visits prior to conducting any interviews. During those field visits I dressed like the participants (in tracksuits and old jumpers) and my familiarity with dogs, cats and (to a lesser extent) donkeys was an advantage in gaining rapport, and in "blending in" to the shelter environment.

I took notes after each field visit in order to preserve the immediacy of the experience and the field-notes focused around how the routine actions in the settings are organised and take place, as Emerson et al (2011) advocate, rather than on 'why'. My participants' concerns and conversations were striking in their focus on the animals at almost all times. Animals were present during most interviews and at all times during my participant observation field visits. I also collected data from Facebook 'posts' of my shelters. I took 'screen shots' of entries and posts which were of relevance to my theoretical interest (Appendix F). In the next section I explicate my approach to data analysis. 


\subsection{Approach to Data Analysis}

Following Vico (quoted in Lock and Strong 2012: 15), in analysing my data I tried to imagine my way into my participants' stance towards working with animals and having got there, work out how their rationality could have been constructed. For Vico (quoted in Lock and Strong, 2012: 19) understanding involves entering into the world of another and working back from the whole to a more detailed rendering of the parts of which it is realized - a two-way trajectory.

In place of universal laws, Vico suggests that varied understandings are grounded in human interactions (in Lock and Strong 2012: 17). One of his key concepts in thinking about people is that they possess a 'sensus communis', a shared sense that emerges when people agree to treat some aspect of their shared world as something significant on which they, and a segment of the public can agree. Shelter animals are thus a social construction.

Similarly, for Gadamer (in Lock and Strong, 2012: 70) the "fusion of horizons" that takes place in understanding is actually the achievement of language. According to Gadamer dialogue was how such differences in the situatedness of people's understandings could be worked out. He advocates being open to being changed through communication with others who have different ideas and values. It is in our interactions with others who do not share our views and familiarities that we are shaken out of ways of being that we take for granted. In this case of this study, my views regarding animals were similar to those of my participants, though it is they who enact those beliefs in their daily work.

Following Denzin (1989) I sought to locate patterns in the taken-for-granted structures of the everyday interaction in the shelters, both human-to-human and human-to-animal. The ethnographic fieldwork was emic, or sought to study experience from within. Borrowing from the poet William Blake, Luker (2008: 125) likens this effort to trying to "see the world in a grain of sand". I was primarily concerned with how social interactions are organised and constructed by the interacting individuals in the shelters. Their work, as I will show, contains its own dialectic and its own internal logic in terms of the shifting times in which they operate. Bakhtin (quoted in Lock and Strong: 92) stresses the unfinalizability of 
meaning in human relationships. The analysis in chapters 5 and 6 does not purport to be the 'last word' on why people stay, but an account of my respondents' living interaction with the shelter environment, and the new meanings they create for animals in their care. Of course as Arluke (2006:11) observes, the question is: "Do people really believe what they tell us or is it just for public consumption?” He goes on to suggest that sociologically, this uncertainty does not lessen the importance of “shared perspectives as devices to give meaning and order to life” (Arluke, 2006:11). Organisations and sense-making are two sides of the same coin; organisations owe their existence to people intersubjectively determining what they are doing and why (Gergen, 2009).

This study adopted a 'sympathetic understanding' approach and thus emphasised processes and meanings as these are constructed by the individuals under study. I understand knowledge to be a social construction, which had important implications for my role as researcher; the way I obtained access, and my relationships with my participants. A different researcher would possibly or even probably have focused on different aspects of the collected data, depending on her values and beliefs. My own are transparent. As Luker (2008: 81) points out: "We are fish studying water, and our very fishiness shapes how we think about it”. This qualitative study was guided by a social constructionist paradigm, or a focus on the artefacts that are created intersubjectively by the group, from their common standpoint (Gergen, 2004) which is embedded in a certain social and political framework. According to Gergen (2004) social constructionism assumes that the ways in which we describe and explain the world are the outcomes of relationships, and gain their significance from their social utility. For Gergen (2004: 102) “our ways of talking about our experiences work not primarily to represent the nature of those experiences in themselves, but to represent them so as to constitute and sustain one or another kind of social order”.

ANT was considered as an epistemological approach but although some insights were retained (for example, I accept that shelter animals have some agency in the social network, though I had little access to their inner worlds) ultimately I adopted social constructionism as a guiding frame instead. Hamilton and Taylor (2013) also note that ANT has limitations for the study of organisations in terms of its requirement to focus on the network rather than the social level. These scholars 
tentatively suggest 'Animal-Network-Theory' as an extension of ANT, as animals are not 'objects' (Hamilton and Taylor, 2013). My own rationale in choosing a social constructionist framework was also because of ANT's neglect of sociality (Jerolmack, 2013) and its focus on how networks are maintained by actants (Latour, 2005) rather than on why, which was the focus of the current study. In other words, I felt that ANT is at too high a level of abstraction and too particularistic to address the research questions posed in these pages. Hamilton and Taylor point out that ethnographic challenges are posed when the settings include animals, who are not "like us" (Hamilton and Taylor, 2013: 166). The focus here was human-centric, not because I adhere to a Human Exceptionalist Paradigm or because I believe only humans have the status of actors (Catton and Dunlap, 1980) but because my curiosity concerned why the shelter workers do the jobs that they do. I wanted to understand the processes by which people derive satisfaction from the onerous work in shelters, and how they 'make meaning' out of such work. To this end, I adopted ethnographic tools throughout.

\subsubsection{Ethnography as Methodological Approach to Analysis}

Ethnography has been defined as the "art and science of describing a group or culture” (Fetterman, in Alvesson, 1989). The crucial thing is to "have been there" (Geertz, 1973). Following Hammersley (2014: Handout prepared for the $7^{\text {th }}$ Qualitative Research Summer School, Dublin City University, May $9^{\text {th }} 2014$ ) I adopted a naturalistic, emic approach in order to try to understand the participants' behaviour and to try to open up fresh understandings of human/animal relations. This approach recognises that while people's perceptions and intentions are important factors in shaping their behaviour, so too are other factors of which they are unaware. I believe that it is through the examination of evidence extracted from the personal experience of shelter workers, when placed in context with contemporaneous and secondary sources, that the sorrows and joys of shelter work can be understood in a more nuanced way. Ethnographic tools were used to attempt to unearth theoretical insights into how this cohort's ideologies emerged and sedimented. I acknowledge that my approach reflects my own identity, commitments and social location, and reflexivity was a significant feature of this research. Research does not happen in some “autonomous realm” as noted by May (2011), the 
researcher does not come to the table as a tabula rasa but is part of the hermeneutical circle as Denzin (1983: 23) frames the issue, following Heidegger. I kept a personal journal throughout, in order to record fieldnotes from my research settings, and my reactions to what I had seen and heard in the shelters. These journals became the repositories of my thinking, and were conducive to theory building as my study progressed.

Ethnography emerged from the discipline of cultural anthropology, and typically involves participating in the daily affairs of those studied, taking careful notes, and producing a thoughtful account of the people in question (Gergen, 2004). For Atkinson, Coffee et al (2001) ethnography is concerned with the meanings of actions and events to the people we hope to understand. Ethnography is a deliberately 'messy' methodology, putting faith in the interpretive competence of the researcher when immersed in a social milieu in all its complexity. The goal, as Hammersley and Atkinson (1995: 131) understand it, is not to produce data that are free from potential bias, rather to "discover the correct manner of interpreting whatever data one has". These scholars advocate combining participant observations with interviews in order that data from each can be used to illuminate the other (Hammersley and Atkinson, 1995:131). Ritchie and Lewis (2003:14) argue that if several reports confirm a statement then it can be considered "true as a representation of a socially constructed reality”. My approach was inductive; I used my interviews and observations as the genesis of my conclusions, although my interpretations were also informed by various theories.

For Emerson et al (2011: 2), ethnography is a way to understand and describe social worlds as interpreted worlds, always under symbolic construction. In order to enhance the validity of my research findings I used a triangulation of methods: I interviewed, I observed and participated, and I studied social media materials prepared by the shelters. I consulted with participants and worked to establish a rapport in order to avoid obscuring their 'true' opinions and thinking about their work.

Participant observation was guided by the research theoretical interests. Observing the study participants carry out their work was important in helping me to examine 
how self-reports correspond to behavioural data. Hamilton and Taylor (2012) contend that participant observation is well suited to appreciate the complexities and imbroglio of organisational realities. In a similar vein, Yanow (2012) reminds us that a key strength of ethnographic methods resides in the freedom to improvise as the research unfolds, to respond to the exigencies of the field as they arise. Vico (quoted in Lock and Strong, 2010: 12) puts forward the view that the way to understand other people and their world is to learn the rules and significance of their methods of expression - "their myths, their songs, their dances"'. Alger and Alger (1999) note that participation observation allows insight into the choice that animals make in their interactions with humans and other animals, that repeated observations enable revision and refinement of interpretations, and that the collection of non-verbal data (omitted from quantitative studies) is a major contribution of the method.

Following Dilthey and Weber's notion of Verstehen, or sympathetic understanding (Lock and Strong, 2010), I tried to move "back and forth" between the world of the shelter and my own referent system, as Scheper-Hughes (1992: 30) advocates. My aim was to analyse the categories involved in shelter work. As the study seeks to answer how and why my participants came to work in animal shelters, and what meanings they bring to their work, a qualitative approach was deemed most appropriate. I was sensitive to the ethnographic fallacies described by Burawoy (2013) and I tried to avoid these pitfalls. All methodologies are fallible, of course, and Burawoy (2013) advocates that scholars should examine the limitations of their own methodologies, rather than those of other scholars. Burawoy (2013) points to the dangers of reifying or homogenizing the world under investigation. Second, he speaks to the danger of treating the present as a point of arrival rather than also as a point of departure. Third (and this observation made an impact on me, as an animallover) the ethnographer should beware the perils of wishful thinking or projecting one’s own hopes onto the actors studied (Burawoy, 2013). O’Riain (2009) suggests three potential interlocking extensions of ethnographic case research. The embodied experience of the researcher represents a personal extension of the case at hand, theoretical extension is possible by efforts to understand the larger structures and processes that shaped the field, and empirical extension seeks to extend the boundaries of the case to the global or historical (O’Riain, 2009). 
Hamilton and Taylor (2012) take the view that ethnography is 'eminently suitable' for the investigation of human-animal interaction. I also contend that ethnography ("writing culture") is suited to bear witness to the "proximate and intimate, yet forever distant and unknowable 'other' because our own destinies lie elsewhere"' (Scheper-Hughes, 1992: vii).

At the initial stage of analysis, the concepts took the loose form of what Blumer (quoted in Hammersley and Atkinson, 1995: 212) calls 'sensitizing concepts', which merely suggest directions in which to look. Sensitizing concepts, according to Hammersley and Atkinson (1995: 212) are the germ of the analysis, and direct further data collection. Some of the early categories I expected to carry explanatory weight, such as the potential of contracting zoonotic diseases or the lack of personal time turned out to be far less important to my respondents than I had expected would be the case.

I read and reread the interview transcripts and I began the process of 'in Vivo' coding (Miles and Huberman, 2014: 74) after about 6 interviews. Similar utterances within and across cases were grouped together and this structure was iteratively tightened as interviews progressed, and. 'Descriptive codes', assigning labels to data to summarize the basic topic of a passage of qualitative data (Miles and Huberman, 2014: 74) were edited. I went about attaching codes to phenomena in order to make sense of the data. As my interviews progressed, I began to develop more analytically significant categories. As more and more respondents told me about the irritation they experience through dealing with some members of the public, and the joy they experience in the daily company of animals in the shelter environment, I became more certain that what they were telling was reliably social, rather than idiosyncratic. The relations between the categories became apparent to me over time. Childhood positive experiences with animals alone were not a sufficient antecedent to shelter work. Rather in catalytic combination with changes in the life course, such as alienation from previous workplaces, their lifelong regard for animals provided a more complete explanation for the pathway to shelter work. As my interviews progressed, I was able to identify a series of commonalities in the narratives of my participants that led to shelter work. I began to draw a distinction between occupational choice and the decision to stay in shelter work, a decision all 22 shelter 
respondents claim to have made. The retired CEO Des would still be in his job but for a personal family matter. As successive participants told me how much they felt saving animals mattered, and that they felt like 'good people', the notion of moral economy began to take root in my mind. Equally, their delight that 'cooped-up' office or factory work was now replaced with outdoor work in the company of animals (who are described as being 'non-judgemental' and loving 'unconditionally'), suggested to me that the shelter settings are providing sanctuary to more than the non-human inhabitants.

Of course, I was alert to people's tendency to engage in impression management (Goffman, 1959). However, my participant observation strengthened and bolstered my emergent themes of moral economy and sanctuary as representing significant compensatory factors for my respondents' work-related sorrows and travails. I bore witness to the joy my respondents feel in the shelter environment, and to how they intersubjectively construct and reconstruct their world view that theirs is moral work. While I have little doubt that my participants presented their 'best selves' during interviews (as would I, were the roles reversed), their daily actions on behalf of the animals in their care speak from the same place. Shelter workers are not a homogeneous group, my participants are from different social backgrounds, vary in age, are of different ethnicities, and genders (although predominantly female). It is all the more striking how many commonalities I found in their accounts of how they came to enter and stay in the shelter.

Where feasible, research took place at the natural work sites where participants carry out their work. I then reviewed all of the data, attempted to interpret it, guided by the participants, and organised it into categories or themes that emerged across all of the data sources. Of course, as Wolcott (1994) humorously observes, there can be no 'pure' description, as that would be akin to 'immaculate perception' (Wolcott, 1994: 13). He goes on to distinguish between description (which addresses the question: what is going on here?), analysis (what are the interrelationships between the features? How do things work ?) and interpretation (what is to be made of it?) (Wolcott,1994: 13). 
Following Denzin and Lincoln (2000) I attempted to make the world of lived experience directly accessible to the reader and endeavoured to capture the voices, emotions and beliefs of those studied. I had an informal relationship spanning years with some shelter workers prior to commencing field work which made it possible for me to empathise with their work. In German, the word for empathy is Einfühlung, or to feel one's way into, and it was not difficult for me to feel my way into my participants' experience of animal work. Nonetheless, when I formalised my engagement to test my ideas I discovered my theoretical presupposition that shelter workers experience a 'calling' to this work was not correct.

After approximately 12 interviews, I reached 'saturation point', the point where I started hearing and seeing the same themes from my respondents again and again. Typically, respondents were voluble and expansive in their responses and I felt as though some people were using me as an intermediary to tell themselves their own stories. Their choice to enter this occupational field took place within a repertoire of possibilities as discussed in Chapter 4. Of course, my interviews were with people who chose and stayed in shelter work, rather than those who quit or those who came to be interviewed unsuccessfully. Further, my respondents' accounts are retrospective personal histories which are liable to be biased by the tendency of most people to make their current choices and lives connected to and developed from earlier remembered experiences. In other words, my respondents' accounts are a construction of how they came to be in the shelter as much or more than why they are actually in this occupation. Nonetheless, the stories told contained common themes and threads for all my shelter respondents.

Though my own interpretations are also present, the research focused on learning the meanings that the participants hold, 'not the meaning that the researcher brings to the research or writers express in the literature' (Cresswell, 2009) in order to elevate the value of knowledge forged through lived experience. Ethnographic fieldwork, according to Marvin (quoted in DeMello, 2012: 125) involves not only 'being there, but being open to the unexpected, in a non-normative way, to the ways of life of those whom we seek to study'. The interpretation attempted to illuminate this occupational choice as temporally and biographically grounded, to incorporate previous findings of HAS literature, and to cohere both strands into a meaningful, 
provisional theory of why people are drawn to animal work. Interviews were semistructured to allow workers to elaborate on their thinking without the constraints of a questionnaire. Notes were taken on each interview in order to capture nonverbal communication - body language, silences, slips of the tongue. Careful reading of examples of best practice of interviews (for example, Bourdieu (1993) and his colleagues in The Weight of the World: Social Suffering in Contemporary Society) was undertaken. From these readings I learned to note everything my participants did and said, but also what they did not say. Following May (2011) similar replies were categorized and indexed under particular headings. Kvale and Brinkmann's (2009: 20) seven practical stages of interviewing were adopted, as well as these scholars' striking metaphor of interviewer as either miner or traveller. In the former conceptualization (Kvale and Brinkmann, 2009: 48) facts are waiting to be discovered by the interviewer and taken home, much like treasure. In the latter, the guiding metaphor for the present study, the interviewer is setting out on a journey from which she will return with stories to tell. In chapters 5 and 6 I will try to convey the complexities and nuances in the participants' accounts, and to avoid what Skeggs (1997: 32) dubs “metonymic freezing”- essentializing parts of the lives of others which then come to epitomize the whole.

The study seeks to document what happens in the participants' workplaces and to tell the story of what working with animals means for people, to understand the lifeworlds of the participants (Kvale and Brinkmann, 2007), or the 'native's point of view' (Geertz, 1973). Preconceptions about what is important were 'bracketed' in so far as this was possible (Emerson et al 2011: 167) in order to attend to indigenous meanings attributed to the work.

An interview schedule was developed but these questions were not asked in a standardised manner, rather these questions were considered dialogic points of vantage to reveal the participants' work lives. I produced initial "in Vivo" codes in the participants' own words, in order to prioritize the participant's voice as Miles and Huberman (2014) propose. I then grouped “in Vivo” and descriptive codes into categories which eventually formed the basis of my more abstract developing theory. Miles and Huberman (2014: 74) define descriptive codes as labels to summarise in a word or short phrase the topic of a passage of data (early on in the current study, as 
'disenchantment with other workplaces', for example). I also added emotion codes (Miles and Huberman, 2014: 75) to provide insights into my participants' perspectives and actions (for example, "I hated that call centre work"). Over the course of more than four years of iterative analysis, I developed theory as an interpretive structure to try to render the occupational choice of shelter work understandable.

Following Zuboff (1988) I tried to focus on the implicitly, felt sense of my respondents' understanding of their work. In general, I found that my respondents were eager to talk about their work (especially informally), and to be heard. I was not emotionally detached from their accounts, and some interviews and field experiences produced affective responses in me, as I discuss in Chapters 5 and 6. Similar utterances within and across cases were grouped together rigorously and systematically, and from two early themes, pathways and “dark sides”, and subthemes emerged. These categories were refined in the successive, iterative process of data condensation and as further interviews and participant observation were conducted.

MAXQDA was considered as an analytic tool. However there are well documented concerns about removing segments from their context (Spence et al quoted in Ritchie and Lewis, 2003). Therefore teasing out meanings in context was favoured, in order to stay as close as possible to the transcribed texts.

In-depth interviews were necessary to untangle the complexities and nuances of animal care work. Following Gadamer's method of arriving at a shared meaning through 'fusing horizons' (in: Lock and Strong, 2010: 68), I attempted to hermeneutically reconstruct structures, codes and narratives that exert causal power in the animal shelter work setting. The aim was to provide a coherent conceptual framework for the draw to animal work by moving back and forth between my own reference system and the less familiar world of the shelter. Such interpretation was of necessity tentative because, as Gadamer observes “experience cannot be exhausted in what can be said of it or grasped as its meaning” (quoted in Lock and Strong, 2010: 68). Further, as Hammersley and Atkinson (1995: 143) observe, respondents are often aware that they are "in some sense speaking for posterity" and this may 
have an effect on what they say, and how they say it. Hammersley and Atkinson's (1995: 143) observation has resonance with my experience of interviewing. Oftentimes, my participants used strikingly lyrical or metaphoric language to express themselves during our interviews, although during informal conversations they generally did not.

My personal journal throughout fieldwork was used as a repository for jottings or what Miles and Huberman (2014: 93) call “analytic sticky notes”. As recommended by Miles and Huberman (2014: 94) my journal includes my inferences about what participants were "really saying, my personal reactions and emotions in the field, and mental notes of issues to be pursued further at a next meeting”. As Miles and Huberman (2014: 99) advise, I prioritised memoing; when an idea about something said during interview struck me, I stopped whatever I was doing and set it down on paper. Often, I awoke in the mornings with ideas, or what Miles and Huberman (2014: 99) call “little conceptual epiphanies”. Following O’Riain (2009: 292) I contend that: "At the heart of ethnography is the body of the ethnographer - a thinking, feeling, sensuous person constantly collecting ‘data' from around them”.

My feelings of empathy and sorrow when introduced to abused animals, my delight in walking shelter dogs, my frustration at some of the puny surrenderer excuses which participants shared with me - all helped to form my understanding of work at a shelter that would not have been possible without my ethnographic participation.

\subsection{Social Media Analysis}

May (2011) notes that documentary analysis is fraught with difficulties. First, there is the question of authenticity; the document may have internal inconsistencies. Second, there is its credibility to consider. This refers to the extent to which its content is sincere and free from error or evasion. Representativeness is also an important consideration; why does one interpretation of a phenomenon predominate to the exclusion of others? Finally, the meaning of the document, or its clarity and comprehensibility to the researcher can be challenging (May, 2011: 206-208).

In a similar vein, Hammersley and Atkinson (1995) caution that authors will have interests in presenting themselves in a certain (usually favourable) light and may therefore put certain glosses on their accounts. However, Hammersley and Atkinson 
(1995) go on to argue, these potential sources of bias are, looked at from another perspective, sources of data in themselves (Hammersley and Atkinson, 1995:160).

Although participant observation and interviews were the primary means of data collection, some shelter documents (historical SPCA documentation, current 'posts' as disseminated to the public on Facebook) were analysed for their ideological properties in order to complement the other methodological tools used. Fairclough (1995) notes that textual analysis is suited to ethnographic or organisational analysis. My main focus of 'documentary' concern for the purposes of this study was to review my shelters' self-presentation on social media (Appendix F). Their accounts in those virtual spaces of their travails, sorrows, consolations and joys were broadly similar with what they told me in interviews and with what I observed in the field. The emphasis was often different however, as I document in Chapter 6. The shelter literature was used as a further source of evidence about the process of meaningmaking in the animal care environment. Shelter literature frequently gives descriptions of animals to be fostered or adopted, as well as narratives explaining where they were found, in what condition and so forth.

Mumby (1988: 110) observes that where narrativity is present in any account of reality, we can be sure that a "moralizing impulse"' is present too. An analysis of such accounts was valuable in attempting to understand how animals are interpreted and constructed by the participants. Properties of texts such as vocabulary, presuppositions, metaphors, style and structure can be regarded as ideological (Fairclough, 1995). Belsey (2002) agrees that ideology is inscribed in signifying practices - in discourses, myths, presentations, and argues that the way things 'are' are to this extent inscribed in language. The triangulation of methods (participation observation, interviews, and documentary analysis) attempts to paint a more complete picture of the phenomena under investigation.

\subsection{Chapter Summary}

This chapter maps the course of my trajectory as ethnographer in the world of the animal shelter. It discusses the methods and process of conducting this study from preparatory work through to the profiles of the participants involved. In chapters 5 and 6 I try to grasp the indigenous understandings logical to my respondents and to 
make those evident. As Goffman reminds us (quoted in Lock and Strong, 2010: 206): "It is against something that the self can emerge...Our status is backed by the solid buildings of the world; while our personality often resides in the cracks”.

All of my study participants are 'against' animal neglect and cruelty, though as will be seen, for some animals more than others. Though each story is unique in the detail, the pathways into animal work, and “dark sides” inherent in the work, are consistent across shelters caring for a range of other species. The next chapter deals with the organisational field within which the choice of shelter work is enabled and constrained in Ireland. 
Chapter 4 


\section{Chapter 4 The Organisational Field: Animal Welfare in Ireland into the Twenty-First Century}

The public value of an enriched and well-maintained repertoire, making possible individuals' choices among elements, depends on social structures in so many ways (Stinchcombe, 2000: 23).

The practice of the sociological imagination requires an awareness of these popular stories of the personal issues of lived experience, and the construction of connections with the accounts of the epoch (Bauman, 2014: 5).

\subsection{Introduction}

This chapter presents the organisational field of animal welfare in the Republic of Ireland in the Twenty-First century. This field represents what Stinchcombe (2000) terms the "repertoire of choices" and structures the occupational choices for shelter workers. Even in the case where an individual or group of individuals set up their own shelter from scratch, they do so within a pre-existing legislative and humane society framework. As Luker (2008: 34) observes: “True, people do make meaning out of their surroundings, but to paraphrase Karl Marx, not as they please”. Some of my respondents moved into the Third Sector because of restricted choices in the public or private sectors, although it must be noted that they say they feel happier in their shelter work than hitherto. In this sense, the alternative organisational fields and their legislative framework provide bases for occupational entry, the theme of chapter 5. The range of shelters (see table 3.1.) where I spent time include a Pound (Organisation I) which was established to control the stray dog population, a SPCA (Organisation A) which does not run a shelter but focuses on animal advocacy, 'nokill' shelters engendered by concern about euthanasia and in receipt of partial funding from local government in exchange for providing shelter services (Organisations B, D, E and H) and shelters existing solely on public and corporate donations (Organisation C). Some features (legislation shaped by the presence of animals in society) are general to all these organisations, whereas at the organisational level some features are specific to certain shelters. For example, in Organisation E I observed the imposition of formal procedures with regard to 
volunteer training and subsequent dog-walking, whereas a less formal approach is adopted in the smaller Organisation $\mathrm{H}$.

The shelter structures arose out of moral economy in the $19^{\text {th }}$ century. Founding figures in the establishment of the Society for the Prevention of Cruelty to Animals (SPCA) - the 'Royal' was added later - in 1824 in the UK were Richard Martin (nicknamed 'Humanity Dick'), the Reverend Arthur Bloome and William Wilberforce. Each realised the need to educate the public about animal welfare issues: the conduct at the Smithfield meat market, cat skinning, the use of dogs as draft animals, the abolition of dog-pits etc. Sister societies sprang up abroad: the British charitable model was adopted in Ireland in the latter part of the $19^{\text {th }}$ century (Fairholme and Pain, 1924). The SPCAs could not have been established, nor could they continue to exist now without my participants and their ilk, nor could they without public support. Shelter structures are sustained and continue to exist because of moral economy.

I first lay out the current animal welfare legislation as decreed in the 2013 Animal Welfare Act and its precedent Acts on equine and canine welfare. Next I examine the role played by the Department of Agriculture, Food and the Marine (DAFM), both legislatively and in terms of funding allocation to welfare organisations. Then I trace the development of the two largest SPCAs in this country: the ISPCA and the Dublin SPCA, as well as the ISPCA (currently waning) involvement with running the Dog Pound system at county level, as the Animal Collection Services (ACS) case in section 4.3.1.below exemplifies.

The recent entry of Dogs Trust into the animal rescue sphere is outlined, followed by an explanation of the multiplicity of other shelters that exist and of the RSPCA guidelines for the design and management of animal shelters. Finally, I lay out the social media presentation and common fundraising techniques used by the various organisations.

\subsection{The Legislative Platform: Animal Welfare Act 2013}

The then Minister for Agriculture was interviewed on Irish radio in 2012 about the proposed Animal Welfare Bill (Coveney, 2012). Prior to that interview a recording 
of ISPCA's Chief Inspector Conor Dowling was broadcast in which he explains the frustration inherent in dealing with animal cruelty cases without proper legislation. He related harrowing details of a then recent incident in the Wicklow/Wexford area: five dogs were left to starve to death in a trailer. A hole was blocked up by someone to prevent the dogs from digging their way out of the trailer. Minister Coveney maintained that this would be proactive rather than reactive legislation, that dogfighting would henceforth be a criminal offence, and puppy farms subject to stringent inspections. He claimed that the legislation would be about changing attitudes towards animals and imposing a common standard on people who own animals (Coveney, 2012). Welfare organisations had been invited to make submissions to the government in 2009 as part of a public consultation process so the shelter replies are an exemplar of moral economy in action. I helped to write and submit the Kilkenny SPCA branch suggestions, on behalf of the KSPCA, where I served as volunteer fundraiser at that time and sent it to the 'Animal Health and Welfare Bill Section', Agriculture House, in 2009. Our suggestions included the introduction of fines up to 25,000 euro in severe cruelty cases and a lifetime ban on keeping an animal, incentivised spay and neuter programmes (for example, by applying a reduced dog licence fee if evidence of neutering is produced), the introduction of regulatory measures for dog breeding establishments, the introduction of modules on animal care and welfare in schools, the allocation of more legislative powers to the SPCA to seize animals in cases of suspected cruelty, inter alia. These suggestions - many of which would have been made by other welfare organisations or shelters - were adopted, notably in relation to the banning of tail-docking, the increased regulation of dog-breeding establishments, and prohibition of dog-fighting or baiting, and the enhanced powers granted to the SPCA inspectorate to seize animals in cases of suspected cruelty. My shelter respondents welcome the provisions of the Act, however many express concern that legal repercussions for animal cruelty are far too lenient (Interviews, 2014). Few concessions are made to the welfare of 'farm animals' which are defined under the Act as being 'animals bred or kept for the production of food, skin, wool, fur or feathers' and where such do apply these relate to disease control and prevention of farm animals straying, or 'damaging the flora and fauna of the surrounding environment where the animal is contained' (DAFM, 2015:11). Other animals have a 
different nomenclature under the terms of the Act: 'protected animals' and for these the five freedoms must be upheld (DAFM, 2015). The five freedoms are (ISPCA, 2015):

- $\quad$ Freedom from thirst, hunger and malnutrition

- Freedom from discomfort

- $\quad$ Freedom from pain, injury and disease

- Freedom to express normal patterns of behaviour

- $\quad$ Freedom from fear and distress

The Animal Welfare Act was passed in 2013 (DAFM, 2014) and does improve the legislation around animal protection in several ways, some of which are outlined below. Part 3 of the Act refers to animal welfare; other sections deal with animal disease, destruction and disposal. The 2013 Act moves away from a prosecution approach, which required proof of cruelty, post facto, towards a 'Five Freedoms Approach', which suggests how animals should be looked after to meet physiological and psychological needs.

Legislation will further require all dogs to be micro-chipped by March $31^{\text {st }} 2016$, which serves the dual purpose of enabling lost/stolen dogs to be reunited with their owners, and providing a trail in suspected cruelty cases (ISPCA, 2015). My respondents welcome this legislation (Interviews, 2014) although it is a doubleedged sword as it makes transporting dogs to the UK or Scandinavia more expensive for them. Further, my participants point out that convictions for animal cruelty are rare, and penalties derisory. Even the new legislation provides scope for tensions in the moral economy of the shelter.

Under section 3.1 of the Act, a person who has a protected animal in his or her possession or under his or her control commits an offence if he or she fails to take all necessary steps to ensure that the animal is kept and treated in a manner that safeguards the health and welfare of the animal. Where a person has been convicted of an offence under this section, the court may, in addition to any penalty it imposes, order the person to make such contribution, as it considers appropriate, towards veterinary or other expenses incurred in respect of the animal or its upkeep. Where 
an authorised officer has reasonable grounds for believing that an offence is being or has been or will be committed, he or she may seize and detain the animal concerned (and any dependant offspring of the animal) and remove it or arrange to have it removed to a place of safety. The Act further makes it an offence to fight, wrestle or struggle with an animal or attend or participate in dog-fighting, cock-fighting or animal-baiting. Tail-docking is also now illegal under the provisions of the Act. It could nonetheless be construed as a somewhat contradictory 81 page document; for example it employs the nebulous term 'unnecessary suffering' frequently, which tacitly assumes that some suffering is 'necessary' and excludes activities undertaken in the 'ordinary course' of fishing, hunting, or coursing, unless the hare has no 'reasonable chance' of escape, in the latter case (Department of Agriculture 2015, Section 15.1).

There are separate provisions for equine welfare, set out under the terms of the 1996 Control of Horses Act.

\subsubsection{Control of Horses Act 1996}

Under the terms of the 1996 Act (Department of Agriculture 2015) microchipping, passporting, and registering are legally required for horse-owners. This is difficult to enforce for some members of the ethnic minority known as the Travelling Community, according to my study participants, as ownership can be denied and is exceedingly difficult to prove. Travellers define themselves as a community of people who are identified (by themselves and others) as people with a shared history, culture and tradition, including historically a nomadic way of life on the island of Ireland (Pavee Point, 2016). One dedicated welfare group, the Wicklow Traveller Animal Welfare Help and Advice Group was set up in 2006 by Fiona Gammell, a former inspector for Wicklow SPCA. This Help and Advice group work with local Traveller social services and educational centres. Their activities range from giving talks on animal welfare, to educating the Traveller Community about zoonotic diseases, which are diseases that can be transmitted between animals and humans, and providing free worming and vaccination services (ISPCA, 2015). The Traveller advocacy organisation Pavee Point do not have a detailed animal welfare policy according to their website (Pavee Point, 2016) which is understandable given this 
organisation's weighty stated concerns: Traveller health, employment, and racism and discrimination (Pavee Point, 2016). However, Pavee Point (2016) are officially opposed to sulky-racing (harness racing in which horses race pulling a two-wheeled cart called a sulky) on public roads and call on local authorities to engage with Traveller organisations and the Garda Síochána (The Irish Police Force) to investigate how to allow this long-standing tradition to continue in a safe and legal manner.

Under the Control of Horses Act 1996, an authorised person or a member of the Garda Síochána who has reasonable cause to suspect that a horse is in pain, distress or acute state of neglect as to be in need of veterinary attention, may require the owner or keeper of the horse to obtain any necessary veterinary attention. Further, an authorised person of a member of the Garda Síochánamay seize and detain any horse that the person or member has reason to suspect is a stray horse, causing a nuisance, not under adequate control or being cruelly treated. The main equine rescue centre in the Republic of Ireland is the Victor Dowling Equine Centre in Mallow, Co. Cork, and is run by the ISPCA (ISPCA, 2015). This shelter was not studied due to the geographical restrictions of this study.

There is also separate legislation to oversee the running of dog-breeding establishments, colloquially called 'puppy farms'.

\subsubsection{Dog Breeding Act 2010}

This Act stipulates that dogs in breeding centres must be adequately supplied with suitable food, drink and bedding, adequately exercised and inspected at suitable intervals. Records must be kept and made available for inspection by an authorised person or the local authority. One of this Act's most important provisions stipulates that breeding bitches do not give birth to more than 6 litters of pups each (DAFM, 2015). I deem this provision important because I have personal experience with rescue bitches from breeding establishments who were too traumatised to make eyecontact with humans, and who displayed symptoms of fear or aggression around male dogs. Two minority reports (Department of the Environment, 2015) were submitted by the Irish Greyhound Board and The Dog Breeders Association of 
Ireland. The former organisation's report is concerned with delineating the supposed 'clear differences' between greyhounds and other breeds of dog. Therefore, this body claims, the limit of six litters should not apply to greyhounds. The Irish Greyhound Board further stresses how, since the welfare of this breed is 'critical to success', 'animal welfare is ensured', or at least while the animal is 'successful', one might well surmise. The Dog Breeders' Association's main objection to the proposed Animal Health and Welfare Bill concerned planning issues; the necessity to consult local authorities for the keeping of kennels would effectively end the dog-breeding industry in Ireland, this association claims. Further, this organisation complains about the antagonistic behaviour of some SPCA inspectors (Department of the Environment, 2015).

\subsection{The Department of Agriculture, Food and the Marine (DAFM)}

The DAFM is the body which allocates grant aid to the SPCAs and some, but not all, other animal rescue organisations. Several conditions must be adhered to by animal welfare organisations in receipt of DAFM ex-gratia funding. The 'Five Freedoms' outlined above should underpin best practice at the organisations.

The funding application document (DAFM, 2015) goes on to note that in light of increased numbers of abandoned animals, shelters should consider whether 'longterm accommodation' is appropriate for some animals, thereby precluding rescue of other more needy neglected animals. How one decides which animals are 'more needy' is not defined however. The guidelines to be eligible for funding also urge the shelters to heighten public awareness of their existence via local newspapers and radio and to put in place helplines, 'ideally' (a rather weighty request) a 24 hour helpline in which members of the public may report suspected cases of animal cruelty. Other notable requirements include: the introduction of Trap, Neuter and Return programmes (TNR) whereby feral cats are neutered/spayed, the need for shelters to maintain detailed records of all animals rescued, re-homed and euthanized. Further, all organisations must comply with the Control of Dogs Act, 1986 and be familiar with its provisions regarding notifying a dog warden when stray dogs are found. From 2016 new regulations will come into force that will make it mandatory for all dogs to be micro-chipped and owners should be advised of this 
when dogs are re-homed from shelters. Organisations involved in the transport of dogs or cats on long journeys (to the UK, for example) must ensure that the dogs have an EU Pet Passport showing microchip identification and valid rabies vaccination (DAFM, 2015).

Welfare organisations must if requested allow DAFM officials access to premises and inspect the animals present and records. Procedures must be put in place on how to deal with the disposal of live animals. Dogs with a history of attacking sheep must be euthanized rather than re-homed (DAFM, 2015).

In 2014, DAFM allocated a total of 1, 867, 200 euro to a total of 142 equine, dog, cat, all-animal rescue organisations (Appendix $\mathrm{H}$ ). As outlined above, animal welfare organisations must adhere to certain conditions in order to be in receipt of DAFM ex-gratia funding, such as observing the Five Freedoms for the animals in their care, and reporting cruelty to the Gardaí Síochána (the Irish police force). The two largest allocations went to the two largest animal welfare organisations: the ISPCA and the DSPCA , at 210,000 euro for each organisation, but most payments were in the order of 5000 euro, rendering most rescue organisations almost wholly reliant on public donations in order to meet veterinary bills and run their shelters; fundraising initiatives are outlined in section 4.7. below. Next I turn to the Irish SPCA and the Dog Pound system in the Republic of Ireland.

\subsection{ISPCA and the Pound System}

Following on from the creation of the Royal Society for the Prevention of Cruelty to Animals (RSPCA) in England in 1824 (RSPCA, 2016), the ISPCA was established in May 1949, by a group of committed volunteers from across Ireland, and is also represented internationally through active membership of the World Society for the Protection of Animals. The RSPCA philosophy mutated into an Irish version, followed by the establishment of a proliferation of smaller shelters. Ireland is a copy of the British charitable model (and unlike in many other spheres, the Catholic Church did not play a role in animal welfare). Ireland ISPCA Inspectors investigate complaints of abandoned, neglected and cruelly treated animals. It is their role to establish the facts of each case and to decide whether to proceed with a prosecution, 
which is undertaken as a last resort. Where possible, the inspectorate attempts to educate the public about how to care for their animals. If the owners are unable to do so, they are offered the opportunity to surrender the animal (ISPCA, 2015). The inspectorate work closely with the DAFM and the Garda Síochaná, as well as with local authorities. Each year the ISPCA cruelty helpline receives over 20,000 calls resulting in over 4000 investigations, over 700 animals seized or surrendered, and 25 prosecutions, with 9 from 2013 finalised. The ISPCA has 1 Chief Inspector and 7 Inspectors (ISPCA, 2015). The ISPCA Strategic Framework 2016-2020 (ISPCA, 2016) explains that the inspectorate was expanded in September 2015 by recruiting two new members. The AHAW Act 2013 allows ISPCA inspectors to carry out statutory powers including seizing animals.

Figure 4.1. Source: ISPCA 2015

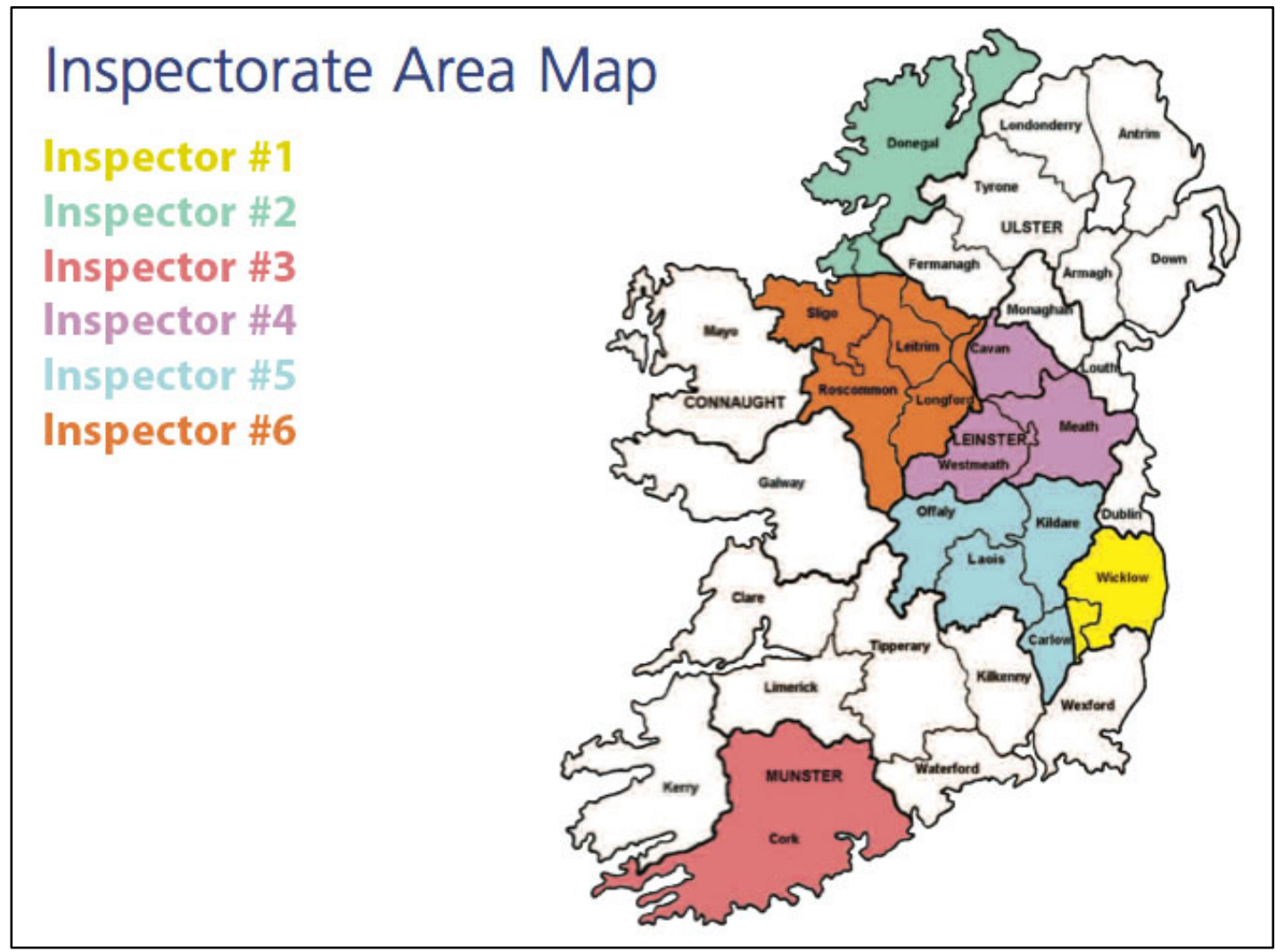

The ISPCA, located in Longford, is the umbrella organisation for 19 affiliated local animal welfare organisations and runs seven of Ireland's Pounds in conjunction with 
local county council, although this is a mutable situation. At the end of December 2014, the ISPCA began the process of withdrawing from the day-to-day running of pounds in Carlow/Kilkenny, Offaly and Roscommon, citing financial and logistical demands (D’Alton, 2014).

In 2002, of 10, 953 dogs 'seized' by Irish Pounds, 21, 357 were 'destroyed', a figure representing $81 \%$ of the dogs 'seized'. The situation has improved, in 2015 'only' 1,824 dogs were euthanized, or 14\% of the total (Department of the Environment 2016). There has thus been a huge reduction in euthanasia of dogs, probably due to the education efforts of the SPCAS and Dogs Trust, and concomitant enhanced public awareness of the need to spay and neuter dogs. When a dog is picked up by a dog warden and enters the Pound system as a stray, the Pound has a legal obligation to keep the dog for five days in case the owner comes forward. However, when a dog is handed over by its owner, the Pound has no legal obligation to keep it for any length of time and the dog could be put to sleep the same day (Department of the Environment, 2015). The majority of these dogs are healthy animals, surrendered by owners who cannot, or will not, care for their pet any more. The declaration of animal rights (ISPCA, 2015) contends that "we share the earth with other creatures great and small" and that animals "have the right to live in harmony with their nature, rather than according to human desires”. Their mission statement is to promote animal welfare, prevent cruelty to animals and relieve animal suffering (ISPCA, 2015). Specifically, the ISPCA seeks to embed the Five Freedoms concept in the national approach to animal welfare and to promote and reinforce ISPCA values through the delivery of a comprehensive, consistent and continuous ISPCA programme of education, advocacy and advice activities (ISPCA, 2015). The document speaks of 'all' animals although it is unclear to me how intensively farmed chicken or pigs are free to express normal patterns of behaviour. The ISPCA mission statement has come somewhat unstuck through its dichotomous relationship with running the Dog Pound system in many counties. One ensuing controversy is laid out in the next section when Animal Collection Services (ACS) successfully tendered to run the Carlow/Kilkenny Pound. 


\subsubsection{Dog Pound Controversy February 2014: The Case of ACS}

In late 2014, the ISPCA announced its intention not to renew its contracts after December $31^{\text {st }} 2014$ to oversee the running of several pounds, including the Carlow/Kilkenny pound. At that time, I thought it likely that the ISPCA might wish to distance their organisation from Pounds which are often perceived by the public as unsympathetic towards dogs, on whose donations the ISPCA largely depends. Dr. Andrew Kelly, CEO of the ISPCA recently corroborated this belief (Treacey, 2015: 2) when he commented to the Carlow Nationalist; "It was becoming more difficult to be seen as both a dog saviour and a dog catcher” (Treacey, 2015: 2). Therefore the ISPCA intends to focus more on animal welfare than control in the future and plans to withdraw from the running of other pounds.

A Protecting Pound Dogs Kilkenny/Carlow Facebook page was set up in February 2015 in order to lobby for the tender for Carlow/Kilkenny Dog Pound to be awarded to an Animal Welfare organisation with a "no kill” policy, defined as euthanizing dogs as a last resort, in the case of disease or aggression. The Mayor of Kilkenny, Andrew McGuinness, called on the Local Authority to adopt a policy to maximise re-homing of dogs by the new service provider to the Carlow/Kilkenny Pound. Candlelight vigils, attended by over 150 people and their dogs were held to this end in Carlow and Kilkenny in February 2015 (Cody, 2015: 25). Stray dogs were not allowed to be commodified by concerned members of the public in this instance, and this Pound is still run by the ISPCA (July, 2016). Animal Collection Services (ACS) (now trading under Four Seasons) was awarded the tender to run the Dog Pound at Paulstown from August 2015, following the ISPCA strategic decision to withdraw from the running of the Pound (see Chapter 4). There is very little information available online about this organisation; the company directors names are online but the nature of the business operations is unspecified.

Here was a nexus of interests around a problem and solution. Following public opposition comprising vigils, a petition with over 16,000 signatures, a public meeting on July $27^{\text {th }} 2015$ in Kilkenny and the establishment of a Dog Welfare committee chaired by Cllr Andrew McGuinness, ACS (Cody, 2015) ACS officially 
withdrew from the process. "In truth, the food riot did not require a high degree of organization. It required a consensus of support in the community, and "an inherited pattern of action with its own objectives and restraints” (Thompson, 1971: 199). Thompson's (1971) definition applies to the community opposition to ACS.

I attended this public meeting in July 2015 and took contemporaneous notes. It was attended by members of the public, one animal shelter representative, members of Carlow and Kilkenny County Council, one current staff member of the Pound under dispute, a local journalist, the Kilkenny Animal Welfare Committee, and to my surprise the Chairperson of the Irish Farmers Association, who was vocal about the need to retain current Pound staff who he maintained, did a very difficult job, especially the Dog Warden who went “places one wouldn’t necessarily want to go”. He did not clarify this assertion. He went on to affirm that dogs who savage sheep should not be retained in Pounds as farmers' incomes are “decimated” by dog attacks on sheep. A member of the public retorted that collies are the most common breed in Irish Pounds and the Chair restored order to the meeting. There was general consensus that ACS should not take over the running of the Pound, which they ultimately elected not to do. The market 'demoralizes' social relations; supply and demand do not always determine the common good, according to Thompson (1971: 94). Pounds, Councils, and the State are engaged with shelter work in the same field, and participate in the ideological conflicts that delineate its stakes.

The County Council are currently (February 2016) reconsidering their options in relation to the running of the facility, which is being run by the ISPCA in the interim (state of play, July 2016).

"The charter has clearly set out its policies which make it very difficult for anyone other than an animal welfare organisation to run the Pound", Cllr McGuinness is quoted in a Kilkenny People article (Cody, 2015). ACS is a case of competition between people who are structurally diverse. In this instance the shelter view prevailed although the ultimate outcome is unclear. That only one animal charity was in attendance points to the wider context and the conflicts faced by animal charities. On the one hand they are partially dependent on DAFM grants, and on the other they oppose free market logic when this impinges upon saving animals' lives. The ACS 
case shows how the organisational field, as well as the repertoire of roles is contested and constructed. ACS is but another example of a long history of resistance to market encroachment into animal welfare. Dogs Trust (2014) resists the commodification of dogs (their slogan is: “A dog is for life, not for Christmas”) and lobbies the commercial organisation Bord na gCon (The Irish Greyhound Board). The ISPCA takes legal action against 'puppy farms' (ISPCA, 2015). Recently (Walsh, 2016) a group of Irish celebrities lodged a formal objection to a bid for retention permission for a puppy farm in co. Cavan, following a BBC Panaroma documentary into the conditions on this 'farm' (Walsh, 2016).

Pound employees refer to the days when dogs are euthanized by a veterinary surgeon as PTS (Put to sleep) days. Table 4.1 depicts the percentage of the aggregate of seized and surrendered dogs destroyed in the 11 year period for which Department of the Environment figures are available (Department of the Environment, 2015). It is important to note that these official statistics do not include dogs euthanized by members of the public or by veterinary surgeons on request. The terminology 'Destroyed' prior to 2005 changed to the more euphemistic 'Put to Sleep' thereafter. The percentage of dogs in pounds euthanized fell to under $50 \%$ for the first time in 2008. In 2009, the year Dogs Trust entered the Irish Welfare sphere, the figure fell to $40 \%$. This is probably not coincidental, as Dogs Trust have a high intake of dogs from the Pound - about 70\% of their intake of dogs (Dogs Trust, 2016). Since then, the trajectory has been steadily downward with the exception of 2013.

There is a geographical disparity in terms of kill rates. To take one example from 2012, Roscommon Pound's PTS percentage was 61\% of all dogs seized or surrendered, as against a national average of $26 \%$. Wexford Pound's was recorded as 39\% (Department of Environment, 2015).

Table 4.1: Official Pound Statistics 2004-2015

\begin{tabular}{|l|l|l|l|l|}
\hline Year & Seized & Surrendered & Destroyed/PTS & Percentage Destroyed/PTS \\
\hline 2004 & 9,749 & 14,823 & 16,598 & $68 \%$ \\
\hline 2005 & 10,254 & 15,078 & 16,546 & $65 \%$ \\
\hline 2006 & 7825 & 16,338 & 14598 & $60 \%$ \\
\hline 2007 & 7723 & 15,587 & 12,649 & $54 \%$ \\
\hline
\end{tabular}




\begin{tabular}{|l|l|l|l|l|}
2008 & 7,942 & 12,707 & 10,069 & $49 \%$ \\
\hline 2009 & 6,845 & 9,568 & 6,506 & $40 \%$ \\
\hline 2010 & 5,008 & 11,065 & 5,244 & $33 \%$ \\
\hline 2011 & 6,140 & 11,246 & 5,586 & $32 \%$ \\
\hline 2012 & 6,903 & 10,574 & 4,500 & $26 \%$ \\
\hline 2013 & 6,668 & 8,813 & 3,516 & $37 \%$ \\
\hline 2014 & 6,015 & 8,544 & 2,896 & $20 \%$ \\
\hline 2015 & 1,650 & 11,401 & 1,824 & $14 \%$ \\
\hline
\end{tabular}

Carlow/Kilkenny Pound had the lowest euthanasia rate of all the Pounds in 2015; only 12 (2\%) dogs in total were euthanized. I theorize that the explanation may lie in the large number of dogs transferred to local shelters, along with the public outcry (and consequent greater public involvement in rehoming this Pound's dogs) against the proposal of ACS taking over the running of the Pound (see Chapter 4 below). The highest rates tend to exist in Pounds run by private operators, rather than by the ISPCA, or other SPCA. Wexford Pound had the highest euthanasia rate in 2015 (55\%) and is run by a private operator.

The plight of surrendered greyhounds is significantly worse. From the year 2010, statistics for greyhounds have also been compiled separately and available on the Department of the Environment website (2016). The percentage of these dogs put to sleep has remained quite constant over the 2010-13 year period at around 8 in 10 dogs, although this situation improved in 2014 (57\%) and 2015 (55\%). This discrepancy is explicable by the Irish societal tendency to view greyhounds as unsuitable pets. In Scandinavia, greyhounds are very popular companion animals and many Irish shelters export these dogs to Scandinavia every year (Interviews, 2014).

Table 4.2: Official Pound Statistics (Greyhounds) 2010-2015

\begin{tabular}{|l|l|l|l|l|}
\hline Year & Seized & Surrendered & PTS & Percentage PTS \\
\hline 2010 & 249 & 573 & 672 & $82 \%$ \\
\hline 2011 & 42 & 658 & 546 & $78 \%$ \\
\hline 2012 & 18 & 510 & 404 & $77 \%$ \\
\hline 2013 & 66 & 496 & 427 & $76 \%$ \\
\hline
\end{tabular}




\begin{tabular}{|l|l|l|l|l|}
2014 & 35 & 397 & 245 & $57 \%$ \\
\hline 2015 & 10 & 356 & 203 & $55 \%$ \\
\hline
\end{tabular}

The DSPCA is the other largest SPCA in the Republic of Ireland, and as such merits attention in these pages.

\subsubsection{Dublin Society for the Prevention of Cruelty to Animals (DSPCA)}

The DSPCA, according to its website (DSPCA, 2014), was established in 1840, which seems difficult to reconcile with the calamitous events that took place in 1840s Ireland (Woodham-Smith, 1962).

The DSPCA was based at Grand Canal Quay in Dublin City from its formation in 1840 up until 1990, and generations of Dublin people were familiar with it as "The Dogs and Cats Home" and at times as "The Cats \& Dogs Home" (DSPCA, 2014).

In 2003 the Society moved to its new premises on Mount Venus Road, Rathfarnham where facilities were built to continue the work of the Society (DSPCA, 2016). The Dublin SPCA continues to care for the sick, injured and cruelly treated animals in Dublin City and County and employs 52 fulltime and part-time staff and is aided by almost 400 volunteers (DSPCA, 2016). Smaller SPCA affiliated organisations in the current study are run by 5 fulltime volunteers, with wider public assistance, as a contrast. The facility offers shelter and care to a wide variety of animals including dogs, cats, horses, donkeys, goats, cows, pigs, rabbits, ferrets, gerbils, and all manner of farmyard fowl. The centre is also a rest stop for a number of injured and young wildlife awaiting release including swans, foxes, badgers and small birds (DSPCA, 2014).

During one visit to the DSPCA in June 2012 I was allowed access to boxes filled with scrapbooks, newspaper clippings and minutes from meetings from the $19^{\text {th }}$ century. The oldest archival material I found dated from 1876, which was a DSPCA Annual Report documenting various cruel practices such as: the manner of loading 
cattle on railways and steamboats, overcrowding and depriving them of food and water, overstocking (the practice of not milking cows before market in order that the present the appearance of 'good milkers'), the practice of plucking geese alive, and the overcrowding of fowl in crates. Deaths of active members, supporters, and legatees were also recorded (DSPCA field visit, June 2012):

"The committee continue to notice with regret the small penalities imposed on offenders in many cases”, and goes on to compare the Irish situation unfavourably with penalties in England. Accounts, Subscriptions and Donations are noted in the 1876 Annual Record. The amount donated is recorded in $£$, s. and d, and the same names appear year after year.

The 1891 Annual Record of the DSPCA records that: “The committee have to regret their dissatisfaction at the totally inadequate penalties awarded by magistrates in too many instances" and "trivial and disproportionate fines for offences against poor dumb animals". In 1892 the committee were "anxious to put a stop to the rabbit coursing matches”. Plus ça change, plus ça la meme chose springs to mind.

In 1900 the Annual Record states: "This is the opening of a century in which it is hoped the advances of the past century will be eclipsed, for in a Christian country cruelty to dumb animals ought to be unheard of but the fact of such conduct existing proves that such a society as ours is needed”. In 1916 cruelty convictions noted in the Annual Record included: "beating a pig with a stick and kicking” (DSPCA field visit, 2012).

The goals, activities and mission statement of the contemporary DSPCA are, unsurprisingly, broadly similar to those of the ISPCA described in the preceding section. The DSPCA runs mobile clinics to provide accessible veterinary treatment. Like the ISPCA and Dogs Trust, the DSPCA lobbies policy-makers and works on legislative changes to improve protection for animals (DSPCA, 2015). Archival material was sparse and it was explained to me that much of the records were lost to fires, floods, and a 'new girl erroneously putting archives in a skip' in the 1960s in the DSPCA office near the Fitzwilliam hotel. Staff dogs were in the foyer and sitting in beds under tables on that visit; staff members bring their dogs to work every day 
(DSPCA, field visit, 2012). The new Pet Boarding Centre opened in November 2010 and the Vet Clinic and the Dog Park opened in 2011.

I undertook several other informal visits to the DSPCA and on one such occasion took part in volunteer orientation training (DSPCA, $22^{\text {nd }}$ September 2012). The two presenters told 'before and after' narratives of rescued animals. 40 people attended this training 35 women, 5 men. The presenters pointed out that in cruelty cases where dogs are attacked with a machete (one of the before and after narratives) that one must ask what is going on in that house; it is a bigger social picture. Therefore the DSPCA works closely with the Gardaí Siochána, the Irish police force. They also explain that while it is a last resort, and always a veterinary decision, sometimes animals who are too sick or behaviourally disturbed to be re-homed must be put to sleep. The importance of fostering "baby dogs and cats" was explained; very young animals are liable to pick up diseases in shelters.

The DSPCA fundraising initiatives include that organisation's onsite 'King of Paws' dog training centre, Pet Boarding Kennels, Dog park, and Veterinary Clinic. All the profits go back into running the society. This was described as a social business model (DSPCA, field visit, 2012). At that time, the DSPCA had 34 staff and 400 plus animals in care. The pivotal importance of volunteers was reiterated. The options for volunteering range from working in the Boarding Kennels, in the Care Kennels, as an Adoption Assistant, which entails showing dogs to potential adopters. In the latter role, we are cautioned that we should not say anything negative about any dog; the Adoption Counsellor gives all the details about the dog, at the adoption stage. We were reminded that a tetanus booster vaccination was essential prior to volunteering. Finally, one presenter spoke briefly and emotionally about her experiences working in DSPCA for the previous 5 years. She deemed the shelter a “fantastic place to be involved with”. Despite having seen some atrocious cruelty, she had also seen how these dogs, after 4 or 5 months in the shelter skip out the door to their new homes. That is a wonderful feeling, she explained (DSPCA field visit, 2012).

We were shown around the shelter by a long-term male volunteer who has primary responsibility for the equines. He was articulate and tattooed. He told me that horses 
love polo-mints and went on to demonstrate the veracity of his statement (DSPCA field visit, 2012). Many of the workers in my smaller shelters also sported tattoos (see Chapter 5). I volunteered as dog-walker several more times in 2012.

\subsubsection{Other SPCAS}

Although the ISPCA and DSPCA are by far the largest SPCAs, there is a SPCA branch in most of the 26 counties. Some counties share a SPCA (Kildare and West Wicklow) in others, there are more than one (North Dublin SPCA, DSPCA). The size and scope of the SPCAs vary; some SPCAs have no holding facilities for injured or abandoned animals. They respond to calls from the public and bring injured animals to a veterinary surgeon, and transport abandoned animals either to the Dog Pound or to foster homes. Animals in the latter category are 'advertised' as needing homes on the SPCA website. Other SPCAs are run from veterinary surgeries, as is the case for the Wexford SPCA (ISPCA, 2015). Unlike the larger SPCAS and Dogs Trust (see next section) positions in small SPCAs and shelters are often filled on an ad hoc basis, and are often filled by volunteers. Formal qualifications are not usually necessary. Job advertisements state that love for animals is essential, along with an ability to do manual, tiring work. Further, cat shelter work tends to be feminised and Dog Warden positions tend to be filled by men (Interviews, 2014). In other words, social structures create different kinds of occupations in terms of pay, moral choices, and gender. Dogs Trust is a recent entrant to Ireland, and is quite regimented in its structure, with even canine carers subject to appraisal through key performance indicators (KPIs).

\subsection{Dogs Trust}

Dogs Trust was founded in England in 1991 and is the largest dog welfare charity in the UK (Dogs Trust, 2016). Dogs Trust began a Nationwide Subsidised Neutering campaign in 2005 in Ireland. In order to stop unwanted puppies and prevent straying each year, Dogs Trust have financially helped over 90,000 people on means tested Social Welfare benefit to get their dog neutered. Through a network of over 265 vets nationwide, they continue to neuter over 10,000 dogs every year (Dogs Trust, 2015). 
In 2006 they began an Education Campaign, offering free workshops to primary schools in Leinster, Munster and South Connaught. The focus is on teaching 5 -12 year olds about responsible dog ownership, and how to be safe around dogs through curriculum linked workshops. The children also get the opportunity to meet one of the Dogs Trust 'education dogs'.

In 2009 Dogs Trust opened their Rehoming Centre in Finglas, Dublin and employs 60 fulltime staff. Due to the high destruction rate in Irish pounds, Dogs Trust rescue and rehome over 1,000 puppies/dogs each year. Their subsidised neutering and microchipping campaign offers low cost neutering for dogs whose owners are on means tested Social Welfare benefits (Dogs Trust, 2015).

Although the organisation employs 60 fulltime staff (Dogs Trust, 2016) Dogs Trust are not one of the 142 welfare organisations in receipt of ex-gratia funding from the DAFM (see Appendix I). Dogs Trust made the strategic decision not to apply for this annual payment for three reasons. First, Dogs Trust lobbies and interacts with government and civil service officials, and accepting state funding might conflict with this activity. Second, they did not want to divert funds from smaller animal welfare charities, in greater need of financial assistance. Third, their fundraising activities are at such a level that such governmental subvention is not essential (personal email communication, 2015).

Dogs Trust works with UCD academics who are the vets on site and takes in final year veterinary students on placement to give them practice at surgery etc (Interviews, 2014). One of my participants describes Dogs Trust as an NGOacademic liaison which is rather novel in Ireland (in the UK this is more usual: the University of Bristol is at forefront of animal welfare research). Dogs Trust developed a 'Diploma in Animal Training in the Shelter Environment' in collaboration with University of Bristol. There is a wide range of occupational roles at DT: Canine Carer, Puppy Rearer, Behaviourists, Post-adoption Advisor (who contacts the re-homing family after 3 weeks, and again after 6 weeks to pre-empt and resolve any problems that might result in dog being returned to the shelter).

The vocational draw can be a problem as some employees come in with rose-tinted spectacles and find that much of the job involves dealing with people (Interviews, 
2014). Dogs Trust is the $12^{\text {th }}$ largest charity in the UK and has over 1000 employees, with a turnover of $£ 90 \mathrm{~m}$; the organisation is a business as well as a charity. Dogs Trust Ireland has spent 80,000 euro over 6 years on dog neutering programmes. The number of dogs put to sleep in Irish pounds has dropped in that time-frame, and the Dogs Trust neutering programme is part of the reason why (Interviews, 2014).

\subsection{Other Shelters}

Apart from the SPCAs and Dogs Trust, there is a plethora of other animal welfare organisations in Ireland. Exact figures are difficult to ascertain; a central site for all welfare organisations in the 32 counties lists 157 organisations (Rescue Animals Ireland 2015), ranging from Pounds to Reptile and Exotic Pets sanctuaries (of which it lists 5). This list is not exhaustive however; two of my respondent shelters do not appear on the list, despite both having been ex-gratia funding recipients from the DAFM in 2014 (DAFM, 2015). There are also some breed-specific shelters such as the 'Sera Husky Rescue' but none were participants in the current study. The DAFM list of organisations in receipt of funding in 2014 contains 142 recipient shelters. $1,867,200$ euro in total was awarded in funding. The largest amounts were paid to the ISPCA and DSPCA (210,000 euro each), followed by the Donkey Sanctuary in Co.Cork $(87,000)$ and the Irish Blue Cross $(70,000$ euro) which operates a mobile dispensary. The organisations are in the main specialising in canine, feline or equine rescue but not all: Seal Rescue Ireland is based in Co.Wexford, the National Exotic Animal Sanctuary in Co. Meath, and Little Wings Bird Sanctuary in Co. Sligo. Nor is the DAFM list exhaustive; some organisations (for example Dogs Trust) do not apply for funding, others are unsuccessful in their application (DAFM, 2015). Yet other organisations are unregulated and run from people's homes, with help from public donations. It seems very likely that over 150 animal rescue organisations were in operation in Ireland in 2015.

Shelters need help with designing and managing shelters, of course. The RSPCA has published guidelines on this theme (RSPCA, 2015). 


\subsection{Royal Society for the Prevention of Cruelty to Animals (RSPCA) Guidelines}

The RSPCA is the world's oldest animal welfare organisation. Founded by William Wilberforce, an abolitionist, and by others in 1824, the Society aims to prevent cruelty and promote kindness to animals. It publishes a booklet setting out all the areas to consider when building an animal shelter. First, animal shelters must take cognisance of animals' basic needs: physiological, social, psychological, environmental and behavioural. Before deciding to build a shelter, the existing shelters in the area should be assessed with regard to their capacity and the areas they serve. The RSPCA suggests that the possibility of a collaboration should be considered. Financial planning is very important; whether the shelter will be funded from public donations or local authority funding, or from a combination of both. The RSPCA booklet also cautions against the potentially deleterious effect of taking on a contract on stray animals on a shelter's public image which is echoed in the ISPCA's withdrawal from the running of several Pounds, as depicted above. The RSPCA booklet recommends creating a foster network of dedicated volunteers to take abandoned dogs and cats into their homes temporarily. Such a network has the potential to house a far greater number of animals than a shelter ever could. All of my participant shelters avail of fosterers to care for injured or ill animals who need time to heal before being permanently homed.

The RSPCA booklet suggests that common difficulties faced by shelters include: funding, location, planning permission, local support, attracting and retaining volunteers, disease control and internal disagreements. The establishment of shelter policies is important to help guide an organisation's work, ensure continuity of animal care and compliance with relevant legislation. The RSPCA advocates the neutering of domestic animals prior to re-homing. With regard to euthanasia, the guidelines point out that a strict 'no-kill' policy, while conducive to a positive image in the eyes of many of the general public may not be viable. Euthanasia of animals that are not suitable for rehoming (e.g. aggressive animals) avoids long-term kennel stress and allows space for animals that can be rehomed. The RSPCA accepts with reluctance that in certain circumstances, for example if good homes are not available, euthanasia may be necessary. The booklet then lays out the planning process for designing a shelter. Capital non-recurring expenditure items include the purchase of 
land and consultancy fees (architects, surveyors etc.), building materials, services connection (electricity, water, drainage) etc. Day-to-day running costs are comprised of food, veterinary bills, insurance, light/heat/water, cleaning materials and staffing costs. A realistic estimate of the shelter's annual income from ex gratia grants and from fundraising should be prepared as part of the financial plan. The layout of the building usually includes a reception area, an administrative office, a medical room, a cold storage room for carcasses in the case of open admission shelters and pounds, an animal food preparation area and a hygiene area for staff. The floors in the animal space should have smooth impervious surfaces e.g. tiles. Walls should have no cracks or gaps that could harbour disease. Floors should slope towards and outside drain. The provision of mains sewers, a cesspit or septic tank is necessary (RSPCA, 2015).

\subsection{Shelter Social Media Self-presentation and Fundraising Activities}

With the exception of the Pound, all of the organisations in this study are my Facebook 'friends' as part of my research protocol. Certain themes are common across these organisations' Facebook presence. First, before-and-after narratives feature often. For example, a photo of an emaciated dog or kitten is juxtaposed with a picture of the healthy animal following care in the shelter. Such posts elicit congratulatory messages from members of the public, and sometimes derogatory comments about the person or persons who 'allowed' the animal to get into such a situation. Moreover, shelters often praise members of the public who send in photographs of their rescue dogs, reminding their 'followers' that adopting a pet saves two lives; the one you adopt, and the one who takes its place. In this way, shelters constantly reproduce the discourse that humane treatment of animals is normative and that cruelty is norm-violating (Appendix F). Noteworthy is also how frequently animals are infantilised; kittens are commonly referred to as “my babies”, and photographs depicting cruelty often draw responses such as 'poor baby' from members of the public (Appendix F). For example, on February $29^{\text {th }} 2016$, one shelter posted a picture of an emaciated lurcher on their Facebook page. This dog had been tied to a tree in a forest near Abbeyleix, Co. Laois. Despite the best efforts of the shelter and their veterinary surgeon, the dog died the day after he was rescued. One of the more measured 'follower' reactions to this event in the comments section 
stated: "I hope the pain, suffering and loneliness inflicted on this poor, innocent creature follows the person, or people, responsible for the rest of their days on this earth”.

A web presence is thus an opportunity for rescue organisations to promote their view of cruelty and to increase awareness of their mission. “Amid cruelty’s perfect mess lies sociological opportunity”, as Arluke frames the issue (2006: 178). Equine cruelty cases, of which there are many in Ireland often draw ethnically disparaging comments from members of the public, though these tended to be coded, for example: "We all know who owned the horses". 'Cute' or amusing photos of animals are also common. Recent examples include a photograph of a hen cuddled up beside a sleeping cat, and a donkey who appears to be sticking out his tongue at the photographer. It is notable how rural are most of the scenes depicted; shelters are often in scenic locations. Almost every shelter worker I interviewed or met said s/he likes the outdoors and by contrast, dislikes 'cooped-up office' jobs they had previously held (Interviews, 2014). Allied to being close to 'nature' is the notion of sanctuary for the shelter workers. The dark sides of shelter work do not go unremarked on their websites; a final recurrent theme is the despair and fatigue which sometimes engulfs this occupational group (Appendix F).

'Likes' for Shelter Facebook Sites range from 1,199 to 58, 426 for the largest rescue in the study (January $16^{\text {th }}, 2014$ ). Clearly, a cohort of society cares about the work that shelters do.

Fundraising activities include Paypal or direct debit - which is very important as it ensures some continuity of income for shelters - pub quizzes, street-collecting, 'celebrity' events. For example, in 2008, when a volunteer for the Kilkenny SPCA I organised for the TV3 personality 'Pete the Vet', Dr. Pete Wedderburn, to give a presentation on animal welfare in Kilkenny. Wedding favours are sold by several larger charities (Dogs Trust, 2015), marathons and mini-marathons are undertaken for fundraising purposes, charity shops where stock is donated by concerned members of the public are common. Petfood Multinationals are often supporters of shelters, and that support is acknowledged on Facebook pages or in newsletters (Appendix F). Finally, estates and wills are a very significant source of income for 
well-known organisations. Larger organisations such as Dogs Trust have Marketing and PR departments, and are self-sustaining; smaller shelters face a constant struggle to survive.

\subsection{The Labour Market: Central Statistics Office}

The occupations of 'Veterinary Nurses' (code:6131) and 'in Animal Care Services' (code:6139) are from the socio-occupation classification (CSO, 2015). Unfortunately, these classifications were used for the first time in the 2011 census. The 2011 data shows 440 VNs (which is not broken down by private practice and shelter work) and 1,198 in 'Animal Care Services n.e.c.'. Some of my respondents write 'animal shelter work' on the census form, others write 'unemployed', as they are volunteers and in receipt of job-seekers' allowance. It is therefore impossible to be precise about the percentage of 1,198 which is accounted for by shelter workers. The 2006 census shows 2,449 employed in 'veterinary activities', which is not a clearly defined term. What is clear is that organisational type and regional location shape the context of shelter work.

\subsubsection{Barriers and Enablements to Occupational Choice}

The organisational field depicted in this chapter is linked to the structure of occupations and the conditions and experiences of work open to my shelter participants (see Table 3.1. Chapter 3) in five principal ways.

First, organisations without holding facilities (Organisation A) would not be a desirable workplace for most of my respondents who prefer to be surrounded by animals during their working day and to 'see the animals through to their forever home'.

Second, euthanasia - which is an inevitable part of the Pound setting - would constitute a barrier to entry for my respondents who advocate a 'no-kill' policy. There are different moral rationalites at play in this instance; my Pound respondent (who loves animals) accepts with sadness the necessity of euthanizing dogs who are sick or aggressive, or who cannot be rehomed because they do not appeal to the adopting public. 
Third, the 'choice' to become a CEO of a large organisation (C and E) necessitates business qualifications or prior experience, which would preclude many of my participants. Large organisations would not appeal to many of my respondents as workplaces, as they prefer the relative informality of a less regulated work environment (although all my shelters are routinized to some extent, as animals require routine care).

Fourth, electing to set up or run one's own shelter (Organisations B, D, H) requires the ownership or lease of a suitable premises in which to give animals shelter until they can be rehomed, a willingness to dramatically curtail one's personal free time, and the nous to engage with policy makers and the wider public in order to ensure the financial survival of the shelter.

Finally, the 'choice' to be a dedicated volunteer requires an alternative income source. For my volunteer participants these sources are: retirement income, spousal or familial financial support, jobseekers' allowance, or supplementary work such as dog-grooming. The research settings I studied include large shelters following the British charitable model with 40 or more employees (Organisations C and E), medium sized shelters set up by private individuals with 5 to 10 employees, some on a part-time basis (Organisations D and H), and small shelters or SPCA subsidiaries

run by volunteers (Organisations $\mathrm{A}, \mathrm{B}$ and $\mathrm{F}$ ). The analysis which follows in chapters 5 and 6 thus represents the spectrum of animal shelters in Ireland.

In the next section, I try to shine some light into the daily life of an animal shelter.

\subsection{A Day in the Life of a Shelter Worker}

The daily routines in the two shelters with facilities ( $\mathrm{E}$ - all-species and $\mathrm{H}$ - mainly dog) in which I spent most time partaking in activities were organised as follows: the kennels and cages and animals are inspected in the morning and if necessary treated for lice or mange. Kennels, cattery, utensils and service buildings are cleaned and disinfected, and faeces scooped. This is an essential activity because if parvovirus a highly contagious viral disease - spreads in shelters the consequences for the dogs are devastating, and almost always prove fatal for puppies. Clearly, this is not work for people with “delicate sensibilities” as Harbolt (2003: 84) observes. In the case of dog shelters, the kennels are architecturally designed so that every dog has an indoor 
sleeping area and a separate outdoor 'run'. This design is essential in order to facilitate cleaning the areas daily, and to reduce kennel-related stress by allowing the dogs some agency over their environment (they can retreat to their bed if they desire). Larger organisations such as E employ animal carers, inspectors, educational officers, fundraisers and marketing staff, whereas in smaller shelters such as $\mathrm{H}$ shelter staff tend to do all of these activities, as well as caring for the animals.

Food is then prepared and the animals are fed. Food for dogs usually consists of dried kibble, sometimes with the addition of cooked chicken pieces, and is often donated by petfood organisations or via supermarket appeals to the public. Feeding, cleaning kennels and cages take up much of the day. Intake, initial assessment of each animal as an individual, reducing stress and enriching their environment is also important (Miller and Zawistowski, 2015: 145). According to Miller and Zawistowski (2015) appropriate housing and husbandry can mitigate the negative impact of many of the detrimental features attributed to shelters. Tailored husbandry offers the best possible quality of life in the shelter, and crucially, the best chance at adoption (Miller and Zawistowski, 2015). Details are noted about each dog: name, breed, where they came from (for example, found straying), age, colour, sex, and vaccination, neutering and microchipping details.

Each dog is exercised every day, or employees or volunteers play with cats, in order to keep them stimulated and socialised for re-homing purposes. This is very labourintensive work, as the following excerpt from my fieldnotes depicts:

Karl and I take three or four dogs per walk, always following the same path back and forth from the well, a 20 minute circuit. Several dogs become uneasy as we approach the shelter after their walk. It is clear to us that they do not want the walk to be over. After three hours, we are hot and tired and have still only walked about one third of the dogs. It is very, very difficult to pass the kennels of dogs who are barking and appear to be pleading to take their turn. We decide to come back the next day. (Fieldnotes, Shelter H, July $31^{\text {st }}$, 2014).

Shelter workers interact with the animals, talk to them, stroke them, and make allowance for what they perceive to be idiosyncratic preferences of some animals. For example, some male dogs do not 'get on' with other males, and are accordingly 
kennelled with female dogs. Some cats prefer wet food to dried kibble, and shelter workers observe and act upon such preferences. Preparing animals for adoption is the main goal of shelter work. Volunteers are essential to fulfil this task in the case of the dog shelter; it would not be feasible for staff members to walk in excess of 100 dogs a day. Dog-walking in all weathers is hard work; some breeds, for example Staffordshire Terriers are very strong, and can be difficult to control. Attire is important; long hair is best put in a ponytail, and long earrings eschewed - these act as magnets for cats' claws. Warm clothing and raingear is essential in the colder months. Social activities, such as barbeques are sometimes hosted for the volunteers in order to express appreciation for the pivotal role volunteers play in the running of the shelter.

Front office positions are also onerous; members of the public must be attended, both for intake and re-homing requests. The telephone must be answered and administrative work done. Dealing with members of the public can be the most stressful aspect of shelter work, a theme to which I return in Chapter 6, which examines the dark sides of this occupation. People sometimes drop off ill dogs they 'found' that belong to them, according to my respondents, or because the dogs are 'difficult to manage' and the resultant bewilderment of the forsaken dog is hard for shelter workers to behold (Interviews, 2014).

School visits by 'education officers' are an integral part of SPCA work, and of larger rescue organisations (Dogs Trust, 2015). Large organisations in the current study such as shelter E offer positions such as animal carers, inspectors, veterinary nurse, educational officer, fundraiser, PR and Marketing executives. In the smaller shelters typically the animal carers, shelter manager and CEO fulfil all of these roles. For both smaller and large shelters, animal admissions occur several times in an average week, and sometimes daily. Behavioural assessments are carried out on dogs to ascertain whether they are sociable with other dogs, children and cats. The validity of such assessments is contested; for example an artificial human hand is sometimes placed in the dog's feeding bowl while s/he is eating to try to ascertain whether the dog displays 'guarding' behaviour around food. Some animal behavioural experts point out that puppies or even older dogs sometimes chew what they clearly perceive 
to be 'things', although they would not harm a human hand (Mills, 2014, personal communication).

Injured animals must be brought for treatment to veterinary surgeons and if successfully treated, cared for, either by shelter staff or foster homes must be found. If the injured animal cannot be saved, shelter staff comfort the animal while it is euthanized by the veterinary surgeon. In the Pound system, staff members must sometimes comfort healthy animals who, due to overcrowding or simply by dint of being unlikely candidates for re-homing, meet the same fate. Large, black dogs, for example, are difficult to rehome (Interviews, 2014) possibly because some members of the public perceive such dogs to be dangerous or unfriendly. Home visits are carried out by some of my shelter participants, others lack the staff to conduct home visits and must trust their instincts to 'vet' potential owners. It is essential for all my shelter participants that the dog or cat will be allowed in the house; a dog kept outdoors is not a loved dog, in their eyes. Some larger shelters request that somebody is at home most of the day for dogs who suffer from separation anxiety, a stipulation that would preclude many would-be adopters.

In the evening the animals are bedded down and then fundraising activities are planned and social media presentation is undertaken. Sometimes the latter activity would seem to be prompted by despair, sometimes to express gratitude for public support or to garner more, and sometimes to share the 'happy story that makes it all worthwhile'. Appeals for donations to thrift shops aligned with the shelters, or attendance at fundraising events are common. Security issues are crucial for dog shelters; sometimes members of the public will try to retrieve injured dogs when the dogs have been successfully treated. Of course, there are seasonal variations in the shelter world; the kitten overpopulation is particularly demanding in the summer months, for example. Equine need is greatest during wintertime when dearth of grazing and water supply and low temperatures can be life-endangering. Shelter work is a 24-hour a day, 365 day-a-year occupation. Only in the largest organisations do my animal carer participants ever take a holiday of more than one week. 


\subsection{Chapter Summary}

This chapter sought to lay out the legislative framework surrounding animal welfare in the Republic of Ireland, and to document some of the organisations who struggle to deal with the uncomfortable legacy of the huge numbers of abandoned, neglected and abused animals in twenty-first century Ireland. This contemporary organisational field provides the repertoire of choices which enables or constrains occupational entry, and is important in light of this study which seeks to understand why people choose and remain in animal welfare occupational roles. The organisational field State, ISPCA as charitable foundation, smaller shelters which are more informally regulated, and the arrival of a major new player in the shape of Dogs Trust - shapes qualifications needed, employment conditions, and work behaviours which in turn enable or constrain my participants’ occupational choices. Large shelters (such as E) and smaller shelters (such as $\mathrm{H}$ ) are the two dominant modes of animal welfare organisation in Ireland which structure the occupational choices in the field. The rest of this thesis examines those choices within the repertoire of roles set before my participants.

The next chapter examines the multiple pathways and processes that combine to result in the occupational choice of shelter work. 
Chapter 5 


\section{Chapter 5 Pathways to Entry: Making Sense of the World}

So they left me dying behind this desk - adding bleeps

subtracting chunks - and I would

give a bowl of wild blossoms

some rain, and two shakes of my

fist at the sky to be living.

John Engman, "Work”.

\subsection{Introduction}

The last two chapters presented the methodological and epistemological approaches used for this study and empirically laid out the organisational field within which shelter work is chosen. The next two chapters illustrate the ethnographic findings of this study. This chapter examines the processes and pathways which combined to result in my respondents' occupational outlet of shelter work. It is profoundly important to understand why people do the things that they do, and especially what constraints and opportunities characterise the behaviour. This occupational choice can be described as counter-cultural in the sense that it repudiates the prevalent free market value system. Chapter 6 goes on to analyse the choice to stay in this field despite its many difficulties and travails.

This chapter contributes to the occupational choice literature because the former was not conceived with animal shelter work in mind, nor did it view occupational choice as a process (Blau et al 1956). Blau's (1956) seminal paper also omitted the nature of culture in occupational choice; culture as the shared knowledge passed on by learning that unites a group, and is shared and transmitted within a particular group (Birx, 2011). Following Hall (2003) I argue here that culture is not an essence but a process. The psychological literature does acknowledge the developmental paradigm (Savickas, 2007) but from a sociological view, occupational choice unfolds in a processual way for many people and within a broader socio-historical context. Stuart Hall (2003) defines culture thus: 
Culture, it is argued, is not so much a set of things - novels and paintings, TV programmes and comics - as a process, a set of practices. Primarily, culture is concerned with the production and the exchange of meanings between the members of a society or group. To say that two people belong to the same culture is to say that they interpret the world in roughly the same ways and can express themselves, their thoughts and feelings about the world, in ways which will be understood by each other. Thus culture depends on its participants interpreting meaningfully what is happening around them, and 'making sense' of the world, in broadly similar ways (Hall, 2003: 2).

Careerism is a taken-for-granted part of contemporary culture in the Republic of Ireland. As I document below, many of my respondents are tattooed or have multiple ear or nose piercings. In the context of a bank occupation, say, tattoos would probably still be looked at askance. In this sense, I contend that shelter workers are joining a tribe. They reject normalised culture to some extent because they are not normalised in the mainstream market economy. As a cultural community, they have rejected aspects of mainstream culture. I am expanding on the HAS and occupational choice literatures by taking the processual nature of entry into account, and distinguishing between antecedents to caring about and caring for animals (unlike Arluke and Sanders,1996, Alger and Alger, 1997, Irvine, 2007 and others who appear to presume loving animals is the reason for entry). Loving animals is not enough. My data finds little evidence of the institutional or interpersonal oppression Harbolt (2003) argues as the reason for entry. For a subset of four respondents natal or social influences were negative and ignited a backlash which resulted in loving animals, but none linked this to their eventual occupational choice. Taylor (2007) sees entry as counterhegemonic and as my respondents are not co-opted into the mainstream, my data has resonance with her thesis but counter-hegemony alone is not a sufficient explanation either, other processes (which my data explicate) are at play.

Occupational choice literature has been subsumed into the gendering literature where gender is presented as a powerful ideological tool used in everyday interaction to construct and reconstruct distinction between the sexes. 'Doing gender' occurs on three levels (West and Zimmerman, 1987) - individual, interactional, institutional and results in the naturalization of attributes associated with each sex. The articles in journals such as Gender and Society or Gender, Work and Organisation very rarely 
take zoocentric occupations as their focus, and even where they do (Irvine, 2010) institutionalized inequality tends to be thematic. While shelter work is clearly feminized, gender is not my primary focus here as the reasons given for entry and staying are similar for my male and female participants, including the two male less 'hands-on' CEOs. Instead I wish to expand the literature on shelter work to take account of the complex processes which combine to form multiple pathways to entry. The 4:1 female: male ratio is similar to most other shelters, although interviewing other male nitty-gritty workers would be valuable for future research, as there may be other categories of male entrants.

Below I characterise the reasons my respondents gave for entry into the social world of the shelter. This description is a construct of both the participants' narratives and the researcher's interpretations of these, and an attempt to develop theory from the patterns of thought and behaviour which emerged from the field data. Data reduction was necessary in order to make data manageable for analysis (Miles and Huberman, 2014) although reducing data may have led to losing some insights. I attempted to arrive at an understanding of the core reasons why people make this occupational choice.

I present my findings in two sections: antecedents which served to sensitive my participants to animals such as early exposure, and pathways that led to shelter work, such as alienation from alternative workplaces. This alienation led to a choice of downward social mobility for many of my participants, although of course they would not describe it thus. My research challenges the notion of social mobility based solely around occupational categorisation and income.

\subsection{Choices Within the Organisational Field of Shelter Work}

We have seen in the preceding chapter the repertoire of roles set before my respondents which were created through long, historical processes that they simply inherited. In other words, my respondents' freedom to forge a work identity was constrained. Even though a small number of respondents set up their own shelters (Fran and Tommy, Jen) they did so within pre-existing structures and regulatory conditions. I was primarily concerned with the processes that led to this occupational choice. To study these, I asked how my respondents came to be in the shelter and 
what this occupational choice meant to them. Though each story is unique in the detail, the pathways into animal work are consistent across shelters caring for a range of other species. 18 out of 24 respondents above are Irish, two are Dutch, one Swedish, one North American, one British, and one is Czech. The respondents' ages are from 20 to 67, and most are in their thirties and forties. Verbatim quotations illustrate both the content of thought and style of expression of the respondents. My wish was to allow the interviews speak for themselves.

\subsection{The Dog That Did Not Bark: Shelter Work as Calling}

As a theoretical presupposition, the Weberian notion of a work 'calling' was not borne as a primary reason for occupational entry. Only two respondents, Tommy and Molly (Interviews, 2014) described their work in vocational terms. Nonetheless, the constructed meaning of shelter work is much closer to the 'calling' than to the 'job' or 'career' definitions of work (Wrzesniewski et al 1987), a theme which is revisited in Chapter 6. Jean (Interview, $4^{\text {th }}$ February 2014) described the notion of a 'calling' as "bullshit", which rather turned my theoretical pre-notion on its head. Wrzesniewski et al (1997) describe a job orientation as an exclusive interest in the material benefits of the job. A career orientation suggests a deeper personal involvement in work but for the purposes of achievement and career advancement. An individual who views her work as a calling sees the work as inherently valuable and an end in itself (Wrzesniewski et al 1997). While my respondents do not generally report that they felt 'called' to shelter work, clearly in this tripartite set of relations to work, vocation or Beruf are nonetheless closest to how they view their work. Shelter work is poorly paid, usually at the minimum wage level which is 9.15 euro per hour (Interviews, 2014) and offers few opportunities for career advancement; it is however deeply personally fulfilling according to my data. In his well-known essay on politics as a vocation, Weber writes: "Here I stand; I can do no other. That is something genuinely human and moving. And everyone of us who is not spiritually dead must realise the possibility of finding himself at some time in that position". 
Weber goes on to quote Tolstoi: "Science is meaningless because it gives no answer to our question, the only question important for us: what shall we do and how shall we live?”

(Weber quoted in Geerth 2009: 127).

Further, Conklin's (2012) study of nine environmental workers finds that similar antecedents to shelter work exist, namely, the introduction (in Conklin's study to nature) at an early age, and the significance of childhood experience and the influence of like-minded others as the foundation on which a lifetime passion would build. Third, he finds evidence that career development through a 'lens of love' was important to his study participants (Conklin, 2012). All of these factors hold true for my respondents and indubitably, their work orientation resembles a 'calling' over a job or career orientation, even though they do not speak in those terms. Dobrow's (2007) study of musicians' callings also has some resonance for my respondents. Nonetheless, 'calling' is arguably only part of the concentric processes that lead to this occupational choice, but even then only retrospectively constructed as such by two out of 24 participants (Tommy and Molly, Interviews 2014). Not one respondent reported having felt an urge to do shelter work, or a 'transcendental summons' or that it was what they 'had to do' (Bunderson and Thompson, 2009). This occupational 'choice' was much more unintended that the calling literature suggests; chance encounters feature markedly in my participants' accounts. Therefore it would constitute a distortion to represent their occupational choice as a 'calling'. Instead a range of other intertwined factors emerge as implicated in the decision to choose shelter work.

\subsection{Antecedents of the Occupational Choice of Shelter Work}

Through listening deeply to my respondents' stories and immersion in the field I have come to understand this occupational choice as a processual journey. I understand process in this sense as a sequence in time and space, and as morphological and descriptive (Gregory et al, 2009). Osterman (quoted in Stern and Eichorn, 1989) also raises doubts about whether people moving haphazardly from job to job can be construed as intentional information-gathering leading to deliberate 
career choice. Nor are choice-centred theories of occupation supported by my data. I advance social constructionism against rational choice arguments - process, context, changes in the life course were most instrumental in leading my respondents to shelter work. Arguably, though the antecedents described below pave the pathway to shelter work, they are more decisive in terms of people's later positive attitudes toward animals, rather than the decision to enter the field. Many of these antecedents are present in my own life course but I have never considered entering a zoocentric occupation, although I do volunteer with animals when my work schedule permits. Unlike Arluke and Sanders,1996; Taylor, 2007; Alger and Alger, 1999 who often appear to assume that loving animals is a sufficient prerequisite for the occupational choice of shelter work, my data finds evidence that it is only a part of the whole.Therefore, I have divided the factors into two sections: antecedents which lead to caring about animals, or sensitising a person to animals. Secondly, I discuss other life events which more directly underpin the pathway to shelter work, which entails caring for animals. The distinction is that while the former contribute to developing empathy for animals, the latter provide the ultimate impetus to make this occupational choice. Table 5.1. below presents these findings. 
Table 5.1. 'Loving' Animals

\begin{tabular}{|c|c|c|c|c|c|c|c|}
\hline Name & Age & Sex & Childless & Occupation & Early Experiences & Significant Other & $3^{\text {rd }}$ Level \\
\hline Nick & 62 & $\mathrm{M}$ & Yes & CEO, Animal Rescue & Grandparents' farm, family dogs & Yes, wife loves animals & No \\
\hline Jean & 54 & $\mathrm{~F}$ & $\begin{array}{l}\text { Grown-up } \\
\text { children }\end{array}$ & $\begin{array}{l}\text { CEO, Animal Shelter, } \\
\text { SPCA }\end{array}$ & Adoptive parents' farm, family pets & Yes, adoptive father & No \\
\hline Emma & 26 & $\mathrm{~F}$ & Yes & Shelter volunteer & Rural life, multi-species pets as a child & No & No \\
\hline Lisa & 46 & $\mathrm{~F}$ & Yes & $\begin{array}{l}\text { Rescue Board member, } \\
\text { runs cattery }\end{array}$ & Yes, family dogs and cats & Yes, parents & Yes \\
\hline Mike & 46 & M & $\begin{array}{l}\text { One teenage } \\
\text { child }\end{array}$ & CEO, large dog rescue & Yes, family horses, dogs and cats & Yes, uncle-in-law & Yes \\
\hline Joan & 37 & $\mathrm{~F}$ & Four children & Volunteer for cat shelter & Yes, family cats and dogs & Yes, parents loved dogs & No \\
\hline Fran & 63 & $\mathrm{~F}$ & $\begin{array}{l}\text { Grown-up } \\
\text { children }\end{array}$ & CEO, Animal Shelter & Yes, always had dogs and cats & Yes, parents & Yes \\
\hline Tom & 62 & $M$ & $\begin{array}{l}\text { Grown-up } \\
\text { children }\end{array}$ & CEO, Animal Shelter & Dog taken away by his mother & Yes, negatively & No \\
\hline
\end{tabular}




\begin{tabular}{|l|l|l|l|l|l|l|l|}
\hline Fiona & 34 & F & Yes & Shelter worker & Family pets, rural background & Yes, parents & No \\
\hline Des & 67 & M & $\begin{array}{l}\text { Grown-up } \\
\text { children }\end{array}$ & $\begin{array}{l}\text { Retired CEO of large } \\
\text { Animal Shelter, SPCA }\end{array}$ & $\begin{array}{l}\text { Family pets, grandparents lived in a } \\
\text { rural location. }\end{array}$ & Yes, grandparents & No \\
\hline Suzi & 33 & F & Yes & Animal Shelter worker & Yes, dogs and horses & Yes, mother and twin & Yes \\
\hline John & 64 & M & $\begin{array}{l}\text { Grown-up } \\
\text { children }\end{array}$ & Veterinary Surgeon & Yes, childhood on farm & $\begin{array}{l}\text { Local veterinary } \\
\text { surgeon }\end{array}$ & Yes \\
\hline Katja & 25 & F & Yes & Shelter worker & Yes, dogs popular in Czech culture & Yes, parents & Yes \\
\hline Jen & 54 & F & Yes & CEO, Animal Shelter & Yes, family pets & Yes, parents & Yes \\
\hline Sally & 30 & F & Yes & Animal Shelter worker & Yes, horses and family pets & Yes, parents & No \\
\hline Jon & 45 & M & Yes & Animal Shelter worker & Yes, a dog & Yes, negatively & Yes \\
\hline $\begin{array}{l}\text { Helen } \\
\text { a }\end{array}$ & 20 & F & Yes & Animal Shelter worker & Yes, family pets and cultural influence & Yes, mother & Yes, negative socio- \\
\hline Maria & 23 & F & Yes & Animal Shelter volunteer & Yes, family pets & No \\
\hline
\end{tabular}




\begin{tabular}{|l|l|l|l|l|l|l|l|}
\hline Molly & 28 & F & Yes & Animal Shelter worker & Yes, farming background, family pets & Yes, grandfather & No \\
\hline Agata & 43 & F & Yes & $\begin{array}{l}\text { Animal shelter in own } \\
\text { home }\end{array}$ & Yes, grew up around animals & $\begin{array}{l}\text { Yes, negative socio- } \\
\text { cultural influence }\end{array}$ & Yes \\
\hline Maura & 39 & F & Two & Animal shelter worker & Yes, grew up on smallholding & Yes, parents & Yes \\
\hline Holly & 42 & F & Three & Special Needs Assistant & Yes, cats as a child & No & No \\
\hline Anna & 31 & F & Yes & Dog Pound worker & Yes, grew up with animals & No & No \\
\hline Colm & 26 & M & Yes & Animal Shelter worker & Yes, grew up with cats and dogs & Yes, father & Yes \\
\hline
\end{tabular}




\subsubsection{Early experience with animals and in rural settings}

Just as Kendall's (2003) quantitative survey research predicts, my participants' affection for, and attitude to animals is rooted in childhood experience. Early experiences are accentuated by all respondents as factors in the later decision to choose shelter work (see Table 5.1 above). Like Arluke’s (2003) 'supernurturing' children, all my shelter respondents saw animals as important, a solace, and identified as ‘animal people’ from an early age.

Even though this early experience with animals could, at first blush, be considered an antecedent to shelter work, it is not a causal factor for entry. Early experiences predisposed the respondents to love and care about animals, but not, in most cases, to enter shelter work and care for animals.

Nonetheless early socialization with animals appears to be intertwined with the choice of animal shelter work in later life. A universally expressed phenomenon is the early experience around animals which sowed the seeds for the later decision to enter shelter work. This early exposure is inherent in participants' statements such as: "I grew up around dogs, pigs, cats" or "I suppose I always felt at home with animals really" and is consistent with Sanders'(2010) finding that veterinary technicians had grown up with animals, although this factor alone is not the reason for entry. Often respondents attribute quasi-mystical qualities to animals they knew years before. As Nick explained:

The other dog I remember was my grandfather's. Rex was a terrier. He was amazing. What I remember about him was that my grandfather worked for a company called -'s garage which is Furniture now, and that dog would know when my grandfather was finishing work. And he would finish at different times but every time..you knew he was finished because Rex would go to the door and wait for him (Interview with Nick, $14^{\text {th }}$ January, 2014).

[For Jean] - was a very special cat. I had a huge, huge bond with him. He was snow-white and deaf. He was always an indoor cat because if you let him out he would perish. He came everywhere with me and acted more like a dog than a cat. I remember bringing him to the - show and he would spend the whole day beside me on 
the ground and everyone would greet him. I still feel his presence to this day (Interview with Jean, $4^{\text {th }}$ February, 2014).

Like Irigaray (quoted in Atterton and Calarco, 2012: 195) all respondents paint a picture of a childhood, wherein the greatest joys were "bound to animals". As observed above, retrospective personal histories are often biased by the tendency of most people to make their current choices and lives aligned to earlier experiences. Nevertheless, an early love of nature and being around animals, either on farms or in the family home suffuses the stories told. This is consistent with Holland's (1973) conclusion that people try to match their personality 'type' to their occupation; loving animals makes such a choice congruent. Unsurprisingly, many choose shelter work to be in the presence of animals, whose companionship is valuable in their eyes but other processes are under-scrutinised in the literature. My participants' attitude to animals is rooted in love and empathy, and thus akin to the application of the care ethic to the moral status of animals (Adams and Donovan, 2007). Only two of my participants say they "always knew" they would work in animal care. For the majority, the road to the shelter was paved with other occupations, part-time jobs, volunteering with animals, and dawning realisations prior to seeking employment in the shelter.

\subsubsection{Social and Demographic Characteristics as Determinants}

Socio-demographic factors are significant in making this occupational choice possible. Because of the unpredictable nature of the hours worked, and poor terms and conditions, fulltime animal shelter work is only possible, with rare exceptions, for people who are childless or have grown-up children. Blau et al (1956) note how social and economic structures impose constraints on occupational choices. Not having children, or not having children living at home seems to be connected to choosing animal shelter work. Out of 22 participants engaged in animal work only four have dependent children (see Table 5.1 above). 15 are childless (and say they have no intention to have children in the future or are beyond childbearing age): "I'd have a problem changing a baby's diaper probably for some reason, but dog poo is okay” (Interview with Katja, $4^{\text {th }}$ July, 2014). Nesbit (2012) too finds that having a 
child decreases a person's likelihood of volunteering and hours devoted to voluntary work.

Four respondents have grown up children who no longer live at home. Shelter work is incompatible with caring for young children. Shelter work, especially running one's own shelter, requires an enormous time commitment, as does child-rearing. Obviously, the availability of childcare supports or being a lone parent constitute significant barriers to female participation in many other occupations in the Irish labour market (Turner and McMahon, 2011). In the animal arena, the hours are particularly unpredictable and zoonotic diseases and parasitic infections are common (mange, ringworm, fleas). I did not ask my childless participants whether this was by choice, but most told me, unprompted, that they chose not to have children.

Of the four respondents who have adult children who no longer live at home, their shelter journey began when their children were in their late teens or early twenties. Mike, a highly paid CEO of an animal organization has one teenage child, Maura has two children whom she home-schools and who help her foster animals, and Joan has four school-age children (Interviews, 2014). Joan, as 'outlier' respondent was adamant that she was "not an animal person, but a cat person" and is not engaged in hands-on animal work, which she said she would find distasteful (although this account did not entirely tally with her practice of feeding semi-feral cats and housing them in her garage). Instead she does the book-keeping for a cat shelter. She also displayed the least dissonance about her non-vegetarianism:

There are no vegetarians in this house; everyone's got to eat. If somebody's hunting rabbits and that's going on the dinner table, I have no problem with that. I have a problem with sport, hunting just for sport but not for food, because that's what mankind has been doing for billions of years, or whatever it is ... (Interview with Joan, $25^{\text {th }}$ February, 2014).

This apparent lack of dissonance stands in marked contrast to the majority of respondents who displayed visible discomfort about the dichotomous relationship between loving some animals and eating others, a theme which I revisit in the next chapter. 
All but three participants are married or partnered. My findings help to dispel common misconceptions that shelter workers are lonely 'cat people'. Indeed the majority of (female) respondents cited financial support from a partner engaged in more lucrative work as an enablement to their own work in the shelter. This is not to suggest that my interviewees would be offended by the label "cat-lady"; indeed many cheerfully identify as such (Interviews, 2014). The cap fits. This section outlined the early love of animals which rendered this occupational choice a possibility for my respondents. The extra time afforded by being childless (or having adult children) emerges as an enablement.

Shelter work is a bastion of female activity and I now turn to gender and 'class' as antecedents of shelter work.

\subsubsection{Gender, Class and Care Work}

One of the most consistent factors associated with animal shelter work is gender. 16 out of 20 shelter care-workers in the current study are female. At the structural level, shelter work is conventionally gendered as more women than men do the care work. At the interactional level I observed that it is not conventionally gendered: hegemonic masculinity/femininity was not present in my shelters. Women wearing wellington boots are not presenting themselves for the male gaze, and the four male care-workers mobilise the feminized aspects of the work (care, gentleness) and these aspects are compatible with their own lives. The only shelter where I established that the male: female ratio was predominantly male was a large donkey sanctuary in the South of Ireland (18 male: 15 female workers) which would be an interesting avenue for future research. A similar turn is apparent in Veterinary Science studies; during my interview with a local veterinary surgeon he observed: "When I was in UCD 40 years ago, there were three girls out of a class of 60 . Now it is nearly the other way around" (Interview with John, 28 ${ }^{\text {th }}$ June, 2014). I advance the explanation that the bar to entry to Veterinary Medicine is high in terms of Leaving Certificate points, and that women increasingly outperform men academically. Second, the mechanisation of farming has rendered the male/female disparity in physical strength on the part of veterinary surgeons all but irrelevant. Third, small-animal practices are 
now very common, which was not the case 40 years ago, and may appeal more to women than farm-based veterinary practice.

Herzog (2007) found that women show higher levels of positive behaviour and attitudes to animals, much higher involvement in animal activism, and much lower levels of animal abuse. Neumann (2010) found that animal welfare volunteering in North America is overwhelmingly feminized. Herzog (2007) found that women express more concern for the wellbeing of individual animals, whereas men are more concerned with species preservation and habitat restoration. This study mirrors those findings; all the animals are given names by the (in the main) female shelter workers and volunteers and the semi-structured interviews yielded few mentions of ecological or environmental concerns. Much more, the conversations told details about the individual life stories of the animals in the shelter and of previous 'happy ending' narratives. This 'micro' stance on animal welfare is typified by statements such as this respondent's: "I can only save what's in front of me. I know all the cruelty and I don't agree with it but if I was to let that get to me, I wouldn't be able to function during the day” (Interview with Jean, $4^{\text {th }}$ February, 2014). As noted above women are not always expected to be the main 'breadwinner' and are frequently supported by their partners in their work (Interviews, 2014).

This begs the question as to whether women are 'naturally' more drawn to care work as would appear to be the case. Some scholars (Crompton, 2006: 253) point out that the reason women choose care work more frequently may stem from the "ideology of domesticity" or the belief in a "natural hierarchy" which tends to relegate care work to women. Others (Gilligan, 1982) do argue for the existence of a feminine personality or a "womanly ethos" but as a moral alternative to the male-bias inherent in the justice perspective (Gilligan, 1982). A further explanation I propose in chapter 2 may be that the predominantly feminised and working class shelter workers do not have the same career expectations placed upon them as their middle class peers. Equally, it could be surmised that most men do not have the same opportunity to do 'menial' animal shelter work as late capitalism places expectations of 'success' upon them. As noted above a perusal of the gendering literature of the last decade reveals very few articles on animal care work. 
Perhaps the most important consideration, as is my own position, and as Midgeley (2011, ISAZ conference, personal communication) contends, is whether feminized care work is sufficiently rewarded under conditions of advanced capitalism. As I will show in Chapter 6, shelter workers provide a service to society, often at enormous personal cost emotionally and financially. In effect, they do our "dirty work" so that we do not have to see what they have to see. Some of us may assuage our guilt by dog-walking as a volunteer from time to time or by making financial donations, but the shelter workers 'do' the work. It is they who care for the abandoned, the abused, and often traumatised animals who come in through the shelter gates from ownersurrenderers, concerned members of the public, or from the Pound system (described in Chapter 4). Oftentimes dogs are simply tied to the gates of the shelter at night, or puppies left outside in a box, to be discovered in the morning (Social Media, Appendix F), alive or sometimes not.

In addition to the arguments about gendering of occupations, the gendering literature offers rich insights into general processes of occupational choice, for example, how choice can be structured by cultural expectations of the self and others, and how occupations have cultural meanings. The gendering literature is thus compatible with the symbolic interactionist approach. The gendering literature often assumes that women have to either preserve hegemonic masculinity in male-dominated occupations or cleave towards 'feminine' occupations (Crompton, 2006). Although my data shows that this is a feminised occupation, my female respondents' choice challenges the assumption that women make restricted or culturally or gender-based choices.

Far from being repressed or oppressed, my female respondents are enabled by others to do work that they love, rather than work they actively disliked. It is as though fairly 'conventional' gendering allows an escape from the career trap. Most of my 16 female respondents are enabled to do their work because of familial or partner support, or simply because earning a higher salary is less important to them than is doing a job they love. My six male shelter respondents have other enablements; one is a highly paid CEO, others are retired and sought a challenge (Mike, Nick and Des, Interviews, 2014), or like their female counterparts are not motivated by money. As 
Lear (quoted in Crawford, 2009: 44) writes: "Indebtedness could discipline workers, keeping them in routinized jobs in factories and offices, graying but in harness, meeting payments regularly”.

In terms of the socio-economic and educational status of shelter workers, again my expectations were not entirely upheld. Although Neumann's (2010) animal welfare volunteers were educated, female and middle-class, I expected most fulltime shelter workers to be of 'lower' socio-economic status. However, Jon was previously employed as a software engineer, Katja has an honours degee in linguistics, Agata is a $\mathrm{PhD}$ student in Philosophy, Colm has a degree in Zoology, for example (Interviews, 2014 and 2015). Even the less formally-educated study participants had held better paid jobs as waitresses, in human care work and as tradespeople. Clearly, this occupational choice is far from being a last resort for my respondents (Interviews, 2014).

Many respondents display 'markers' in terms of language, dress, demeanour. Out of 22 shelter respondents (John is a veterinary surgeon in his 60s, and Holly an SNA) 11 have either tattoos - not of animals (at least nowhere visible) but of flowers, celtic symbols, or names of human loved-ones - multiple body-piercings, or both. This is not the case for the older CEO male respondents, but it is for Jon and Colm (Interviews, 2014). Out of 22 shelter respondents, 11 or $50 \%$ smoke compared to the general population in Ireland in which approximately $23.5 \%$ of males identify as smokers, and 20.5\% of females (Department of Health, 2015). Tattoos and multiple body piercings are not usual for corporate or office employees. My respondents not only choose shelter work for its intrinsic properties it seems, but because it represented an alternative to workplaces in which they felt they did not 'fit'. According to Skeggs (1997) tattoos and piercings are signifiers of deflecting "middle-classness" and conventionality. My respondents thus signify nonconformity with mainstream society. A tattoo, according to De Mello (2000) positions individuals within communities and turns human beings into social beings. 


\subsubsection{The Influence of a Significant Other}

The question many interviewees find hard to answer is why they felt love for the animals around them; what were the origins of those experienced feelings? The majority cite significant others as the source; parent or grandparent or other person who loved or seemed to understand animals: "I'd seen vets tell what was wrong with animals and I was amazed” (Interview with John, $28^{\text {th }}$ June, 2014). So it is that the sociological subject is formed in relation to significant others who mediated to my participants the values and meanings of animals.

Blau et al (1956) discussed social stratification as a rationale for occupational choice, although their theory was not developed for the case of animal shelter work, rather to explain how parental social status affects the occupational opportunities of their children. There is current research to suggest that parental influence still figures in occupational choice (Oren et al, 2013). For most shelter respondents in these pages, love was learnt early from parents or significant others. For a typical respondent, Lisa, her mother loved animals: "In fact I had an allergy to dog and cat hairs. Mum said: "I'm sorry, but we had the animals long before we had you, so you'd better get used to it”. I did through exposure” (Interview with Lisa, $11^{\text {th }}$ February, 2014). Jean tells how: "I grew up on a small farm. So I always had my own pig. Always had my own lamb. Always had my own calf. And then I'd be devastated when suddenly they'd disappear" (Interview with Jean, $4^{\text {th }}$ February, 2014). In a similar vein, Mike, CEO of a large rescue organisation, relates: "My family always had dogs at home. I'd be very close to my - and he always bred and kept show-jumping horses. So yeah, animals have always been a part of my life” (Interview with Mike, $18^{\text {th }}$ February, 2014).

Nonetheless, these early experiences only formed part of the process that led my respondents to the occupational choice of shelter work. The theme of nature is intertwined with animals for many respondents, a theme taken up in the next chapter under the theme of joys of shelter work. By nature in this context I refer to a preference for the rural and countryside as opposed to the town or the city. Des recalls fondly: "I had my first cat when I was four. My mother was from the country 
and I spent all my childhood summers in B-, Co.-. It's just a wonderful place” (Interview with Des, $15^{\text {th }}$ April, 2014). Thirteen of my respondents grew up in rural locations or on small farms and most speak of the joy "being outdoors” brings them.

In symbolic interactionist terms, the meaning of animals was negotiated early through the way other people acted towards animals and through interaction with animals. The central place of animals in my respondents' young lives modified their point of view and laid one stepping stone down on the path to the choice of shelter work, many years later. Animals mattered and had meaning from early on for my respondents, even though this meaning may have lain dormant until years later in their lives.

We have seen (Handlin et al, 2012) how animals can elevate oxytocin levels in owners and this may explain the comfort Sally derived from the present of her childhood dog, who was indeed a 'significant other' for her, which extends the term 'significant other' to include animals: "For me personally as a child there would have been a few family issues and I found my dog as a friend I could talk to and he'd never, ever judge me like” (Interview with Sally, $4^{\text {th }}$ July, 2014).

Sally appears to have constructed her childhood dog as an ideal being who loved her unconditionally, without judgement or prerequisite.

For Jon, his dog was constructed as his family:

It is family. Your dog is your family and my dog, he really became my family. I have family in C-, O-, -, my family is very split up. So I don't really see my family and he was the only family I had and he meant so much to me (Interview with Jon, $7^{\text {th }}$ July, 2014).

Some participants rejected received meanings about the nature of our relationships to animals however.

\subsubsection{Negative Influence of Significant Others or Socio-cultural milieu}

For a subset of four respondents, their childlike empathy towards animals was aroused as a result of witnessing what they perceived to be cruel adult or societal behaviour. In these cases, the influence was negative and spawned a slanting of my 
respondents' normativity towards animals. For two respondents, the natal context was significant. Tommy, 62, recalls,

When I was about six years old, my dog was taken away with the explanation that it was 'inconvenient' for my mother. I never saw my dog again, and I never forgot the word 'inconvenient' in this context. It made me love dogs even more (Interview with Tommy, $4^{\text {th }}$ March, 2014).

The following account by Jon reveals the effect of the natal context. Jon's mother also took away his dog when he did not adequately perform cleaning duties:

I had one dog as a kid, but of course I never looked after it properly. My mother was a very strict, if there is a typical X mother, so she was very zero tolerance. She was black and white; there was her way, or no way. Bear in mind that she was born in WWII and she had not had an easy life. Anyway, we never had another dog and basically I'd wanted one for years. So when I finally bought my own house in $\mathrm{X}$, homes are very affordable in $\mathrm{X}$, the first thing I did was get a dog..a beautiful rescue greyhound. They are legally considered livestock there you know (Interview with Jon, $7^{\text {th }}$ July, 2014).

For Maria and Agata, their socio-cultural milieu, and its structural limitations seem to have ignited an empathy and concern for animals:

I lived in a block of flats in a bad area and there was a kid who was bullying me and he seen me petting the dog, so he beat the dog. I cried and I cried. He was a teenager and I decided that when I'm bigger like him, I'm going to do something about it. So that's how it started (Interview with Maria, $9^{\text {th }}$ July, 2014).

For Agata, in another country, two decades earlier, the socio-cultural milieu of Northern Italy in which she grew up was a factor in prompting her later decision to give animals sanctuary:

In the North of Italy it's quite normal, or it was in the past, for families to have a few chickens, a calf, a pig, and rabbits and all sorts. I witnessed the slaughter of turkeys, and pigs and all sorts. I think I always knew it was not right. I had recurrent dreams as a child of animals that needed help and there was nothing I could do to help them (Interview with Agata, 22 ${ }^{\text {nd }}$ August, 2014).

These latter two accounts have some resonance with Harbolt's (2003) conclusion that shelter workers have often experienced institutional or interpersonal alienation 
and attempt to control their social environments through their work. However, my data does not suggest that experiencing oppression led any other of my respondents to the shelter, or even that it was the reason for the four who did at some level. The Italian respondent, Agata, is one of three vegan/vegetarian respondents (Maura and Suzanne are vegan and vegetarian respectively), so has carried her compassion for animals into her dietary and lifestyle choices.

While all the preceding factors served to sensitise all of my respondents to animals, a later set of processes helped to lead to this occupational choice: changes in the life course, alienation from previous workplaces, epiphanic or serendipitous events, and love of nature. Changes in the life course preceded entry for all of my participants, ranging from injury to job loss to moving domicile. Alienation from formerly held jobs or courses of study undertaken was also common to all of my respondents, bar Mike who wanted a fresh challenge following a move, Molly who has never held, or ever wanted to hold any job but animal care-worker, and Agata who liked her job as an Animal Studies tutor, which she put on hold to complete her $\mathrm{PhD}$ in Philosophy. Epiphanies were cumulative rather than borne out of damascene moments for my respondents, with the exception of Fran and Tom, for whom the rescue of a puppy about to be drowned played a significant role in their later decision to set up a shelter, and possibly Jon, whose attitude to hunting (and to vegetarians) was altered permanently by the death screams of a wild boar he had shot. Chance or serendipitous events were reported by all shelter respondents however - random remarks that sedimented over time, chance meetings, signs in veterinary surgeries etcetera. Every shelter respondent speaks of his or her love of the 'outdoors'. This data is displayed in Table 5.2. below which is ordered chronologically by date of interview: . 
Table 5.2. Pathways to Entry

\begin{tabular}{|c|c|c|c|c|}
\hline Name & Changes in Life Course & Alienation from Workplace & Epiphanic or Serendipitous Event & Nature \\
\hline Nick & $\begin{array}{l}\text { Retirement due to back } \\
\text { injury, move home to Ireland } \\
\text { from the UK }\end{array}$ & $\begin{array}{l}\text { Yes, tired of manual nature of job } \\
\text { as heating engineer }\end{array}$ & $\begin{array}{l}\text { Yes, realised at SPCA meeting he } \\
\text { could help run it as a business }\end{array}$ & $\begin{array}{l}\text { Yes, loves wildlife and being } \\
\text { outdoors }\end{array}$ \\
\hline Jean & $\begin{array}{l}\text { Yes, retirement due to } \\
\text { stressful nature of work }\end{array}$ & $\begin{array}{l}\text { Yes, had mental problems due to } \\
\text { stress of care work for adults with } \\
\text { intellectual difficulties }\end{array}$ & $\begin{array}{l}\text { Yes, a chance encounter with } \\
\text { local branch of SPCA }\end{array}$ & $\begin{array}{l}\text { Yes, loves animals and being } \\
\text { outdoors }\end{array}$ \\
\hline Emma & Lost job due to restructuring & $\begin{array}{l}\text { Devasted at loss of job in } \\
\text { bookmaker's }\end{array}$ & $\begin{array}{l}\text { Yes, noticed a sign in a veterinary } \\
\text { surgery and realised how she } \\
\text { could help }\end{array}$ & $\begin{array}{l}\text { Yes, rural childhood and } \\
\text { loves the countryside }\end{array}$ \\
\hline Lisa & $\begin{array}{l}\text { Got married and moved to } \\
\text { Co. Kilkenny }\end{array}$ & $\begin{array}{l}\text { Yes, hated bureaucratic nature of } \\
\text { civil service job }\end{array}$ & $\begin{array}{l}\text { Yes, a friend asked why she didn't } \\
\text { 'do something with animals' }\end{array}$ & $\begin{array}{l}\text { Yes, lives in an idyllic country } \\
\text { cottage and keeps hens, } \\
\text { cats, dogs }\end{array}$ \\
\hline Mike & $\begin{array}{l}\text { Returned to Ireland from the } \\
\text { UK }\end{array}$ & $\begin{array}{l}\text { Took a career break and wanted to } \\
\text { do 'something new' }\end{array}$ & $\begin{array}{l}\text { Saw an ad for a Training Manager } \\
\text { with SPCA and thought he would } \\
\text { be perfect for the role }\end{array}$ & $\begin{array}{l}\text { Yes, lives in rural Galway } \\
\text { location and commutes to } \\
\text { Dublin during the week }\end{array}$ \\
\hline Joan & $\begin{array}{l}\text { Lost } 12 \text { stone and wanted to } \\
\text { 'do something that matters' }\end{array}$ & $\begin{array}{l}\text { Works in the home and needed } \\
\text { 'something more' }\end{array}$ & $\begin{array}{l}\text { Had explosion of stray cat } \\
\text { population in her garden and } \\
\text { asked local SPCA for help in }\end{array}$ & $\begin{array}{l}\text { Yes, lives in rural location } \\
\text { with family and } 12 \text { cats }\end{array}$ \\
\hline
\end{tabular}




\begin{tabular}{|c|c|c|c|c|}
\hline & & & return for volunteering & \\
\hline Fran & $\begin{array}{l}\text { Decided to move from } \\
\text { Holland to Ireland }\end{array}$ & English teacher, found job boring & $\begin{array}{l}\text { Yes, saw a man about to throw a } \\
\text { dog in a river and saved the dog }\end{array}$ & $\begin{array}{l}\text { Yes, home is in a beautiful } \\
\text { rural location she describes } \\
\text { as 'paradise' }\end{array}$ \\
\hline Tom & $\begin{array}{l}\text { Decided to move from } \\
\text { Holland to Ireland }\end{array}$ & Ran taxi service, was not fulfilled & $\begin{array}{l}\text { Yes, saw a man about to throw a } \\
\text { dog in a river and saved the dog }\end{array}$ & $\begin{array}{l}\text { Yes, home is in a beautiful } \\
\text { rural location he describes as } \\
\text { 'paradise' }\end{array}$ \\
\hline Fiona & $\begin{array}{l}\text { Left secondary education } \\
\text { and starting volunteering }\end{array}$ & $\begin{array}{l}\text { Never wanted any job but to work } \\
\text { with animals }\end{array}$ & No, had volunteered for years & $\begin{array}{l}\text { Yes, loves the rural shelter } \\
\text { workplace which is near her } \\
\text { home }\end{array}$ \\
\hline Des & $\begin{array}{l}\text { Decided to retire and } \\
\text { wanted a 'project' }\end{array}$ & $\begin{array}{l}\text { Disillusioned with the greed he } \\
\text { experienced as heating contractor }\end{array}$ & $\begin{array}{l}\text { Attended SPCA meeting with } \\
\text { spouse and realised he could } \\
\text { 'make a difference' }\end{array}$ & $\begin{array}{l}\text { Yes, his Dublin conservatory } \\
\text { is designed to 'let the garden } \\
\text { in the house' }\end{array}$ \\
\hline Suzi & $\begin{array}{l}\text { Did not want to practise } \\
\text { journalism and wanted to } \\
\text { work with animals }\end{array}$ & $\begin{array}{l}\text { Felt you had to be too nosy to be a } \\
\text { journalist (her course of study) }\end{array}$ & $\begin{array}{l}\text { Yes, friend put up finance and } \\
\text { asked her to run donkey } \\
\text { sanctuary }\end{array}$ & $\begin{array}{l}\text { Yes, loves the countryside } \\
\text { and being outdoors }\end{array}$ \\
\hline John & $\begin{array}{l}\text { No, wanted to be a vet since } \\
\text { childhood }\end{array}$ & $\begin{array}{l}\text { No, although might not choose to } \\
\text { study veterinary surgery if 'starting } \\
\text { over' }\end{array}$ & $\begin{array}{l}\text { Local vet attending his childhood } \\
\text { farm seemed 'like a magician' to } \\
\text { his childhood self }\end{array}$ & $\begin{array}{l}\text { Yes, loves horses and being } \\
\text { outdoors }\end{array}$ \\
\hline Katja & Yes, came to Ireland with & Yes, was bored by translation work & Yes, she saw a sign asking for & Yes, loves dogs and walking \\
\hline
\end{tabular}




\begin{tabular}{|c|c|c|c|c|}
\hline & partner & & volunteers & in the countryside \\
\hline Jen & Yes, lost job in Marketing & $\begin{array}{l}\text { Yes, was disillusioned by profit } \\
\text { imperative }\end{array}$ & $\begin{array}{l}\text { Yes, her mother asked why she } \\
\text { didn't start her own shelter, } \\
\text { instead of volunteering }\end{array}$ & $\begin{array}{l}\text { Yes, loves dogs and donkeys } \\
\text { and the outdoors }\end{array}$ \\
\hline Sally & $\begin{array}{l}\text { No, starting volunteering } \\
\text { aged } 13\end{array}$ & $\begin{array}{l}\text { No, always wanted to work with } \\
\text { animals }\end{array}$ & $\begin{array}{l}\text { No, transition from volunteer to } \\
\text { employee }\end{array}$ & $\begin{array}{l}\text { Yes, loves the outdoors and } \\
\text { would have disliked office } \\
\text { work }\end{array}$ \\
\hline Jon & $\begin{array}{l}\text { Yes, lost IT job in } \\
\text { restructuring }\end{array}$ & $\begin{array}{l}\text { Yes, viewed corporate } \\
\text { environment as 'brutal' }\end{array}$ & $\begin{array}{l}\text { Yes, Shelter CEO offered him a } \\
\text { job }\end{array}$ & $\begin{array}{l}\text { Yes, loves nature and } \\
\text { disliked being 'cooped up' } \\
\text { indoors }\end{array}$ \\
\hline $\begin{array}{l}\text { Helen } \\
\text { a }\end{array}$ & $\begin{array}{l}\text { Mother runs Swedish rescue } \\
\text { and arranged work } \\
\text { experience in Ireland }\end{array}$ & $\begin{array}{l}\text { Not applicable as respondent has } \\
\text { just finished secondary school }\end{array}$ & No & $\begin{array}{l}\text { Yes, loves the rural area of } \\
\text { Sweden where she lives }\end{array}$ \\
\hline Maria & $\begin{array}{l}\text { Yes, was diagnosed with } \\
\text { Aspergers' syndrome }\end{array}$ & $\begin{array}{l}\text { Does not find it easy to work with } \\
\text { people, and wanted to work with } \\
\text { animals }\end{array}$ & $\begin{array}{l}\text { Yes, she brought a stray cat to the } \\
\text { shelter and became a volunteer }\end{array}$ & $\begin{array}{l}\text { Grew up in inner city Dublin } \\
\text { and moved to rural } \\
\text { Co.Carlow }\end{array}$ \\
\hline Molly & No & $\begin{array}{l}\text { No, always wanted to work with } \\
\text { animals }\end{array}$ & $\begin{array}{l}\text { Volunteered for years before } \\
\text { gaining shelter employment }\end{array}$ & $\begin{array}{l}\text { Yes, grew up in rural } \\
\text { Co.Kilkenny and loves the } \\
\text { outdoors }\end{array}$ \\
\hline Agata & $\begin{array}{l}\text { Yes, came to Ireland from } \\
\text { her native Italy to get }\end{array}$ & Philosophy PhD student and & $\begin{array}{l}\text { Yes, had nightmares as a child } \\
\text { about animals being slaughtered }\end{array}$ & $\begin{array}{l}\text { Yes, lives in a rural location } \\
\text { with cats, hens, dogs, }\end{array}$ \\
\hline
\end{tabular}




\begin{tabular}{|l|l|l|l|l|}
\hline & married & Animal Studies tutor and happy & in her family smallholding & chinchillas \\
\hline Maura & $\begin{array}{l}\text { Yes, left position as factory } \\
\text { QA }\end{array}$ & $\begin{array}{l}\text { Yes, disliked the 'emptiness' of } \\
\text { factory shift-work }\end{array}$ & $\begin{array}{l}\text { Yes, decided she would make } \\
\text { volunteer work a career }\end{array}$ & $\begin{array}{l}\text { Yes, loves the outdoors and } \\
\text { dislikes corporate } \\
\text { environment }\end{array}$ \\
\hline Holly & $\begin{array}{l}\text { Yes, realised SNA had school } \\
\text { holidays }\end{array}$ & $\begin{array}{l}\text { Jobs were hard to come by in the } \\
\text { 1990s and she wanted to do care } \\
\text { work of some kind }\end{array}$ & $\begin{array}{l}\text { Not applicable } \\
\text { trades and master of none' }\end{array}$ & Bored with waitressing, office jobs \\
Anna & $\begin{array}{l}\text { Got tired of being 'jack of all } \\
\text { Volunteered and decided to apply } \\
\text { for a job in the Dog Pound }\end{array}$ & $\begin{array}{l}\text { Yes, lives with dogs and cats } \\
\text { and fish and loves being } \\
\text { outdoors }\end{array}$ \\
\hline Colm & $\begin{array}{l}\text { Realised zoology too } \\
\text { academic }\end{array}$ & Volunteered and applied for a job & $\begin{array}{l}\text { Yes, loves cats and dogs and } \\
\text { hands-on work }\end{array}$ & Hated call centre work \\
\hline
\end{tabular}




\subsection{Pathways to Occupational Entry}

Occupational choice is rarely a singular event, rather it has a processual dimension that extends over years. A psychological view (Savickas, 2007) is that people change across time, and develop in ways that influence their later choices. A more sociological point of view, the notion of the 'life course', sheds light on the choice of shelter work (Hutchinson, 2011). Several vagaries, constraints, and transitions form part of the trajectory of my respondents' lives and helped to draw them to the world of the shelter. 'Sets of factors' are not enough, it is important to understand the process, which argument I advance below.

\subsubsection{A Sudden Change in the Life Course}

Change of some kind often precedes entry into shelter work for my respondents. In many cases, the macro impinged on their micro life-contexts. The extended longevity of the population, and the increased health of the older population affect the likelihood of people working longer, pursuing second careers, or working parttime or on a voluntary basis in later life (Wuthnow, 2003). This is true of many of my respondents (See Table 5.2.). For example, Mike worked in a senior position and took a career break to come home to Ireland in 2000:

I had no huge idea about what I was going to do and at that time the... (animal welfare organisation) were advertising for someone to train their Inspectorate and it seemed an ideal fit for me. Then I became friendly with $\mathrm{C}$ who was CEO of ..(other animal welfare organisation). So when they set up in Ireland I was approached to see if I'd be interested in the running the Irish organisation. I have a major buy-in to the aims of the charity but if I were CEO of a human health charity, I'd probably have exactly the same viewpoint on it as well (Interview with Mike, $18^{\text {th }}$ February, 2014).

For many other respondents too, unpredictable contingencies led to the decision to pursue shelter work. Not only disaffection with their previous job, but the loss of a job, or an epiphanic episode when the pathway to shelter work presented itself as an alternative to their previous work is being reported by the majority of respondents;

Emma lost her job and was "devastated”, Nick injured his back badly and had to retire, Joan lost 8 stone in weight, and recounts that she wanted to "do something that matters" as a result of her concomitant gain in self-confidence: 
“Like I was so massively overweight. I was - stone and I lost 8 stone. I always cared what people thought, but two years ago this May a lot changed for me. Now I quite literally don’t care. Now I know I can make a difference here” (Interview with Joan, $25^{\text {th }}$ February, 2014).

While Savickas (2007) notes a change in individuals over time as a developmental paradigm, external changes in the life course and circumstances were part of the process of occupational entry for the majority of my respondents. The life course is not a linear path, it contains twists and turns as well as continuities (Hutchinson, 2011:15).

Franklin's theory of ontological insecurity has some resonance in this regard, the "fragility and fragmented nature of aspects of social and cultural life" (Franklin et al 2001) perhaps lead the respondents to seek meaning and 'to be needed' outside of the traditional neoliberal career paradigm. Nast (2006) also refers to post-industrial alienation in a similar vein, though in the context of the curiousness of 'pet-love' in the light of such human-to-human violence, rather than in regard to shelter work.

It seems that in both cases, either disliking one’s job or experiencing a life-changing event, an emotional space might be created which animals fill. This has resonance with Wrzesniewski's (2002) finding that many people in New York turned towards what they perceived as more meaningful work in the aftershock of the 9/11 terrorist attacks in the US. It would seem that what counted as 'successful' prior to the calamitous events of 9/11, was, for some individuals, chimerical in its wake. On a vastly less catastrophic scale, nonetheless either an upset in the normative patterns of life or alienation from the work they did previously, were instrumental for all of the respondents' pathway to shelter work which chimes with my veterinary surgeon's belief that: "I'm not a psychologist but I think they [shelter workers] do it to find meaning, to have a meaningful life”.

The alienating economic sphere, a world where nature is at a remove ("I hated being cooped-up in that office" says Jon), and in which animal cruelty is not addressed is rejected by my respondents. They embrace the world of the shelter, where economic gain is not a primary goal, where they live and work close to nature, and where animal cruelty is normalised as abhorrent. All but one respondent spoke negatively 
of former jobs they had held in their lives. The remaining respondent (Joan) above had lost a lot of weight, prior to her involvement with the shelter, and "needed something more than just being a mother" (Interview with Joan, $25^{\text {th }}$ February, 2014). This alienation, and the consequent quest for a job that matched their values, figures large in my respondents' accounts of the trajectory which ended, for now, in the shelter.

\subsubsection{Alienation from Alternative Workplaces Leading to the 'Moral Choice'}

From the standpoint of self-interest, and in the light of the career-focused hegemony of the market place, there would appear to be an inherent paradox in the pursuit of animal shelter work. Mizzoni (2004) notes how the distinctive attributes of democratic capitalist societies are an emphasis on "self-interest, the individual, the search for wealth”.

Alienation from previous occupations was a very common bête noire for my interviewees. Most of my participants experienced former workplaces as disappointing or even disillusioning. Their previous jobs were not appropriate outlets for their interests and aspirations. I considered using the term 'disenchantment' (Weber, 1947) but I realised that it was not an accurate reflection of my participants' lived experience of their previous workplaces, as they had never been 'enchanted' with those in the first place. I used the term 'alienation' here as a measure of how estranged my participants felt from the previous work that they did, from the people around them and from their own values and aspirations.

Many participants recounted how unhappy they had been in their former 'office' environments and how they could go "never go back to that" (Interviews, 2014) after experiencing what Bellah (2007) terms changing the 'habits of the heart'. From the vantage point of all respondents, their work results in benefits to society, particularly to the vulnerable; children: "They learn about love, loss, everything that matters and they don't come with batteries, they're alive” (Interview with Nick, $14^{\text {th }}$ January, 2014), and the elderly: "The dog is the only other little heartbeat in the house" (Interview with Jean, $4^{\text {th }}$ February, 2014). In that sense, my shelter respondents (including the two hands-off CEOs) recovered a field of vision that is meaningful, and extricated themselves from other, less meaningful work. As Crawford (2009: 5) 
remarks of his change of job from "think tank" Director to motorcycle mechanic: "The sense of uselessness was dispiriting. The pay was good, but after five months I quit to open the bike shop”.

As well as helping vulnerable human beings, shelter workers believe that their occupational choice also results in benefits to themselves, and that it results in saving animal lives. Emma volunteered in a home for the elderly after losing her job in a bookmakers'. She explained that she likes older people and wanted to spend time with them. Instead, the nursing home put her to work in the kitchen washing dishes, so she left and chanced upon the cat shelter volunteering position (Interview with Emma, $5^{\text {th }}$ February, 2014). These findings are elaborated upon in the next chapter in the broader context of consolations and joys of shelter work.

The way my respondents tell their stories, shelter work gives them a harmonious framework, and they feel part of a project of significance. This was not the case for previous positions the majority held. Jean and Emma's care work for humans was stressful in Jean's case, and consisted of washing dishes in Emma's. Jean explained that humans are much harder to care for than animals because humans do not live in the present. Further, the regimented nature of the privatised nursing home where she worked left her little time to comfort the sick or dying people (telephone conversation with Jean, $15^{\text {th }}$ February, 2016). Emma had wished to read to elderly people where she volunteered but was asked to work in the kitchen instead so she left (Interview with Emma, $5^{\text {th }}$ February, 2014). In this sense, this occupational choice is reminiscent of 'a calling', due to its ethical content. Only two respondents alluded to the vocational aspect of their work however, and even for those respondents the 'calling' was constructed after occupational entry rather than presented as a reason for entry as I documented above.

It is also noteworthy that the exchange of disliked previously held jobs (in the Civil Service, in Computing Services, in Marketing, as a Nursing Assistant) for an outdoor 'meaningful job' rescuing animals was seen as an improvement in the participants' work lives. In that sense, my respondents have repudiated the dominant value system in favour of counter-cultural values. Jon's account reveals this repudiation: "We are not corporate dudes Anne. None of us is. It's more like a cooperative here" 
(Interview with Jon, $7^{\text {th }}$ July, 2014). Nast (2006) argues that post-industrial places are characterised by certain conditions that facilitate love of animals (her focus was on pets, not shelter work) such as a decline in family size concomitant with deindustrialisation, human alienation and alone-ness and an erosion of long-term placebased communities (Nast, 2006).

Holland (1973) postulated that heredity and experiences lead to a preference for certain occupations. Shelter workers often dislike systematized workplaces and enjoy how different every day is in the shelter which approximates the 'Artist' personality type (Holland, 1973). They are invariably also 'Realist' in bent due to the physically demanding nature of shelter work. Much of the daily work in the shelter consists of cleaning and disinfecting animal areas (Interviews, 2014 and observation).

One respondent, Maura, recalls the six years she spent working as a Quality Control (QC) lead in a factory in - thus: “I was working shifts and I've got two kids. I was finding it really tough, mentally, emotionally, physically, the whole lot. It was very stressful. Working in a factory..it kind of makes you brain-dead really” (Interview with Maura, $7^{\text {th }}$ October, 2014).

It appears that my respondents are motivated to stay in low-paid 'dirty' jobs in animal shelters because they see higher-paid, ‘clean’ work as a worse alternative:

I could never do a job like that (civil service office work) again. You can imagine the County Council in the 90s. The internet was coming in and I was teaching people to use it. I got a written warning because that was someone else's paid job to be bringing in consultants to do that. Not for me to do it or to be showing initiative. You sat down and you typed your letters and that was that (Interview with Lisa, $11^{\text {th }}$ February, 2014).

In terms of the work environment, former workplaces are described as competitive or 'mind-numbing' by many participants. Their concerns are antipathetic to corporate life. Not so animal shelter work, instead the respondents say they feel united in a common purpose; helping the animals. Even Colm, who always knew he wanted to do "something with animals" found the academic nature of using his BSc in Zoology off-putting; he wanted to be "hands-on” with (presumably live) animals (Interview with Colm, $2^{\text {nd }}$ October, 2015). Higher-paid work is deemed worse because it constitutes less meaningful work with less peer support and fewer 
rewards. As my respondents tell it, previous jobs they held did not constitute as rich a working life as does their shelter work:

"You get to see the pictures of the dogs in their new homes, up on couches, and you think of them when they came in..that's the best part of the job like. I couldn't see myself doing anything else now" (Interview with Sally, $4^{\text {th }}$ July, 2014).

Jon's poignant account of losing his job as a software engineer illustrates this point:

I was starting to get a little old, and the US economy had taken a dive. They're not going to hire some 40 year old-engineer that's been 6 months here, and 6 months there, they want somebody that's been with a company forever, basically so..I had difficulty getting tech jobs even in Austin. The ageism is really what got me, and that snuck up on me, cos when you're in your mid-thirties you don't think you're old but suddenly you're 39. So I found myself competing with these fellas, for a job I didn't want (laughs) (Interview with Jon, $7^{\text {th }}$ July, 2014).

What an unappealing position in which to find oneself; enduring competitive pressure for an unwanted job. Jon's experience has much in common with the ex-AA skilled workers described by Dobbins et al (2014). Jon too, faced a paradox of being highly skilled but superfluous to labour market requirements. Unlike the ex-AA workers, however, he was fortunate enough to find more richness in working in the shelter than the "make do and mend" alternative (Dobbins et al 2014). Jon did what he could about what he cares about (dogs) in painful circumstances not of his making or choosing (Interviews, 2014).

Archer (2007: 323) observes that as paperwork and cost effectiveness takes precedence over people, workers experience a "contextual incongruity" with their values. She identifies three consequences: workers become critical of workplaces, they often resign, and when they do, they show a marked tendency toward the Third Sector (my italics) (Archer, 2007: 323). Jean (telephone conversation, February $15^{\text {th }}$, 2015) decided to leave her job as a care assistant in a nursing home for adults with profound physical and intellectual difficulties. I asked her to explain the differences between how caring for humans and animals made her feel. Jean explained that there was no difference; she feels the same about caring for vulnerable humans and animals. She told me that the huge (Jean's verbal emphasis) difference was the stress 
she felt in looking after people. The nursing home was too regimented and if somebody was dying they might have nobody with them. Jean experienced her work in the nursing home as very stressful. Caring for humans is much more difficult than caring for animals, in Jean's opinion, because animals live in the moment, even when sick or dying, whereas people (and their families) worry about all the things they did or did not do in the past. Jean gave me the following example: "For example, I rescued a cat caught in a rabbit snare on Valentine's day yesterday. His leg had to be amputated. My stress came from his owners who were distraught. The cat wasn't dwelling on the snare or worrying about his leg. Animals live in the now". Jean sent me the following diagrammatic illustration of what she meant (Figure 5.1 below). She added that you can make a decision to end an animal's suffering, which is not the case with human patients (Telephone conversation with Jean, February $\left.15^{\text {th }}, 2016\right)$. 


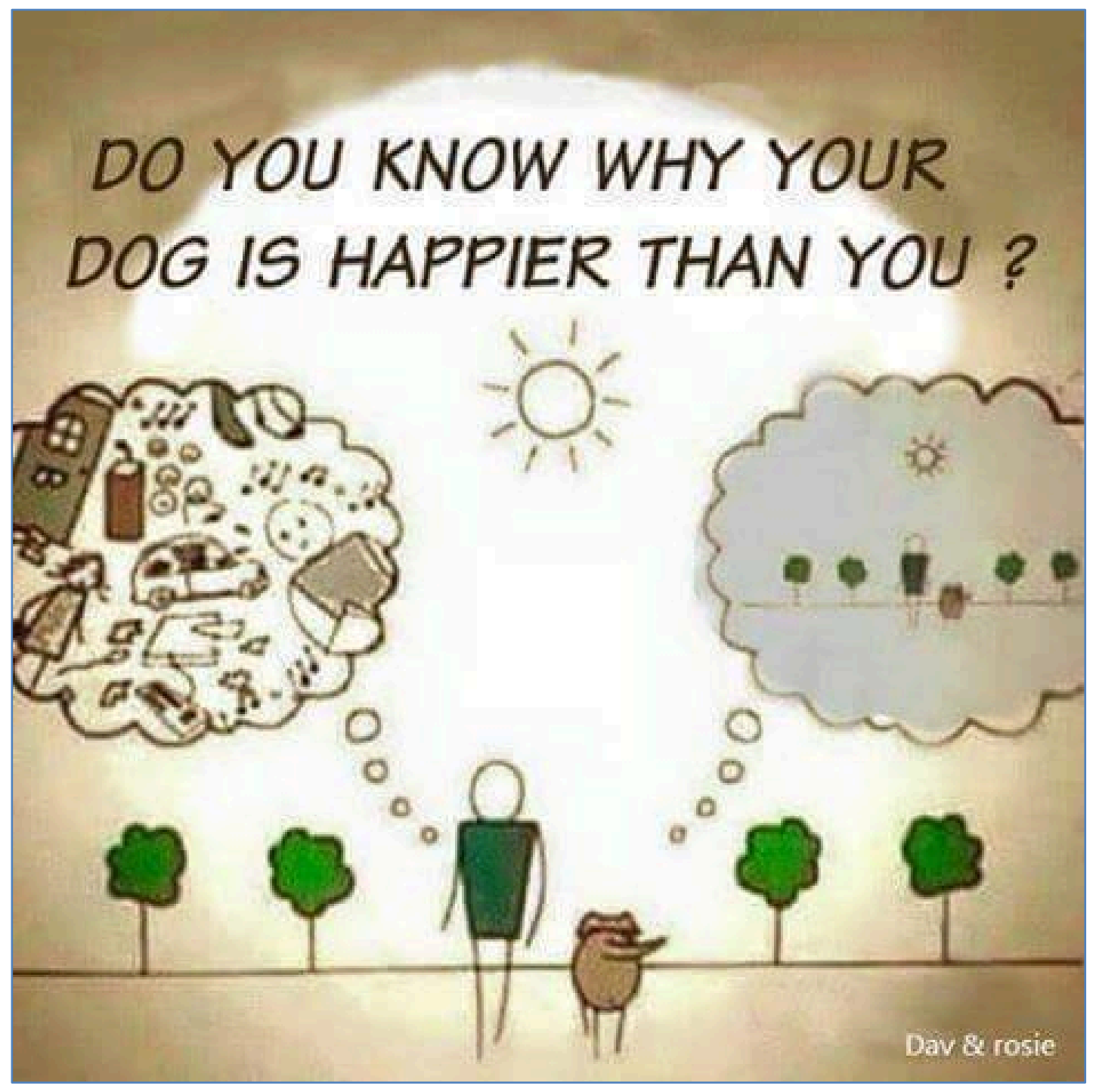

Fig. 5.1. Do you know why your dog is happier than you?

For Maria, this disaffection extended beyond alternative workplaces to include social interaction with people. Maria has been diagnosed as being on the Autistic/Aspergers spectrum:

For me, I've got autism and Aspergers and for me, with animals it's like I get to see them properly, they see me properly. They like..if there weren't animals around I probably wouldn't be able to have a conversation with anyone, even you now. Before I moved down here, even to get me to walk into a shop..So now I have my rat - in my pocket and if I start to panic I just pet him. So they're my confidence for me, animals, to go out and do things (Interview with Maria, $9^{\text {th }}$ July, 2014). 
Most shelter respondents earn a living by dovetailing their interest in animals with their extrinsic needs. My volunteer respondents either pursue alternative animalrelated work, such as running a cattery, or draw unemployment assistance. As Chapter 6 will attempt to unpack, Polanyi's (1957) and Thompson's (1971) concept of the moral economy would therefore seem an apposite lens through which to consider animal shelter work. Drawing on Polyani’s work, Bolton and Laaser (2013) recognize that people are ethical, reflective social agents, that it is possible for people to defend social commitments from the erosive tendencies of economic progress, and that social dependency within a "web of reciprocity" presents opportunities for people to flourish (Bolton and Laaser, 2013).

Animal care is also distinctive from other types of care work in that is frequently physically dangerous (I was bitten and scratched myself several times during fieldwork, and once head-butted by a donkey; most of my respondents are around animals every day), pays less than most alternative care jobs, and extends our moral compass to include other species. This work is seen as moral work by my respondents, a theme which Chapter 6 takes up in order to apprehend why people stay in this physically, financially, emotionally onerous work. In Chapter 6, I endeavour to expand upon Arluke and Sanders (1996) and Taylor's (2010) work on emotional management strategies by adding a moral career dimension. My respondents do not report making this choice on moral grounds however. Often happenstance and serendipitous events led them to shelter work.

\subsubsection{Unintended Choices: Epiphanic or Serendipitous Experience}

A 'falling into' shelter work quasi-accidentally is reported by many participants. The role of epiphanic experience is evident in the pathways to shelter work in many respondent accounts: a sign noticed in a veterinary surgery, a friend's suggestion, a man about to throw a puppy in a plastic bag into a river. Jean recalls how she became involved in shelter work thus: "It's about 17 or 18 years ago now, and I was in the supermarket and they were collecting food for animals. I said if they needed a digout I'd help and gave them my number. It all kind of escalated from there" (Interview with Jean, $4^{\text {th }}$ February, 2014). 
Emma remembers how she was in the veterinary surgery: "I seen they had a collection box. So I said, "What? Give me that woman's number. And I rang her up and I went: "Hi, I’m a cat-lady too! The second I walked in that door, I was in the fold!” (Interview with Emma, $5^{\text {th }}$ February, 2014).

Lisa's friend's throwaway remark led to her volunteering and later, opening her own cattery:

So I said no way am I ever doing anything like that again (Civil Service). So then we moved down here and I was thinking about what I wanted to do. And I remember I was sitting here with a College friend one day, and she said: "Can't you do something with animals? You've always loved animals, why not work with them?” So then I think it slowly kept seeping in, the idea (Interview with Lisa, $11^{\text {th }}$ February, 2014).

Lisa's friend's perspicacious remarks show evidence of strategic thinking, of how to steer a course to balance Lisa's intrinsic interests in animals with her extrinsic interest in earning money. Chance encounters such as these are reported as having being part of the process of the occupational choice of shelter work. Chance encounters are important, but people had to be 'ready' to turn those chances into a 'choice', of course. Nonetheless, these interactional moments created transformational experiences for some respondents and are often interpreted by these respondents as turning point experiences. Denzin (1989: 17) distinguishes between four forms of epiphany: the major, the cumulative, the minor and the illuminative. Major epiphanies occur when an experience shatters a person's life, for good or for ill. Only Joan, who lost 8 stone in weight might be deemed to have had a major epiphany. Minor and illuminative epiphanies occur, according to Denzin (1989) when the underlying tensions in a situation are revealed. The epiphanies recounted by those of my respondents who experienced epiphanies at all can be categorised as cumulative; the epiphany occurs as the result of a series of events that has built up in the person's life. The 2008 credit bubble, disaffection with alternative work environments, the rise of the Animal Welfare Movement in Ireland (to which the steady decline in euthanized dogs in Pounds in recent years attests (See Chapter 4) all constitute the larger historical, institutional and cultural arenas within which my interviewees’ epiphanies occur. Blau et al (1956) allude to the twofold significance of social structures for occupational choice; on the one hand it leaves a mark on the 
personality development of the choosers. On the other, it defines the parameters within which choice is possible. This occupational choice is thus part of a larger life trajectory embedded in a particular historical point in time and many respondents appeared to relish telling me their personal story of the 'flukes' that led them, in combination with other processes, to the job they see as the most valuable of their lives.

\subsubsection{Becoming a Volunteer}

Volunteering before seeking either fulltime or part-time employment at a shelter is a very common pathway to this work. Seven out of 22 shelter respondents are regular volunteers. Apart from Mike, all my shelter respondents had volunteered prior to obtaining paid employment in the shelters (Interviews, 2014). This is unsurprising; from the individual's perspective she has an opportunity to understand the nature of the daily work routines before committing to seeking a shelter job. From the organisation's perspective, a volunteer is a 'known entity' who has proven herself as a loyal volunteer and as capable of animal care. I observed no competition between committed volunteers and paid staff, I observed a common sense of purpose helping animals. Nick is retired and CEO of an SPCA in a voluntary capacity. However, he receives certain benefits in kind, for example, he also uses the charity vehicle for private use. Lisa runs a cattery and volunteers for the same SPCA. Jean and her two ‘staff' are volunteers but donations also fund Jean's supplies of food and crates for the animals she takes into her home. Agata is a $\mathrm{PhD}$ student and part-time lecturer in Philosophy and she also runs a sanctuary from her home. The other 16 respondents are paid (the minimum wage for most) but most supplement their income with jobs as dog-groomers or 'doggy day-care' on their days 'off' from the shelter. Many of my female respondents have partners who are engaged in more lucrative employment and who are supportive of their shelter work. The process of selection must also be taken into account in order to explain why people end up in certain occupations and not others, of course. In the case of a subset of respondents, volunteering led to opening their own shelter (Jen), or running a small sanctuary from their home (Agata). 
As Mike states: “I can’t remember the last time we didn’t fill a job with a volunteer, apart from the Marketing posts up there” (Interview with Mike, $18^{\text {th }}$ February, 2014). Mike observes that some regular volunteers are unable to keep dogs in their rented accommodation, and volunteer at the shelter in order to 'wind down'. These volunteers benefit from intrinsic work enjoyment. All of my respondents (volunteers or paid) report enjoying the task of helping animals per se, as well as the social interaction with their peers. Meier and Stutzerl (2008) find evidence that people who become unemployed are less likely to volunteer. Several of my respondents (Emma, Jen, Jon, Maura) began to volunteer after leaving or losing their jobs however. These respondents did not retreat from society, or become lethargic, despite their shock and sense of insecurity following redundancy or their sense of alienation from former workplaces (Interviews, 2014).

The majority of my respondents volunteered for the shelter in which they are currently employed, seven are regular (five days a week) volunteers because they are either self-employed, recently made redundant in the workplace, or have partners who are in fulltime employment. Colm, for example, volunteered one day a week and then applied for an internship, after which he was offered a fulltime job (Interview with Colm, $2^{\text {nd }}$ October, 2015). In terms of why volunteers and paid workers enter and stay in the shelter, I find the reasons to be the same. Two of the SPCAs in the current study depend on the work provided by volunteers. These organisations exist only because people voluntarily offer their work free of charge. Even the two largest shelters in this study are greatly aided in their efforts by the time freely given by volunteers. Only Des and Mike are highly remunerated (Des is now retired) for their work, although Mike observes that he would be much more highly remunerated in the private sector (Interviews, 2014).

The antecedental picture is thus that my respondents had early positive life experiences with animals and were inter-subjectively influenced by significant others, both human and animal. Changes in the life course propelled many into shelter work. For all of my respondents (including the veterinary surgeon and the SNA) their work is seen retrospectively as a dignified moral choice, as an alternate way of experiencing the economy. This view is an important factor in the choice to 
stay, the theme of Chapter 6; not one respondent reported having initially chosen this field because it was a 'moral decision'.

\subsection{Chapter Summary}

In sum, my ethnographic observations and interviews lead me to conclude that shelter work is an occupational realisation of my respondents' sense of compassion in dealing with animals. Nonetheless, the picture that emerged of the reasons why people enter is messier and more complex than simply 'loving animals' since formative childhood experiences. I expand the occupational choice and moral economy literatures to include a processual dimension. Various processes, from early experiences to random or serendipitous events played a part in this occupational choice for almost all participants, as did changes in the life course, and cumulative epiphanies. Further, a disillusionment with former workplaces and a sense of the 'pointlessness' of former experiences of the economy is expressed by a majority of respondents.

I argue that there are two choices at play: the choice to enter shelter work which is processual, and perhaps more importantly, the choice to stay. I also question the whole notion of occupational 'choice' in the typical sense. In the next chapter I unpack the processes by which people stay, despite all the travails and moral dilemmas. As Arluke (2006: 120) acknowledges, shelter workers have to "clean up” after a society that holds non-human life in low esteem. I explore how they negotiate meaning to create identities for themselves and others. Chapter 6 concludes that people view working with animals as a different and moral experience of the economy. The dialectical processes by which my respondents shape and are shaped by moral considerations in symbolic interaction are analysed, as well as the sanctuary the animal shelter affords the human workers. I conclude that this sanctuary operates on two levels: as sanctuary from alternative workplaces and as sanctuary in nature, as embodied by other species. 
Chapter 6 


\section{Chapter 6 Shelter Work: Part of the "Moral Economy of the Crowd" ?}

By the notion of legitimation I mean that the men and women in the crowd were informed by the belief that they were defending traditional rights or customs; and in general, that they were supported by the wider consensus of the community (Thompson, 1971:78).

\subsection{Introduction}

Chapter 5 focused upon how my participants come to endorse a set of values regarding animals and how they ended up in shelter occupations as an expression of their value- commitment. I documented how occupational entry into shelter work illustrates the processual nature of social reality. Archer (2007: 289) notes how lack of self-knowledge and lack of information about occupations leads to "false starts" over the life course for many people.

In this chapter I address the complex question of staying in shelter occupations, for the choice to stay is arguably the more difficult choice. The choice to stay in shelter work is intersubjectively shaped in the infinite discourse about its consolations and joys. An understanding of shelter work as a moral economy and as a sanctuary from alternative work is evident in my interviews, participant observation and in the digital media presence of the shelters. I see the moral dimension as operating on two levels. First, my participants express the view that they are "doing the right thing" in helping animals. The notion that doing good is akin to being good is as old as Aristotle and indeed there is contemporary evidence that eudaimonic activity through engaging in meaningful endeavours is conducive to well-being (Steger et al 2008). Second, shelter workers do not construct this view in isolation, but with support and recognition from segments of the public, as reflected in the high number of Facebook 'likes' and positive comments for the shelters and in public donations. Therefore, the "moral economy of the crowd" (Thompson, 1971) is also evident in the wider social relations of the shelter. The beliefs and practices that shelter workers and others in wider society accept sometimes run counter to market ideology, act as a form of resistance to the imposition of market norms and thus change social and economic norms over time. Not only the shelters, but segments of the public reject the notion that economic imperatives matter more than abandoned animals, as the case of 
Animal Collection Services (ACS) demonstrates (see Chapter 4). The State, though it supports many shelters with ex gratia grants, is, in the common or garden term, caught between a rock and a hard place; there is often a tension between free market ideology and moral economy. "The awkward realities of commerce and consumption [here the place and value of animals] were in friction” (Thompson,1971: 83).

It is important to note the total socio-economic context within which shelters are operating in $21^{\text {st }}$ century Ireland. These are times of austerity, post the credit bubble of 2008. Equally, these are times when the position of animals in society is being revisioned, after the AHWA of 2013 (part of the moral economy as documented in Chapter 4) and in light of increasing public awareness of the plight of abandoned animals.

The status quo depends upon a particular set of social relations, a particular equilibrium between "paternalistic authority and the crowd” (Thompson, 1971: 129). The existence and continued survival of animal shelters demonstrates that the market remains a social as well as an economic nexus. There is a processual dimension to the moral economy; it is an ongoing inter-subjectively created construction.

As authors of meaning, my respondents' moral code is derived and constructed from the passion for saving animals and defined in social interaction in groups and through interspecies relationships over time and through various processes. I supplemented my observations and interviews with qualitative studies of shelter social media sites. All of my shelters have a Facebook presence and use these sites to relate cruelty and rescue narratives, to communicate their frustrations about their work, and to seek donations from the public. Shelter work has its share of sorrows, travails, consolations and joys. It is rooted in dialectic tensions, and in opposing forces. For example the public fosterers, donors, veterinary surgeons and volunteers are extolled by my respondents as essential to their work. The moral economy shelters interact extensively with commercial economy veterinary surgeons. However, my shelter respondents choose to deal with vets who are sympathetic to shelter work, and who often work pro bono, and allow shelters to run up large debts.

Yet dealing with the public emerges as one of the principle travails inherent in shelter work. What the shelters do not say is as notable as what they do say. Two 
omissions are particularly clear on analysing social media (Appendix F). While disparaging remarks about some members of the public were frequently made during interviews and informal field conversations, negative remarks are very rarely made on shelter social media sites. Indeed details of surrendered animals are often given with the exhortion : “No negative comments please”. This recalls Goffmann’s (1959) notion of "front stage" regions of portrayal. The joys inherent in shelter work tend to be positioned as exclusively pertaining to the rescued animals on social media sites. Personal benefits and joys arising out of subjective wellbeing or the sanctuary afforded to my human participants do not tend to feature. In contrast, my data and ethnographic observations lead me to conclude that the shelter workers and volunteers receive sanctuary from the work that they do; that sanctuary is a two-way process. Sanctuary is given to animals and also received from animals, co-workers, the natural sanctuary, and the wider moral economy.

My interviews and ethnographic study lead me to the belief that three main sources of sorrow pertain to this occupation: broader institutionalised and normalised illtreatment or killing of animals, the non-normalised cruelty to which shelter workers bear witness in the course of their work, and third, the death of animals, either their own companion animals or shelter animals which could not be saved. The travails which loom large in accounts pertain to dealing with the public, the difficulty of animal-related practices of some members of ethnic groups, and financial strains and constraints. I find that the well-spring of consolation comes from the respondents' constructed belief that their work is 'moral work' which results in the betterment of animals' lives and of society in general. Public recognition, which forms part of the "moral economy of the crowd" (Thompson, 1971) and help is another factor which consoles my respondents in their challenging and often distressing work. From a processual vantage point of moral economy, four processes emerge from my data as salient. First, for the most part, shelter workers reject the norms of a career driven by economic considerations and find reward in things other than monetary gain, for example, the love they receive from animals, working in 'nature', and in public affirmation. Second, they place value on animals who have little or no value from a market perspective. Third, they rely on a wider belief among segments of the public that animals have an inherent value that is non-economic, in order to sustain their 
activities and legitimate the work that they do. Fourth, shelter workers can and do draw upon this wider belief in society to resist changes to the status quo driven by the market economy.

Helping animals and the concomitant human-animal relationship rewards emerge as a strong consolation as does the sanctuary from alternative ways of being in the economy afforded to the workers. I use the term'sanctuary' here in a wider sense than the etymological (Branchi, 2010) to characterise my respondents' refuge from the mainstream labour market and in their relationships with animals. The joys are also threefold and are a powerful antidote to the sorrows: loving the animals brings joy to my respondents, as does experiencing their work as morally 'good'. Third, my respondents experience a sense of sanctuary in their nurturing relationships with animals and from alternative workplaces whose disappointments were discussed in Chapter 5. Sanctuary is both a consolation and a joy (Interviews, 2014). As I will demonstrate, shelter workers have to meet the challenges of different social expectations: dealing with the public, soliciting help from the public in the form of donations and maintaining dignified lives throughout and meeting moral strictures upheld by the shelter community. Shelter work is replete with sorrowful experiences: bearing witness to cruelty cases, having to euthanize animals, dealing with distressed animals who take a long time to find what shelter workers refer to as a "forever home”. While my participants' accounts of occupational entry were retrospectively constructed and self-reported, I was able to observe the 'staying' in situ. Therefore, I include more excerpts from fieldnotes in the current chapter.

The dialectical tensions inherent in shelter work are represented in Table 6.1 below and are discussed under the overarching themes of sorrows, travails, consolations and joys. 
Table 6.1 Dialectical tensions in Shelter Work

\begin{tabular}{|l|l|l|}
\hline SORROWS AND TRAVAILS & VS & CONSOLATIONS AND JOYS \\
\hline Institutionalised cruelty & vs & Rationalisation and helping animals \\
\hline Cruelty and neglected animals & vs & The ones you save \\
\hline Euthanasia and Death & vs & Somebody held him and loved him \\
\hline Dealing with the public & vs & Generosity of the public \\
\hline Financial worries & vs & $\begin{array}{l}\text { Generosity of the public, Moral } \\
\text { economy, Sanctuary }\end{array}$ \\
\hline Lack of personal time, money & vs & Sanctuary, Moral economy \\
\hline
\end{tabular}

\subsection{Sorrows}

Some scholars have written about the sorrows inherent in working with animals (Bunderson and Thomson, 2009; Arluke and Sanders, 1996; Sanders, 1995) and the emotionally painful and saddening side of this occupation was apparent to me in both interviewing and during field work at the shelters. Several participants (Interviews, 2014) became emotional during their interviews and on some occasions (such as when interviewing Joan who told of the "gentlemanly" cat used for dogbaiting) I did too. The sorrows described by my participants can be categorised as caused by wider societal cruelty towards animals - with which my participants have non-direct interaction, and by specific cruelty cases, the periodic euthanasia of shelter animals, and the death of loved companion animals - with which they do. 


\subsubsection{Broader Societal Institutionalised Cruelty towards animals: Non-Direct Interaction with the Public}

Much of the societal cruelty described by my participants related to the treatment of 'food' animals or to institutionalised cruelty or neglect. Nick recalled childhood memories of taking pigs from his grandparents' farm to the abbatoir thus:

My grandfather used to keep them at the back of the garden when you were allowed to do that and I used to feed them. Ironically, when I was younger, a lot younger, I used actually to have to take them to the slaughterhouse. The noise. The screaming..that kind of always stayed with me. I suppose that embedded something deep in me. Like they..God..shouldn't have to do that (Interview with Nick, $14^{\text {th }}$ January, 2014).

Likewise, Jean formed attachment to newborn farm animals and remembers her consternation when they would 'disappear':

I always had my own pig, always had my own lamb, always had my own calf. As soon as they were born, they were mine. I'd be involved with them when they were small and then devastated when suddenly they'd disappear. That's reality, everyone has to eat. If I don't like something, I just don't eat it, but I don't go OTT about it. I mean, I can only save what's in front of me. I know all the cruelty and I don't agree with it but if I was to let that get to me, I wouldn't be able to function during the day (Interview with Jean, $4^{\text {th }}$ February, 2014).

All the animals in my shelters either had names or were given names by staff on admission. The process of naming - only humans have the power to bestow a name - appears to establish a distinctive biography

For one respondent, an epiphanic experience altered his socially acculturated attitude towards hunting wild animals. He described how he used to kill his "own meat” and shoot a lot of deer in Texas. Once he shot a wild boar and it made a "blood-curdling scream”. He has not hunted since then, which was 15 years ago and says that he no longer makes fun of vegetarians (Interview with Jon, $7^{\text {th }}$ July, 2014).

For agricultural workers, an instrumental attitude to farm animals is common, although Wilkie (2010) observes that this depends on the stage of the production process and on the type of farming (whether hobby farming or intensive). Such an instrumental attitude is evident in the following extract from my field notes taken 
after one of the many sessions I sat in on veterinary clinics at a local veterinary surgery:

The second client is a farmer who parks his trailer across the newly tarmacadumed road, and the vet invites me to join him for the consultation. Perhaps the farmer thinks I am a veterinary student; in any case, he does not remark on my presence or appear to find this strange. The brown and white calf is unable to support himself on his hind legs and repeatedly falls over in the straw. The vet delivers a grim prognosis: the problem is neurological, caused by a tumour on the spine, most likely. The vet says to the calf: “Ah, you poor old fella”. The farmer remarks: "He’s no use so.” The vet suggests bringing the calf into surgery the following day to be put to sleep as conducting an autopsy would be interesting. He tells the farmer: "Children and calves get cancer too" (Participant observation, July $30^{\text {th }}, 2013$ ). The farmer's instrumental attitude to animals is common to some members of the Traveller community, according to my participants (Interviews, 2014). Such institutionalised cruelty is of course not merely a phenomenon in the Traveller community however; there is more continuity with the wider public than my respondents perhaps allow. Shelter workers are social critics; they readily identify structural constraints that hinder them in their efforts to help animals. One of these is the perceived lack of policing of some members of minority groups.

According to my respondents, some members of the Travelling Community engage in practices such as badger-baiting and 'lamping', or in rabbit-hunting using dogs (usually the lurcher breed which is a light breed and very fleet of foot). Lamping aims a high powered lamp on a badger or rabbit and a lurcher is "let slip" to make the kill (DSPCA, 2015). Of course, this 'sport' is not uniquely practised by some members of the Travelling Community, but my respondents suggest that this is primarily the case (Interviews, 2014). Second, the practice of sulky horse-racing, also culturally normalised among some members of the Travelling Community, is deemed very cruel by many of my respondents. Jen's comments epitomise the attitude of my respondents to the betimes poor treatment of dogs and to sulky-racing:

We've seen a big increase in- , which might be because of the ethnic minorities that are down there that weren't in - . Usually it's malnourishment and mange; severe neglect. Nobody does anything 
about it. I mean, you've seen all these situations where......I was speaking to the ISPCA Head yesterday, we were at a meeting, and he said that horse in Kilkenny, you know, the sulky, that the horse's two front legs were severed and they just walked away and left it. He said it took a good while for the vet to get there to put the animal to sleep. The guards are afraid of them, the Council are afraid of them. Like, we need a visit from Al Capone, I think (loud laugh). Look, people are getting away with cruelty too much. The ISPCA have 6 inspectors for the 26 counties; it's just not possible (Interview with Jen, $4^{\text {th }}$ July, 2014).

My respondents do not usually use the term “Travelling Community”, instead they tend to use the term "ethnic minorities" or simply "they" perhaps in order to avoid discrimination on the basis of ethnicity. The following correspondence exemplifies this tendency:

No respect for others, no respect for the laws of this country or for their fellow countrymen. I'm afraid that even if they [Fran is alluding to members of the Traveller community] break the law and are caught doing so, there is still no appetite to prosecute. A few years ago (shelter) was broken into $3 \mathrm{x}$ in one week. The third time they were intercepted by the Gardai, our lurcher still in the boot of the car. Not only did the guard in question not understand why they couldn't just have the dog as that seems to be what we are doing, give dogs in our care to people who want them. Long story short, we went in and made an official complaint, we got our dog back and that was the end of it. They came from $\mathrm{X}$ in Kilkenny. It makes you wonder whether it pays off to live a decent life (Email from Fran, $5^{\text {th }}$ March 2015).

I myself had a very unpleasant experience in 2015 of lurchers being trained near my home. Lurchers were chasing cars which had tin cans attached down a narrow slip road near my home. I had to move into the hedgerow with my two dogs in order to avoid the cars and packs of dogs. Young children were present in an adjacent field and one child was holding a dead hare or rabbit aloft. I was sufficiently concerned to contact the then Minister for Agriculture, Simon Coveney's office to lodge a complaint. The somewhat Orwellian reply from his secretary reflects the grey legal area surrounding blood sports in the Republic of Ireland. (Email correspondence, Appendix D).

While most participants (apart from Suzanne, Agata and Maura who do not eat meat, Interviews, 2014) appear to have normalised the more hidden side of animal production in the case of 'food' animals - meat-eating is so normalised in our culture 
as to be all but invisible - all participants are visibly upset when they relate stories of individual companion animals who were cruelly treated before being admitted to the shelter.

\subsubsection{Non-normalised Cruelty or Neglect Cases}

While the broader plight of animals was a cause of regret for most respondents, especially in its intensive forms, the most sorrow was reserved for individual cruelty cases with which they had dealt. The exceptions to this were the three vegetarian/vegan respondents (Suzanne, Agata, and Maura): these respondents expressed the view that our treatment of all animals is cruel.

Some respondents tended to blame cruelty or neglect on the ignorance or lack of education of the public and most reiterate the need for education about the need to spay and neuter companion animals to avoid further unwanted animals coming into being (Interviews, 2014).

Others told harrowing stories of the abuse of individual animals:

Just going on experience, I'm $100 \%$ sure that cat was used for dogbaiting. It is more common than people realise. People are very shocked when you tell them that this has happened and it does happen. And I tell you now, I wish it didn't but it does. A lot of people's cats that are friendly and suddenly vanish, that's where they're going, which is very sad (Interview with Jean, $4^{\text {th }}$ February, 2014).

Joan became visibly upset when relating the fate of a cat who came to her shed to die, having been used for the purposes of dog-baiting. This practice uses tethered young dogs or cats to 'blood' dogs who will later be used for fighting or hunting. She subsequently took the cat to her local shelter and he was put to sleep by the veterinarian. Joan surmised that there must be a beacon above her house that only cats can see.

So I kind of gently slid him in the catbox, and he was quite willing. He had cuts around one of his ankles but I didn't want to pull at him so I couldn't actually see that there was ligature marks on all four of them. So he'd been restrained. Literally - a beautiful...my kids had called him Walter because he had that kind of gentlemanly look about him (Interview with Joan, $25^{\text {th }}$ February, 2014). 
Des recounts the dismal equine welfare situation in the Republic of Ireland which in his opinion is worse than in the last two centuries. He believes that poverty and ignorance was at the root of animal cruelty in the last two centuries but that poverty does not explain the current animal abuses. He noted with sadness that horses (who can live 35-40 years under normal conditions) were often dead within two weeks of being bought at the horse market in Smithfield, Dublin: "I've got no problem with people owning a horse once you look after it; it's not a bicycle” (Interview with Des, $15^{\text {th }}$ April, 2014). Jean explains how she uses Facebook to 'get it out there':

"It's not all cute kittens. This is the way they come in and this is the way they go out. To get that awareness out there is huge” (Fieldnotes, Shelter B, July $30^{\text {th }}$, 2013).

Interestingly, the DSPCA archives from 1900 (accessed during visit to the DSPCA, June $15^{\text {th }}, 2012$ ), indicate the society members' hope that the $20^{\text {th }}$ century would see an improvement in animal welfare: "This is the opening of a century in which it is hoped the advances of the past century will be eclipsed for in a Christian county cruelty to dumb animals ought to be unheard of but the fact of such conduct existing proves that such a society is needed" (DSPCA, 1900. Field visit, $22^{\text {nd }}$ September, 2012).

Sally's description also suggests that animal welfare societies are still sorely needed as we proceed into the twenty-first century:

I remember there was a dog in there, it was some sort of pitbull or something but they had to keep her there because there was a Court Case coming up, it was after being abused. Some dude beat the crap out of it with a hammer or something, so they had to..this dog lived in a dog lived in a Dog Pound for a year before they put it to sleep and it was just..everytime you went in you saw this dog and you wanted to just take it with you home and give it a hug or whatever. And that poor dog was in the Pound for a year, obviously the staff got to know it or whatever, but it was put to sleep without anybody that loved it or held it (Interview with Sally,4 $4^{\text {th }}$ July, 2014).

In some cases, the cruelty depicted stems from personal problems of the perpetrator which seem to result in hoarding behaviour. This appears to form a different category of abuse for my respondents as moral culpability does not tend to be attributed to the hoarders. Maria described a case where an elderly lady had so many unneutered cats that she had resorted to drowning kittens in the toilet bowl in her 
home. Such was the extent of the (inbred) cats' deformities that the majority had to be euthanized. Maria explained that the woman was "not a bad person" and she did love cats, she just got overwhelmed. "I wanted to hold them while it was happening, so we got to hold them (catch in voice) and it was sad" (Interview with Maria, $9^{\text {th }}$ July, 2014).

Although sadness and frustration are the most common reactions shown by participants to such cruelty cases, anger is evident in some interchanges I had with shelter workers, such as Tommy:

Tommy and I walk up the hill to see the outside dog kennels and dogs. He asks if I had noticed what had happened to a bull lurcher (a cross between a pitbull and a lurcher). I had not but on observation, realised that the tip of his nose is missing, exposing raw, pink membrane. Tommy goes on to explain that the owner told local people that as soon as the bull lurcher is "fit for duty" (badger-baiting) he would steal him back. Tommy says he put the word out that "if that man shows his face here he will be shot”. I feel shocked by this remark and by the fervour with which it is expressed (Participant observation, $3^{\text {rd }}$ August, 2013)

Nick also alludes to criminal cruelty-related activities of which he is aware:

Unprompted, Nick tells me about illegal dog-fighting rings in Ireland and in the UK and furnishes some very unpleasant details about these groups, for example that the paraphernalia found in dog-fighting locations includes needles, used by these groups to inject dogs with pain-killers, so that the dogs can continue fighting after sustaining severe injuries. He points out that it is extremely difficult to apprehend these individuals, as they are covert, and careful to change locations at the last minute. This description of these groups' activities reminds me of the modus operandi of drug rings, as depicted in the HBO series, “The Wire”. I was deeply surprised to learn that dog-fighting rings frequently include female members (Field work with Nick, August $2^{\text {nd }}, 2012$ ).

A common thread through interviews and in informal conversations in the field is that shelter workers disparage the notion that problematic animal behaviour is to blame for their ending up in the shelter. For example Sally (Interview with Sally, $4^{\text {th }}$ July, 2014) observes that "we blame the wrong end of the lead". In making this 
statement, Sally was typical of all shelter participants, who never perceive dogs to be intrinsically aggressive or at fault. The blame for aggression in dogs tends to be laid firmly at the owner's door by my respondents. Through symbolic interactionism my shelter workers ascribe meaning to animals' behaviour that other people might not; if interpreted differently, aggressive behaviour can result in a dog's demise. Unsurprisingly, all respondents express sorrow about the inevitable need to euthanize injured or un-rehomable animals.

\subsubsection{Euthanasia of Shelter Animals}

All of the shelters in this study, apart from the Dog Pound, claim to be "no-kill”. Of course, in practice, animals that are injured, aggressive, or animals with behavioural problems are often euthanized. Shelter workers use the more gentle term "put to sleep”.

The least pleasant aspect is when you know an animal is so badly injured that you know you'll take it in and it's going to be put to sleep. I tend to talk to them or put music on. What you tend to remember most is not what you see but what you smell. It's the smells you remember. You know, if an animal's got gangrene, if it's got mange or some form of skin problem, that gives off a certain smell and it gets into your head. A lot of times if it's gangrene the chances of the poor thing surviving are minimal. It's even more harrowing when they have to shoot them ... watching the animal be shot (Interview with Nick, $14^{\text {th }}$ January, 2014).

Parovirus is a big problem in dog shelters. It can be brought on, or aggravated by stress and in puppies, almost always fatal, as is canine hepatitis. This proves very difficult for shelter staff. Peer support is very important at those times (Interview with Mike, $18^{\text {th }}$ February, 2014).

For one Pound employee, euthanasia is the worst part of her job, though she accepts its inevitability, given all the unwanted dogs, and the public's reluctance to spay and neuter companion animals. She observes sadly that sometimes the healthy ones have to be "put to sleep” (PTS) or the "ugly ones" that nobody wants (Interview with Anna, $28^{\text {th }}$ November, 2014). Anna finds the public's negative attitude to euthanasia activities highly hypocritical, given that the public's refusal to spay and neuter pets prima facie causes the problem. Reeve and Rogelberg (2005) investigated the psychological ramifications of euthanasia-related work. Results indicate that 
euthanasia-related strain is prevalent among shelter workers and is associated with increased levels of job stress, somatic complaints and lower levels of job satisfaction (Reeve and Rogelberg, 2005). Only Anna (Interview with Anna, November $28^{\text {th }}$, 2014) routinely encounters euthanasia in her work as a canine carer in a Dog Pound. She expressed her relief that the "PTS day" is usually on her day off from work, and describes euthanasia as the worst part of the job. All the other shelters in the current study identify as "no-kill”. Of course, when full to capacity, transferring dogs to the Pound or being unable to admit dogs or cats is inevitable. Jean told me of one such “endpoint” (her terminology) in the course of her interview and she became visibly uncomfortable in the telling (Interview with Jean, $4^{\text {th }}$ February, 2014).

Arluke and Sanders' (1996) landmark ethnographic study of various zoocentric settings examines how shelter-workers engaged in euthanasia shore up the normative order by supplying “myths and techniques to assuage troubled feelings” (Arluke and Sanders, 1996: 82). Arluke (Arluke and Sanders, 1996) conducted ethnographic research over a seven-month period in a "kill-shelter" and directly observed the euthanizing of animals and the training of workers to perform this task. Based on his observations and 16 open-ended interviews, he concludes that shelter workers deal with their uncomfortable feelings through coming to see shelter animals as "virtual pets” - lying somewhere between the status of pet and object- by being compassionate and tender during euthanasia ("They get more love in the last few seconds than they ever did" in the words of one worker) and by displacing blame onto the owner-surrenderer. Finally, shelter workers try to perfect their "technique" so as to make death quick and painless for the animal (Arluke and Sanders, 1996: 82106). My 'no-kill' workers use similar techniques to manage their sorrows, and also report peer support and the 'love' they receive from the animals as significant mitigating factors.

Every (including CEOs, SNA, and vet) respondent cares for one or more companion animals, either horses, donkeys, cats or dogs and in the case of Lisa and Agata less common companion animals such as chinchillas or cockerels (Interviews, 2014). As companion animals' lifespans tend to be shorter than ours, their demise is an inevitable part of the human-animal relationship. 
Participants report the death of companion animals as "heart-breaking”. Often, these animals are buried in respondents' gardens, their graves marked with a dated headstone, a plant or perennial flowers (Interviews with Lisa, Des and Joan, 2014). While telling me about the demise of her brother George, Des cradled his cat Elsa in his arms and talked to her in my presence (Interview with Des, $15^{\text {th }}$ April 2014). This is arguably uncommon behaviour for a working-class Dublin man but I had become accustomed to such displays of male affection in the shelters. Animals can be used to 'do gender' (a man walking a pitbull to denote hetero-masculinity or a Chihuahua toted in a woman's handbag to denote femininity, for example) but in my shelters gender is completely minimised, although further research would be valuable to establish if this is true of shelters more broadly. The nature of the ethic of care which pervades the shelter allows those who work within it to transcend gender norms and stereotypes.

If cruelty and death are sources of grief for my respondents, other elements inherent in shelter work are sources of frustration and annoyance. I expected the "dirty work" of animal care (Sanders, 2010) to figure in these accounts but it was rarely mentioned, nor were zoonotic diseases. Instead, chief amongst the travails is the need to deal with other people who do not share the shelter workers' intersubjectively constructed view of the importance of clemency towards (companion) animals.

\subsection{Travails}

Many structural and social factors combine to stoke the dialectics of unease and frustration in my respondents. On the one hand, the public provide ballast to the shelter workers in the shape of donations, fostering, volunteering inter alia. On the other hand, dealing with the public and other wider constraints frequently cause difficulties for my participants.

\subsubsection{Dealing with the Public: Direct Interaction}

Back inside the house Jean tells me a story about a member of the public who rang to say she had 6 kittens and that it would cost too much money to put them to sleep. So she brought them to Jean's shelter, and explained that she had to go on a pilgrimage to Lough Derg (a lake in County Donegal, best known as a site of religious 
pilgrimage on the lake's Station Island). Jean told the woman that she found her attitude somewhat hypocritical and tells me: "She told me she reared 8 children. Well, I hope you done a good job on them, I said” (Field notes, cat shelter, November $\left.19^{\text {th }}, 2013\right)$.

Shelter workers must deal as much, if not more, with people than with the animals in their care. Members of the public admit animals, surrender animals, make complaints about animal cruelty, and perpetrate cruelty themselves. Equally, members of the public adopt or foster animals, volunteer at shelters, make donations, fundraise, and offer moral support and bear witness to the work done at the shelter. Nick memorably refers to this phenomenon as "the good, the bad and the ugly". He further observes that his work is akin to social work as sometimes mental or addiction issues can be at play and outside agencies need to be contacted. For example, a person with a drink problem might adore an animal but not be able to look after it properly because the time of the day is blurred (Interview with Nick, $14^{\text {th }}$ January, 2014).

Further, the high expectations of the public are a common source of irritation for my respondents. For example, people expect shelters to collect stray cat colonies from their garden which is outside the bounds of possibility for already overstretched shelters.

Nick partially attributes these expectations to the proliferation of animal rescue programmes on television:

Then there's the programmes, the animals A\&Es, they help but they also put more pressure on us because people see them and see soundbites and things that may have taken the rescue organisation 3 or 4 weeks to deal with, in the programme the problem is fixed in 15 seconds! (laughs) (Interview with Nick, 14 ${ }^{\text {th }}$ January, 2014).

Sometimes there are calls about dogs not being walked or that they are overweight. "So the dog is fat, so is half the country, what can I do about it?" laughs Nick (Fieldnotes, August $2^{\text {nd }}, 2012$ ). These are commonly referred to as "bullshit calls" and often they occur because of grudges between neighbours, according to many of my participants. On one occasion when I accompany Nick during his working day, we drive over $20 \mathrm{~km}$ to visit a home about which a complaint had been made. The dog in question was perfectly well-fed, had a kennel in the garden, and was in fact 
sitting on the sofa when we arrived (Fieldnotes from day "on the job” with Nick, August $\left.2^{\text {nd }}, 2012\right)$.

Two public attitudes which are frequently cited as sources of frustration for shelter workers are attitudes to surrendering animals and towards neutering and spaying companion animals.

Animal surrenderers are sometimes described as "looking for an easy way out” and as not having "genuine” reasons for surrendering the animal to a shelter. Invalid reasons for surrendering described by my respondents include: moving home, pregnancy, the dog becoming too large or boisterous, moulting hair, or unforgettably "going to the toilet in the garden”. Genuine reasons include: animal-related allergies, owner emigration or the dog snapping at children. Even in the latter case, respondents express scepticism as animals are frequently pronounced to be "for life" and dog snapping is seen as a correctable problem, attributable to lack of training. Likewise, a lack of funds to feed a companion animal tends to be viewed with scepticism, as this excerpt from an interview with Molly suggests:

The minute the recession hit we saw all the big breeds first. We were getting St. Bernards..like you can get a $15 \mathrm{Kg}$ bag of feed for 12 euro and that'll last you a month minimum. So I can't understand when people say they can't afford it. But then you had a lot of people emigrating because of the recession and that can be genuine. Personally, if I was emigrating I'd bring them with me. If you're an animal person, you're an animal person (Interview with Molly, $22^{\text {nd }}$ July, 2014).

The difficulty in persuading the public to neuter or spay companion animals is a major source of annoyance for all respondents. This negligence is being alleviated due to the educational efforts of shelters, SPCAs and Dogs Trust all of which undertake school awareness campaigns. Many members of the public still fail to recognise the importance of neutering either due to inertia, unwillingness to incur veterinary fees, or the belief that it is 'cruel' not to allow a dog or cat produce a litter (Interviews, 2014).

Hamilton and Taylor (2013: 107) note with irony that it is perhaps the "undesirable humans who constitute the dirty work" for shelter employees and volunteers. Although all shelter workers in the current study share a common worldview in 
regard to animals, relations between shelters are not always harmonious. I attribute this phenomenon partly to the competition for public support and donations, and partly because of differences of opinion about what constitutes an acceptable standard of living for rescued animals.

\subsubsection{Dealing with Staff and with Other Shelters}

As I observe throughout this thesis, people do not tend to enter or stay in shelter work out of pecuniary or career enhancement motives, rather because of a passion for animals and for the affective relationships from which they themselves benefit. This can make them excellent at dealing with animals and less proficient at dealing with the public (Interview with Mike, $18^{\text {th }}$ February, 2014).

Inter-shelter rivalry is also sometimes evident on Facebook shelter sites (Social Media, Appendix F). One Kerry-based shelter has even attracted an unwelcome Facebook page devoted to denigrating its rescue efforts. It is difficult to ascertain whether the stories about overcrowding and poor treatment of animals are 'true' or whether the animosity stems from professional jealousy (the shelter in question is successful in attracting donations and has over 97,000 Facebook 'likes'). This rivalry may on the one hand stem from the need to compete for scarce resources in the form of donations, and on the other by scepticism about another shelter's motivation to do this work. For example, Nick compared some shelters to hoarders as it would not be possible to keep as many animals in one's home as it is in the shelter (Interview with Nick, $14^{\text {th }}$ January, 2014). Jean, on the other hand, is scathing about SPCAs without holding facilities: she feels that the money such organisations deploy on offices and cars should go to animals in need (Fieldnotes, Shelter B, July $30^{\text {th }}$, 2013).

This rivalry can sometimes result in quite personal comments being made on digital media as Mike observes:

Some people involved in animal welfare can let their emotions get the better of them. Digital media is a very important part of our work, in terms of fundraising and raising profile. The downside is.. people will say things that they would never dream of verbalising or even putting in a normal email. This veneer of anonymity gives people carte blanche in certain ways. So that is tough, and it's tough for our digital people next door (Interview with Mike, $18^{\text {th }}$ February, 2014). 
Just as other people's actions and expectations represent a major difficulty for shelters, so too does the constant financial struggle in which all respondents are engaged. The moral economy has dark sides.

\subsubsection{Financial Strains and Constraints}

As described in Chapter 4, most but not all shelters are recipients of Department of Food, Agriculture and Marine (DAFM) grants. These grants tend to be relatively small and must be heavily supplemented with other fundraising activities and by volunteer and fosterer support. Effectively, as well as caring for sick, injured and abandoned animals shelters must constantly fundraise. This they do through special events such as pub quizzes, charity balls, sponsored runs, direct debit donations (the latter are particularly valued as they represent a predictable income supply), court orders to donate to animal charities, and legacies (Interviews, 2014). This pressure is evident in Jen's comments:

We get 28 thousand in January, the annual grant, and our running costs are 245 thousand, so you do the maths! Put it this way, by the middle of January, I had it spent, the vet, the food bill, the vehicle repairs, so nobody's out there paying us to do it. There are some groups out there getting 150 thousand that don't do anything, but there you go, who are we to complain and then we'd lose our money. It was a raise, in previous years, we only got 20 thousand (Interview with Jen, $4^{\text {th }}$ July, 2014).

It is important to note that Jen states that making complaints would be potentially injurious to the continued receipt of DAFM ex gratia grants. This highlights the dialectical tensions faced by shelters in their experience of the moral economy. Only one (large) organisation in the current study elected not to apply for DAFM grants. The CEO explained to me that receiving a grant might impinge on the organisation's ability to lobby institutions such as the Greyhound Board (Bord na gCon) and that his organisation's own fundraising efforts were sufficient so as not to warrant seeking State assistance. For the other shelters in the current study, financial worries pervade their working lives. They cherish an ideal and find it impossible to live up to it; the animals keep coming and the veterinary bills mounting. The donkey sanctuary in the current study (which had 29 donkeys in September 2015) reports on its website the high costs of caring for these animals: annual flu and tetanus vaccinations are 30 euros per donkey, hoof care every eight weeks 25 euros per 
donkey, and worming every eight weeks 58 euros per donkey. These financial and time constraints also have implications for the personal lives of my respondents, of course.

\subsubsection{Lack of Personal Time and Money}

Shelter workers (and volunteers) sacrifice personal time in the service of animals. Their pay (even in larger shelters this is true for the animal care occupations) is low usually minimum wage which is 9.15 euro per hour (Citizens Information, 2016). As noted in Chapter 5, most (female) respondents have partners who are engaged in more lucrative occupations. Animal rescue work encroaches upon my respondents' personal time as the admission of animals is unpredictable. For the same reason, shelter workers rarely take holidays lasting more than a few days (Interviews, 2014). Nonetheless, this does not emerge as a major negative factor for any respondent. Suzanne is typical in her seemingly cheerful acceptance of the nature of shelter work:

It can be anti-social, you know the hours. It's not 9 to 5 . If a donkey has colic or is in any way poorly you're up all night and when you finish in the evening at 7 or 8 you are wrecked and exhausted and you don't necessarily want to get ready and go out and meet people and be sociable. But I'm not complaining (Interview with Suzanne, $14^{\text {th }}$ June, 2014).

The inroads into personal time are particularly severe when my participants are caring for newborn animals, as the following excerpt from fieldnotes reveals:

Jean feeds three, purring 5-day old kittens who are in a cat carrier on a heated blanket. She explains that they have to be fed every three hours, even at night. The kittens are about the size of a pack of cigarettes, and they are all ginger in colour. Jean carefully cleans their bottoms with a damp towel after the feed, as the mother cat would do with her tongue. Kittens cannot do this themselves until they are 9 or 10 days old. She tells me that their mother got killed by sitting in a car engine (cats often do so, as they like the residual heat). The driver heard the kittens and brought them to Jean (Fieldnotes, July $\left.30^{\text {th }}, 2013\right)$. 
There is no contradiction between loving animals and feeling burdened by this work, and many of my respondents freely admit that the terms and conditions are onerous although they do not constitute a 'deal-breaker' for any of my respondents at the time of writing in August 2016.

Animal work is betimes precarious, not just because one could be bitten, but because of zoonotic diseases. I got a tetanus vaccination before entering the field in 2012 and was vigilant about hand-washing after feeding or walking the animals in the course of field work. Such concerns were barely mentioned by my respondents.

\subsubsection{Injury or Zoonotic Diseases}

Animals can transmit various diseases to humans such as mange, ringworm or parasites such as fleas and lice. To my surprise, few respondents mentioned this phenomenon as a downside of working with animals. When directly asked, Sally's response was indicative of other respondents' comments in this regard:

I've had mange, it's like scabies in people, it's a tiny little mite that lives under the skin but it can only live in people for 24 hours. You just get a rash, it's itchy like..I've had ringworm, I suppose like anything I've ever contracted from the dogs it's been there for a week or whatever but em..it would never put me off. Like people come in and they see a mangy dog, and they're like Oh God but I'd be in there hugging the dog because it needs a bit of TLC like (Interview with Sally, $4^{\text {th }}$ July, 2014).

Cat litter trays smell unpleasant and there is a remote possibility of contracting toxoplasmosis, a parasitic disease, from cat excrement. I offer to help clean the litter trays and Jean says: "I'd feel terrible for you to do that". I reply that it is nothing I did not do for my own (now deceased) cat for 13 years, and Jean relents reluctantly (Fieldnotes, July $30^{\text {th }}$, 2013).

I felt somewhat chastened by my respondents' nonchalance in the face of the possibility of contracting unpleasant medical conditions. Ultimately, with repeated field visits my own concerns faded to the back of my mind. My respondents' attitudes to non-companion animals were oftentimes conflicted. 


\subsubsection{Reconciling Contradictory Positions towards Animals}

Although I seldom asked any respondent directly about their dietary preferences, in the main they seemed to assume that as my study concerned HAI, that it was a case for animals. Jean asked me directly whether I ate animals (Field notes, November $19^{\text {th }}$ 2013). This was an assumption I found telling. For the wider public the deprivation of contact with other animals (apart from 'pets' who share our homes with us) and the 'hidden' business model of factory farming arguably goes some way to explain indifference towards factory farming methods. Indeed Foar (2009: 59) points out that the term 'factory farming' will probably soon fall out of use for the dearth of any other kind of farm with which to compare it. People divorced from the day-to-day reality of being with animals can easily dissociate from the source of meat on their plates. The veterinary surgeon, John, whose work exposes him to the killing of food animals, stated that he could never eat a horse for he loves them. For shelter workers who often take in pigs, lambs or injured birds, loving some animals while eating others is a much more complex issue. This is why I suspect many respondents seemed pre-sensitised to questions of diet (Interviews, 2014).

Two respondents (Maura and Agata) are vegan, which means that they eat or wear no animal produce. Agata is a more rigid adherent to veganism, while Maura explains that she sometimes wears leather shoes as vegan shoes are expensive and fall to pieces quickly. Suzanne has been a vegetarian since childhood, although she sometimes eats fish which would not adhere to the Vegetarian Society of Ireland's guidelines for membership (Interviews, 2014).

For other respondents, talking about 'food animals' was a more conflicted terrain. Fran (Interview, $4^{\text {th }}$ March, 2014) asked me what would happen to all the cows in the fields if everybody became vegetarian (see Engster, 2006 for a discussion of whether it is more caring to give 'food' animals a good life up to the moment of slaughter, or desist from bringing them into existence at all for that purpose).

Jean recalls how as a child her named and beloved farm animals would sometimes disappear and she would be very upset although these occurrences were never discussed (Interview with Jean, $4^{\text {th }}$ February, 2014). Emma doesn't like to “think about it” either and also seems conflicted: 
Em..em.. I don't really think about it. Like I eat meat but I wouldn't watch any of that, and people say would I get a few pigs up there but I couldn't kill my own pigs, like they'd have a name. Even if I had chickens up there I wouldn't be able to...end of the earth I'd go to for any animal..(Interview with Emma, $5^{\text {th }}$ February, 2014).

Many respondents believe that names make a difference and that you could never “name anything you're going to eat” (Interview with Lisa,11 ${ }^{\text {th }}$ February, 2014).

Some respondents use humour to apparently lessen the tension they experience when talking about animals other than companion animals. For example, Mike lightens his apparent slight discomfort when I asked about animals besides dogs:

All animals are equal but some are more equal than others? (laughs). To be totally honest, I don't get overly hung up on it. I take a very pragmatic view that as long as these animals are farmed to the highest welfare standards that has got to be the priority. Most people in animal welfare would probably think along those lines. But there are people who..a very funny example of that, I'm going off on a tangent now. I was at an AGM in Brussels last year, and at the buffet dinner, I just couldn't stop giggling..they had listed: "Vegan, Vegetarian, Normal" (both laugh) (Interview with Mike, $18^{\text {th }}$ February, 2014).

Maria, my participant who identifies as being on the Autist/Aspergers spectrum, was of particular interest in this regard because she believes animals make it possible for her to be agentic in the world (see Chapter 5). She explained that she tried to eat a vegan diet but found it too limiting in terms of the foods allowed. Her sister pointed out the dichotomy between loving and eating animals on one occasion when they were eating a burger in a fast-food chain and Maria told her it was "a bit too late to save this cow”. She does however make an effort to buy free-range meat and eggs: "Like I know they die in the end but at least they have had a better life" (Interview with Maria, $9^{\text {th }}$ July, 2014). Maria's attitudes mirror those of the majority of respondents. It may be that children have not fully learned the dominant scripts towards food animals. Wilkie (2010) relates an anecdote in which one of her (hobby farmer) respondent's children persisted in asking which pig they were eating (the pig had been named Ophelia) and finally asking which leg, at which point her mother abandoned her lunch entirely (Wilkie, 2010: 156). Many of my respondents, wisely it seems, say that they could never eat an animal they had named (Interviews, 2014). 
These conversations mirror deeply conflicted societal attitudes towards animals; where do we draw the phylogenetic line? I have not eaten red meat or chicken for almost 30 years but I do eat shellfish and very occasionally non-farmed fish. While I have no doubt that pigs and chickens endure mental and physical suffering under conditions of $21^{\text {st }}$ century intensive farming, I do not believe that this holds true for say, prawns. That is where I have drawn the 'sociozoologic' (Arluke and Sanders, 1996: 170) line in the sand, and it is as arbitrary a line as any other. I also eat free range eggs and dairy produce, a practice many vegans see as deeply exploitative of animals, citing for example, the practice of removing day-old calves from their mothers so that mother-milk may be sold and consumed by humans. Like Maria, I find adopting a vegan diet an extremely difficult proposition. In my own home, I often prepare vegan meals but outside of home, it is very difficult to find vegan options. I was invited for scones, lunch and dinner by some respondents and had I been vegan, I could not have eaten what they kindly prepared for me. Nonetheless, my own position is that veganism is the ethically most consistent diet, and not only out of consideration for animals but for ecological reasons; it is indisputable that intensive farming is deeply connected to climate change (Wilkie, 2010: 11), a situation likely to become more critical as India and China grow more affluent.

Yet my respondents are unanimous in their condemnation of individual acts of cruelty (usually by unknown perpetrators). Perhaps it is easier to vilify faraway evils than it is to condemn structural systemic violence. The killing of Cecil, one Zimbaweean lion, provoked widespread public outrage (The Guardian, 2015) which is sociologically curious given that approximately 9 billion land animals are killed each year in North America (Humane Org, July 2015).

At first blush it seems not entirely credible that people would choose to remain in an occupation fraught with such emotional demands and interpersonal and financial difficulties. My respondents manage their sorrows and travails interactionally and emotionally however, and they remain. They derive solace from public and peer support and joy from the HAR and from the 'success' stories when animals are rehomed. An analysis of the data sheds light on the consolations and deeper joys that make staying possible and leaving very difficult. 


\subsection{Consolations}

SPCAs and animal shelters arose as social institutions; they constrain what might otherwise be nefarious attitudes towards animals. By situating the employment relationship within a more social and multidimensional context, a moral economy framework makes it possible to grasp the apparent contradictions inherent in shelter work. Polanyi's (1957) thesis is that the economy is embedded in social institutions and cannot function as an autonomous self-regulating market. “To separate labor from other activities of life and to subject it to the laws of the market was to annihilate all organic forms of existence and to replace them by a different type of organisation; an atomistic and individualistic one” (Polanyi, 1957: 171).

Further, when unregulated it tends to destroy man and nature. I contend that shelter work intervenes into forces jeopardizing "man and nature”. Polanyi (1957) and Thompson (1971) approach economics in a similar way; they are opposed to the ideology of free market capitalism which sees the economy as functioning independently of people's affective relationships, values and needs. According to neo-liberal ideology, shelter workers are not rational actors because they are not acting out of economic interest. Yet they themselves define their institutions as embodiments of meaning and purpose (Interviews, 2014 and Field notes 2012-2014). My respondents are not immune to market concerns of course; the need to make money (and raise sufficient funds to keep the shelter gates open) is pressing. Partners engaged in more lucrative work, jobseekers' assistance, public financial support, other commercial activities they undertake, and a general indifference to earning a lot of money all contrive to enable the moral economy in which shelter workers operate. Interspecies connectivity provides an opportunity for my participants to flourish and at the same time to feel that their work matters to wider society. Through the lens of a processual moral economy their pathways, individually and collectively, have been part of the ebb and flow of hegemony, resistance, stability, and change overtime. Many of my respondents allude to the "one big family in here”, which is not a common refrain in academia, for example. Although organisational theory may claim otherwise, employee commitment to managerial goals is not widespread in industry either, in my opinion. Shelter workers gravitate towards one another for support, validation, and collective identity. My respondents' 
belief that they are not only helping animals but also other people constitutes a kind of consolation for the sorrows and difficulties they face in the course of their working lives.

\subsubsection{Moral Economy: Helping animals, Helping people}

What is pronounced among my interviewees is the importance they attach to living according to their values. Their value-commitment to animals is prioritised and nurtured. They also believe that their work assists vulnerable people, by reuniting them with lost animals or by offering them the opportunity to know the love of an adopted companion animal.

\subsubsection{Helping animals}

Helping animals is a source of consolation and joy to all participants. It appears to bolster many participants' identity as a 'good' person. Additionally there are relationship rewards for the shelter workers; animals are not wholly non-agentic. Animals can and do show their appreciation for human kindness, particularly if they have not known kindness in their pre-shelter existence. In Emma’s opinion:"The lovely ones would be all up in your face, you know rubbing against you. I think animals just know if you like animals, you know. Like they know if you're a good person or not” (Interview with Emma, $5^{\text {th }}$ February, 2014). The implication here is that one cannot be a 'good' person unless one likes, and is liked by animals. The second assumption is that animals can make moral judgements which are more reliable than human judgements. I understand this reasoning - dogs, for example, are entirely truthful in their responses, in my experience - they possess no simian ability to dissimulate.

For Joan, it is important that animals feel they are loved, even when they are close to death:

I remember feeling at the time, he's not going to suffer, it's over for him now and he obviously knew he would be looked after if he came to my house. So like the way I look at it, is they get their last night in comfort, and they get fed and they get cuddled so they go out thinking somebody cared about them (Interview with Joan, 25 February, 2014). 
Maria, like most respondents, takes solace and joy from effecting positive change in the lives of the shelter animals. She lights up when describing how seeing new owners of shelter animals post stories and photographs "makes all the bad ones worth it”. For her this is the best part of the job (Interview with Maria, $9^{\text {th }}$ July, 2014).

On the other hand, a majority of respondents express frustration that they cannot do more to help animals because of shelter space, time and financial constraints, and some admit to feeling helpless in the face of the scale of abandoned and abused animals. As solace many speak to the importance of saving each individual animal.

An illustrative parable is often invoked on shelter digital media and in newsletters. This depicts a wise man telling a young man about the fruitless nature of the latter's effort to throw starfish into the ocean, given the miles of shoreline and thousands of starfish. The young man throws another starfish into the ocean and replies: "It made

a difference to that one” (Social Media, Appendix F). Matthew Scully (2002: 395) employs a similar rhetoric to dignify the life of a man whose mission in life is to protect sea-turtle eggs on the Western coast of Sri Lanka : “ This man can know that in a brutal and vengeful world, he, at least, has taken the side of life. And long after he is gone the seas will be filled with silent witnesses to his kindness” (Scully, 2002: 395).

The significance of helping individual animals is a constant theme in my respondents' explanation of what consoles them in their work. Even if my respondents cannot effect systemic or structural change in a wider societal system (even in the case of ACS, systemic change was not achieved, see Chapter 4), they can try to help every individual animal who comes into their care to find a "forever home”. For most of my respondents, their work extends beyond the realm of helping animals and into the domain of helping other people.

\subsubsection{Helping people}

The belief that their work helps other people, especially children and the elderly is extremely common among my respondents. This holds true for all respondents, including my veterinary surgeon. “Animals are important in people’s lives, they're very important in people's lives. For children especially, because kids can learn loss, 
care, everything that matters. And they don't come with batteries, they're alive” (Interview with Nick, $14^{\text {th }}$ January, 2014).

Lots of people who live on their own will tell you that. 'Cos lots of people have a companion in their lives and when that door closes it's only them and their cat or their dog. And that is so important to a lot of people. Particularly older people, say the people who are retired. The children are gone. The husband or wife has passed away..whatever. And they'll tell you that's their other heartbeat in the house. And it gets them up in the morning, and it gives them a reason to keep going (Interview with Jean, $4^{\text {th }}$ February, 2014).

Jean's account of the psychosocial benefits of animals for the elderly has similarities with Irvine's (2013) finding that their companion animals gave homeless people a reason to continue living; in some cases her participants considered their animals to be life-savers. Elderly people who live alone and homeless people could be considered as among the most vulnerable amongst us and animals are often perceived by them as loved and loving companions. These accounts underline the need to revisit the question of the meaning of animals.

Jean also tells a story about the kittens she rehomed to a bereaved family in which two young girls had lost their mother. Their father rang after a few days to tell Jean that it was the first time his younger daughter had smiled in six months (Interview with Jean, $4^{\text {th }}$ February, 2014). Shelter work thus goes beyond an economic model of work, this toil would seem to be part of something larger, or "part of a wider project of significance” (Giordan, 2007). As noted in Chapter 5 most of my participants did not feel 'called' to do shelter work. Nonetheless their narratives are exemplars of doing fulfilling, socially useful work, and therefore I contend that vocation (Wrzesniewski et al, 2007) is part of the processual nature of staying in this occupation. Shelter work involves engaging in work that serves animals, society and self and represents the intersection between the talents and interests of my participants with the needs of animals and society and as such is part of the moral economy. According to Polanyi, the moral economy functions as a safeguard against man destroying his surroundings; society takes measures to protect itself (Polanyi, 1957: 171). Shelter work is of course recognised and appreciated by many members of the public (Facebook Analysis, section 6.8.). 


\subsubsection{Public Recognition}

Ironically, it's people that give you the lift when they may knock on the window of the van, which somebody did on Saturday, and hand you 20 euros and say, “Thanks, you're doing a great job”. And that gives you..that thanks. When somebody does that to you, you kind of say: now I know why I do it. It's a form of recognition. It doesn't happen very often but when it does, it does give you a lift (Interview with Nick, $14^{\text {th }}$ January, 2014).

Nick's words echo human flourishing seen through a moral economy lens as defined by Bolton et al (2012). Moral economy, these scholars contend, views employment as a "relationship rooted in a web of social dependencies, and considers that 'thick' relations produce valuable ethical surpluses that represent mutuality and human flourishing”. Although this perspective was not developed with animals in mind as constituting part of those 'thick' relations, it reminds us that human wellbeing is the most central purpose of social and economic life (Bolton et al 2012). Shelters are not atomistic, bounded or isolated groups. They are intertwined and interconnected with other members of society.

Sally was nominated for, and subsequently won a "Animal Charity Employee of the Year” award and described receiving a trophy and recognition for her work as “amazing” (Interview with Sally, $4^{\text {th }}$ July, 2014). The process of social construction and maintenance of the shelter includes such public affirmation as the workers proceed through their working lives. Helping animals is thus a kind of communion with other people and with one’s future legacy. As Des (Interviews, 2014) told me, "We are all a chain of creatures on this earth".

Another crucial strand in the web of social dependencies for shelter workers is the financial and other help received from their public supporters.

\subsubsection{Public Help}

If public recognition is part of the stuff of flourishing as Bolton et al (2012) contend, then help from the public is the lifeblood of my participant shelters. The DAFM annual grants to shelters are welcome, but wholly insufficient to run these organisations. This help comes in many forms: veterinary surgeons are widely praised by shelter workers for their understanding and willingness to allow bills to 
mount. Members of the public help shelters by acting as fosterers, volunteers, fundraisers, by giving donations or by leaving bequests (Interviews, 2014).

Volunteers draw particular praise from all my participants. Mike’s comments are representative:

This is a labour-intensive job. I sometimes worry that we can't give some of the dogs in our care the amount of time that they require. That's where our volunteers come in, you know we've got a very good cohort of volunteers and even a volunteer to sit in a kennel for an hour and play with that dog, that's a huge help (Interview with Mike, $18^{\text {th }}$ February, 2014).

While the support of "the crowd" constitutes solace for my participants, the joy they describe experiencing in their work comes from three principle sources: the interspecies relationships, the belief that they are doing the 'right thing', and the sanctuary they not only provide, but also receive.

\subsection{Joys: Animals, Moral Economy, Sanctuary}

The consolations my respondents describe in the previous section may make the difficulties of their job bearable, but consolations are not the same as joys. Consolation implies a kind of recompense for feeling sad about other issues; one does not have to need recompense in order to experience joy. Chief among my respondents' joys is the love they give and receive from the animals in their care.

\subsubsection{HAR rewards: For the Love of Animals}

As I documented in Chapter 2, human beings often reap psychosocial benefits from their relationships with animals (Sanders, 2003; Barlow et al, 2012; Pedersen et al, 2012). Unsurprisingly, shelter workers report feeling joy about interactions with the animals in their care; in their case, work and joy are therefore inextricably linked (Interviews, 2014). These rewards are expressed poignantly by Jon (excerpt):

I'm sure you've heard that dozens of times but, as anybody who's been in that relationship can tell you, it is the unconditional love that is the nice thing about having a dog. Who was it that said, you want to become the person that your dog thinks you are (laughs). It kind of pushes you to become a better person. As I told you, my mother was very strict, black and white, and I tend to be that way sometimes. But uh, instead of me being a bit of a dick, I think it 
helps me be a better person, it's hugely stress-relieving, and it helps our own soul, in some way (Interview with Jon, $7^{\text {th }}$ July, 2014).

Nick also experiences joy in his work and feels empathy with his colleagues in other organisations:

I think anything dealing with wild animals I'd class as a privilege because it's not the norm. Even in rescue it's not the norm. We get badgers, we get otters, we get hawks...It's an honour when it's a wild animal. But you know in general, you get joy out of this work. I know your Bella [my 8 year old Border Collie] was from the Pound; that would have been a good day at the office for them, you know what I mean? (Interview with Nick, $14^{\text {th }}$ January, 2014).

Towards the end of a volunteer orientation which I attended in 2012, the presenter speaks briefly but emotionally about her experiences working in the shelter for the previous five years. She says: "This is THE most fantastic place to be involved with. I have seen some atrocious cruelty but I have seen how these dogs, after four or five months with us, skip out the door to their new homes, and that is a wonderful feeling”(Field notes from Volunteer Orientation, $22^{\text {nd }}$ September 2012).

On the day of my visit to one shelter on June $15^{\text {th }} 2012$ it was the occasion of the former CEO's retirement party and we had a long, informal conversation in the course of which he told me that his retirement plans included "driving Miss Daisy" (his wife) and that he felt "people like me would be reading about people like him" in the archives in the centuries to come: “And they can never take that away”.

On a separate occasion, Jen explains that her 14-year-old dog is suffering from a condition called megaesophagus, where insufficient muscular contractions lead to regurgitation. This can be fatal because the dog can inhale during an episode of regurgitation, bringing food into the lungs. So Jen holds the little dog upright for 10 minutes after he eats his bowl of food. He is quite calm during this procedure. I feel almost as if I am intruding upon a private moment. Jen's beautiful silver-coated greyhound sits beside me and places his head solemnly on my lap. (Fieldnotes from Shelter H, August $2^{\text {nd }}, 2014$ ).

On another occasion, Jean introduces me to a little lamb in a pen in her back garden. Jean rubs noses with the lamb (who was one of triplets and who was not expected to survive, so Jean "gave her a chance”) who reciprocates, bleating loudly. I count 52 
animals in the shelter, mostly cats, 4 dogs, and a cockatiel. The premises is spotlessly clean (Fieldnotes, Shelter B, August $12^{\text {th }}, 2013$ ).

These joyful relationship rewards help my respondents in their endeavour to manage their sorrows emotionally and to bear the many travails which they face in the course of their work. The scales in the 'trade-off' between the 'good' and the 'bad' sides of their work fall in the direction of the former. All of my respondents make statements such as: "The ones you save make it all worthwhile".

Over the course of more than four years spent in shelters during this study, I bore witness to the joy that contact with the animals brings employees and volunteers. Notwithstanding the frail or injured state of many of the animals admitted, all is not doom and gloom in the shelters. For the animal-lover, it is difficult not to experience delight in the present of wriggling, squealing puppies and kittens, for example. Animals do not speak, but they certainly communicate. Joyful mutual human-animal interactions are commonly observable in the shelters, and help to orient the workplace culture and keep my respondents coming back: “I can’t wait to get into work on Monday to see who has come in over the weekend” (Interview with Colm, $2^{\text {nd }}$ October 2015). Indeed I experienced joy in the presence of the animals myself. My own dogs, used to human affection as the normal course of affairs, do not respond with the same (what looks a lot like) gratitude at being stroked or taken for a walk as do kennelled shelter dogs. For the latter, a brief respite from the monotony of the kennel appears to be a source of boundless joy; they often jump up and lick their 'saviour's' face or skip out of their kennel. Experiencing such a dog's delight is very gratifying and I do not have to take my participants at their word.

\subsubsection{Animal Shelter Work: Moral Work?}

I couldn't imagine not working and I like the charity sector. I think we're making a difference, and I know that sounds dreadfully clichéd but all my family are in business, you know. And they're far wealthier than I am (laughs) and I work equally as hard as most of them, but I think they're far less fulfilled than I am in the work that I do. The bottom line, the dollar is God, you know! My son, I've got one - year old - loves the fact that Dad works at X; it's cool for school (laughs) (Interview with Mike, $18^{\text {th }}$ February, 2014). 
Mike's comments are echoed by my other respondents who believe that the way society treats animals is informative about that society. Often my participants say that they feel they are 'good people' because of the work that they do: "I'm spiritual more than religious but I'm just a good person” (Interview with Jean, $4^{\text {th }}$ February, 2014). After false starts in other occupations, my interviewees have found an occupation in which they wish to invest themselves and this comes across strikingly in interviews.

As has been discussed, animal shelter work offers little in the way of pecuniary rewards for the care workers frequently entails dirty work, and abandoned animals have little or no economic value: "People would do it for nothing, if they had to, like me. They don't do it for thanks, or they don't do it for money, or they don't do it for glory. And certainly not for the holidays or benefits (laughs)..”(Interview with Jen, $4^{\text {th }}$ July, 2014).

None of these factors is concomitant with a rationalized view of people, or with utility logic. Polanyi’s (1957) central concept is "embeddedness", which pinpoints that economic life is enmeshed in social institutions. This would situate shelter work in a space closer to a pre-modern Gemeinschaft in which the economic is embedded in the social and serves human needs, rather than to the dominant capitalistic Gesellschaft model (Bolten and Lasser, 2013) in which economic transactions are disembedded from the social and labour and land commodified. Ferdinand Tönnies’ (quoted in Jackson and Carter (2007): 184) comparative concepts of the Gemeinschaft and the Gesellschaft characterise the basic principles of interrelationships. The Gemeinschaft is characterised by community, interrelationships based on human community, and mutual exchange. The Gesellschaft is characterised by large-scale organizations, contractual and impersonal relationships, instrumentality and exchange mediated by money. The desire for the Gemeinschaft is visible in the world of the shelter where the work is produced and reproduced as an ongoing dignified moral choice.

According to Mizzoni (2004) if we look beyond an economic model of the nature of work, and draw on non-economic traditions, then our toil may become part of something larger than private. The majority of my respondents did not see their 
original choice to enter shelter work as a 'calling'; synchronicities or changes in life circumstances, as well as disaffection with alternative workplaces constituted more significant pathways to entry. Nonetheless, all of my respondents all describe shelter work as ‘work that matters' or 'makes a difference', even if they did not feel called.

Further, it is difficult to reconcile my ethnographic findings with the notion of shelter work as 'just a job’ or as offering opportunities for advancement. Shelter work involves engaging in work that serves animals, society, and self and represents the intersection between the talents and interests of my participants with the needs of animals and society, and as such is part of the moral economy. Respondents claim to be "making a difference" and saving lives and often describe their work as a privilege without which the world would be "a sadder place" (Interview with Des, $15^{\text {th }}$ April, 2014).

It is striking how all of my study participants compare shelter work favourably to other jobs they have held in the for-profit sector. Obviously, my respondents have chosen to remain in shelter work, so selection bias is an inevitable limitation of any conclusions drawn in these pages. However, the Ariadne's thread of 'the best job' or 'the only job’ runs through my interviews and on-site observations, and strongly suggests that my respondents see their work in moral terms, if not explicitly as a vocation. They were willing to accept lower pay in order to leave jobs incommensurate with their values in preference for shelter jobs, which are. Archer (2007: 251) argues that it is "not possible to have a genuine concern and do nothing about it”. In that sense, shelter workers preserve old-style community because their work means that they are embedded in the social, and supported by some members of wider society. Further, the collegiality among shelter workers is clear; they reach out to each other and support each other (though not always intra-shelter) in a manner that would arguably be atypical in many for-profit organisations. Cooperation exists in market organisations also, of course, though not in the same form, I contend. I classify shelter work as inherently co-operative, because all the workers are deeply invested in the organisational goals; to rehabilitate and rehome the animals in their care. 
By situating the employment relationship within a more social and multidimensional context, a moral economy framework makes it possible to better grasp the apparent contradictions inherent in shelter work. Interspecies connectivity provides an opportunity for my participants to flourish and to feel that their work matters to wider society, as Nick describes:

You have to tend to be a social worker. There are mental issues, social issues that affect the animal. It's not necessarily the animal side you have to look at, you have to deal with, contact other agencies who deal with the problems you come across. And that in turn, helps the animal (Interview with Nick, $14^{\text {th }}$ January, 2014).

I do not propose that shelter work is 'moral' in any 'absolute' way - the validity or merits of any particular viewpoint cannot be determined absolutely, but only within a particular frame of reference - or that it represents an idealised pre-modern Gemeinschaft. However it exists as a moral economy in the sense that the social is not external but inherent in economic practices. Shelter work is deeply embedded in society - albeit arguably in a world of its own to which relatively few members of the public are privy - and meets human (and animal) needs, and is viewed by incumbents and by a wide section of the public (even the State supports the shelters, as documented in Chapter 4) as a moral space which is connected to their values, aspirations, and mores. All my respondents compared shelter work favourably with other jobs they had held in offices, the Civil Service, factories. Their labour in the shelters forms part of life for my respondents, indeed is indistinguishable from their lives. Their employment is less about financial gain (non-extant in the case of volunteers) than about deeper ethical concerns. The rituals of meaning-making in shelters - the constant reinforcement of the value of animals, sharing and reproduction of this conviction on social media, and belonging to a social and occupational group of like-minded individuals - are deployed to help my respondents make sense of their common purpose. The gentle manner in which my respondents interacted with and referred to the animals in their care was a constant reminder of their empathy and respect for their unique, individual animal selves (Participation Observation, 2014). The presence of the animals is central to my respondents' collective acts of meaning-making.

Though immersed in the traditions of a particular social order my respondents can find an alternative experience of the economy, one in which they can and do flourish. 
Things are achieved collectively in the shelters, purposes are pursued. But this coherence is not a reflection of an external, given reality, rather it derives from an ideology which elevates stray, abandoned, injured animals to importance. This is the rubric which shelter workers use to make sense of the world and which gives meaning to their toil.

Drawing on Polanyi (1957) and E.P. Thompson (1971) to describe the tension between a moral and human society and the economic practice of self-regulating markets, Bolton and Laaser (2013) argue that embedded sociality of the economy raises questions about how to support the human capacity to flourish; to create a space where people can use their skills and gain recognition for it.

Bolton et al (2012) propose the lens of moral economy as a useful ethical framework through which to assess HRM practice, with a particular focus on the strategic use of contingent work. They argue that a moral economy lens views employment as a "relationship rooted in a web of social dependencies, and considers that 'thick' relations produce valuable ethical surpluses that represent mutuality and human flourishing”. This perspective reminds us that employment is both economic and social; human wellbeing is the most central purpose of social and economic life (Bolton et al 2012).

People may resist economic practices that violate their sense of morality. EP Thompson (1971) rejects the overly-simplistic notion that the riots were merely “rebellions of the belly" (Thompson, 1971: 77). Thompson (1971) adds a sense of community and class consciousness to Polanyi's work and stresses the agentic capacity of people who are capable of making moral evaluations of their community based on their inherited norms and values and of opposing unfair or immoral economic practices.

Moral economy is thus about the traditions and values of the wider society, or a segment of the wider society. The market utopia model has an ideological basis but the reality of economic institutions is that they are embedded in society and come into conflict with those values and traditions which do not necessary have an economic basis. Sometimes that conflict is quite overt and will rein back the logic of the market which would otherwise destroy traditions. The DAFM funds these 
charities and tries to force a logic on them which does not take into account the values and traditions which do not have an economic basis. These shelters use wider society to battle against the logic of the market (see social media below; there are assumptions made which would probably not get the same response in India, for example). There is an assumption on the part of the shelters that they have public support.

A case in point is the recent withdrawal of Animal Collection Services (ACS) from the contract to run the Carlow/Kilkenny Dog Pound. Thompson writes about "The way in which popular resentment could arise as old market practice changed" (Thompson, 1971: 87). Such Nietzchean 'ressentiment' arose when it was proposed to transfer the running of one Dog Pound from the ISPCA to a private company (see Chapter 4), Animal Collection Services (ACS).

Taylor (2010) observes that shelter work is akin to a resistance against hegemonic beliefs regarding the human-animal divide. It seems clear that animal shelters are not resisting in in isolation; the campaign against ACS running the Pound was forged and won by wider community sentiment. Structural change is a collective enterprise and a similar social media campaign is underway regarding another Dog Pound, in Co.-.

Staying in the field requires constant fundraising and a social media presence is a key instrument to meet this end.

\subsection{Facebook Thematic Analysis on Sorrows, Travails, Consolations and Joys.}

Shelter workers' engagement with sites like Facebook do not simply rely on the wider moral economy of the crowd evident in society for support, but are in fact actively participating in constructing and reinforcing this moral economy on a daily basis. My Facebook analysis allows me to examine how workers try to construct a moral order within a broader world of economy, dealing the public, and social structures.

Shelters tend to garner widespread public support on such sites, as reflected by the high number of positive comments and Facebook "likes". For example, the largest shelter in the current study had 63,837 "likes" on September $6^{\text {th }}, 2015$. The smallest 
shelter had 2,253 "likes" on the same date. When one compares with a charity for homeless people, the NGO, The Simon Community whose Facebook site had 15, 428 "likes" on that date, we see that animal charities enjoy a very broad reach across society as a whole. This is a very active and constructive reinforcement of a widely embedded moral economy that reaches across all segments of society, all classes, genders.

There are inevitably differences between the public media self-portrayals of shelters and what my participants tell me in interview. What participants say on digital media is perforce filtered and designed to elicit emotional responses from the public in order to maximise donations and other public support. Social media constitutes a positioned, “front stage” (Goffman, 1959) point of view. Therefore, it is important to compare what they say, and do not say on digital media with our interviews and informal conversations.

The sorrows chronicled on shelter sites tend to refer to abused and suffering animals in their care. Animals that could not be saved are sometimes mentioned but euthanasia or being too full to take animals are usually absent from shelter sites despite the inevitability of these occurrences given shelters' limited space and resources. One recent (August, 2015) FB post described the harrowing case of 'Angel' a young female lurcher who had been found straying and brought to the shelter. Angel was so traumatised that she was exhibiting "pressed head" syndrome which the shelter depicted in a video showing the little dog pressing her head against the wall and averting all eye contact with the shelter workers. The dog's logic appeared to be that if she could not see, she in turn could not be seen. The shelter post went on to explain that female lurchers are considered less 'valuable' than their male counterparts and are therefore often badly treated. I was told in interviews and during informal conversations that lurchers are usually owned by members of the Travelling Community, but this was not raised on the site. There was a public outpouring of sympathy for Angel, and many members of the public announced their intention to donate. Sometimes shelter workers feel sorrow about rehoming animals to whom they have become deeply attached: “Jimmy Beagle, I was just a stepping stone between what was and what is now..I'll miss you buddy. Keep up the high fives and love your new family” (Appendix F, Social Media). Mild admonishment to 
members of the public is also not unusual on shelter social media, for example this quote from Schweitzer: "Think occasionally of the suffering of which you spare yourself the sight” (Appendix F, Social Media).

The principle travails described on social media can be categorised into three main areas: financial difficulties faced by the shelters, overcrowding, or sometimes a plea to the public to neuter their companion animals (Table 6.2.) When shelters ask for donations, they often request that these be paid directly to offsetting their veterinarian bills. These requests are always on behalf of the animals, and never to pay workers' salaries. While the rationale for staying in shelter work cannot be pecuniary, nonetheless shelter workers must be paid.

Difficulties with members of the public are rarely alluded to on such sites, though these were in every interview I conducted. This reflects the dialectical tension endured by shelter workers who depend on the public for support while at the same time seeing the public as the cause of the problem of unwanted animals. The public sometimes refuse to neuter companion animals, they support 'puppy farms' by buying dogs on internet sites, they surrender animals for what the shelters perceive to be spurious reasons. These issues were the subject of bitter complaint in many of my interviews, but they do not tend to be reflected on social media (Appendix F).

Shelters draw solace from the recognition and support of the public and such support epitomizes the "moral economy of the crowd" (Thompson, 1971) to which this FB post (July 2015) thanking the public for their donations attests:

The response has been heart-warming and reassuring that [shelter]..is needed and respected very highly and that has made us very proud indeed. Maybe this is just what we needed to keep going. I cannot thank you all enough for your donations (Social Media, Appendix F).

Successful rehoming efforts are often described in glowing terms, for example:

"We had a phenomenal amount of enquiries about the puppies. Almost 500 good people enquired. A huge collective thank you to everyone who cared enough to enquire "(Social Media, Appendix F) 
In this way, shelters feel their efforts to rescue animals are legitimated by the wider consensus of their community. My shelter workers try to construct a moral order within a broader world economy, and they are bolstered in this endeavour by the joys inherent in their work.

The joyful side of shelter work is invariably depicted in terms of successful outcome for the animals, either through successful rehoming or 'happy ever after' narratives and sometimes in terms of the successful rehabilitation of a traumatised or injured animal. In the case of Angel, the fearful lurcher, the shelter posted an update post (August, 2015) showing her running joyfully around a dog run and licking her carer's face. The meaning and symbolism of these pictures and their accompanying texts is clear; Angel is not "just" an animal; her health and mental well-being are of import. And so the prevailing norms and attitudes of the shelter are communicated for others to see; companion animals should be included in our moral order. She is the focal point of the photos and videos, while the human carers appear 'off-stage', as a disembodied voice or on the periphery of the photographs. As such Angel is important in her own right and the human-animal divide blurs into a "Möbius strip" (Bourke, 2011) vision. Taylor (2010) argues that the political angle of shelter workers is a form of resistance to hegemonic beliefs about the inferior status of companion animals in society. Shelter social media sites support her thesis; kittens are referred to as 'babies', deceased animals are referred to as 'crossing rainbow bridge' or 'running free', donkeys are described as 'cheeky' and imbued with distinctive personality traits. Joy is sometimes expressed in language evocative of a collective struggle on behalf of animals: "One week ago, we were drowning in a sea of debt and despair. But instead of bottling it up, we shared it with you, our loyal supporters and you came to our aid like cavalry” (Appendix F, Social Media).

Shelters are very careful to avoid disparaging comments about abandonment cases on their FB shelter pages, for example, often including a request for "No negative comments please”. In interviews, no such barriers exist, and my participants are frank in their disdain for animal surrendering for "bullshit reasons". Further, the benefits of sanctuary are not mentioned overtly and can only be inferred in situ and confirmed by my participants, as this concept was. I do not question the sincerity of shelter Facebook texts or photographs, and much can be learned and inferred from 
these depictions. Nonetheless my interviews and ethnographic observations suggest a different story in some respects and so a hermeneutical doubt is required.

My data indicates that animal shelter work also brings joy because it represents a kind of sanctuary, not only for the rescued animals but also for the humans, to which Figure 6.2. below attests. 
Fig. 6.2. "Who Rescued Who"?

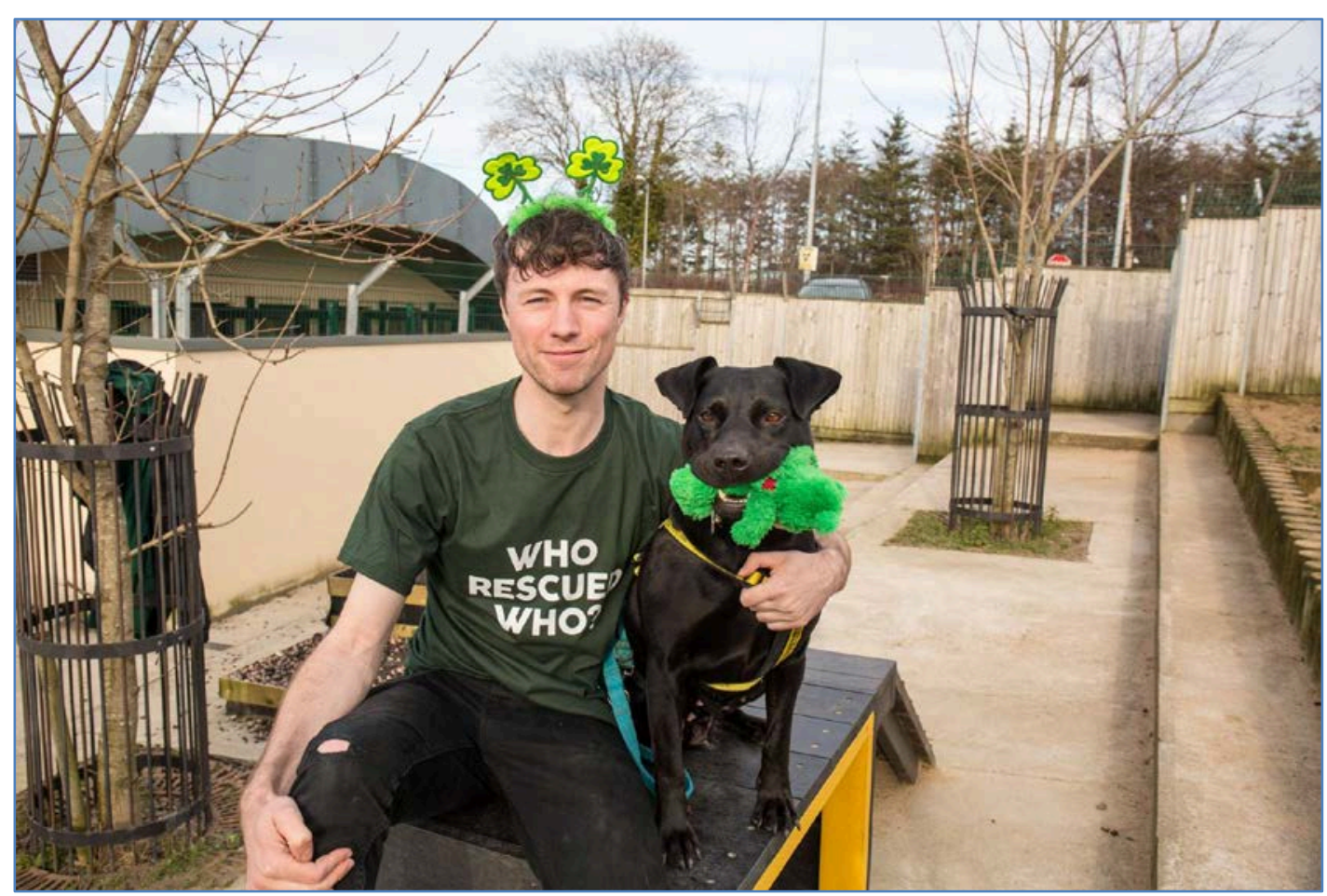

\subsection{The Joy of Sanctuary}

Morgan (quoted in Miles and Huberman, 2014: 280) calls a boxer “a tiger in the ring” which evokes fierceness, grace and power while ignoring fur, fangs and fourleggedness. Metaphors are thus a partial abstraction (Miles and Huberman, 2014: 280). Metaphors, these scholars argue, are data-condensing devices, taking particulars and making a "single generality of them". Metaphors help to move up to a more inferential or analytical level than mere description (Miles and Huberman, 2014: 280). The overarching quasi-metaphorical concept of sanctuary came to me relatively late in this study, after most interviews and participant observation had been conducted. Sanctuary is my conceptual term, and not an emic term used by my interviewees, but it is they who suggested this conceptualisation to me.

The word 'sanctuary' has religious roots ('sanctus') and those connotations remain: holy place, safe haven, site of retreat (Branchi, 2010) though it originally referred to a time when criminals sought and found asylum in a sanctuary. Nobody was allowed to harm someone who had sanctuary; they were untouchable, the Greek word for ‘asylum’ (Branchi, 2010: 135). For the nonhuman animals in shelters, sanctuary may 
be understood in terms of a reserve, a refuge from danger, a place where they are immune from the sometimes deleterious effects of capitalist organisations. As regards my human respondents, for my purposes, 'sanctuary' connotes a safe space where goals and assumptions are shared. My respondents gain sanctuary from alternative work in capitalist organisations and in the human-animal and humanhuman relationships in the shelter. Further, animal shelters are typically located in rural spaces where spiritual refreshment from the urban is possible. Lisa's home is a sanctuary with bees, a pond, chickens, a cattery, several rescue dogs and cats and most respondents allude to the physical beauty of their workplace settings and their love of the outdoors (Interviews, 2014).

In terms of sanctuary from alternative experiences of the economy, many respondents tell how much they would dread returning to "a job which you just have to pay the bills”. Dogs Trust canine carers sometimes wear t-shirts bearing the slogan "Who rescued who?” (Figure 6.2). Being in a position to give to animals thus saves my respondents from other sorrows and hardships in alternative workplaces as Chapter 5 analyses. The experience of sanctuary from alternative work ranges across a spectrum from boredom or dislike of other work to more extreme negative consequences of previously held jobs. Being in a position to "be completely oneself" around the shelter animals is also a common refrain among my participants; animals do not care if one tends to them while wearing pajamas and wellington boots (Interview with Jen, $4^{\text {th }}$ July, 2014). Other participants claim that if they won the Lotto they would stay in this job because they love the work environment (Interview with Suzanne, $14^{\text {th }}$ June, 2014). The animals thus represent a kind of sanctuary, as do like-minded colleagues. For a subset of respondents this sanctuary from other workplaces is essential; Jean suffered exhaustion and mental health difficulties in her previous position as a carer for physically and mentally challenged adults. She says shelter work keeps her sane. Emma was “devastated” after losing her job in a bookmakers and tells how she loves animals for their "innocence”: “They're just going around in their little world and I'm just looking at them going..yous have no idea, there's a recession going on, yous just don't care” (Interviews with Jean and Emma, 2014). 
For Jon, the loss of his job as a - resulted in him experiencing suicidal ideation. The shelter provided him with a haven where he says he feels "safe and useful again" (Interview Jon, $7^{\text {th }}$ July, 2014).

Agata also believes that sheltering animals gives her a sense of "love and purpose" and interconnectedness (Interview with Agata, 22 ${ }^{\text {nd }}$ August, 2014). Harbolt (2003: 10) concludes that the shelter workers' reasons for helping animals are not only motivated by the wish to nurture but by a connection to other creatures in this world. This "mysterious space between us" and other creatures, as Harbolt terms this connection (Harbolt, 2003: 11).

For Maria too, who has been diagnosed with high-functioning Aspergers' syndrome, animals make living in the world possible for her. "I couldn't do a normal job. I probably couldn't even talk to you now if the cats weren't here" (Interview with Maria, $9^{\text {th }}$ July, 2014). Many of my female respondents refer to the animals in their care as "my babies" though no male respondent did so (Interviews, 2014). This terminology has resonance with Nast's (2006) thesis that the "anthropomorphic malleability" of animals means that to some extent they can be shaped into whatever you want them to be - a best friend, a lover, an occasional companion (Nast, 2006). It is important to note that my respondents, despite some employing the term "babies", do not treat the animals in their care like babies. Instead, dogs are treated like dogs and cats like cats; my respondents display a deep understanding of the species-related needs of animals.

Animal shelter work thus constitutes sanctuary from alternative experiences of the economy; though sentient and responsive, animals do not judge human beings based on their career status, appearance or economic status.

Collegial relationships can also be described as providing sanctuary for my respondents, as Emma depicts:

Ah, it's just wonderful like, you know what I mean, it's just like a big family. No-one knocks on the door, they just walk in, and then when you walk in you have to go and hug everyone before you can sit down and have a cup of tea. And then when you're leaving, everyone is hugging and kissing and ..everyone just has this bond already because we're all there for the same reason. So we already 
know that they're good people because they wouldn't be here if they weren't (Interview with Emma, $5^{\text {th }}$ February, 2014).

Though based in a different shelter, Katja echoes Emma’s comments: (On staff)

“They're a bunch of crazy hippies, like a real interesting crowd and you meet people from all over the world, all animal lovers so the same kind of interests as me, the same kind of people” (Interview with Katja, $4^{\text {th }}$ July, 2014). Unlike my findings, Alger and Alger's (2003) study of a cat shelter finds a high turnover of staff due to internal tensions and disputes. In my shelters, intra group cultural levelling is the norm, and based on my ethnographic observations and interviews, I believe that this constitutes part of the reason which encourages people to remain in this occupation.

Animal work also provides sanctuary not only because of the resultant reprieve from jobs my respondents disliked or did not keep but because of the importance of working in the outdoors for most participants. My interviewees have crafted jobs in natural settings for themselves. Interviews took place in the gardens of some participants or in rural, idyllic shelter settings. One sanctuary for donkeys states on its own website: "Despite our idyllic surroundings we need your help to keep our donkeys fed and healthy” (Social Media, Appendix F). In the one exception, the respondent returns every weekend to his home in rural Ireland. Most respondents express a love for 'nature', and a belief that their work is more meaningful than office or other jobs they had previously held. Most respondents express their preference to work closely in tandem with 'nature' rather than in an office or in other occupations. Despite our increasingly globalized society within a neoliberal and promarket ideological paradigm, our social world is nonetheless inextricably bound up with other animals and with the natural world. In the words of one (retired) respondent Des on his former work: "It will be there when I am gone. We are all a chain of creatures on this earth” (Interview with Des, 15 ${ }^{\text {th }}$ April, 2014). Shelter workers bring this moral topography to their work.

\subsection{Chapter Summary}

In the various ways documented above, shelter workers are involved in constructing sorrows, travails but also the returns from their working lives. Their employment is not a matter of material rewards, rather it concerns self-fulfilment through the construction that making a difference to animals matters. This meaning they do not 
construct alone, but with the wider consensus of segments of society, as part of the moral economy which is not subject to purely economic concerns. Shelter Facebook posts depicting rehomed dogs on sofas, at play, and firmly embedded in human lives make a sociological statement that animals are members of society. The "moral economy of the crowd” (Thompson, 1971) supports that view and sustains shelter workers' beliefs about the importance of companion animals in society. Shelter workers thus share meaning scripts with other actors in relational networks. Though some members of the public are seen as ignorant of animal welfare, or even abusive, others provide a source of consolation and affirmation.

Not only is shelter work constructed and continuously reconstructed as meaningful, 'moral' work, it also offers sanctuary from alternative workplaces and in HAR and rural settings. None of my interviewees uses the term "sanctuary” when describing the joys inherent in their work. Nonetheless, the majority use terms such as "safe haven”, or suggest that this occupation keeps them "sane”, express joy that they do not have to do a job "where you are just paying the bills", or take delight in the rural "slice of paradise" which is their workplace (Interviews, 2014). I understand these varying definitions as constituting sanctuary for my participants, and as part and parcel of their 'choice' and staying in this occupation. The 'choice' of animal shelter work is a kind of haven from alternative, less 'moral' occupations and in nature, as embodied by the animals to whose care my participants are devoting their working lives in the Third Sector. Their decision to stay in the shelter is an active part of the process of choice. It is difficult to (overtly, at any rate) reject the 'market' hegemony whilst working in a corporate organisation. In the shelters, HAR are prioritised over exchange relations, in correspondence with my participants’ desiderata. 
Chapter 7 


\section{Chapter 7 Concluding Words on Shelter Work: The Best Job in the World?}

In our estrangement from nature we have lost sense of the community of life and lost touch with the experience of other animals. And because everything about life occurs along a sliding scale, understanding the human animal becomes easier in context, seeing how our human thread is woven into the living web among the strands of so many others (Safina, 2015: 2).

\subsection{Conclusion and Further Research}

Bauman finds a modicum of anger to be a supreme stimulus to thought (2014: 61). The introductory chapter of this thesis lays out the motivation to this study which had its seeds in my lack of awareness in 2007 that the Dog Pound system routinely euthanizes surrendered dogs. Most of my anger thereafter was self-directed. I felt complicit in the death of a young dog, whom I had wished to save. Hammerhead (see Chapter 1) was needlessly euthanized because I did not understand the Pound system. I also felt dismay at the wider social structures that enable the life of a dog to be held in such low regard. As I documented in the introduction to this thesis, HAS is not a thriving research area in Ireland, and so I also felt that my proposed study was swimming against the dominant stream.

On a broader level, my (incorrect) theoretical pre-notion that shelter workers make this occupational choice out of a sense of 'calling' provided an impetus to undertake this study. This thesis contributes to three domains. First, I make an empirical contribution by producing unique data on shelter work in the Republic of Ireland, based on two years of ethnographic observations in seven shelters and one veterinary surgery, 24 semi-structured interviews, and an analysis of shelter social media. Outlined in this chapter are implications for future research following on from this thesis within the fields of HAS, occupational choice theory and in the wider context of sociological theory of our complex, messy and ambivalent relationships with other animals.

Second, I challenge the very concept of choice and problematize the dominant assumption that shelter work is undertaken as a result of the individual caring about animals. I thus make a contribution to occupational choice theory. While the HAS 
literature explains shelter entry as counter-hegemonic and based on loving animals, as documented in Chapter 5, I provide evidence that these antecedents are insufficient. My contribution to the HAS literature lies in my finding that the occupational choice of entry to shelter work is processual, as much a matter of life's chances as life's choices.

Third, the decision to stay is a separate decision which I explain through the theoretical lens of moral economy, and using the concept of sanctuary as an organising conceptual device. The HAS literature on staying in shelter work focuses on emotion management strategies. While shelter work indubitably entails 'emotion work', to this insight I add a moral economy lens and the overarching, binding symbolic notion of sanctuary to explain why my respondents persist in their work. The consolations and joys of shelter work outweigh the sorrows and travails for my participants, and therefore they remain in the shelter.

In terms of methodology, this study adopted a more-than-human approach to ethnography, which is to say that it acknowledged the interconnectedness and inseparability of my respondents from their nonhuman charges. Although the point of vantage I was investigating was that of shelter workers, I sought to extend ethnography beyond the solely human realm, and to replace a dualist ontology by a human-animal relational perspective. I contend that my respondents' entanglements with animals must be theoretically integrated into the account of their work and lives. The human-animal aspect changed this ethnography in many ways; the presence of the animals changed everything. Animals were always present during my field visits, and the focus of my participants and my own focus was always more on the animals than on researcher/researched. The presence of the animals also reduced tension in the researcher/researched relationship. As Jean (15 ${ }^{\text {th }}$ February 2016) explained to me in our telephone conversation, people complicate everything. Care work (especially end of life care) with people is fraught, in her eyes, because it involves people's families, people's own regrets about what they did or did not do, and regimented structures of privatised care facilities. None of these factors, which Jean (February $15^{\text {th }}, 2016$ ) describes as very stressful are present when one is caring for animals. 
Listening and hearing others is important for the productions of accountable and responsible knowledge (Bauman, 2015:167). My respondents enabled me to understand how they came to make the occupational choice of shelter work, and why they remain, and so they have made a contribution to academic debate.

Following the literature review, a 24 month ethnographic field study was undertaken. I was unable to be in my research settings every day, but I worked with animals alongside my human participants every time I was present, and I tried to know what they know. This field study revealed the dialectical complexity of shelter work which involves dealing with public neglect of animals, while simultaneously relying on the public to support its endeavours. A review of the HAS and occupational choice literatures led me to frame three core research questions.

My first research question pertained to the particular context of animal shelters in Ireland: what were the repertoires within which the choice of shelter work is possible, and the legislative and regulatory frameworks surrounding this work?

My second question related to the reasons for occupational entry. My concern was to establish whether caring about animals - as is often tacitly maintained in the HAS literature - is sufficient to precipitate this choice, or whether there are commonalities in the sequence of events in the life course of my study participants.

Third, I aimed to establish whether this choice can be understood as a calling, or whether there exists a valid alternative explanatory framework. I wished to discover what other reasons, apart from the emotional management strategies discussed in the literature, enable my respondents’ persistence in their unglamorous, physically and emotionally demanding occupation. Below I lay out the original contributions of this thesis in each of these domains.

Chapter 4 looked at the particular set of alternatives within which the occupational choice of shelter work is possible in Ireland. I problematized the dominant assumption that occupational choice is individual, arguing instead that it is a complex decision structured by social processes.

This chapter thus attempted to develop what Bauman calls "an account of the epoch" (Bauman, 2014: 4) or the context within which people act. The postulate of 
'sociological hermeneutics' (Bauman, 2014: 52) demands that whenever we pursue the meaning of human thoughts or actions we ought to look into the socially and culturally determined conditions of people whose thoughts or actions we intend to understand or explain (Bauman, 2014: 52).

Stinchcombe (2000) argues that people's choices are structured by social processes and so must be viewed within the existing repertoire of choices in the labour market economy. Bauman (2014: 5) maintains that the sociologist should situate work, "at the hinge between the account of the epoch and the lived experiences of men and women”. As O’Riain (2014) reminds us, individual choices are only possible within institutional structures and attached cultural meanings. The former must be considered before considering the repertoire of choices available to individuals making decisions in the economy. In Chapter 4 I laid out the repertoires in which the choice of shelter work is possible in early $21^{\text {st }}$ century Ireland, as well as the current legislative and regulatory frameworks surrounding shelter work. The latter are a part of my respondents' moral economy. Personal life and biography is intimately connected with historical events and structural processes, although clearly my respondents also had agency. A placing in a situation sets apart moves that are feasible from those that are not, and the more probable from the less probable, but it never eliminates choice altogether (Bauman, 2014: 51). The repertoire of roles for shelter workers includes: care-worker, manager, fundraiser, adoption advisor, PR representative, animal advocate. In the smaller shelters, there is considerable overlap between these roles. As noted in Chapter 4, while my participants welcome the AHWA 2013, it does not go far enough. In their eyes, the Act fails to give sufficient power to the SPCA inspectorate, and even when convictions are made, the penalties are risibly lenient. They also believe that compulsory micro-chipping of dogs will not be enforced, and will not solve the overbreeding of the lurcher breed in particular. Freedom is a scarce resource, I also found; some of my female respondents' freedom to work in a shelter is at the expense of their partner's freedom about occupational choice (see chapter 5).

Chapter 4 also sought to avoid ascribing more 'rationality' to my respondents' occupational choices than is warranted. Liberalism, Stinchcombe (2000) argues, 
backgrounds the collective aspect of choice and foregrounds the individual choice aspect.

The choice of shelter work is structured by the politics of the field; my respondents had various options, including setting up their own shelter, working in an SPCA, in a shelter with holding facilities, a Dog Pound, or in a larger shelter organisation at a higher rate of salary. Further, most of my respondents volunteered prior to working fulltime in a shelter. Within the field of shelter work there are different social constructions which are the basis of rivalry (holding vs. no holding facilities for animals, for example). Different kinds of care occupations are constructed and it is a contested area. Larger shelters often require formal qualifications when filling job vacancies, local shelters often take on volunteers on an ad hoc basis. Some shelter work is masculinised (Dog Warden) and some feminized (cat shelter work) and some is more gender neutral (donkey shelter work in the largest sanctuary in Ireland, for example). Social structures create different kinds of occupations in terms of pay, moral choices, gender inter alia. So there is a structuring of the menu of jobs from which to choose. The reasons for entry were consistent across the different types of shelter organisation however, and for both volunteers and paid workers, as Chapter 5 documents.

I document how the occupational choice of shelter work illustrates the processual nature of social reality. My contributions to HAS and occupational choice theory lie in my finding that entry antecedents fall into two categories: those antecedents which predispose my respondents to care about animals, and those which more directly form part of the choice to care for animals in the shelter. The former antecedents are comprised of factors such as early childhood exposure, the influence of significant others, or social demographic characteristics (female, childless). I find that these processes prepared the soil in which later moral awareness could grow, and increased the likelihood of moral attitudes towards animals being acted out in later occupational choice. The latter antecedents are related to changes in the life course, false starts and cumulative epiphanies. This distinction is reminiscent of Bauman's (2014: 8) observation that there are different kinds of experience, as encapsulated in the nuanced German words for experience: Erfahrung and Erlebnis. For example, a divorce lawyer might have substantial Erfahrung of divorce while being happily 
married (thus without having had the Erlebnis of divorce). In a similar vein, while I have had a lot of Erfahrung with animals, I do not share the Erlebnisse of my shelter respondents who care for animals in their quotidian working lives. Caring about animals and for animals are therefore different concepts because caring about animals does not require a daily commitment to enact this care.

This thesis makes a significant contribution to HAS and occupational choice theory by debunking the notion that 'loving animals' explains the occupational entry into shelter work. Loving animals is a necessary but not sufficient condition. Harbolt (2003:137) argues that it is likely that people drawn to shelter work have had emotional experiences similar to a dog abandoned in a shelter: separation, isolation, lack of understanding, and loss of connection. I find scant evidence to support this claim. Although shelter work is an occupational realisation of my respondents' longheld sense of compassion towards animals, the recipe for occupational entry that emerged is far messier than simply composed of formative childhood experiences, either negative or positive. Instead I find that there are 'human' causes, by which I mean the occupational choice was away from bureaucratised, corporate capitalism as much as it was towards animals. This occupational choice is composed of a complex set of processes, which include cumulative epiphanies, alienation from alternative workplaces, and I argue, a yearning (realised or experienced post facto) for a kind of sanctuary with animals, and from alternative experiences of the economy.

Shelter work is generally feminized, as my data reflects. However, I do not find my respondents to be “doing gender" (West and Zimmerman, 1987) in a normative sense. The shelter environments I studied are places where people are permitted to behave counter to gender norms. The women in my study are not afraid of Rottweiler dogs, for example, which could hardly be described as 'doing feminine'. The few male respondents in my shelters are nurturing and openly affectionate towards the animals in their care, which is not 'doing masculine' in a conventional sense either. There is a noteworthy difference between my male shelter workers' nurturing behaviour around animals and males' behaviour around animals more generally. As an illustration, males walking their companion dogs very rarely (in my observation on daily walks for almost ten years with my own dogs) express physical affection towards their dogs; in my shelters such expressions are the norm. My 
contribution to occupational choice theory concerns the distinction I make in these pages between entry and staying as two different and separate processes, as well as the focus in these pages on the structuring of choices, which is compatible with the gendering literature. I find that both genders find sanctuary from market exchange relations, gender norms, and bureaucratic hierarchy. My arguments are broadly compatible with the gendering literature but I add moral economy and sanctuary to explain my respondents' accounts, and these factors are equally true of men and women in this study, and in similar ways. Both my male and female participants said they disliked the dominant ethos of hetero-masculine organisations, and both found sanctuary in the animal shelter. Sanctuary, I find, is arguably afforded even more so to the male workers; the shelter appears to be a degendered realm, where men can escape contexts of masculinisation, although more research is needed in order to establish where this holds true for other male carers in other shelters.

Arluke and Rolfe (2013) also point out the difference in socially acceptable roles for men and women in reference to human-feline ties as depicted in photographs in the period from 1890-1940. These scholars found relatively few photographs of adult males with cats in any pose. They surmise that the men might have been preoccupied taking the photographs, or might have been unwilling to have their photographs taken with cats, or might have felt they were not in significant enough relationships with cats to merit having a picture taken with them (Arluke and Rolfe, 2013).

This thesis also makes a significant contribution to our understanding of the processes which enable people to remain in their occupation. There are many travails and sorrows inherent in shelter work documented in these pages and therefore tensions in the moral economy of the shelter. Dealing with constant financial strain, lack of personal time, and exasperating behaviour of a cohort of the public (who surrender animals for spurious reasons or persist in the mistaken belief that spaying or neutering animals is 'cruel') constitute the chief travails. Of deeper consequence are the harrowing experiences shelter workers routinely undergo in the course of their work; they must bear witness to appalling cruelty and neglect cases which sometimes result in the ineluctable decision to euthanize animals. Succour for these factors is found, I demonstrate, in the consolations and joys that spring from the sense of helping animals and in the concomitant HAR rewards but also reach into 
the realms of moral economy and sanctuary. Without delving too deeply into Polanyi's (1957) theory of markets and their interactions with social relations and structures, I view shelter work through its lens. Shelter work, as an economic activity is socially structured and institutionally embedded. The measure of the validity of my narratives in chapters 5 and 6 is the extent to which they resonate with lived experiences - the respondents I asked tell me that they do - and not quantitative.

I conceptualised moral economy as operating on several levels. First, my respondents construct shelter work as an inherently eudaimonic - the Aristotelian idea that doing good equates to being good - activity and the importance they attach to work in accordance with their values is pronounced. Second, they are bolstered in this view by wider public support and recognition. Third, shelter workers rely on public support to sustain and legitimate their activities. Finally, shelter workers also draw on this support to resist changes in the status quo, as the ACS case documented in Chapter 4 exemplifies.

I have argued that shelter work is an exemplar of how the market remains a social as well as economic nexus. Shelter work is what Polanyi (1957:171) terms an organic form of existence; interspecies connectivity provides an opportunity for my participants to flourish. From a processual vantage point of moral economy, shelter workers reject the norms of a career driven by economic considerations. They invest valueless - according to market logic - animals with moral value.

Interlinked with moral economy is the sanctuary shelter work affords my respondents via their deeply constitutive relations with animals. Sociology is fond of metaphors as Bauman (2014: 76) notes. He defines a metaphor as a "familiar notion used to evoke a vision in which the phenomenon in question can be placed to intuit its features” (2014:77) This sanctuary also manifests itself in the respite from market relations and bureaucratic hierarchy they experienced in previously held occupations, which ran the gamut from disliked to despised. This study makes a significant contribution to HAS, by demonstrating how non-human interaction provides the possibility of sanctuary from human workplaces. Jen (Interviews, 2014) observed that you could turn up in your pyjamas and the animals would not mind. Suzanne who works in a donkey sanctuary, dresses very stylishly in branded Wellington boots 
and expensive wax jackets, but how she dresses is equally irrelevant because it displays the full range of what is acceptable, i.e. anything goes because dress carries so little currency in the shelter environment. This implies a release form everyday societal expectations regarding how one must present oneself to the world; it implies sanctuary.

For my shelter workers, sanctuary from gender relations is also a by-product of the shelter environment. The ability and resourcefulness to save and care for animals takes precedence over culturally or gender-based norms for my shelter workers; the former are the currency of the realm. The care ethic is alive and thriving in my shelters, to which the following text message I received from a shelter worker attests: "He had mange too, poor mite. At least he knew a loving hand before he passed away. Someone who actually cared (heart)” (SMS message, $9^{\text {th }}$ November, 2015).

This thesis has contended that shelter workers feel more connected to nature through their work with other species but not as some kind of Arcadian ideal, or "peaceable kingdom” (Arluke and Rolfe, 2013) but also as a link to society. This ongoing tension between loving some animals and eating others makes the notion of “peaceable kingdom” (Arluke and Rolfe, 2013) vastly more complex for most of my participants. However, through their work they come closer to that kingdom than do most of us under conditions of $21^{\text {st }}$ century capitalism.

To draw the contradictions into the light does not mean they are resolved as Bauman observes (Bauman, 2014: 49). I did not resolve these contradictions, and it is not up to me, but to my respondents themselves. Just as Arluke and Sanders theorised of the shelter workers in their study (Arluke and Sanders, 1996) the tensions my respondents display could be said to be reflections of wider societal contradictory attitudes towards animals writ small.

I do not discount the role that shelter animals play in shaping how workers interact with them but the primary focus is on my human respondents; why they enter, why they remain in this occupation. I conclude that entry is processual and staying can be understood as operating through a process of moral economy, as an alternative to the exchange economy, within a certain social context. I find that shelter work, despite its sorrows and travails, contributes to what Sayer (2005: 217) calls "flourishing”. 
The present study also calls into question new understandings about the purpose of work and about more than human lives, with which I contend our own are inextricably bound. If work does not contribute to human wellbeing, this begs an obvious question I contend.

As with all research, the current study has flaws and limitations. Social development is dialectical; the answer in these pages may be inadequate for questions raised by new developments of activity in shelter work in the future, at a different historical point in time.

Although I spent 100s of hours in my shelters, this study was subject to financial and time constraints as I lecture fulltime. This study is therefore necessarily limited in terms of its empirical breadth and reach. Seven shelters were included - big charities and smaller shelters, which are the dominant modes of animal welfare organisations in Ireland - all in the east coast, and a large equine shelter was not included. However, I contend that my data would not be significantly different, had a horse sanctuary been included. Horses constitute an 'industry' but so too do greyhounds. Horses are not 'pets' in the same way as dogs or cats perhaps but they are sentient beings in the same way and I believe that the reasons for entry and staying will be similar for my human respondents. It would however be interesting to discover why the gender balance is more equal (18 male: 15 females) in the largest donkey sanctuary in Ireland than is usually the case.

Future studies could consider why people leave the field of shelter work - 'negative instances' in order to add a further layer of theoretical depth. The tension between loving some animals and eating others among this cohort also warrants further research. The capacity of my participants to reconcile their love for animals with non-vegetarian dietary choices was very interesting. In the main they did so by distancing themselves from an agri-industry they did not wish to contemplate, and by making 'free-range' choices. Naming, my respondents tell me, makes a difference, and it is no coincidence that all shelter animals are named on admission (even the rescue pigs were named 'Bacon' and 'Sausage' in one multispecies shelter (Fieldnotes, $3^{\text {rd }}$ August, 2013). A comparative study between the statistically significantly lower euthanasia rates for dogs in Scotland than in Ireland and their 
sociological explanation would be valuable. Further, research on the reasons why people fail to spay or neuter companion animals would be useful in marketing its necessity to the wider public, a theme that was underlined by all my shelter workers and by my veterinary surgeon participant.

A comparative study with human-to-human care work would shed light on how working in animal care may differ in enhancing experienced meaningfulness of work. The latter is much less stressful according to Jean (telephone conversation, February $15^{\text {th }}, 2016$ ) who has experience in both domains. Following on from this, the experienced meaningfulness of animal work as a counterpoint to the ideology of progress as solely defined in terms of endless economic growth warrants further investigation. As would, I contend, a study on whether shelter workers or workers in the sectors of the 'mainstream' economy enjoy their work more. Meier and Stutzerl (2008) find that volunteers in human contexts are more satisfied with their life than non-volunteers.

I found entry and staying in shelter work to be intimately connected with process, moral economy and sanctuary. These findings have potential implications for other occupational fields; other occupations where people find sanctuary and enact moral economy would also be a fruitful area for future exploration. Laaser (2013) argues that contemporary and past employment relationships enable or constrain people's flourishing and concludes that even under poor working conditions social and moral dimensions of humanity persist and enable workers to humanise the labour process. Moral economy is not just applicable to care work, much less animal care work, according to Laaser (2013), and this is also an important area to explore further. An archival, historical analysis of SPCA literature - although this is scant - over the last 150 years would also constitute a valuable contribution to knowledge.

This thesis provides documentation of my observations of the work lives of animal shelter workers, people who bottle feed newborn kittens every three hours for weeks, clean dog or donkey faeces, and sometimes comfort dying animals. My point is not to idealize the life of a shelter worker, rather to bring its features into view. My ethnographic observations and interviews lead me to conclude that they are not "just in it” (Taylor, 2007) for the animals, but also for themselves. The 'language' of 
animals is one of acceptance, forbearance, and affection in shelters, and I found that there is joy to be found in the sanctuary environment.

I hope to have written a partial account of 'the truth' of shelter work in these pages. Of course, I neither can, nor wish to have the 'last word'. With all its sorrows, travails, consolations and joys, I maintain that shelter work is a struggle for sanctuary and moral work within the economy.

I ventured here that the occupational choice of shelter work was for my respondents activated at a certain time in their lives and under certain social conditions, but within the narrower context of their norms and values. I presented evidence that their choice to persevere in this work is bound up with sanctuary and moral work within the sanctuary gates and in their own rationalities. Their consolations and joys are intrinsic rather than extrinsic; my respondents have crafted a moral space for themselves in the economy.

Intra-shelter conflict is not based on "kill" versus "no-kill" shelters because in the main the Pounds take on this difficult task (although when shelters are full, shelters inevitably transfer dogs to Pounds). Therefore, all the shelters in the current study identify as "no-kill". Instead, for my shelters, the conflict tends to be based on holding facilities; some SPCAs have none and while they rescue injured animals and bring them to veterinary surgeons, these animals ultimately are brought to other shelters upon recovery. Of course, this means that work is shaped differently for noholding shelters; animal care is much less pervasive in their lives as they 'pass the animal on'. Shelter workers in shelters with holding facilities, on the other hand, are almost always in the presence of rescue animals.

Where will our relationship with 'other' animals go in the twenty-first century? Some scholars (Nast, 2006) see the presence and importance of pets as a testimony to an enduring and necessary link between humans and nature that provides albeit incompletely, in ecologist Paul Shepard's words: "a glimmer of that animal ambience, sacredness, otherness” (quoted in DeMello, 1996:141). On the other hand, the global demand for animal-derived products shows little sign of abating. Our contemporary cultural ambivalence towards animals is encapsulated in the contradiction between increasing concern and intimacy versus increasing intensive 
farming (Safina, 2015). Intensive farming is at the epicentre of the climate crisis which according to Kirby (2008) is now upon us. The climatic crisis point which Lovelock (quoted in Kirby, 2008) likens to sailing blithely toward the Niagara Falls was not the subject of the current study but it is inextricably bound up with the question of the animal.

Despite his sympathy for animals, Derrida (quoted in Calarco, 2008: 115) is sceptical that fundamental changes in our thinking and relations with animals are possible through existing ethical and political discourses and institutions.

Unlike Derrida (quoted in Calarco, 2008: 115) I believe that there is reason for some optimism in regard to the future in this regard. Humans have power to affect the world in a way other animals do not. Arluke and Sanders (1996) noted two decades ago that the 'sociozoologic scale' was crumbling (1996: 191). Our attitude to animals is a historical work in progress. The more we learn about the abilities and feelings of animals, the more many people realise that the border between animal and human is porous, shifting, and culturally-based. Over the four or more years of this study, I have found my own sanctuary and sacred spaces in the company of my respondents and their (in the main) quadriped charges. I have been struck by how other species immerse themselves in the present, how they are so deeply in life. I have also been deeply surprised and moved by shelter workers' stories of cruelty and neglect towards animals, and by their resilience in the face of these daily realities. I am humbled by my respondents' joy, despite their despair in their work, and so I honour them. Despite my own love for animals, I was always acutely aware that I am not "one of them"; shelter workers bear witness to cruelty, and they do work that I will never experience to the extent that they do.

I have begun to further modify my dietary choices, as a result of my readings about industrial farming of what in my eyes - if not then in Beston's (1928) - are our animal kin. In my late teens, I stopped eating meat but I am now gradually adopting a vegan diet, and growing accustomed to soya products as a substitute for dairy. I find this dietary choice consolatory, in the sense that like Scully's (2011) protagonist who saves sea-turtles' eggs in Sri Lanka, I am doing something. So this decision could also be said to be in my own interests. 
We "tie a knot in the Möbius strip in order to declare: Here! is the fully human. There! are the others.” according to Bourke (Bourke, 2011: 378). From Bourke (2011) I borrow the notion of the fluidity of the Möbius strip which challenges tyrannical dichotomies such as human/animal. This thesis attempted to shed light on the processes by which shelter workers carve out spaces that subvert the dominant economic system, and by which they come to untie that knot. In doing so, they help not just the animal 'others' but their human selves. In untying the knot my shelter respondents safeguard themselves from the emptiness of a myopic market mentality. As the epigraph from Safina argues, our understanding of our human selves is deepened when we give consideration to beings beyond the human, and acknowledge that we are but part of a chain of life on this earth.

This thesis is the story of how shelter workers construct a realm - and social media communication enables them to do so more effectively than ever before - in which neither the animals in their care, nor their own labour is commodified. This is also a story that began in anger and sadness emerging out of my misapprehension which ended in a dog's premature demise. Over years, it became a story that ends on a positive note based on deeper understanding of shelter work as representing a contextual congruity with the values of my participants. It is also a story of the sanctuary to be found in shelters, both from antipathetic corporate workplaces and in the company of other animals. 
Appendices 


\section{Appendix A}

\section{Hammerhead}

That day, you heard a low whine

Coming from the building site. Jesus

He was thin, ribs easily numbered

Through the skin. Ugly

Too. His large skull

Reminded you of a hammerhead shark

After a small show of baring teeth

He let himself be comforted

Two gulped cans later

You took him to the Pound

For twelve miles he kept his head on your lap

His eyes on your eyes

It was the right thing to do. You had no time, no room

Who could love a dog with a head like that

Kilkenny Poetry Broadsheet, 2009 


\section{Appendix B}

\section{Interview Participant Consent Form}

Working Title of the research study: An ethnographic study of animal shelter work in Ireland.

Researcher's contact details: Anne O’Connor Telephone number: 0851545635 Email: ANNE.OCONNOR.2013@nuim.ie

Supervisor: Prof. Seán O’Riain, Department of Sociology, NUI Maynooth.

\section{Background and Procedures:}

The purpose of this study is to contribute to the sociological literature on humananimal interaction (HAI) in order to open up new vistas on social behaviour and paint a more complete picture of human social life. This study focuses on why humans are drawn to helping animals, in shelters and in other work settings.

All data will be anonymised, and will be stored on encrypted PCs and usb memory sticks, or kept in a locked filing cabinet, accessible only to the researcher. The use of this data is for research purposes only. Subsequent uses of records and data will be subject to standard data use policies which protect the anonymity of individuals and institutions.

If during your participation in this study you feel the information and guidelines that were given have been neglected or disregarded in any way, or if you are unhappy about the process, please contact the Secretary of the National University of Ireland Maynooth Ethics Committee at research.ethics@nuim.ie or +353 (0)1 7076019. Please be assured that your concerns will be dealt with in a sensitive manner.

\section{Declaration (Please read and sign if you agree):}

I have read this consent form, and have had the opportunity to ask questions and all my questions have been answered to my satisfaction. I understand that all information collected in this study will be treated as confidential and that my identity, and that of my workplace will remain confidential. I freely and voluntarily agree to be part of this research study, though without prejudice to my legal and ethical rights. I have received a copy of this agreement and I understand that the results of this research may be published. I understand that I may withdraw from this study at any time.

Statement of investigator's responsibility: I have explained the nature and purpose of this study to the person named about, and I believe that the person named above understood my explanation and has freely given consent.

\section{Participant's name:}

Contact number:

Participant's signature:

Date:

Investigator's signature:

Date: 


\section{Appendix C: Ethical Approval}

NATIONAL UNIVERSITY OF IRELAND, MAYNOOTH

MAYNOOTH, CO. KILDARE, IRELAND

Dr Carol Barrett

Secretary to NUI Maynooth Ethics Committee

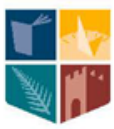

NUI MAYNOOTH

oliseail na heireasn us nuad

04 October 2013

Anne O'Connor

Department of Sociology

NUI Maynooth

RE: Application for Ethical Approval for a project entitled:

"Minding animals: a study of the motivations, attitudes and work lives of animal shelter workers."

Dear Anne,

The Ethics Committee evaluated the above project and we would like to inform you that ethical approval has been granted.

Kind Regards,

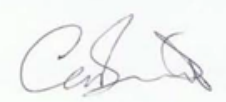

Dr Carol Barrett

Secretary, NUI Maynooth Ethics Committee

Cc Dr Eamonn Slater 


\section{Appendix D: Email Correspondence}

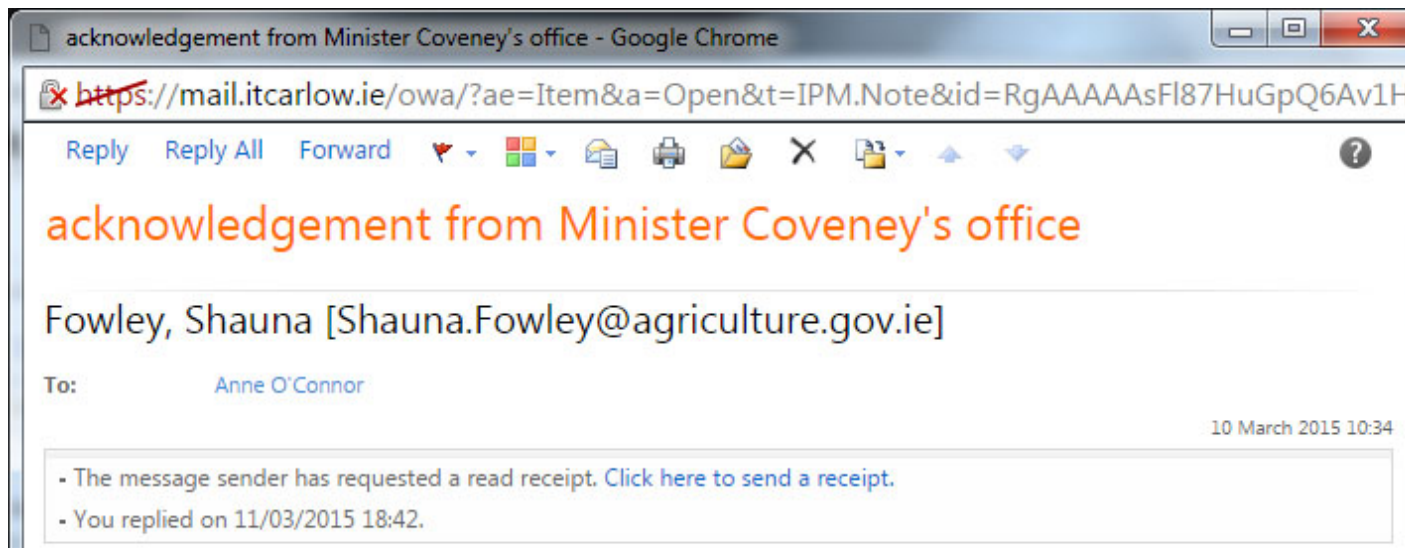

Our Ref: $2015 / 52496 \mathrm{~N}$

Dear Ms. O'Connor,

I would like to acknowledge your recent correspondence addressed to Mr. Simon Coveney, TD, Minister for Agriculture, Food and the Marine in relation to issues pertaining to sulky racing and hare coursing. I will bring your correspondence to the Minister's attention at the next practical juncture. In the interim I have forwarded a copy of your correspondence for the attention of relevant Department officials.

Kind regards

Graham Lennox

Private Secretary

Department of Agriculture, Food and the Marine

The information contained in this email and in any attachments is confidential and is designated solely for the attention and use of the intended recipient(s). This information may be subject to legal and professional privilege. If you are not an intended recipient of this email, you must not use. disclose copy distribute or retain this message or any part of it. If you have received this email in error, please notify the sender immediately and delete all copies of this email from your computer system(s).

An Roinn Talmhaiochta, Bia agus Mara

Tá an teolais san riomhphost seo, agus in aon ceangláin leis, faoi phribhléid agus faoi rún agus le h-aghaigh an seolai amháin. D'fhéadfadh ábhar an seoladh seo bheith faoi phribhléid profisiúnta no dlithiúil. Mura tusa an seolai a bhi beartaithe leis an riomhphost seo a fhaili, tá cosc air, nó aon chuid de, a usaid, a choipeal, no a scaoleadh. Má thainig sé chugat de bharr dearmad, téigh idteagmhail leis an seoltoir agus scrios an t-ábhar ô do riomhaire le do thoil. 


\section{Appendix E: BSA AHSG}

\section{BSA ANIMAL/HUMAN STUDIES GROUP (AHSG)}

\section{Membership Form}

The British Sociological Association (BSA) Animal/Human Studies Group (AHSG) is a forum for academics, researchers and students, who are interested in exploring, discussing and/or actively researching the multifaceted, ambiguous and challenging nature of animal/human related-issues.

Membership of the AHSG is free for all BSA members, students and unwaged, but non-BSA members with institutional support are asked to pay a one-off joining fee of $\mathbf{£ 4 0}$. However, when unwaged and student members, who are not BSA members, enter into paid employment they will be asked to pay the one-off joining fee of $£ 40$ should they wish to continue their Group membership. To keep fully informed of the Group’s activities all members will receive an e-newsletter every two months and will be added to the Group's emailing list; postgraduate students will be added to the Group’s PG-emailing list too. On joining, new members will also be given a password so they can access and contribute to the Group's growing bibliography database. 
Appendix F: Social Media of Shelters 


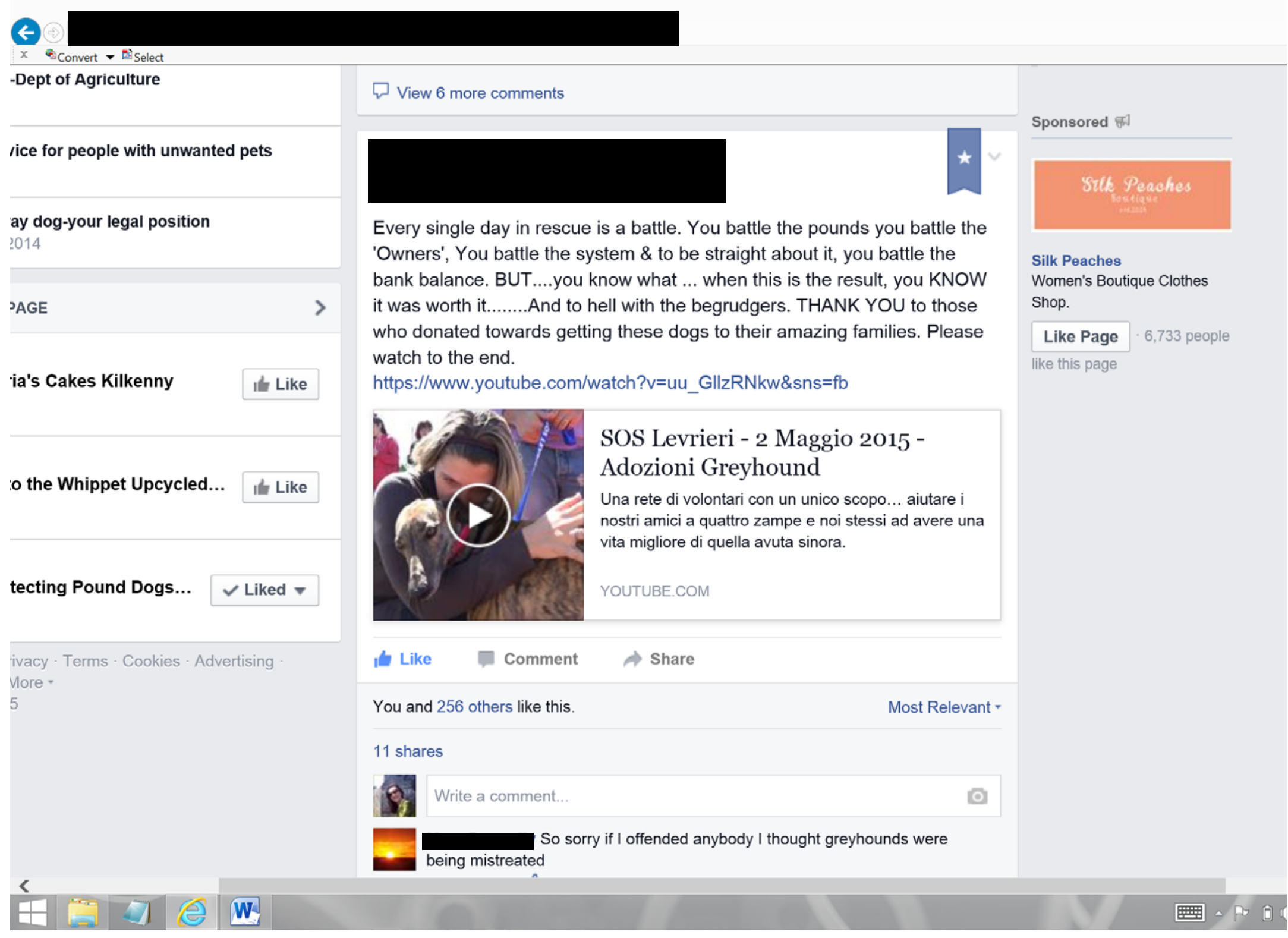




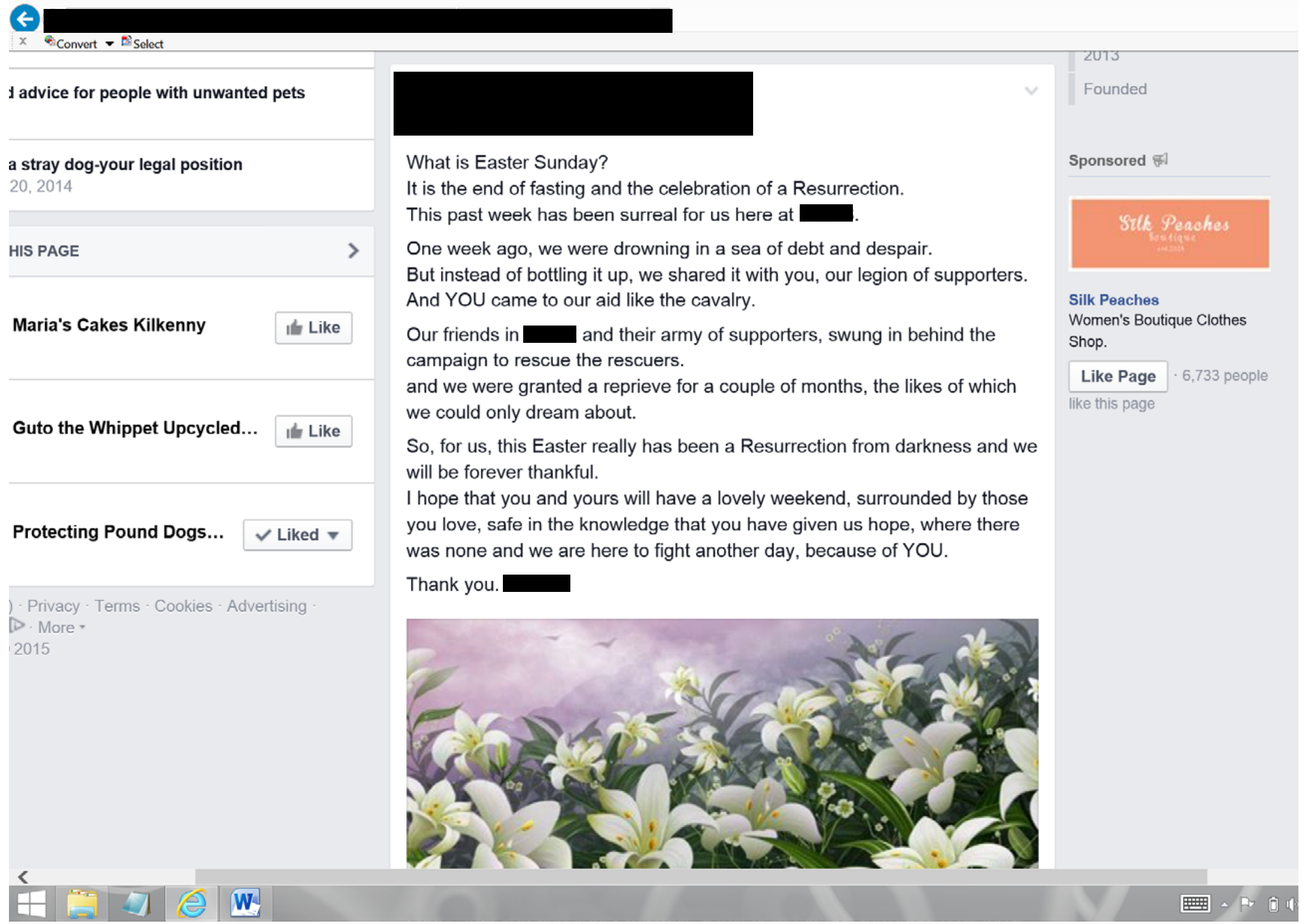




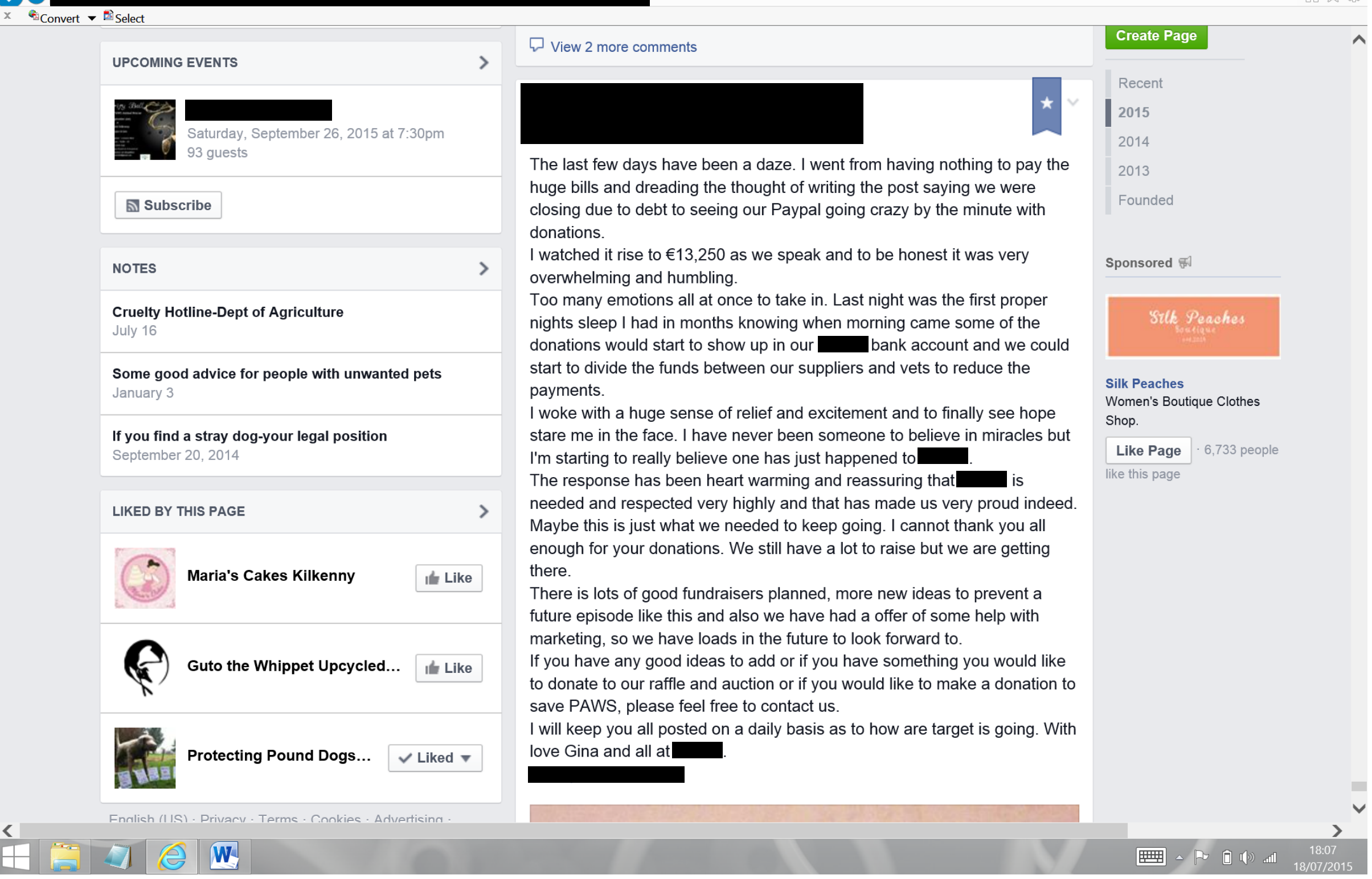




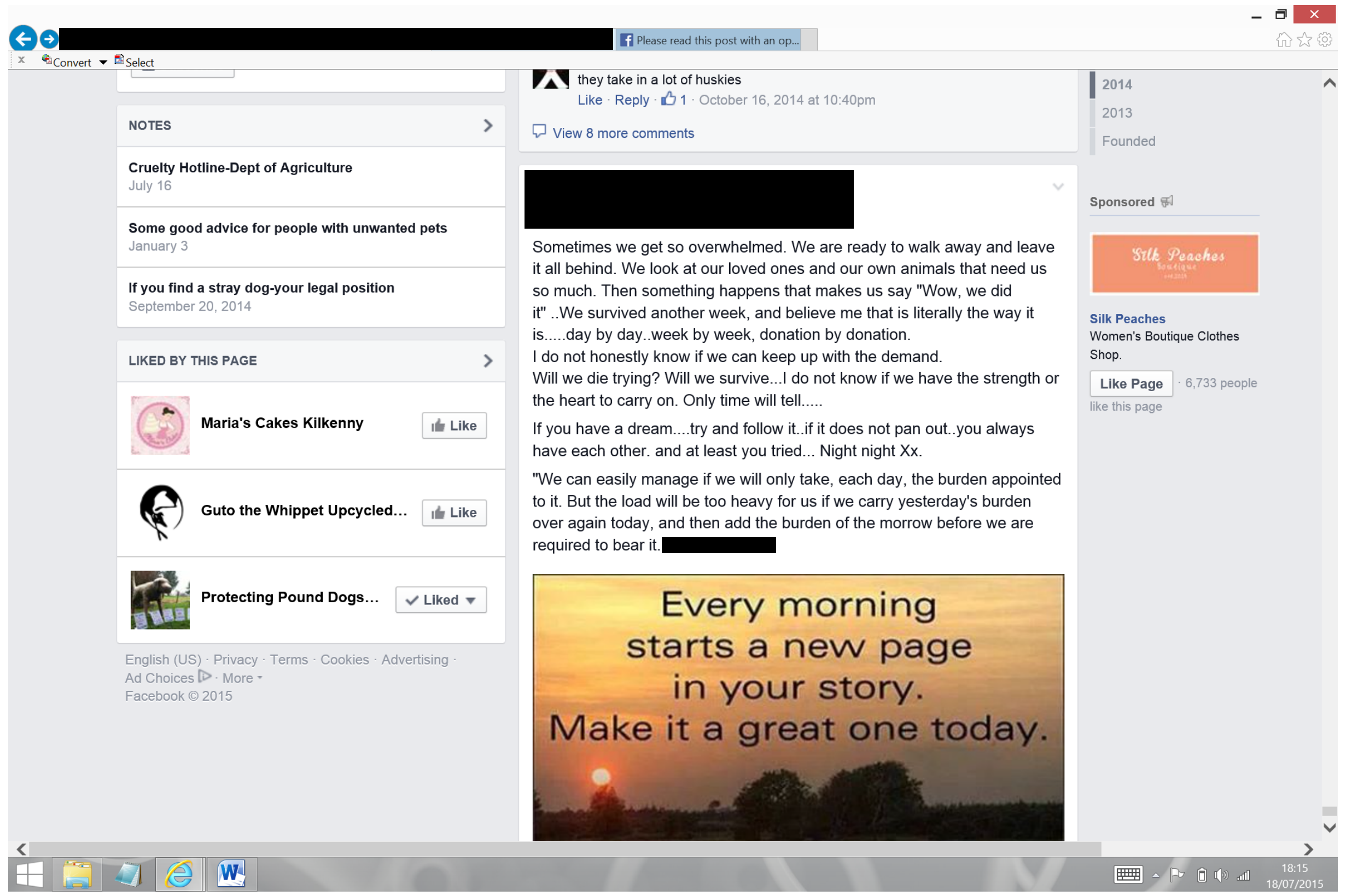


If $\square$ SPC $Q$ Anne Home Find Friends \&

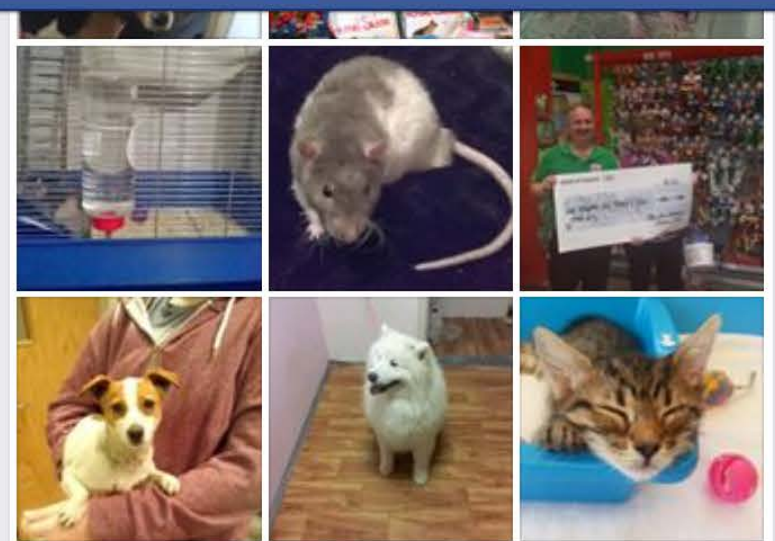

NOTES

HORSE LOCATION PREMISES TO BE REGISTERED - I... February 16, 2012

\section{THE PROTECTION OF ANIMALS ACT, 1911}

February 16, 2012

Protect Irish cats - inclusion in Animal Welfare Bill February 4, 2012

POSTS TO PAGE

\section{Patricia Carr}

July 16 at $1: 57 \mathrm{pm}$ (2)

四 My cat has been missing since monday 13th july.

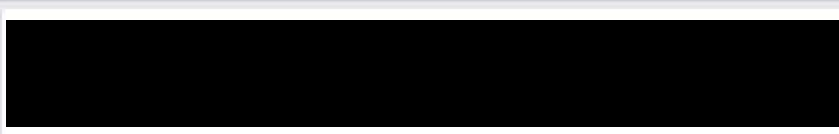

Wु".

The past six weeks for

SPCA have been stressful to say the least. The amount of animals in crisis is unbelievable. The calls about sick, injured and abandoned animals is overwhelming. Please respect the fact that

is $100 \%$ voluntary and we can only do so much. We do our best to the best of our ability. The amount of calls wanting us to find homes for animals that already have homes has seriously increased. Animal rescue is for animals in crisis and not for rehoming other people's pets. When we say we can't help we really can't and the emotional blackmail of well we will just dump or have to put to sleep the animal does NOT have any impact on us. Statements like that we just have to leave with the caller as the onus is on them. We are not a dumping ground for your pets. The easy way out for some people is out of sight out of mind. Instead of ringing us respect the fact that when you find a stray dog firstly try to establish is it stray or has it just got out of where it lives. Keep the dog safe or find someone who will. Take it to the nearest Vets and check for a microchip. Let the dog warden service (legally your obliged to do so) local vets, Garda, local radio and social media facebook and twitter know you have found the dog. Owners are found quite quickly by taking these steps. Use your common sense when you decide to pick up a dog as the responsibility now lies with the finder.Please respect the fact that $\square$ SPCA is doing is utmost for animals in crisis.

\section{$\Rightarrow$ Share}

10 people like this.

I found too dogs this morning. I don't have anywhere I can keep them safe, unfortunately, and they were beside a busy road. I didn't think about microchipping, I brought them to my house but that didn't work because

\section{Create Page}

Recent

2015

2014

2013

2012

2011

Sponsored क्ञा

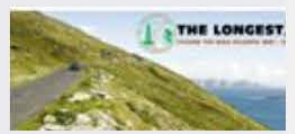

The Longest Irish Road In August 2015, Ben Cunningham and Wathik Alaaraji will cycle the entil length $(2,500 \ldots$

Like Page $\cdot 1,314 \mathrm{pt}$ like this page 
4 (5) https://www.facebook.com/pages Convert - ESelect

\section{iléidigh}

pm $\theta$

all black and white female dog re
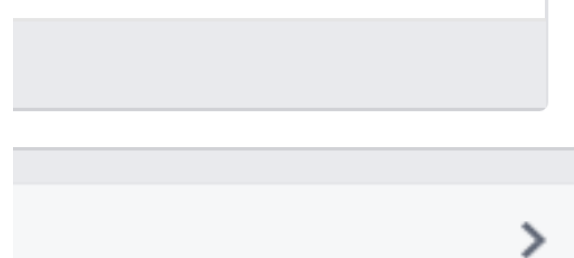

| For Animal W... Il Like

er animal welfa... It Like

lin

is · Cookies · Advertising
My self and

added 11 new photos.

have taken in these five adorable Shih-tzu $\mathrm{x}$ terrier puppies.

The puppies have been looked after and socialized to perfection by an older ...

See More
Like
Comment
$\rightarrow$ Share

Top Comments

17 people like this.

Write a comment.

Hi are any still available?

Like - Reply - June 7 at 8:15pm

SPCA UP DATE..... Because we had a phenomenal amount of enquires about the puppies. Almost 500 good people enquired. My self and decided to not to do the adoption day next week that we were planing. There is no need as we managed to find suitable homes with out doing so. It's heart warming to see how many people care about rescue animals. A huge collective thank you to every one who cared enough to enquire. As of now the puppies are all spoken for and will be homed in the next few days.

Like $\cdot 31$. June 7 at 8:25pm 
$(-2$ https://www.facebook.com/page

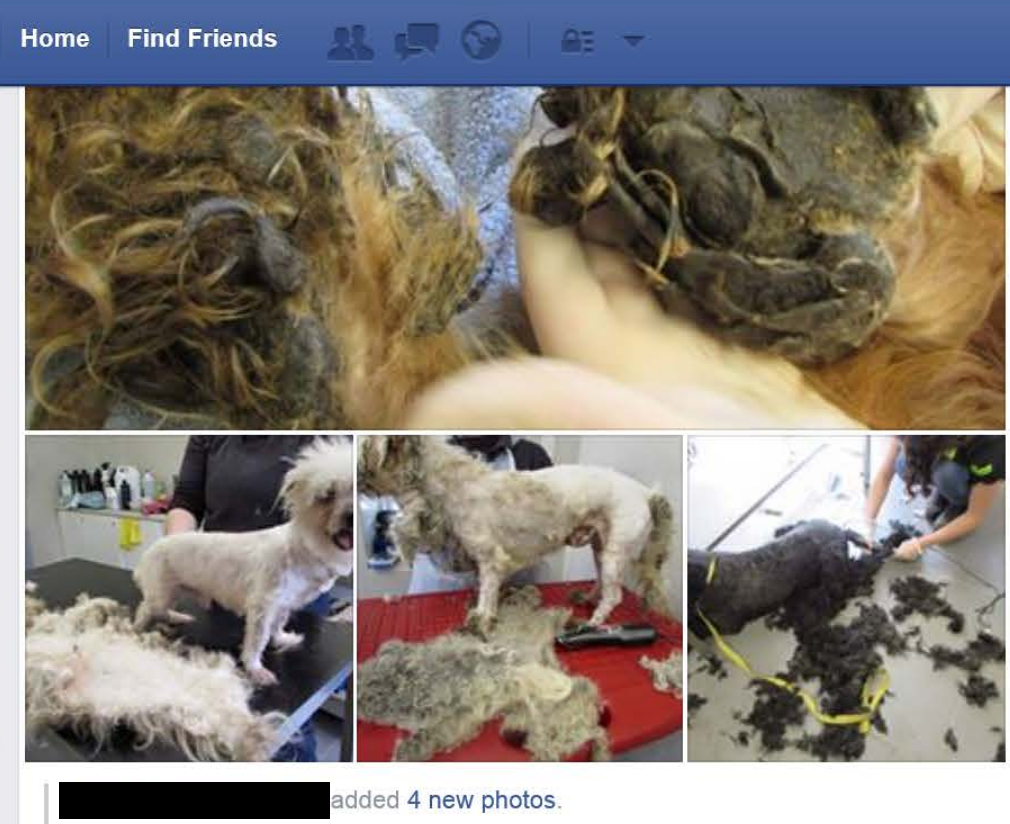

LIKED BY THIS PAGE
Ireland United For Animal W... IL Like

(1) I support better animal welfa... II Like

Coł̌ Aide Cats' Aid Dublin

It Like

The huge task to clean up and rehabilitate the Myshall puppy farm dogs continues and will continue for a long time. Please be mindful that almost 400 dogs and that's not counting the puppies that have yet to be born have been filtered out to every available rescue space and foster support family out there. Donate directly to where the dogs are as these are the volunteers that desperately need food and bedding. If you donate to the ISPCA at national level or make sure that they filter the mo.,$y$, fo $\mathrm{O}_{1}$, bedding, etc out to the foster support that need it. This operation is mind blowing. Please also be mindful and remember all the other dogs already in rescue as they all need homes too. Keep sharing and and don't let this horrible dog rescue go quiet. This one will take a long time to come right.
I) Like
Comment
$\rightarrow$ Share

32 people like this.

Top Comments =

English (US) - Privacy - Terms - Cookies - Advertising

8
Write a comment
Create Page

| Recent

2015

2014

2013

2012

2011

Sponsored 액

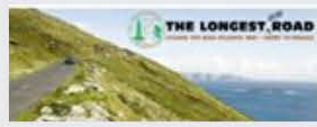

The Longest Irish Road

In August 2015, Ben

Cunningham and Wathik

Alaaraji will cycle the entire

length $(2,500$...

Like Page - 1,314 people

like this page 


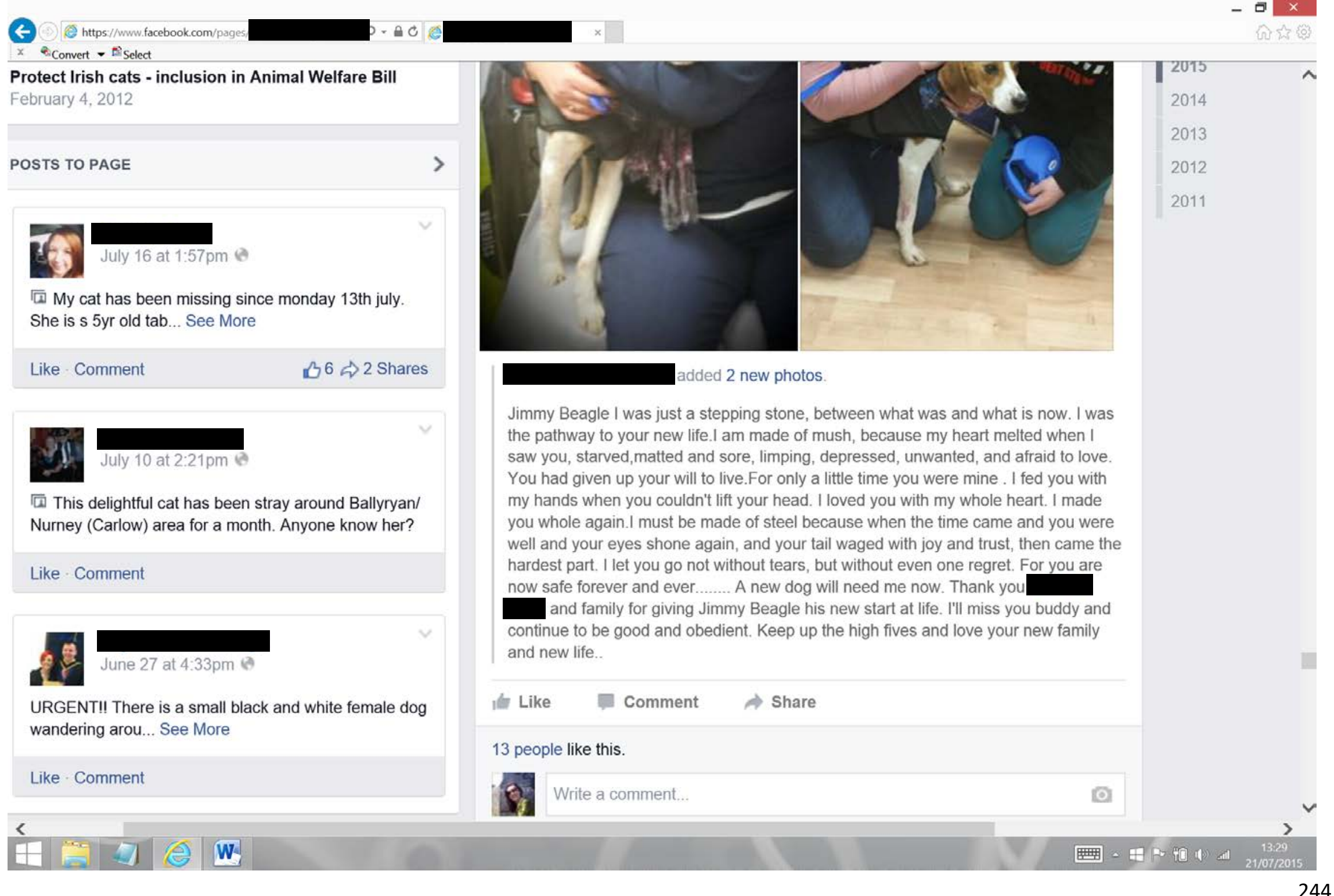


(4) https://www.facebook.com/pages

LIKED BY THIS PAGE o. oc

$>$

Ireland United For Animal W..

It Like

(1) I support better animal welfa... I Like

\section{Kał̌sAide Cats' Aid Dublin}

It. Like

English (US) - Privacy - Terms - Cookies - Advertising Ad Choices $D$. More -

Facebook @ 2015
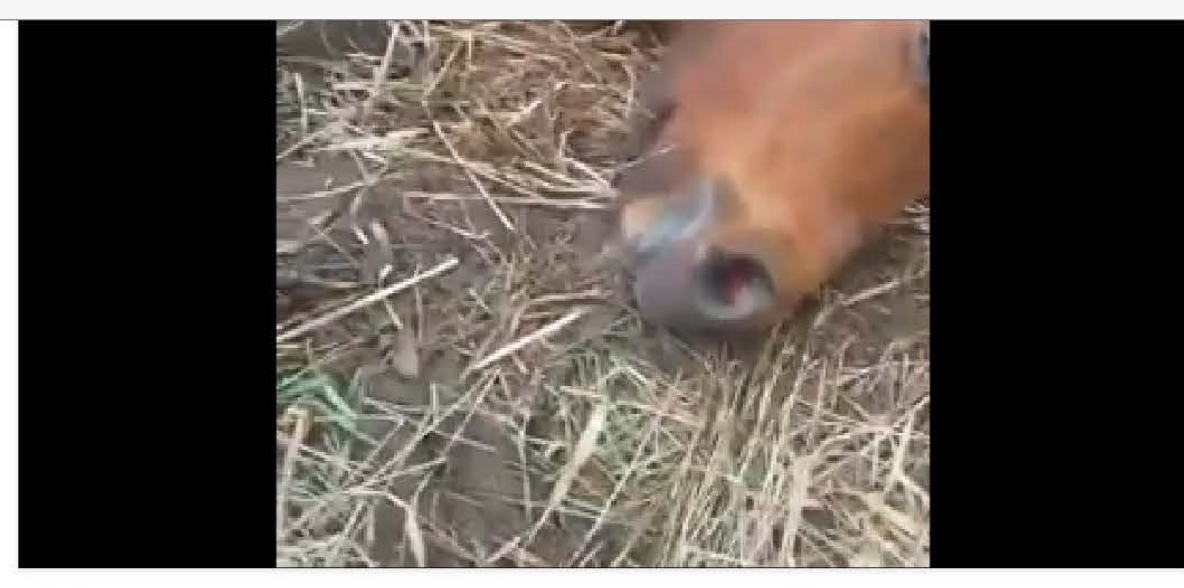

1,905 Views

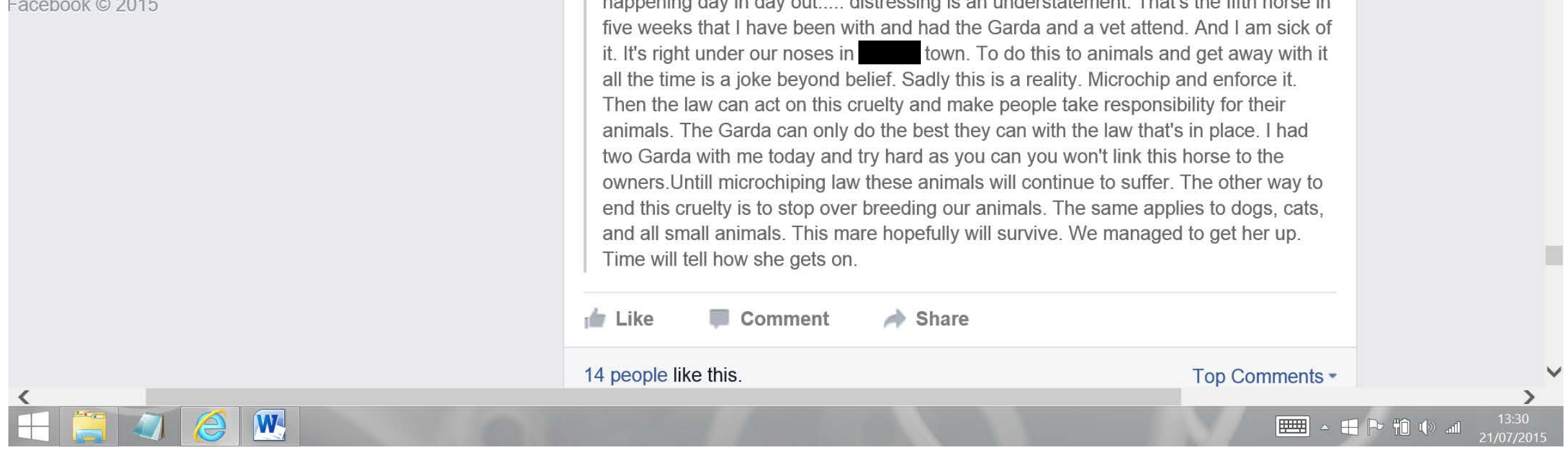

Apologies to anyone this post upsets but I feel it should be seen and shared. This is happening everyday in every county. How are we supposed to put a stop to this

happening day in day out.... distressing is an understatement. That's the fifth horse in five weeks that I have been with and had the Garda and a vet attend. And I am sick o it. It's right under our noses in town. To do this to animals and get away with it all the time is a joke beyond belief Sadly this is a reality. Microchip and enforce it. Garda with me today and try hard as you can you won't link this horse to the ond this cruelty is to stop over breeding our animals. The same applies to dogs, cats, and all small animals. This mare hopefully will survive. We managed to get her up. 
Not only is shelter work constructed and continuously reconstructed as meaningful and moral work, it also offers sanctuary from alternative workplaces and in HAR and rural settings.

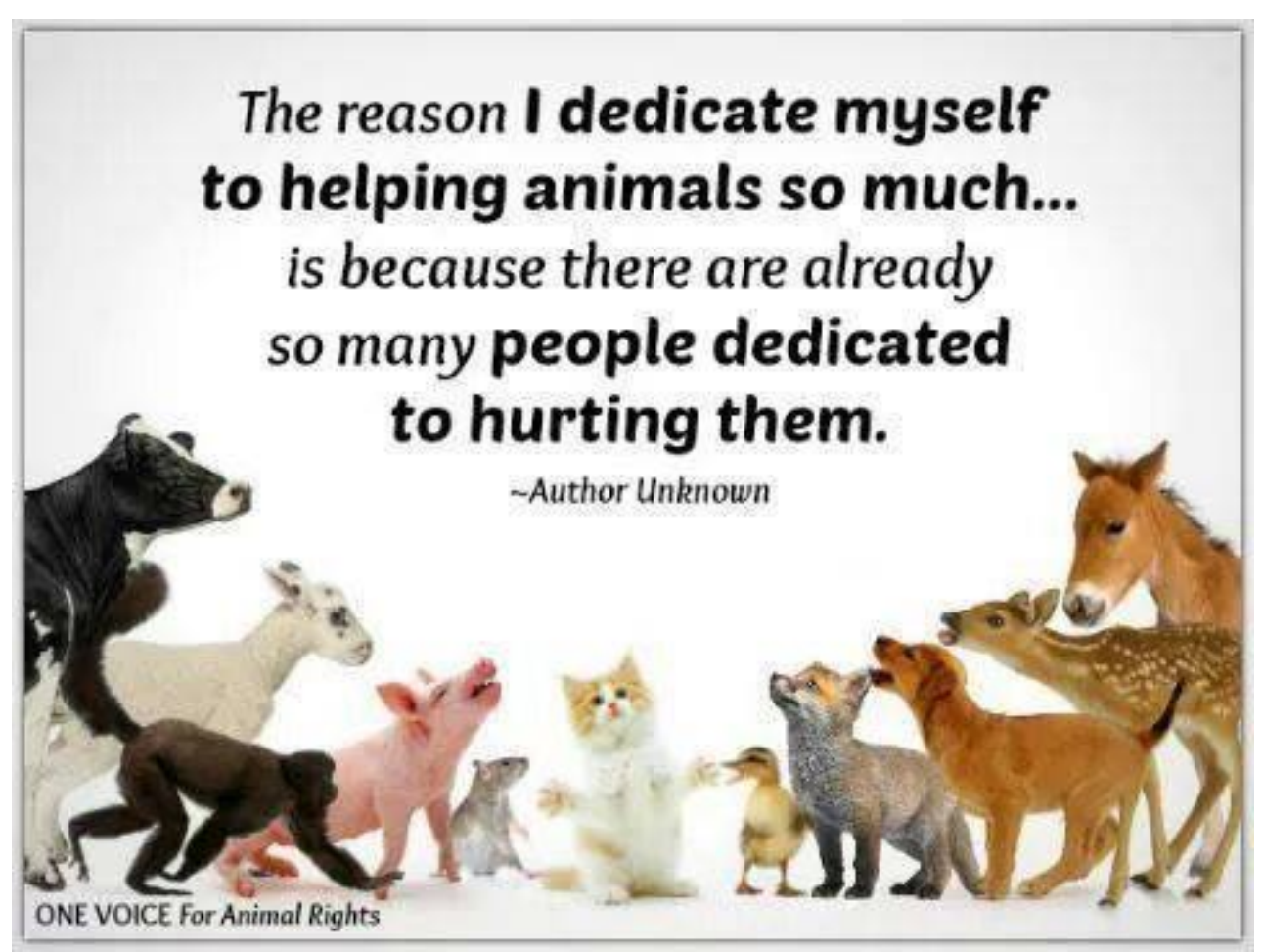




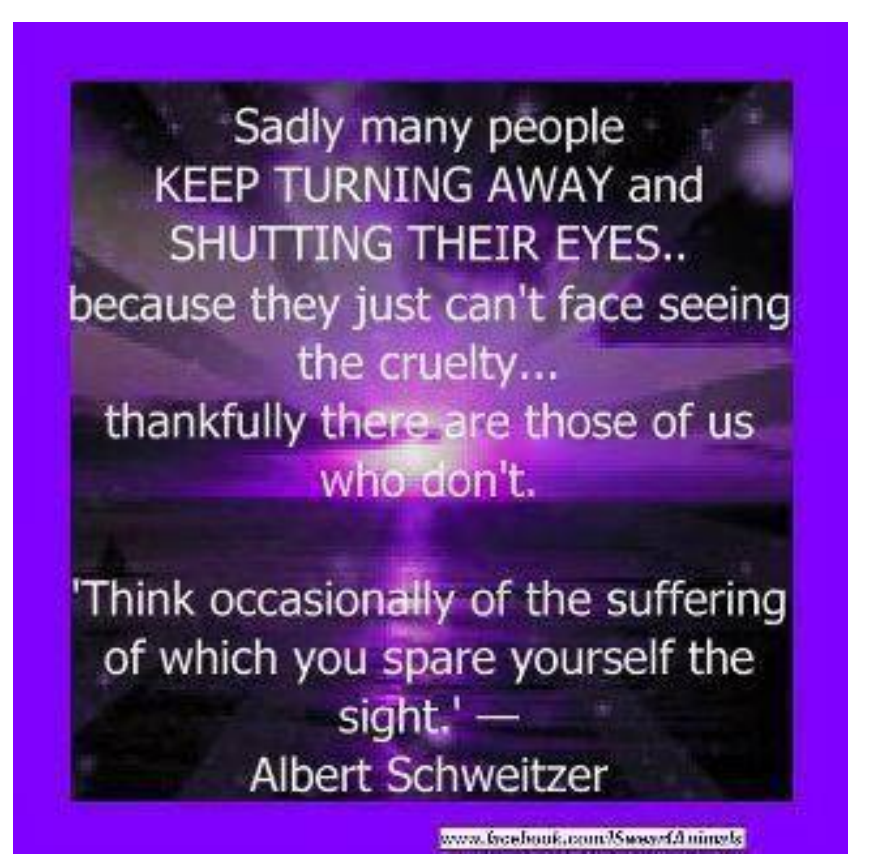


Rescuers, rescue supporters, and volunteers do not walk on water. We don't wear capes and tights or leap tall buildings. We aren't better than anyone else, but we do pursue a cause that we believe makes us better than we were before we started. We make mistakes; we feel we can't do enough; we go broke; we have too many dogs at home; we rant out of frustration; we lose our tempers and get snappy; we have to reject people sometimes for the good of a dog. We are not always likeable. What we do is draining, emotionally, financially, and physically. Please bear with us and forgive us our flaws, because we are doing work that's bigger than we are. Author Unknown 
Can't sleep at night...... tormented and stressed as there are so many animals in trouble that we just can't reach on. My self ar

Ir are doing our

very best to cope with what we have in our care all the time. There is no lull or let up at all. This summer has been so bad that at one stage we had over 80 animals

in our care. Thankfully through adoption we have a manageable number of 37 right now. We are constantly doing and organizing T.N.R all the time.When we ... 


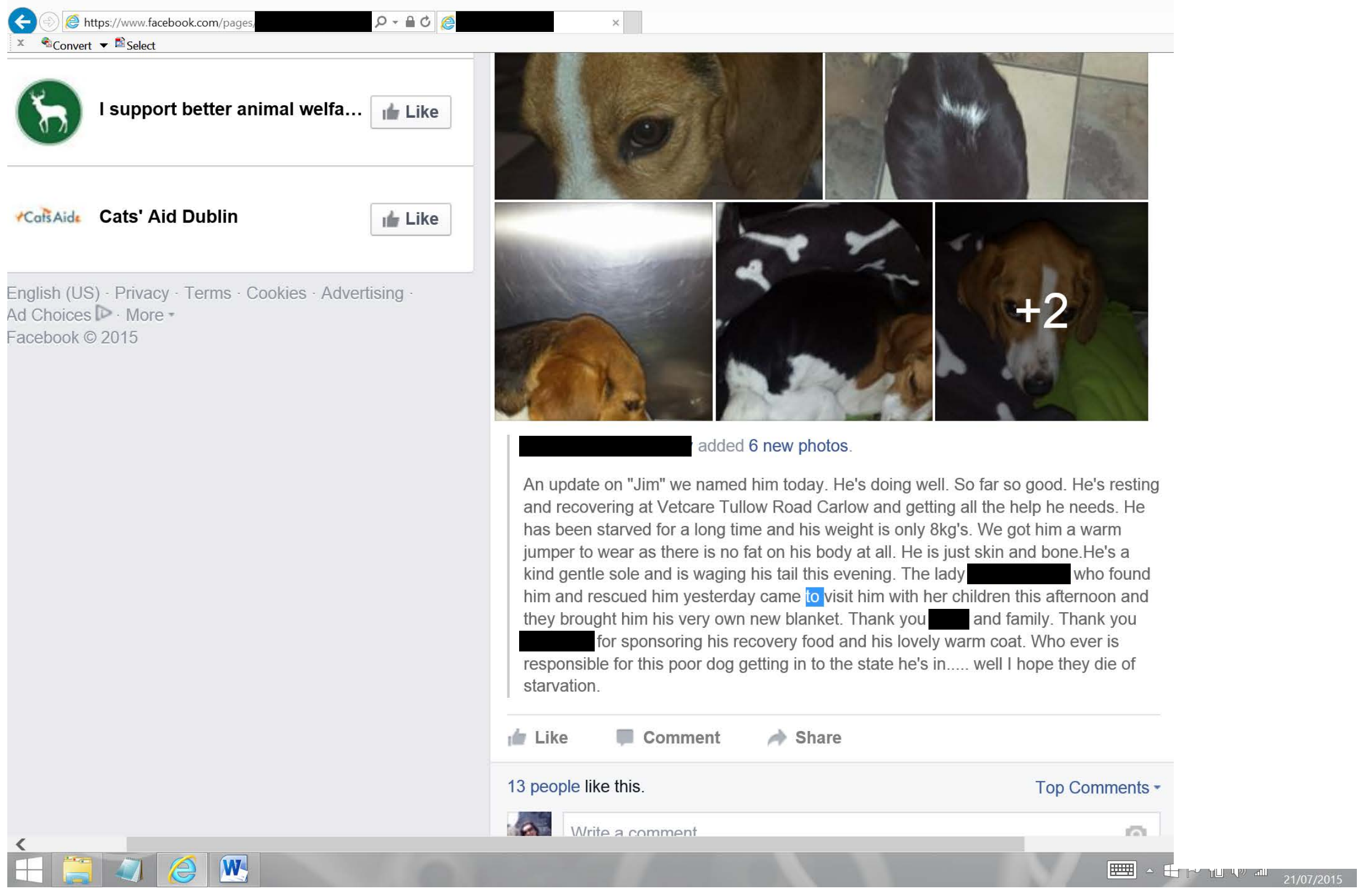




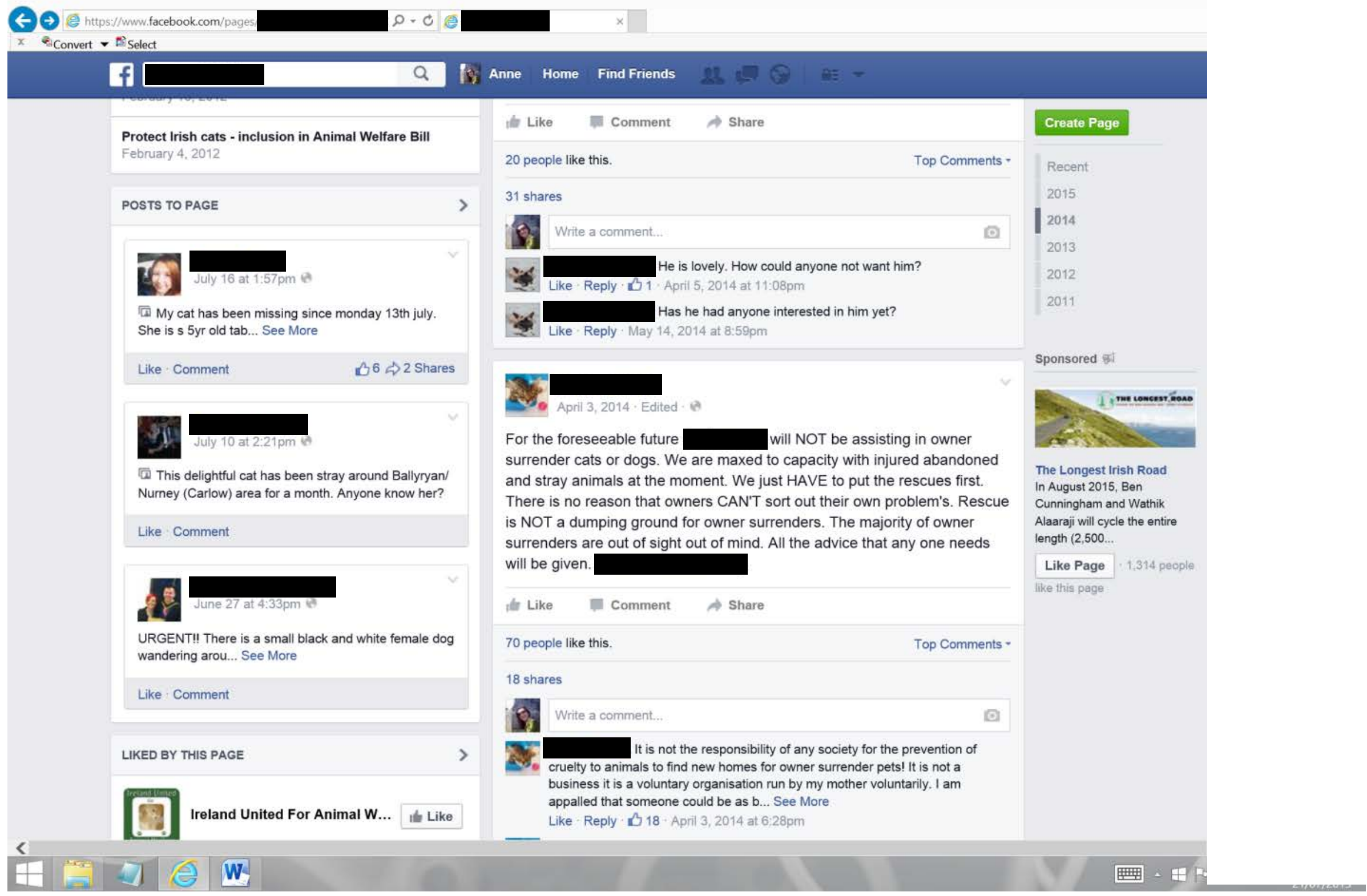




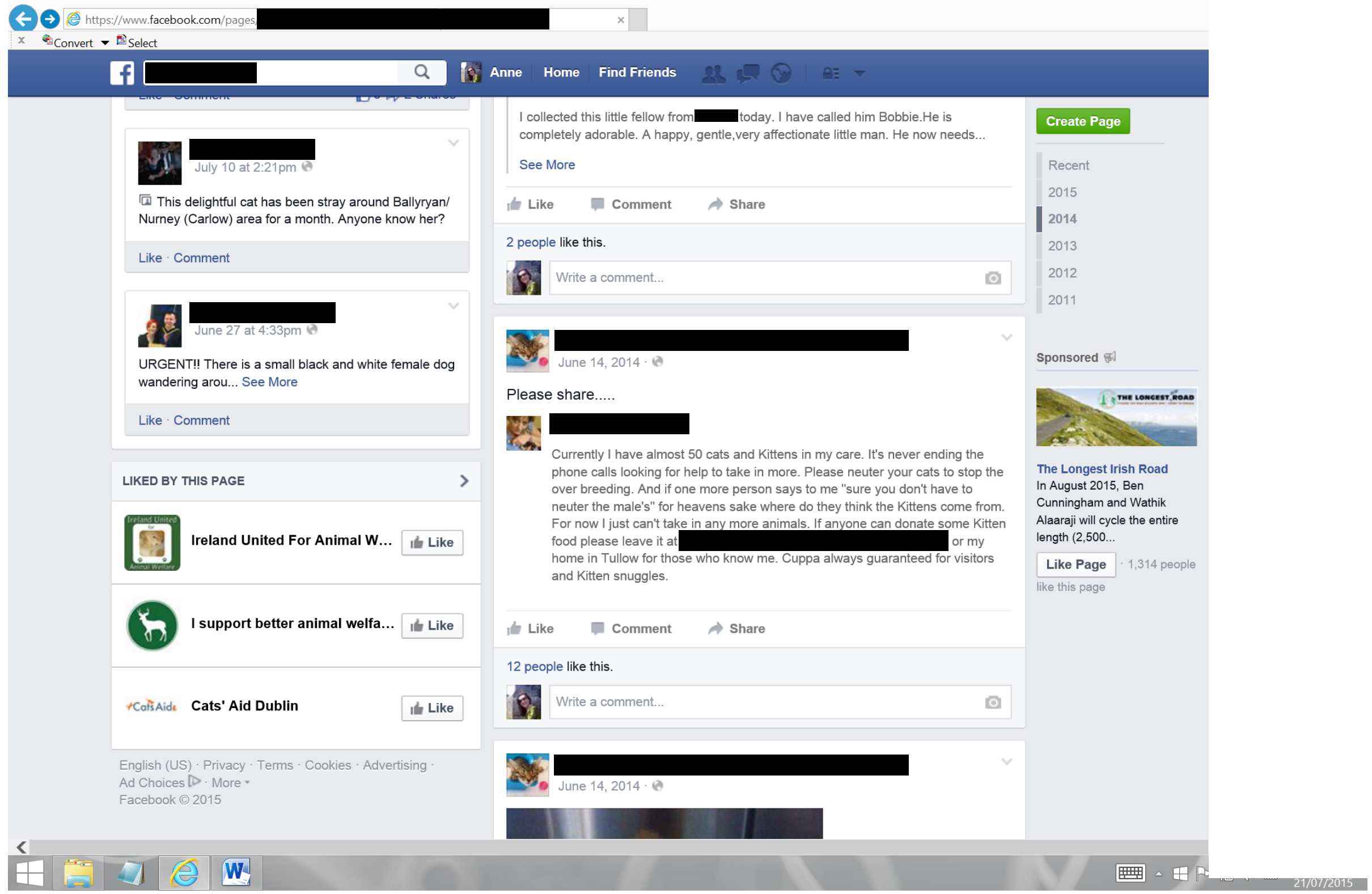




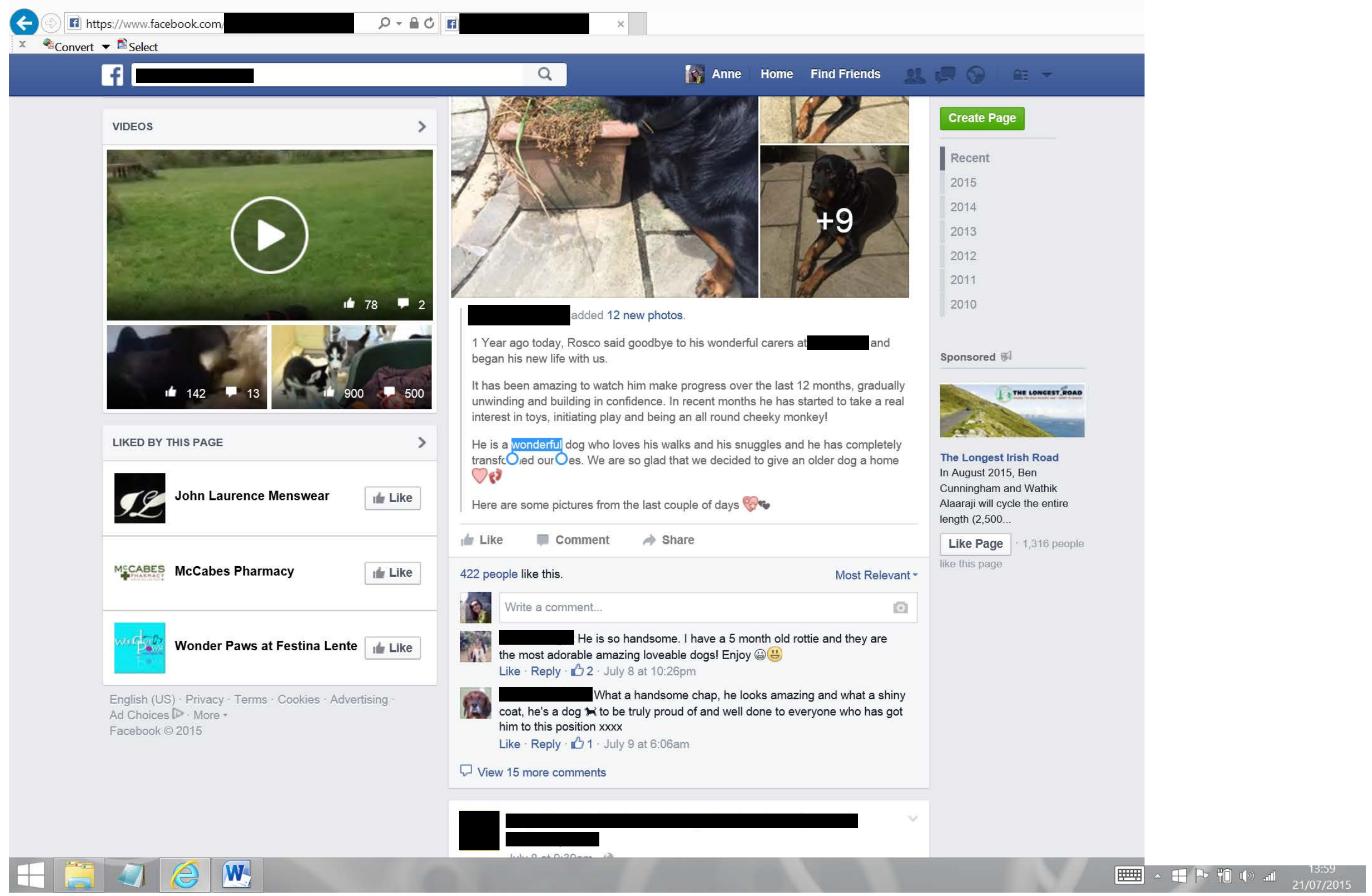




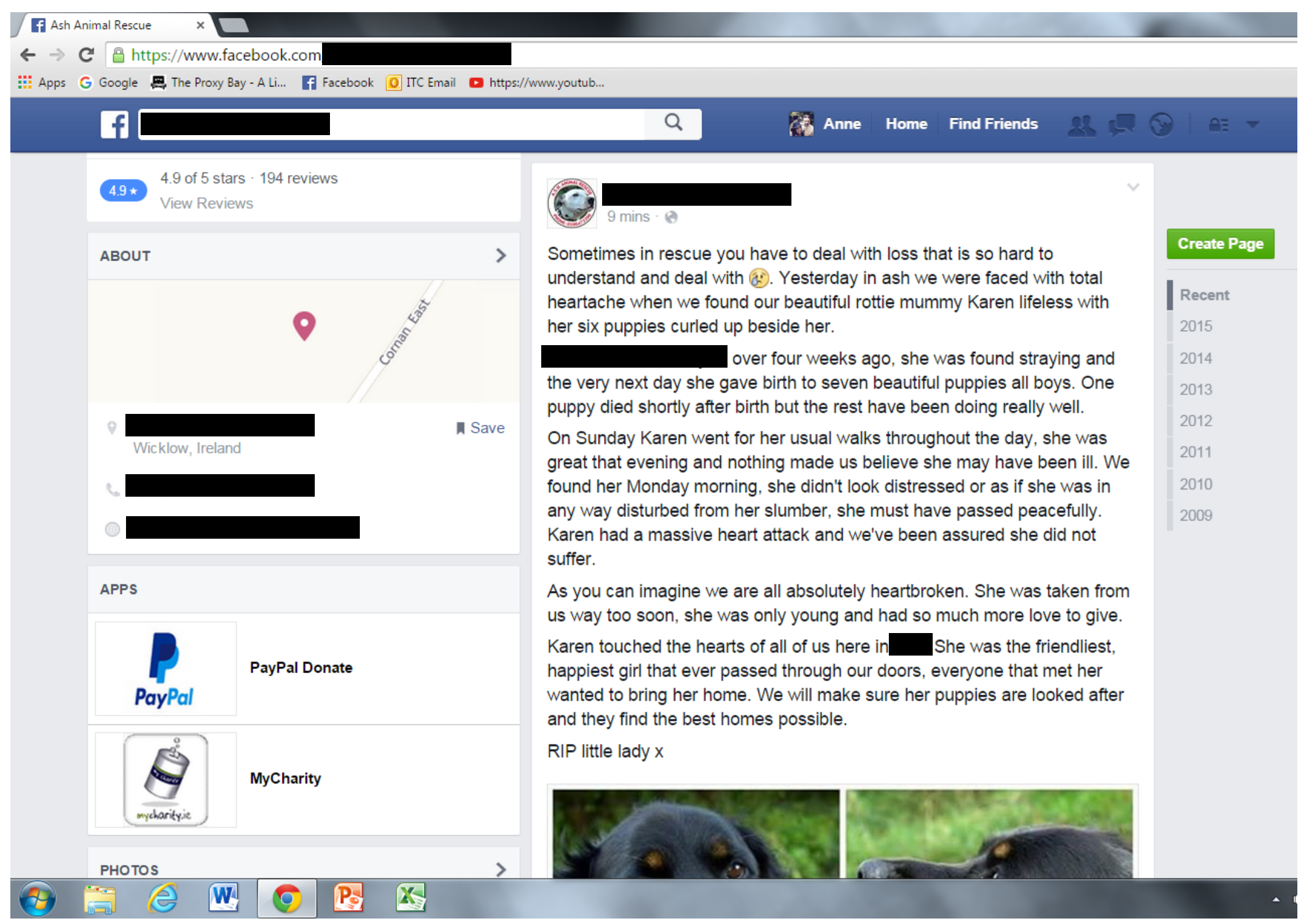




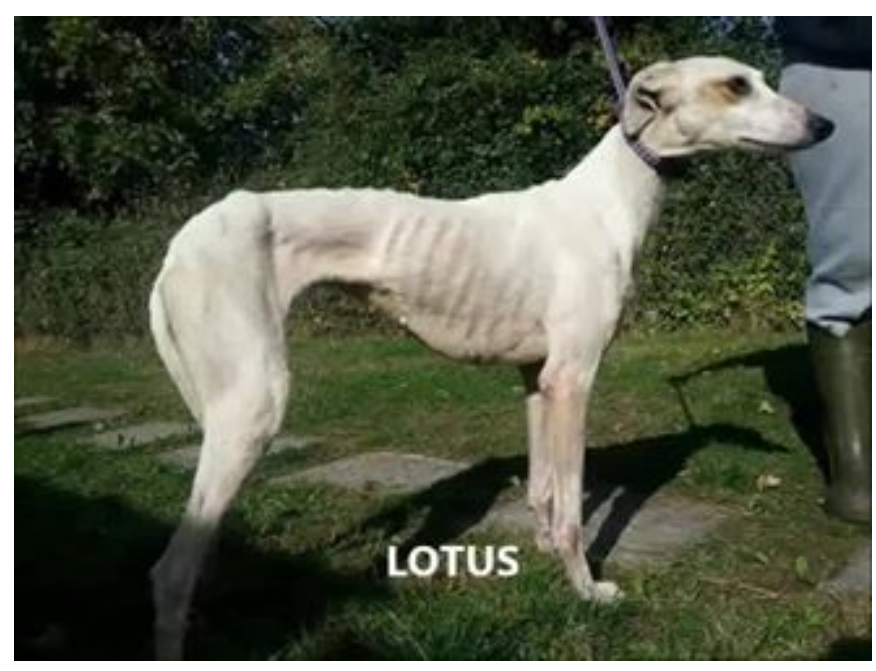

October 25 at 10:33pm.

This has been a particularly difficult weekend for our team. Two of our very special dogs passed over and two long termers that had been rehomed were returned. Every day in animal rescue is a challenge but this weekend has been damn hard. Your moral support for $t$ $\mathrm{m}$ at PAWS is equally as important as financial support. So please keep us in your prayers and thank you for caring. 


\section{OUR GREATEST ONR GRERT CIORY ( GLORY IS NOT IN NEVER FALLING DIT RISTC BUT RIJNG EVERY TIME WE FALL.}

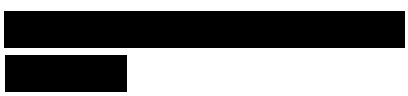


Appendix G: 'Best Job in the World'

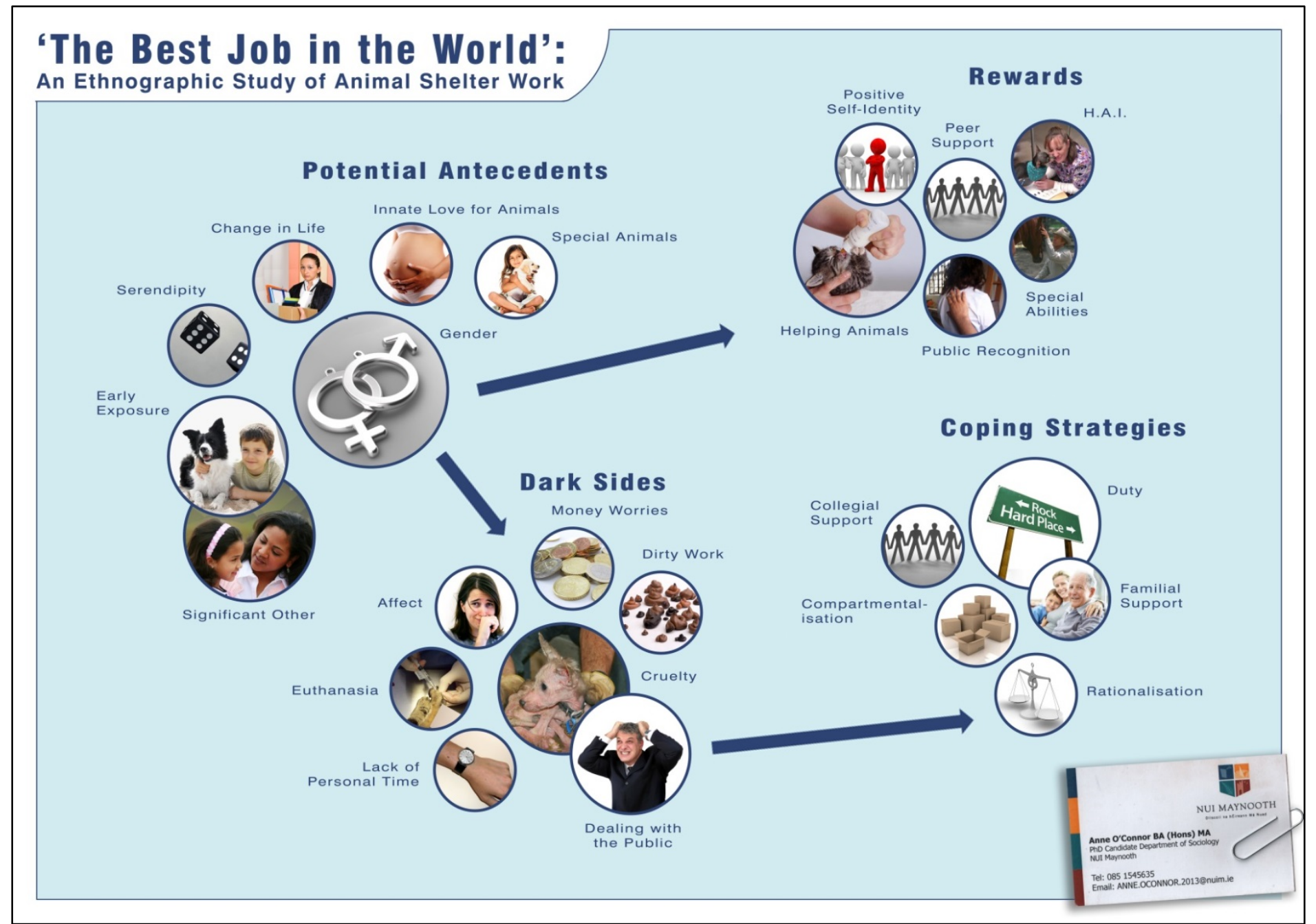




\section{Appendix H: DAFM Grants 2015}

\begin{tabular}{|c|c|c|}
\hline & RECIPIENTS NAME & AWARD \\
\hline 1 & A Dogs Life, c/o Martina Roche, Parkstown Lower, Glenmore, Co. Kilkenny & $€ 2,600.00$ \\
\hline 2 & Ainmhithe Animal Rescue, Thornberry Cottage \& Sanctuary, Rathrea, Kincon, Ballina, Co & $€ 7,000.00$ \\
\hline 3 & An Cat Dubh Sanctuary, Clounlaheen East, Mullagh, Co Clare. & $€ 2,400.00$ \\
\hline 4 & Animal Heaven Animal Rescue (AHAR), Crag, Castleisland, Co. Kerry & $€ 16,000.00$ \\
\hline 5 & Animal Help Net Kerry, Beechlawn, The Kerries, Tralee, Co Kerry. & $€ 2,700.00$ \\
\hline 6 & Animal Rescue Skibbereen, Skeagh, Skibbereen, Co Cork. & $€ 8,000.00$ \\
\hline 7 & Animal Trust Fund, Barristown, Passage East, Co Waterford & $€ 1,100.00$ \\
\hline 8 & Animals In Need, Clareden Drive, Donegal Town, Co Donegal. & $€ 21,000.00$ \\
\hline 9 & Animal Sanctuary Hubasha Ltd / ASH Animal Rescue, Rathangen, Kiltegan, Co. Wicklow & $€ 20,000.00$ \\
\hline 10 & Athlone \& Westmidlands SPCA, Feevaghmore, Dysart, Ballinasloe, Co Roscommon & $€ 4,200.00$ \\
\hline 11 & Athlone Animal Welfare, Connaught Street, Athlone, Co. Westmeath & $€ 4,600.00$ \\
\hline 12 & Avalon Greyhound Sanctuary, Pro Animal Ireland Ltd., Flesk, Woodford, Co Galway & $€ 8,400.00$ \\
\hline 13 & *Blackwater Animal Rescue, Kilworth, Fermoy, Co. Cork * & $€ 1,000.00$ \\
\hline 14 & Burren Animal Rescue, Rockforest, Tubber, Co. Clare & $€ 2,100.00$ \\
\hline 15 & *Cara Rescue Dogs Limited, Cara Cottage, Derrycloney, Mountmellick, Co Laois* & $€ 1,000.00$ \\
\hline 16 & Carrick Dog Shelter, Corlea, Lisdoonan, Carrickmacross, Co. Monaghan & $€ 12,500.00$ \\
\hline 17 & Cat Concern Wicklow,27 Heathervue, Greystones, Co Wicklow & $€ 3,000.00$ \\
\hline 18 & Cats Aid, C/O 7 Ashfield Gardens, Mulhuddart, Dublin 15 & $€ 9,600.00$ \\
\hline 19 & *Cats Friends Rescue, 39 Furryhill, Sandyford Road, Dublin 16* & $€ 1,000.00$ \\
\hline 20 & Cavan SPCA, Shankhill, Co. Cavan & $€ 26,400.00$ \\
\hline 21 & Chippers Sanctuary, Gorey, Co. Wexford & $€ 3,000.00$ \\
\hline 22 & Clare SPCA, Newmarket on Fergus, Co. Clare & $€ 15,000.00$ \\
\hline 23 & Clifden Animal Rescue, Ardbear, Clifden, Co. Galway & $€ 2,400.00$ \\
\hline 24 & Clondalkin Animal Aid Ltd.,91 Boot Road, Clondalkin, Dublin 22 & $€ 4,800.00$ \\
\hline 25 & Community Cats Network, Glanavaud, Kilbrittan, Co Cork & $€ 5,000.00$ \\
\hline 26 & Cork Animal Care Society, Hillview Lodge, Clashbredane, Kilmichael, Co Cork. & $€ 6,000.00$ \\
\hline 27 & Cork Cat Action Trust, C/O Pier View House, Castle Road, Blackrock, Co. Cork. & $€ 10,800.00$ \\
\hline
\end{tabular}




\begin{tabular}{|c|c|c|}
\hline 28 & Cork Dog Action Welfare Group Limited, Moulnahorna, Carriganima, Co. Cork & $€ 9,000.00$ \\
\hline 29 & Cork SPCA, Link Road, Mahon, Co Cork & $€ 40,000.00$ \\
\hline 30 & Cottage Rescue, Longfield, Cashel, Co Tipperary & $€ 7,900.00$ \\
\hline 31 & Cry for Help Cattery, 7 St Agnes Cottages, Mullingar, Co Westmeath & $€ 5,000.00$ \\
\hline 32 & Deise Animal Sanctuary, Knocknaree, Ballymacarbry, Co Waterford & $€ 4,800.00$ \\
\hline 33 & Dog Rescue Coolronan, Ballivor, Co. Meath & $€ 1,800.00$ \\
\hline 34 & Dogs Aid Animal Sanctuary, Meakstown, Co Dublin & $€ 8,000.00$ \\
\hline 35 & Dogs in Distress, Ash Hill, Dunboyne, Co. Meath & $€ 7,200.00$ \\
\hline 36 & Donegal Donkey Sanctuary, Castle Dooey, Raphoe, Co Donegal. & $€ 2,100.00$ \\
\hline 37 & Dr Homes Moate \& Midlands Dog Rescue, Knockdomney, Moate, Co. Westmeath & $€ 5,400.00$ \\
\hline 38 & Drogheda Animal Rescue, Bellscourt, Scholes Lane, Drogheda, Co. Louth & $€ 17,500.00$ \\
\hline 39 & DSPCA, Mount Venus Road, Rathfarnham, Dublin 16 & $€ 210,000.00$ \\
\hline 40 & Dublin Animal Rescue Group, Griffith Avenue, Drumcondra, Dublin 9 & $€ 2,500.00$ \\
\hline 41 & Dundalk Dog Rescue, Walterstown, Castlebellingham, Co. Louth & $€ 5,700.00$ \\
\hline 42 & Dungarvan (SPCA) Rescue Kennels, Garranbane, Dungarvan, Co Waterford & $€ 12,600.00$ \\
\hline 43 & Enniscorthy SPCA, C/O Sinead Brennan, Ballinakill, Marshalstown, Enniscorthy Co. Wexford & $€ 11,200.00$ \\
\hline 44 & Fairyglen Community Animal Sanctuary, Arigna, Co Roscommon & $€ 10,500.00$ \\
\hline 45 & Fellenberg Foundation Ltd., Flesk, Woodford, Co Galway & $€ 1,400.00$ \\
\hline 46 & Fingal SPCA, The Burow, Portrane, Co. Dublin & $€ 3,200.00$ \\
\hline 47 & Forgotten Horses Ireland, Castletaylor, Ardrahan, Co Galway & $€ 3,500.00$ \\
\hline 48 & Friends for Wildlife, Derryinver, Letterfrack, Co. Galway & $€ 2,400.00$ \\
\hline 49 & Friends of Animals, Greenpeace Cottage, Cullionbeg, Mullingar, Co. Westmeath & $€ 5,200.00$ \\
\hline 50 & Fur Babies, Carrick View, Ballygibbon, Edenderry, Co. Offaly & $€ 2,400.00$ \\
\hline 51 & Galway \& Claddagh Swan Rescue, 68 Ashleigh Grove, Knocknacarra, Co. Galway & $€ 3,600.00$ \\
\hline 52 & Galway Cat Rescue, 120 Seacrest, Knocknacarra, Co. Galway & $€ 2,400.00$ \\
\hline 53 & Galway SPCA, 2A St Augustine Street, Co. Galway & $€ 34,000.00$ \\
\hline 54 & Great Hounds in Need, 7 Cois Coille, Kilcash, Ballypatrick, Clonmel, Co. Tipperary & $€ 1,100.00$ \\
\hline 55 & Greystones Kitty Hostel, 7 Rivendell, Greystones, Co. Wicklow* & $€ 1,000.00$ \\
\hline
\end{tabular}




\begin{tabular}{|c|c|c|}
\hline 56 & Hollys Horse Haven, Howes Hill, Knocknagora, Omeath, Co. Louth & $€ 12,000.00$ \\
\hline 57 & $\begin{array}{l}\text { Homes for unwanted Greyhounds, Corrawoolia, Glencuttane Lower, Kilgobnet, Beaufort, } \\
\text { Co. Kerry }\end{array}$ & $€ 2,800.00$ \\
\hline 58 & Hungry Horse Outside, Currygranny, Newtownforbes, Co. Longford & $€ 30,000.00$ \\
\hline 59 & Inistioge Puppy Rescue Ballygub, Inistioge Co. Kilkenny & $€ 8,400.00$ \\
\hline 60 & Irish Horse Protection League, Manor Kilbride, Blessington, Co. Wicklow & $€ 4,500.00$ \\
\hline 61 & $\begin{array}{l}\text { *Irish Horse Rehoming Programme ,C/O Karen Keogh, IHRP, Beacon Stud, Kilcappa, } \\
\text { Cloneygowan, Co. Offaly }\end{array}$ & $€ 4,000.00$ \\
\hline 62 & Irish Horse Welfare Trust, Ballinamona, Woodenbridge, Arklow, Co. Wicklow & $€ 60,000.00$ \\
\hline 63 & Irish Raptor Research Centre/Eagles Flying, Ballymote, Co. Sligo & $€ 8,400.00$ \\
\hline 64 & Irish Red Grouse Association, Oakpark, Co. Carlow & $€ 3,000.00$ \\
\hline 65 & ISPCA, Victor Dowling Equine Rescue Centre, Dromsligo, Mallow, Co. Cork & $€ 14,000.00$ \\
\hline 66 & Irish Whale \& Dolphin Group, Merchants Quay, Kilrush, Co. Clare & $€ 1,800.00$ \\
\hline 67 & ISPCA (Head Office), National Animal Centre, Derryglogher, Keenagh, Co Longford. & $€ 210,000.00$ \\
\hline 68 & ISPCA Carlow Branch, Castlemore, Tullow, Co. Carlow & $€ 7,000.00$ \\
\hline 69 & Joan's Animal Rescue Centre, Glangevlin, Co. Cavan & $€ 2,600.00$ \\
\hline 70 & Kathleen Barrett Valley View Equine Retirement Centre,Knocknagorna, Athea, Co. Limerick & $€ 1,400.00$ \\
\hline 71 & Kaths Kitty Corner, Oldrock, Ballymote, Co. Sligo & $€ 1,200.00$ \\
\hline 72 & Kenmare \& Locality Animal Welfare Society, KLAWS, Letter, Reen, Kenmare, Co. Kerry & $€ 3,400.00$ \\
\hline 73 & Kerry SPCA, Rackett Lane, Tralee, Co. Kerry & $€ 7,200.00$ \\
\hline 74 & Kildare \& West Wicklow SPCA, Mullinasella, Calverstown, Kilkullen, Co. Kildare & $€ 15,400.00$ \\
\hline 75 & $\begin{array}{l}\text { Kilkenny Society For Prevention Of Cruelty To Animals Ltd., Norebank Lodge, Greenshill, } \\
\text { Kilkenny }\end{array}$ & $€ 12,000.00$ \\
\hline 76 & Kitten Cottage, Lurganboy, Virginia, Co. Cavan & $€ 1,100.00$ \\
\hline 77 & KWWSPCA Pound Dogs, 34 Cluain Aoibhinn, Craddockstown Road, Naas, Co. Kildare & $€ 1,400.00$ \\
\hline 78 & $\begin{array}{l}\text { Laois Society for the Prevention of Cruelty to Animals, Pump Cottage, Baltracey, Donadea, } \\
\text { Co Kildare }\end{array}$ & $€ 14,000.00$ \\
\hline 79 & Last Hope Animal Charity, PO Box 56, Navan, Co. Meath & $€ 8,400.00$ \\
\hline 80 & *Leinster Animal Rescue Ltd, Clarendon House, Clarendon Street, Dublin 2* & $€ 1,000.00$ \\
\hline 81 & Leitrim Animal Welfare Centre Ltd., Drumkeeran, Co. Leitrim & $€ 15,000.00$ \\
\hline
\end{tabular}




\begin{tabular}{|c|c|c|}
\hline 82 & Lily's Dog Rescue, Annagheen, Shercock, Co. Cavan & $€ 1,300.00$ \\
\hline 83 & Limerick Animal Welfare Ltd., 19 Hillcrest Drive, Greystones, Co. Limerick & $€ 41,000.00$ \\
\hline 84 & Limerick Feral Cats, 45 Bellevue Court, Father Russell Road, Co. Limerick & $€ 3,000.00$ \\
\hline 85 & Limerick SPCA, 289 Fr. Russell Square, Hyde Road, Co. Limerick & $€ 13,300.00$ \\
\hline 86 & *Little Wings Bird Sanctuary, Delchristy Cottage, Banada, Tourlestrande, Co. Sligo* & $€ 1,000.00$ \\
\hline 87 & Longford SPCA, Unit 2, Market Square, Longford, Co. Longford. & $€ 21,000.00$ \\
\hline 88 & Louth SPCA, St. Alphonsus Road, Dundalk, Co. Louth & $€ 21,000.00$ \\
\hline 89 & Mallow Animal Rescue, Knockane, Ballyclough, Mallow, Co. Cork & $€ 1,000.00$ \\
\hline 90 & Mayo Animal Welfare, Honey Cottage, Kilmeena,Westport, Co. Mayo & $€ 3,000.00$ \\
\hline 91 & Mayo SPCA Ltd, Pattens Park, Ballyhaunis, Co. Mayo & $€ 9,600.00$ \\
\hline 92 & Mo Chara Animal Rescue, 22/23 Liberty Square, Thurles, Co. Tipperary & $€ 7,000.00$ \\
\hline 93 & *Mollies Animal Welfare, Newtown Common, Duleek, Co. Meath* & $€ 1,000.00$ \\
\hline 94 & Monaghan SPCA, Killydonagh, Emyvale, Co. Monaghan & $€ 23,900.00$ \\
\hline 95 & Munster Lost and Found Pet Helpline, Ballynabearna, Ballinhassig, Co. Cork & $€ 5,000.00$ \\
\hline 96 & National Exotic Animal Sanctuary, Coolronan, Ballivor, Co. Meath & $€ 7,000.00$ \\
\hline 97 & New Ross SPCA, Ballyclemock, Foulksmills, Co. Wexford & $€ 14,800.00$ \\
\hline 98 & North County Dublin SPCA, 45 Millmount Avenue, Drumcondra, Dublin 9. & $€ 21,000.00$ \\
\hline 99 & *North Mayo Horse Sanctuary, Garden Street, Ballina, Co. Mayo* & $€ 1,000.00$ \\
\hline 100 & $\begin{array}{l}\text { North West Pet Protection T/A Donegal Pet Rescue, Drumabodan, Ramelton, Letterkenny, } \\
\text { Co. Donegal }\end{array}$ & $€ 18,000.00$ \\
\hline 101 & North West SPCA, Carrowreagh, Killala, Ballina, Co. Mayo & $€ 26,600.00$ \\
\hline 102 & North Wexford SPCA, 4 Glen Aoibhinn, Ardamine, Courtown, Co. Wexford & $€ 19,600.00$ \\
\hline 103 & Offaly SPCA, Market Place, Tullamore, Co. Offaly & $€ 19,000.00$ \\
\hline 104 & Paulines Rescue, Lauragh, Milford, Charleville, Co. Cork & $€ 10,000.00$ \\
\hline 105 & Paw Pourri, Lower Market Street, Ennis, Co. Clare & $€ 1,800.00$ \\
\hline 106 & Paws Animal Rescue, Mullinahone, Co. Tipperary & $€ 28,000.00$ \\
\hline 107 & Petwatch Ltd., 132 Rialto Cottages, Rialto, Dublin 8 & $€ 6,300.00$ \\
\hline 108 & Precious Paws Animal Sanctuary, Guilmore, Gurteen, Co. Sligo. & $€ 1,400.00$ \\
\hline
\end{tabular}




\begin{tabular}{|c|c|c|}
\hline 109 & Renvyle Cat and Dog Rescue, Tullycross, Renvyle, Connemara, Co. Galway & $€ 2,800.00$ \\
\hline 110 & Roscommon SPCA, P.O. Box 10, Castlerea, Co. Roscommon & $€ 17,300.00$ \\
\hline 111 & Roscrea SPCA, Rosemount House, Roscrea, Co. Tipperary & $€ 15,400.00$ \\
\hline 112 & Rosie Campbell T/A Animal Magic, Deebert Cottage, Kilmallock, Co. Limerick & $€ 7,400.00$ \\
\hline 113 & Rover Rescue, Tilly Cottage, Shanaway Road, Ennis, Co. Clare & $€ 3,600.00$ \\
\hline 114 & Rural Animal Welfare Resources Ltd (RAWR) Ratooragh, Schull, Co. Cork & $€ 11,000.00$ \\
\hline 115 & Seal Rescue Ireland, Seamount, Courtown, Gorey, Co. Wexford & $€ 6,500.00$ \\
\hline 116 & Second Chance Animal Rescue Ltd., 20 Sky Court, Shannon Town, Shannon, Co. Clare. & $€ 9,800.00$ \\
\hline 117 & Sligo Dog Welfare, Cullaghbeg, Drumcliffe, Co. Sligo & $€ 2,400.00$ \\
\hline 118 & South East Animal Rescue, Tomnalosset, Enniscorthy, Co. Wexford & $€ 4,000.00$ \\
\hline 119 & South Tipperary Dog Rescue, Farranacliffe, Mount Bruis, Co. Tipperary & $€ 1,500.00$ \\
\hline 120 & St. Francis Dispensary for Sick and Injured Animals, 101 Tyrconnell Road, Inchicore, Dublin 8 & $€ 9,600.00$ \\
\hline 121 & Sunset Appeal, Panwa,8 St. Martinas Park, Ballycullane, New Ross, Co. Wexford & $€ 2,500.00$ \\
\hline 122 & $\begin{array}{l}\text { The Cat and Dog Protection Association, Carmichael Centre, North Brunswick Street, Dublin } \\
7\end{array}$ & $€ 17,000.00$ \\
\hline 123 & The Donkey Sanctuary(Ireland) Limited, Knockardbane, Liscarroll, Mallow, Co. Cork & $€ 87,000.00$ \\
\hline 124 & The Equus Foundation, Punchestown Upper, Rathmore, Co. Kildare & $€ 4,200.00$ \\
\hline 125 & The Inner City Cat Rescue Group, 15 Ardilaun Square, Ballybough, Dublin 3 & $€ 2,700.00$ \\
\hline 126 & The Irish Blue Cross,15A Goldenbridge Industrial Estate, Tyrconnell Road, Inchicore, Dublin 8 & $€ 70,000.00$ \\
\hline 127 & The Sathya Sai Sanctuary Trust for Nature, Lower Cloghogue, Castlebaldwin, Co. Sligo & $€ 12,600.00$ \\
\hline 128 & The Wexford SPCA, The Vet Centre, Distillery Road, Co. Wexford & $€ 40,000.00$ \\
\hline 129 & Tipperary South SPCA, Savannah House, Clonmel, Co. Tipperary & $€ 13,600.00$ \\
\hline 130 & $\begin{array}{l}\text { Tipperary Friends of Animals SPCA, C/o Linda Hehir, Knockalton Upper, Nenagh, Co. } \\
\text { Tipperary }\end{array}$ & $€ 5,000.00$ \\
\hline 131 & Tipp-Off Animal Rescue, Ballykinash, Carrig, Birr, Co .Offaly. & $€ 10,000.00$ \\
\hline 132 & *TNR Roscommon, Cloondray, Mount Talbot, Co. Roscommon* & $€ 1,000.00$ \\
\hline 133 & Traveller Animal Welfare, Avon Hill Farm, Ballyknockan, Rathdrum. Co. Wicklow & $€ 5,400.00$ \\
\hline 134 & *Twin Towns Lost and Found Dogs, Cooladason, Killygordon, Co. Donegal* & $€ 1,000.00$ \\
\hline 135 & Waterford Animal Welfare,13 Seapoint, Riverstown Business Park, Tramore, Co. Waterford & $€ 12,000.00$ \\
\hline
\end{tabular}




\begin{tabular}{|c|l|l|}
\hline 136 & $\begin{array}{l}\text { Waterford Society for Prevention of Cruelty to Animals, Summerland Square, Yellow Road, } \\
\text { Co. Waterford. }\end{array}$ & $€ 23,000.00$ \\
\hline 137 & West Cork Animal Welfare Group Ltd., GortnaGrenane, Clonakilty, Co. Cork & $€ 12,000.00$ \\
\hline 138 & Westmeath SPCA, C/o Jorristown Lodge, Killucan, Co. Westmeath & $€ 12,000.00$ \\
\hline 139 & Westown Animal Shelter, Hidden Valley, Ballymore Eustace Horse Sanctuary, Co. Kildare & $€ 3,500.00$ \\
\hline 140 & Whiskers New Park Animal Sanctuary, Leatra, Williamstown, Co. Galway & $€ 4,200.00$ \\
\hline 141 & Wicklow Cats Rescue, 15 Broudlough View, Greenhill Road, Wicklow & $€ 1,200.00$ \\
\hline 142 & Wicklow SPCA, Sharepeshill, Ballygannon Mor, Rathdrum, Co. Wicklow & $€ 36,400.00$ \\
\hline & TOTAL & $€ 1,867,200.00$ \\
\hline
\end{tabular}




\section{Bibliography}




\section{Bibliography}

Aatola, E. (2011) 'The Philosophy behind the Movement: Animal Studies versus Animal Rights', Society and Animals, 19: 393-406.

Adams, C.J. (2000) The Sexual Politics of Meat: A Feminist-Vegetarian Critical Theory. New York: Continuum Press.

Agamben, G. (2004) The Open: Man and Animal. (trans. Kevin Attell) Stansford: Stansford University Press.

Agar, M. (2010) 'On the Ethnographic Part of the Mix: A Multi-Genre Tale of the Field’, Organizational Research Methods, 13 (2): 286-303.

Alger, J.M. and Alger, S.F. (2003) Cat culture: The Social World of a Cat Shelter. Philadelphia: Temple University Press.

Alger, J.M. and Alger, S.F. (1999) 'Cat Culture, Human Culture: An Ethnographic Study of a Cat Shelter’, Society and Animals, 7 (3): 199-218.

Alger, J. and Alger, F. (1997) 'Beyond Mead: Symbolic Interaction between Humans and Felines', Society and Animals, 5 (1):65-81.

Almquist, E.M, Angrist, S.S. and Michelsen, R. (1980) 'Women’s Career Aspirations and Achievements', Work and Occupations, 7 (3): 367-384.

Apopo (2014): A day in the life of a HeroRAT. Available at: http://apopo.org/en/show-video? (Accessed $6^{\text {th }}$ April 2014).

Archer, M.S. (2007) Making our way through the world: Human Reflexivity and Social Mobility. Cambridge: Cambridge University Press.

Arluke, A. and Rolfe, L. (2013) The Photographed Cat: Picturing Human-Feline Ties, 1890-1940. New York: Syracuse Press.

Arluke, A. (2006) Just a Dog: Understanding Animal Cruelty and Ourselves. Philadelphia: Temple University Press.

Arluke, A. (2001) 'Childhood origins of super-nurturance: The social contexts of early humane behaviour’, Anthrozoös, 16 (10): 3-27.

Arluke, A. and Sanders, C. (1996) Regarding Animals. Philadelphia:Temple University Press.

Arluke, A. (1994) 'Managing Emotions in an Animal Shelter'. In: Animals and Human Society. London: Routledge. 
Arluke, A. (1993) 'Bringing Animals into Social Scientific Research. Associate Editor’s Introduction’, Society and Animals, 1 (1): 5-7.

Alvesson, M. and Willmott, H. (1992) 'On the Idea of Emancipation in Management and Organization Studies', The Academy of Management Review, 17 (3): 432-464.

Alvesson, M. and Skoldberg, K. (2009) Reflexive Methodology: New Vistas for Qualitative Research. London: Sage, 2e.

Ascione, F. (2010) The International Handbook of Animal Abuse and Cruelty: Theory, Research and Application. West Lafayette: Purdue University Press.

Ascione, F. (1993) 'Children who are cruel to animals: A review of research and implications for developmental psychopathology’, Anthrozoös, (6) 4: 226247.

Ashforth, B.E and Kreiner, G.E. (1999) 'How can you do it? Dirty work and the challenge of constructing a positive identity', The Academy of Management Review, 24 (3): 413-434.

Ashkanasy, N. (2009) 'After thirty years: what does the future hold?', Journal of Organizational Behaviour, 30 (1): 15-20.

Atkinson, P., Coffey, A., Delamont, S. and Lofland, L. (2001) Handbook of Ethnography. London: Sage Publications.

Atterton, P. and Calarco, M. (eds) (2012) Animal Philosophy: ethics and identity. London: Continuum International Publishing.

Bain, R. (1928) 'The culture of canines', Sociology and Social Research, JulyAugust: 545-556.

Balcom, S.A. (2000) 'Legislating a Solution to Animal Shelter Euthanasia: A Case Study of California's Controversial SB 1785', Society and Animals, 8 (2): 122.

Balcombe, J. (1999) 'Animals \& society courses': A growing trend in postsecondary education', Society and Animals, 7 (3): 229-240.

Barlow, M.R., Hutchinson, C.A., Newton, K., Grover, T., and Ward, L. (2012) 'Childhood Neglect, Attachment to Companion Animals, and Stuffed Animals as Attachment Objects in Women and Men', Anthrozoös, 25 (1): 111-119. 
Baran, B.E, Rogelberg, S.G., Lopina, E.C., Allen, J.A., Spitzmüller, C and Bergman, M. (2012) 'Shouldering a silent burden: The toll of dirty tasks', Human Relations, 65 (5): 597-626.

Bauman, Z. (2014) What Use is Sociology? Conversations with Michael-Hviid Jacobsen and Keith Tester. Cambridge: Polity Press.

Beatson, R., Loughan, S., and Halloran, M. (2009) 'Attitudes toward Animals: The Effect of Priming Thoughts of Human-Animal Similarities and Mortality Salience on the Evaluation of Companion Animals', Society and Animals, 17: 72-89.

Becker, G.S. (2016) 'Human Capital', The Concise Encyclopedia of Economics: accessed $24^{\text {th }}$ July, 2016.

Becker, H. (1963) Outsiders: Studies in the Sociology of Deviance. New York: The Free Press.

Becker, H. I. (1986) Writing for Social Scientists. Chicago: University of Chicago Press.

Bekoff, M. (2007) The Emotional Lives of Animals. CA: New World Library.

Bekoff, M., ed. (2007) Encyclopedia of Human-Animal Relationships. Westport, CT: Greenwood Press.

Bell, E. and Taylor, S. (2004) 'From outward bound to inward bound: the prophetic voices and discursive practices of spiritual management development', Human Relations, 57 (4): 439-466.

Bell, E. and Taylor, S. (2003) 'The elevation of work: Pastoral power and the new age work ethic', Organization, 10 (2): 329-349.

Bellah, R.N. (2007) Habits of the heart: individualism and commitment in American life. CA: University of California Press.

Belsey, C. (2002) Critical Practice. New York: Routledge.

Bendien, E. (2013) 'The Last Stitch in the Quilt', Gender, Work \& Organization, 20: 709-719.

Benz, M. (2005) 'Not for the Profit, but for the Satisfaction? Evidence on Worker Well-Being in Non-Profit Firms', KYKLOS, 58 (2): 155-176.

Berg, J.M. and Grant, A.M. (2010) 'When callings are calling: crafting work and leisure in pursuit of unanswered callings',Organization Science, 21 (5): 973994. 
Berg, E. (2010)‘Women, Employment and Organizations’, Gender, Work \& Organization, 17: 113-115.

Berger, P. and Luckman, T. (1966) The Social Construction of Reality: A Treatise in the Sociology of Knowledge. London: Penguin.

Berger, J. (2008) Ways of Seeing. London: British Broadcasting Corporation and Penguin Books.

Beston, H. (1928) The Outermost House: A Year of Life on the Great Beach of Cape Cod. Doubleday, Doran and Co.

Binngießer, J., Wilhelm, C. and Randler, C. (2013) 'Attitudes toward Animals among German Children and Adolescents’, Anthrozoös, 24 (2): 191-202.

Birke, L., Hockenjull, J. and Creighton, E. (2010) 'The Horse's Tale: Narratives of Caring for/about Horses’, Society and Animals, 18: 331-347.

Birx, H.J. (2011) (ed) $21^{\text {st }}$ Century Anthropology: A Reference Handbook. CA: Sage.

Black, A.F., Winefield, H.R. and Char-Hansen, A. (2011) 'Occupational Stress in Veterinary Nurses: Roles of the work environment and own companion animal', Anthrozoös, 24 (2): 191-202.

Blau, P.M., Gustad, J.W., Jessor, R., Parnes, H.S. and Wilcock, R.C. (1956) 'Occupational Choice: A Conceptual Framework', Industrial and Labor Relations Review, 9 (4): 531-543.

Blau, P.M and Duncan, O.D. (1967) The American Occupational Structure. New York: Wiley.

Block, G. (2003) The Moral Reasoning of Believers in Animal Rights', Society and Animals, 11 (2): 160-180.

Blouin, D.D. (2012) 'Understanding Relations between People and their Pets', Sociology Compass, 6 (100): 856-869.

Blumer, H. (1969) Symbolic Interactionism: Perspective and Method. Berkeley, CA: University of California Press.

Bogdan, R. and Taylor, S. (1989) 'Relationships with severely disabled people: The social construction of humanness’, Social Problems, 36: 135-148.

Boezeman, E.J. and Ellemers, N. (2009) 'Intrinsic need satisfaction and the job attitudes of volunteers versus employees working in a charitable volunteer organisation', Journal of Occupational and Organizational Psychology, 82 (4): 875-914. 
Bolton, S.C. and Laaser, K. (2013) 'Work, employment and society through the lens of moral economy’, Work, Employment and Society, 27 (3): 508-525.

Bolton, S.C., Houlihan, M. and Laaser, K. (2012) 'Contingent Work and Its Contradictions: Towards a Moral Economy Framework', Journal of Business Ethics, 111: 121-132.

Bourdieu, P. (1993) The Weight of the World: Social Suffering in Contemporary Society. Stanford University Press.

Bourdieu, P. (1986) 'The Forms of Capital'. In J. Richardson (Ed.) Handbook of Theory and Research for the Sociology of Education. New York:Greenwood: 241-258.

Bourke, J. (2011) What it means to be Human: Reflections from 1791 to the Present. London: Virago.

Bradshaw, J. (2013) In Defence of Dogs: Why dogs need our understanding. London: Penguin.

Branchi, H. (2010) Justice as Sanctuary. 119 W Ave 97401: Wipf and Stock Publishers.

Brannan, M., Rowe, M., and Worthington, F. (2012) 'Time for a New Journal for New Times’, Journal of Organizational Ethnography, 1 (1): 5-14.

Briton, D.M and Logan, I. (2000) 'The Epistemology of the Gendered Organisation', Gender \& Society, 14 (3): 418-434.

Brown, D. (2002) Career Choice and Development. CA: Jossey-Bass and Wiley.

Brown, W. and Yoshioka, C. (2003) 'Mission attachment and satisfaction as factors in employee retention’, Nonprofit Management and Leadership, 14 (1): 5-18.

Brunner, J. (2002) Making Stories: Law, Literature, Life. Harvard University Press.

Bryant, C. (1979) 'The Zoological Connection: Animal-Related Human Behaviour', Social Forces, 58 (2): 399-421.

Buechener, F. (1973) Wishful Thinking: A Theological ABC. Harper One.

Bunderson, J.S. and Thomson, J.A. (2009) 'The call of the wild: zookeepers, callings and the double-edged sword of deeply meaningful work', Administrative Science Quarterly 54 (1): 32-57.

Burack, E.H. (1999) 'Spirituality in the workplace', Journal of Organisational Change Management, 12 (4): 280-291. 
Burawoy, M. (2013) 'Ethnographic fallacies: reflection on labour studies in the era of market fundamentalism', Work, Employment and Society, 27 (3): 526-536.

BVNA: UK Veterinary and Veterinary Nursing Professions RCVS 2010 Survey. Available at: www.bvna.org.uk (Accessed 1 June 2012)

Byström, K.M. and Landqvist, C.A. (2015) 'The Meaning of Companion Animals for Children and Adolescents with Autism: The Parents' Perspective', Anthrozoös, 28 (2): 263-275.

Cahusac, E, and Kanji, S. (2014) 'Giving Up: How Gendered Organizational Cultures Push Mothers Out’, Gender, Work \& Organization, 21: 57-70.

Cairns, K., Johnston, J. and Baumann, S. (2010) 'Caring About Food: Doing Gender in the Foodie Kitchen', Gender \&Society, 24 (5): 591-615.

Calarco, M. (2008) Zoographies: The Question of the Animal from Heidegger to Derrida. New York: Columbia University Press.

Cartwright, S. and Holme, N. (2006) 'The meaning of work: the challenge of regaining employee engagement and reducing cynicism', HRM Review, 16: 199-208.

Casaca, S.F. (2012) 'Behind smiles and pleasantness: working in the interactive service centre in Portugal', International Journal of Work Organisation and Emotion, 5 (1): 56-71.

Catton, W.R. and Dunlap, R.E. (1980) 'A New Ecological Paradigm for PostExuberant Sociology’, American Behavioural Scientist, 24 (1): 15-47.

Cerulo, K.A. (2009) 'Nonhumans in Social Interaction', Annual Review of Sociology, 35: 531-552.

Chalofsky, N. (2003) 'An emerging construct for meaningful work', Human Resource Development International, 6: 69-83.

Charles, N. (2016) 'Written and Spoken Words: Representation of Intimacy'. The Sociology Review, doi: 10.111/1467/954x.12376

Citizens Information (2016) Available at: www.citizensinformation.ie (Accessed $22^{\text {nd }}$ August, 2016)

Cody, M. (2015) 'New proposed rehoming policy for dog pound', Kilkenny People, February $11^{\text {th }}: 25$.

Cody, M. (2016) 'Sulky Racing now banned as new bylaws come into force'. Kilkenny People, April $20^{\text {th: }}: 25$. 
Conklin, T.A. (2012) 'Work Worth Doing: A Phenomenological Study of the Experience of Discovering and Following One's Calling', Journal of Management Inquiry, 21 (3): 298-317.

Conklin, T.A. (2012) E-mail to Anne O’Connor, 23 ${ }^{\text {rd }}$ July, 2012.

Cook, G. (2015) “A pig is a person” or "You can love a fox and hunt it” and tradition in the discursive representation of animals', Discourse Society, 26 (5): 587607.

Copeland, M.W. (2012) 'Literary Animal Studies in 2012: Where we are, where we are going', Anthrozoös (25) (Supplement): S91-S105.

Coren, S. (1995) The Intelligence of Dogs: A Guide to the Thoughts, Emotions, And Inner Lives of Our Canine Companions. New York: Bantam Books.

Corneo, G. and Olivier, J. (2010) 'Symbolic values, occupational choice, and economic development’, European Economic Review, 54 (2): 237-251

Coutinho-Sledge, P. (2015) 'Feminized Forestry: The Promises and Pitfalls of Change in a Masculine Organization', Gender, Work \& Organization, 22: 375-389.

Coveney, S. (2012) Interview on: Today with Pat Kenny, RTE Radio One, $7^{\text {th }}$ March 2012.

Crawford, M. (2009) The Case For Working With Your Hands: Why Office Work Is Bad For Us And Fixing Things Feels Good. London: Penguin.

Cresswell, J.W. (2009) Research Design: Qualitative, Quantitative, and Mixed Methods Approaches. London: Sage.

Crompton, R. (2006) Handbook of Gender and Women Studies. Sage: 245-271.

Csikzentmihalyi, M. (1990) Flow. The Psychology of optimal experience. New York: Harper \& Row.

Cullen, J. G. (2011) 'Researching workplace spiritualization through auto/ethnography', Journal of Management/Spirituality \& Religion, 8 (2): 143-164.

Cudworth, E. (2015) 'Killing animal: sociology, species relations and institutionalized violence', The Sociological Review, 63 (1): 1-18.

Curtis, E.A. (2007) 'Job satisfaction: a survey of nurses in the Republic of Ireland', International Nursing Review, 54 (1): 92-99. 
D’Alton, P. (2014) 'ISPCA to Pull out of Several Dog Pounds'. The Sunday Times, $7^{\text {th }}$ December, 2014.

Damon, W. (2003) The Joy of Living a Meaningful Life. (Audiobook) Templeton Foundation Press.

Darwin, C. (1859/1985) The Origins of Species. New York: Penguin.

Davies, B., Browne, J., Gannon, S., Honan, E. and Somerville, M. (2005) 'Embodied Women at Work in Neoliberal Times and Places', Gender, Work \& Organization, 12: 342-362.

Dawson, J. (2005) 'A history of vocation: tracing a keyword of work, meaning, and moral purpose', Adult Education Quarterly, 55 (3): 220-231.

Dayan, C. (2015) With Dogs at the Edge of Life. New York: Columbia University Press.

DeMello, M. (2012) Animals and Society: an Introduction to Human-Animal Studies. New York: Columbia University Press.

DeMello, M. (2000) Bodies of Inscription: A Cultural History of The Modern Tattoo Community. Durham, NC: Duke University Press.

Denzin, N.K and Lincoln, Y.S (2000) Handbook of Qualitative Research, $2^{\text {nd }}$ edition, Thousand Oaks, CA: Sage.

Denzin, N.K. (1989) Interpretive Biography. New York: Sage Publications.

Department of the Environment (2015) Available at: www.environ.ie (Accessed July $\left.2^{\text {nd }}, 2015\right)$.

Dewey, J. (1916) Democracy and Education: An Introduction to the Philosophy of Education. New York: Macmillan.

Dhiman, S. and Marques, J. (2011) 'The role and need of offering workshops and courses on spirituality', Journal of Management Development, 30 (9): 816835.

Dik, B.J., Eldridge, B.M., Steger, M.F. and Duffy, R.D. (2012) 'Development and Validation of the Calling and Vocation Questionnaire (CVQ) and Brief Calling Scale (BCS)', Journal of Career Assessment, 20 (3): 242-263.

Dik, B.J., Duffy, R.D. and Eldridge, B.M. (2009) 'Calling and Vocation in Career Counseling: Recommendations for Promoting Meaningful Work', Professional Psychology: Research and Practice, 40 (6): 625-632. 
Dobbins, T., Plows, A. and Lloyd-Williams, H. (2014) “'Make do and mend' after redundancy at Anglesey Aluminium: critiquing human capital approaches to unemployment, Work, Employment and Society, 28 (4): 515-532.

Dobrow, S.R. (2007) 'The Development of Calling: A Longitudinal Study of Musicians', Best Paper Proceedings of the Academy of Management Conference, Philadelphia.

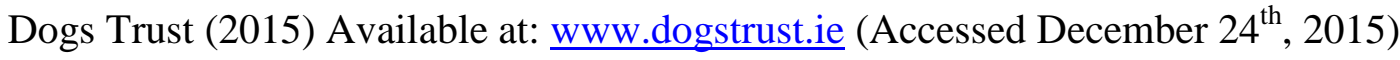

Dogs’ Tales (2016) TV3 Broadcast, August 19 2016.

Doloriert, C. and Sambrook, S. (2012) 'Organizational Autoethnography', Journal of Organizational Ethnography, 1 (1): 83-95.

Donovan, J. and Adams, C.J. (2007) Feminist Care Tradition in Animal Ethics. New York: Columbia University Press.

Donovan, J. and Adams, C.J. (1996) Beyond Animal Rights: A Feminist Caring Ethic for the Treatment of Animals. New York: Continuum.

Doty, M. (2008) Dog Years: A Memoir. London: Jonathan Cape.

Down, S. (2012) 'A historiographical account of workplace and organizational ethnography’, Journal of Organizational Ethnography, 1 (1): 72-82.

Downes, M.J., Clegg, T.A., Collins, D.M., McGrath, G. and More, S.J (2011) 'The spatial distribution of pet dogs and pet cats on the island of Ireland', BMC Veterinary Research. Open access research article. Doi:10.1186/1746-61487-28.

Drost, A. (2002) 'The Dynamics of Occupational Choice: Theory and Evidence', LABOUR, 16 (2): 201-233.

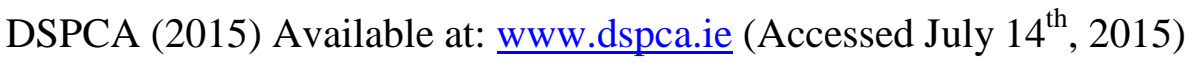

Duffy, R.D, Bott, E.M, Allan, B.A. and Dik, B.J. (2012) 'Perceiving a Calling, Living a Calling, and Job Satisfaction: Testing a Moderated, Multiple Mediator Model', Journal of Counselling Psychology, 59 (1): 50-59.

Duffy, R.D and Dik, B.J. (2012) 'Research on Work as a Calling: Introduction to the Special Issue’, Journal of Career Assessment, 20 (3): 239-241.

Duffy, R.D, Foley, P.F, Raque-Bodgan, T.L, Reid-Marks, L., Dik, B.J., Castano, M.C. and Adams, C.M. (2012) 'Counselling Psychologists Who View Their Careers as a Calling: A Qualitative Study', Journal of Career Assessment, 20 (3): 293-308. 
Duffy, R.D, Dik, B.J and Steger, M.F. (2011) 'Callings and work-related outcomes: Career commitment as a mediator', Journal of Vocational Behaviour, 78 (2): 210-218.

Duffy, R.D and Sedlacek, W.E. (2010) 'The salience of a career calling among college students: exploring group differences and links to religiousness, life meaning and life satisfaction', The Career Development Quarterly, 59 (1): 27-41.

Dunleavy, P. (2003) Authoring a PhD: How to plan, draft, write and finish a doctoral thesis or dissertation. New York: Palgrave MacMillan.

Dwyer, R.E. (2004) 'Downward Earnings Mobility after Voluntary Employer Exits', Work and Occupations, 31 (1): 111-139.

Ekman, K. (2010) The Dog. London: Little, Brown.

Elangovan, A.R., Pinder, C.C and McLean, M. (2010) 'Callings in Organizational Behaviour’, Journal of Vocational Behaviour, 76 (3): 428-440.

Elliot, A. (2010) (ed) The Routledge Companion to Social Theory. New York: Routledge.

Emerson, R.M., Fretz, R.I. and Shaw, L.L. (2011) Writing Ethnographic Fieldnotes. $2^{\text {nd }}$ edition. Chicago: The University of Chicago Press.

England, P. (2005) 'Emerging Theories of Care Work', Annual Review of Sociology, 31: 381-300.

Engman, J. (1998) Temporary Help. Holy Cow Press.

Engster, D. (2006) 'Care Ethics and Animal Welfare', Journal of Social Philosophy, 37 (4): 521-536.

Erikson, E.H. (1950) Childhood and Society. New York: Norton.

Fairclough, N. (1995) Critical Discourse Analysis: the critical study of language. Halrow: Pearson.

Fairholme, E.G. and Pain, W. (1924) A Century of Work for Animals: the History of the RSPCA 1824-1924. London: John Murray.

Ferguson, K.E. (1984) The Feminist Case Against Bureaucracy. Philadelphia: Temple University Press.

Ferguson, N. (2012) China: Triumph and Turmoil. Channel 4.

Fisher, C.D. (2010) 'Happiness at Work', International Journal of Management Reviews, 12 (4): 384-412. 
Flynn, C.P. (2000) 'Battered Women and Their Animal Companions: Symbolic Interaction Between Human and Nonhuman Animals', Society and Animals, 8 (2): 99-127.

Flynn, C.P.(2001) 'Acknowledging the "Zoological Connection": A Sociological Analysis of Animal Cruelty’, Society and Animals, 9 (1): 71-87.

Flynn, C.P. (2000) 'Battered women and their animal companions: Symbolic interaction between human and nonhuman animals', Society and Animals, 8 (2): 99-127.

Foar, J.S. (2009) Eating Animals. Little, Brown and Company.

Fogle, B. (1986) 'The bond between people and pets: A review', Veterinary Annual, 28: 361-365.

Folbre, N. (2001) The Invisible Heart: Economics and Family Values. New York: New Press.

Forfas (2009). Higher Education Authority. Available at: http://www.hea.ie/forfas/guidingprinciplesforsubmission/ (Accessed $4^{\text {th }}$ June 2012)

Fouad, N.A. and Byars-Winston, A. (2012) 'Cultural Context of Career Choice: Meta-Analysis of Race/Ethnicity Differences', The Career Development Quarterly, 53 (3): 223-233.

Foucault, M. (2001) Madness and Civilisation. London: Routledge Classics.

Foucault, M. (1980) Power/Knowledge. In: Selected Interviews and other writings 1972-1977, editor Gordon, C.

Frankl, V.E. (1959) Man’s search for meaning. Boston: Beacon Press.

Franklin, A., Tranter, B., and White, R. (2001) 'Explaining Support for Animal Rights: A Comparison of Two Recent Approaches to Humans, Nonhuman Animals, and Postmodernity', Society and Animals, 9 (2): 127-161.

Frey, B.S. (1997) 'On the relationship between intrinsic and extrinsic work motivation’, International Journal of Industrial Organisation, 15 (4): 427439.

Frey, B.S. (1997) Not just for the money: An Economic Theory of Personal Motivation. Cheltenham: Edward Elgar Press.

Fromm, E. (1997) To Have or to Be? New York: Continuum International Publishing Group. 
Frommer, S.S. and Arluke, A. (1999) 'Loving Them to Death: Blame-Displacing Strategies of Animal Shelter Workers and Surrenders', Society and Animals, 7 (1): 1-16.

Frost, R.O, Patronek, G. , Arluke, A. and Steketee, G. (2015) 'The hoarding of animals: an update', Psychiatric Times, 32 (4): 1-1.

Gaillie, D. (2007) Task discretion and job quality in employment systems and the quality of working life. Oxford: Oxford University Press.

Gaardner, E. (2011) Women in the Animal Rights Movement. NJ: Rutgers.

Gaarder, E. (2008) 'Risk \& Reward: The Impact of Animal Rights Activism on Women', Society and Animals, 16: 1-22.

Gabriel,Y., Gray, D.E., and Goregaokar, H. (2013) 'Job loss and its aftermath among managers and professionals: wounded, fragmented and flexible', Work, Employment \& Society, 27 (1): 58-72.

Gawande, A. (2014) Being Mortal: Illness, Medicine, and What Matters in the End. London: Profile Books.

Gee, N.R, Belcher, J.M., Grabski, J.L, DeJesus, M. and Riley, W. (2012) 'The Presence of a Therapy Dog Results in Improved Object Recognition Performance in Preschool Children', Anthrozoös, 25 (3): 289-300.

Geerth, H.H. and Wright-Mills, C. (2009) From Max Weber: Essays in Sociology. London: Routledge Press.

Geertz, C. (1973) The Interpretation of Cultures. New York: Basis Books.

Geertz, C. (1983) From the Native's Point of View: on the Nature of Anthropological Understanding. In: Further Essays in Interpretive Anthropology, New York: Harper: 19-35.

Gergen, K.J. (2009) An invitation to Social Construction. London: Sage Publications.

Gergen K.J. and Thatchenkery, T.J. (2004) 'Organization Science as Social Construction: Postmodern Potentials’, Journal of Applied Behavioural Science, 40 (2): 228-249.

Giddens, A. (2011) The Politics of Climate Change. $\left(2^{\text {nd }}\right.$ ed) London: Wiley.

Gilligan, C. (1982) In a Different Voice: Psychological Theory and Women's Development. Cambridge: Harvard University Press.

Giordan, G. (ed) (2007) Vocation and Social Context. Boston: Brill: 1-11. 
Goffman (1959) The Presentation of Self in Everyday Life. New York: Doubleday.

Gramsci, A. (1971) Selections from the Prison Notebooks of Antonio Gramsci. Eds: Hoare, Q. and Smith, G.N. New York: International Publishers.

Gray, J. (2003) Straw Dogs: Thoughts on Humans and Other Animals. London: Granta.

Greene, A. and Robbins, M. (2015) The Cost of a Calling? Clergywomen and Work in the Church of England', Gender, Work \& Organization, 22: 403-420.

Greenebaum, J. (2012) 'Managing Impressions: 'Face Saving' Strategies of Vegetarians and Vegans’, Humanity \& Society, 36 (4): 309-325.

Greenebaum, J. (2009)'I'm not an activist!": Animal Rights vs. Animal Welfare in the Purebred Dog Rescue Movement', Society and Animals, 17: 289-304.

Gregory, D. Johnston, R. Pratt, G. Watts, M.J. and Whatmore, S. (Eds) (2009) The Dictionary of Human Geography. Wiley-Blackwell.

Gregory, A. and Milner, S. (2009) 'Work-Life Balance: A Matter of Choice?', Gender, Work \& Organization, 16: 1-13.

Groves, J.M. (1997) Hearts and Minds: The Controversy Over Laboratory Animals. Philadelphia: Temple University Press.

Hackman, J.R. and Oldham, G.R. (1976) 'Motivation through the design of work: test of a theory'. Journal of Organizational Behaviour and Human Performance, 16: 350-365.

Haidt, J. (2006) The happiness hypothesis: finding modern truth in ancient wisdom. New York: Basic Books.

Hakim, C. (2002) 'Lifestyle Preferences as Determinants of Women’s Differentiated Labor Market Careers', Work and Occupations, 29 (4): 428-459.

Hall, S. (2003) Representation: Cultural Representations and Signifying Practices. Sage Publications: London.

Hall, D.T. and Chandler, D.E. (2005) 'Psychological Success: When the Career is a Calling', Journal of Organizational Behaviour, 26 (2): 155-176.

Hamilton, L. and Taylor, N. (2012) 'Ethnography in evolution: Adapting to the animal other in organizations', Journal of Organizational Ethnography, 1 (1): 43-51.

Hamilton, L. and Taylor, N. (2013) Human Animal Studies, Vol 16. Animals at work: identity, politics and culture in work with animals. Boston: Brill. 
Hammersley, M. and Atkinson, P. (1995) Ethnography Principles in Practice. London: Routledge, $2 \mathrm{e}$.

Hammersley, M. (2014) Handout prepared by Martyn Hammersley for the $7^{\text {th }}$ Qualitative Research School, Dublin City University, May 2014.

Hancock, A.N. (2012) 'IIt's a macho thing, innit?' Exploring the Effects of Masculinity on Career Choice and Development', Gender, Work \& Organization, 19 (4): 392-415.

Handlin, L., Hydbring-Sandberg, E. Nilsson, A., Egdebäck, M., Jansson, A., UvriäsMoberg, K. (2011) 'Short-term interaction between dogs and their owners: effects on oxytocin, cortisol, insulin and heart rate - an exploratory study', Anthrozoös, 24: 301-315.

Handy, C. (1993) Understanding Organisations, London: Penguin.

Hannah, D.R. and Robertson, K. (2016) 'Human-Animal Work: A Massive, Understudied Domain of Human Activity', Journal of Management Inquiry, June $27^{\text {th }}$ issue.

Harari, Y. (2014) Sapiens: A Brief History of Humankind. London: Harvill Secher.

Harbolt, T.L.(2003) Bridging the Bond: The Cultural Construction of the Shelter Pet. West Lafayette: Purdue University Press.

Harbolt, T.L. and Ward, T.H. (2001) 'Teaming Incarcerated Youth with Shelter Dogs for a Second Chance’, Society and Animals, 9 (2): 178-162.

Harris, D.A. and Giuffre, P. (2015) Taking the Heat: Women Chefs and Gender Inequality in the Professional Kitchen. Rutgers.

Department of Health (2015) http://www. health.gov.ie (accessed July 14 ${ }^{\text {th }}$, 2015).

Harvey, D. (1995) The Condition of Postmodernity. Oxford: Blackwell Publishers.

Herriot, J.(1998) All Creatures Great and Small. Mass Market Paperback.

Herzberg, F., Mausner, B., and Snyderman, B.B. (1959) The Motivation to Work. New York: John Wiley \& Sons.

Herzog, H.A. (2011) Some we love, some we hate, some we eat. New York: Harper Collins.

Herzog, H.A. and Golden, L.L. (2009) 'Moral Emotions and Social Activism: The Case of Animal Rights', Journal of Social Issues, 65 (3): 485-498. 
Herzog, H.A. (2007) 'Gender Differences in Human-Animal Interactions: A Review’, Anthrozoös, 20 (1): 7-21.

Higgins, G. (2010) 'A question of experience: Dewey and Gadamer on Practical Wisdom', Journal of Philosophy of Education, 44 (2): 301-333.

Hirschi, A. (2011) 'Callings in Career: a typological approach to essential and optional components', Journal of Vocational Behaviour, 79 (1): 60-73.

Hirschi, A. (2012) 'Callings and Work Engagement: Moderated Mediation Model of Work Meaningfulness, Occupational Identity, and Occupational SelfEfficacy’, Journal of Counselling Psychology, 59 (3): 479-485.

Hirschler, C.A. (2011) 'What Pushed Me Over the Edge Was a Deer Hunter: Being Vegan in North America', Society and Animals, 19: 156-174.

Hochschild, A. (2003) The Managed Heart-Commercialisation of Human Feeling. London: University of California Press.

Hofstede, G. (1991) Cultures and Organisations. Software of the mind. New York: McGraw-Hill.

Holland, J.L. (1973) Making vocational choices; a theory of careers. Englewood Cliffs, N.J.: Prentice-Hall.

Hotchkiss, L., Black, M.S., Campbell, R.E. and Garcia, G. (1979). 'Theories of Occupational Choice: A Critical Assessment of Selected Viewpoints', The National Centre for Research in Vocational Education, The Ohio State University.

Howard, V.J. and Reed, F.D. (2015) 'An Evaluation of Training Procedures for Animal Shelter Volunteers', Journal of Organizational Behaviour Management, 35 (3-4): 296-320.

Huang Xu, Van de Liert E.(2003) 'Where intrinsic job satisfaction fails to work: national moderators of intrinsic motivation', Journal of Organizational Behaviour, 24 (2): 159-179.

Hudson, L. (2011) 'A Species of Thought: Bare Life and Animal Being', Antipode, 43 (5): 1659-1678.

Humane Society NA (2015) Available at: www.humanesociety.org (Accessed June $\left.20^{\text {th }}, 2015\right)$.

Husso, M. and Hirvonen, H. (2012) 'Gendered Agency and Emotions in the Field of Care Work’, Gender, Work \& Organization, 19 (1): 29-51. 
Hutchinson, E.D. (2011) Dimensions of Human Behaviour: The Changing Life Course. Sage Publications, $4^{\text {th }}$ ed.

Hughes, E. (1958) Men and their work. Glencoe: Free Press.

Hunter, I. Dik, B.J and Banning, J.H. (2010) 'College students' perceptions of calling in work and life: a qualitative analysis', Journal of Vocational Behaviour, 76 (2): 178-186.

Husso, M. and Hirvonen, H. (2012) 'Gendered Agency and Emotions in the Field of Care Work’, Gender, Work \& Organization,19: 29-51.

Ingold, T. (1994) (ed) What is an animal ? London: Routledge.

Instone, L. and Sweeney, J. (2013) 'Dog Waste, Wasted Dogs: The Contribution of Human-Dog Relations to the Political Ecology of Australian Urban Space', Geographical Research, 52 (4): 355-364

Irvine, L. (2013) 'Animals as Lifechangers and Lifesavers: Pets in the Redemption Narratives of Homeless People', Journal of Contemporary Ethnography, 43 (1): 3-30.

Irvine, L. (2012) 'Sociology and Anthrozoology: Symbolic Interactionist Contributions’, Anthrozoös, (25) (Supplement): S123-S137.

Irvine, L. (2010) 'Gender work in a feminized profession. The Case of Veterinary Medicine’, Gender \& Society, 24 (1): 56-82.

Irvine, L. (2007) 'The question of animal selves: Implications for sociological knowledge and practice’, Qualitative Sociology Review, 3 (1): 5-22.

Irvine, L. (2004) 'A Model of Animal Selfhood: Expanding Interactional Possibilities’, Symbolic Interaction, 27: 3-21.

Irvine, L. (2004) If You Tame Me: Understanding Our Connection with Animals. Philadelphia, PA: Temple University Press.

Irvine, L. (2002) 'Animal Problems/People Skills: Emotional and Interactional Strategies in Humane Education', Society and Animals, 10 (1): 63-91.

International Society for Anthrozoology (ISAZ) Annual Conference, Cambridge The Arts and Sciences of Human-Animal Interaction, 11 to 13 July, 2011.

ISPCA (2015) Available at: http://www.ispca.ie (Accessed December 24 $4^{\text {th }}, 2015$ )

Irish Veterinary Nurses Association (2011) IVNA National Survey 2011. Available at: www.ivna.ie (Accessed 25 ${ }^{\text {th }}$ May, 2012) 
Jackson, N. and Carter, P. (2007) Rethinking Organisational Behaviour-A Poststructualist Framework 2e. Prentice-Hall.

Jacobsson, K. and Lindblom, J. (2013) 'Emotion work in animal rights activism: a moral-sociological perspective’, Acta Sociologica, 56 (1): 55-68.

Jerolmack, C. (2005) 'Our Animals, Our Selves? Chipping Away at the Human Animal Divide’, Sociological Forum, Vol 20: 651-660.

Jerolmack, C. (2009) 'Humans, Animals and Play: Theorizing Interaction When Intersubjectivity is Problematic', Sociological Theory, 27 (4): 371-389.

Jerolmack, C. (2013) The Global Pigeon. Chicago: University of Chicago Press.

Jerolmack, C. and Tavory, I. (2014) 'Molds and Totems: Nonhumans and the Constitution of the Social Self', Sociological Theory, 32 (1): 64-77.

Jobs. S. (2005) Address to Stansford graduates. Available at: www.youtube.com/stevejobs/stansford (Accessed 25th May, 2012)

Joyce, A. (2012) Personal communication to Anne O’Connor. IVNA conference. $19^{\text {th }}$ May, Mullingar.

Kamler, B. and Thomson, P. (2014) Helping Doctoral Students Write: Pedagogies for Supervision. London: Routledge.

Kean, H. (2012) 'Challenges for Historians Writing Animal-Human History: What is Really Enough?’,Anthrozoös, (25) (Supplement): S57-S72.

Kellert, S.R. and Wilson, E.O. (eds) (1993) The Biophilia Hypothesis. Washington, DC: Island Press.

Kellert, S.R. (1985) 'Attitudes toward animals: Age-related development among children', Journal of Environmental Education', 16 (3): 29-39.

Kendall, H.A. (2006) 'Public Concern with Animal Well-Being: Place, Social Stuctural Location, and Individual Experience', Rural Sociology, 71(3): 399428.

Kirby, P. (2008) The Social Sciences in Post-Celtic Tiger Ireland. Inaugural lecture, University of Limerick, February $25^{\text {th }}, 2008$. Available online. (accessed $7^{\text {th }}$ April 2013).

Kleinmann, S. (1984) Equals Before God: Seminarians as Humanistic Professionals. Chicago: The University of Chicago Press.

Knight, S. and Herzog, H.A. (2009) New Perspectives on Human Animal Interaction: Theory, Policy, and Implications. Wiley-Blackman. 
Krau, E.(1997) The Realization of Life Aspirations Through Vocational Careers, CT: Prager.

Krugman, P. (2008) The Return of Depression Economics and The Crisis of 2008. New York: Penguin.

Kruse, C.R. (2002) 'Social animals: Animal studies and sociology', Society and Animals, 10 (4): 375-379.

Kruse, C.R. (1999) 'Gender, Views of Nature, and Support for Animal Rights', Society and Animals, 7 (3): 179-198.

Kvale, S. and Brinkmann, S. (2009) Interviews: Learning the Craft of Qualitative Research Interviewing. CA: Sage Publications, $2^{\text {nd }}$ ed.

Lapointe, K. (2013) 'Heroic Career Changers? Gendered Identity Work in Career Transitions’, Gender, Work \& Organization, 20: 133-146.

Laaser, K. (2013) The moral economy of work and employment in banks. Available at: http://ethos.bl.uk (Accessed 15 ${ }^{\text {th }}$ November, 2015) Doctoral Dissertation.

Lassiter, L.E. (2005) The Chicago Guide to Collaborative Ethnography. Chicago: University of Chicago Press.

Latimer, J. (2013) 'Being Alongside: Rethinking amongst Different Kinds', Theory, Culture \& Society, 30 (7-8): 77-104.

Latour, B. (2005) Reassembling the Social: An Introduction to Actor-NetworkTheory. Oxford: Oxford University Press.

Latour, B. (1993) We have never been modern. (Translated by Catherine Porter) CA: Harvard University Press.

Lawrence, E.A. (1994) 'Seeing in nature what is ours: Poetry and the human-animal bond’, Journal of American Culture, 17 (4): 47-53.

LeCompte, M. and Schensul, J.J. (1999) Designing \& Conducting Ethnographic Research: 1 Ethnographer's Toolkit. CA: Altamira Press.

Levoy, G. (1997) Callings: Finding and following an authentic life. New York: Harmony Books.

Lewin, E. and Damrell, J. (1978) 'Female Identity and Career Pathways: PostBacculaureate Nurses Ten Years After’, Work and Occupations, 5 (1): 31-54.

Lewis, J.E. (2007) 'The Significant Life Experiences (SLES) of Humane Educators', Society and Animals, 15: 285-298. 
Lindenberg, S. (2001) 'Intrinsic Motivation in a New Light', KYKLOS, 54 (2): 317342.

Lim, C. and Laurence, J. 'Doing good when times are bad: volunteering behaviour in economic hard times’, British Journal of Sociology, 66 (2): 319-344.

Lipietz, A. (1993) Towards a New Economic Order: Post-Fordism, Ecology, and Democracy. Oxford: Blackwell Publishers.

Lips-Wiersma, M. (2002) 'Analysing the career concerns of spiritually oriented people: lessons for contemporary organizations', Career Development International, 7 (7): 385-397.

Lock, A. and Strong, T. (2010) Social Constructionism: Sources and Stirrings in Theory and Practice. New York: Cambridge University Press.

Locke, Edwin A. and Latham, Gary P.(2004) 'What should we do about motivation theory? Six recommendations for the twenty-first century', Academy of Management Review, 29 (3): 388-403.

Lowe, B.M. and Ginsberg, C.F (2002) 'Animal Rights as a Post-Citizenship Movement', Society and Animals, 10 (2): 203-215.

Luker, K. ( (2008) Salsa dancing into the Social Sciences: Research in an Age of Info-Glut. Harvard University Press.

Lupton,B. (2000) 'Maintaining Masculinity: Men who do “Women's Work”, British Journal of Management, 11 (s1): 33-48.

Lyotard, J-F. (1984) The Postmodern Condition: A Report on Knowledge. Trans. Bennington, G. and Massumi, B. Minnesota: University of Minnesota Press.

MacGregor, A. (2012) Animal Encounters: Human and Animal Interaction in Britain from the Norman Conquest to World War One. London: Reaktion.

Madden, A., Bailey, C. and Kerr, J. (2015) 'For this I was made': conflict and calling in the role of a woman priest', Work, Employment \& Society, 29 (5): 866-874.

Madison, D.S. (2005) Critical Ethnography: Method, Ethics and Performance. CA: Sage Publications.

Manwai, C. (2011) 'When Does Gender Matter? Gender Differences in Speciality Choice Among Physicans’, Work and Occupations, 38 (2): 221-262.

Markovits, A.S. and Queen, R. (2009) 'Women and the World of Dog Rescue: A Case Study of the State of Michigan', Society and Animals, 17: 325-342. 
Maslow, A.H. (1943) 'A Theory of Human Motivation’, Psychological Review, 50 (4): 370-396.

Maslow, A.H. (1971) The Further Reaches of Human Nature, New York: Penguin.

Massoon, J. and McCarthy, S. (1995) When elephants weep: the emotional lives of animals. New York: Delacorte Press.

May, T. (2011) Social Research: Issues, Methods and Process, 4e, McGraw-Hill.

Mead, G.H. (1934) Mind, Self and Society from the Standpoint of a Social Behaviourist. (Morrie, C. Ed) Chicago: University of Chicago Press.

Meier, S. and Stutzer, A. (2008) 'Is Volunteering Rewarding in Itself ?’, Economica, 75: 35-59.

Messner, S.F. (1980) 'Blau's Theory of Occupational Differentiation', Work and Occupations, 7 (4): 395-424.

Midgeley, M. (1993) Animals and Why They Matter. Athens, GA: The University of Georgia Press.

Miles, M. and Huberman, A.M. (2014) Qualitative Data Analysis: A Methods Sourcebook. CA: Sage Publications.

Miller, C.L. and Zawistowski, S. (2015) 'Housing, husbandry and behaviour of dogs in animal shelters', Animal Behaviour for Shelter Veterinarians and Staff. London: Wiley-Blackwell: 145-160.

Mills, D. (2014) Personal conversation, University of Lincoln.

Mitchell, L. (2012) 'Nonhumans and the Ideology of Purpose', Anthrozoös, 25 (4): 491-502.

Mizzoni, J. (2004) 'Perspectives on Work in American Culture', Journal of Interdisciplinary Studies, 16: 97-100.

Mortimer, J., Hall, R. and Hill, R. (1978) 'Husbands' Occupational Attributes as Constraints on Wives’ Employment', Work and Occupations, 5(3): 285-313.

Mumby, D.K. (1988) Communication and Power in Organizations: Discourse, Ideology and Domination. New Jersey: Ablex.

Myers, O.E., (2003) ' No Longer the Lonely Species: A Post-Mead Perspective on Animals and Sociology', International Journal of Sociology and Social Policy, 23 (3): 46-67.

Nacko, K. and Yanai, J. (2011) 'Dog-Resident Interactions in a Japanese Retirement Home’, Anthrozoös, 24 (2): 155-165. 
Nast, H.J. (2006) 'Loving...Whatever: Alienation, Neoliberalism and Pet-Love in the Twenty-First Century', ACME: An International E-Journal for Critical Geographies, 5 (2): 300-327.

NCPP (National Centre for Partnership and Performance) 2009. The National Workplace Surveys 2009. Available at: $\underline{w w w . i s s d a . i e}$ (Accessed $12^{\text {th }}$ March, 2012)

Nesbitt, R. (2012) 'The Influence of Major Life Cycle Events on Volunteering', Nonprofit and Volunteering Sector Quarterly, 41 (6): 1153-1174.

Neumann, S.(2011) ' Animal Welfare Volunteers-who are they and why do they do what they do?’, Anthrozoös 23 (4): 351-364.

Nibert, D.A. (1994) 'Animal Rights and Human Social Issues', The White Horse Press, 2(2): 115-124.

Nietzsche, F. (1879) (1984a). Human, all too Human. Trans. Marion Feber and Stephen Lehmann, Harmondsworth: Penguin.

Novak, M. (1996) Business as a Calling: Work and the Examined Life. New York: Free Press.

Nussbaum, M. (2000) Women and Human Development: The Capabilities Approach. Cambridge: Cambridge University Press.

O'Riain, S. (2014) The Rise and Fall of Ireland's Celtic Tiger: Liberalism, Boom and Bust. Cambridge: Cambridge University Press.

O'Riain, S. (2009) 'Extending the Ethnographic Case Study' in: The SAGE Handbook of Case-Based Methods, eds Byrne D. and Ragin, C.C. London: SAGE: 289-307.

O’Sullivan, S. and Bennison, R. (2011) 'Riding the Crest of Human-Animal Studies Wave', Society and Animals, 19: 333-336.

Oren, L. Tziner, A., and Caduri, A. (2013) 'Predicting Occupational Congruence: Self-Regulation, Self-Efficacy, and Parental Support', Journal of Career Assessment, 22 (2): 371-385.

Orwell, G. (1946) Animal Farm: A Fairy Story. New York: Harcourt, Brace and Company.

Pachirat, T. (2011) Every Twelve Seconds: Industrialised Slaughter and the Politics of Sight. Yale: Yale University Press.

Pallotta, N.R. (2008) 'Origin of Adult Animal Rights Lifestyle in Childhood Responsiveness to Animal Suffering', Society and Animals, 16: 149-170. 
Palmer, E. and Eveline, J. (2012) 'Sustaining Low Pay in Aged Care Work', Gender, Work and Organization, 19 (3): 254-275.

Parry, J., (2011) 'Sentimentality and the enemies of animal protection', Anthrozoös, 23 (4): 117-133.

Pavee Point (2016) Available at: www.paveepoint.ie (Accessed, April 19 ${ }^{\text {th }}, 2016$ )

Pedersen, I., Martinsen, E.W., Berget, B. , Braastad, B.O. (2012) 'Farm AnimalAssisted Intervention for People with Clinical Depression: A Randomized Controlled Trial', Anthrozoös, 25 (2): 149-160.

Peek, C.W., Nancy, J.B. and Dunham, C.C. (1996) 'Gender, Gender Ideology, and Animal Rights Advocacy’, Gender \&Society, 10 (4): 464-478.

Peggs, K. (2013) 'The Animal-Advocacy Agenda: Exploring Sociology for NonHuman Animals', The Sociological Review, 61 (3): 591-606.

Perlo, K. (2002) 'Marxism and the Underdog', Society and Animals, 10 (3): 304-318.

Peterson, C., Nansook, P., Hall, N. and Seligman, M.E.P. (2009) 'Zest and work', Journal of Organizational Behaviour, 30 (2): 161-172.

Phillips, M. (2014) 'Re-Writing Corporate Environmentalism: Ecofeminism, Corporeality and the Language of Feeling', Gender, Work \& Organization, 21: 443-458.

Philo, C. and Wilbert, C. (2000) Animal Spaces, Beastly Places. London: Routledge.

Pilgeram, R. (2007) 'Ass-kicking' Women: Doing and Undoing Gender in a US Livestock Auction’, Gender, Work \& Organization, 14: 572-595.

Polyani, K. (1957) The Great Transformation: The Political and Economic Origins of Our Time. Boston MA: Beacon Press.

Pope, C. (2014) Animal House. The Irish Times Magazine, April 26 2014.

Potts, A. and White, M. (2008) 'New Zealand Vegetarians: At Odds with their Nation', Society and Animals, 16: 336-353.

Pratt, M. and , Ashforth, B. (2003) 'Fostering meaningfulness in working and at work’. In: Cameron, K.S., Dutton, J.E. and Quinn, R.E., Positive organizational scholarship: Foundations of a new discipline. San Francisco: Berrett-Koehler Publishers.

Preylo, B.D. and Arikawa H. (2011) 'Comparison of vegetarians and nonvegetarians on pet attitude and empathy’, Anthrozoös, 23 (4): 387-395. 
Punch, K.F. (1998) Introduction to Social Research: Quantitative and Qualitative Approaches. London: Sage Publications.

Reeve. C.L., Rogelberg, S.G., Spitzmüller, C. and DiGiacomo, N. (2005) 'The Caring-Killing Paradox: Euthanasia-Related Strain Among Animal-Shelter Workers', Journal of Applied Psychology, 35 (1): 119-143.

Regan, T. (1983) The Case for Animal Rights. Berkeley, CA: University of Berkeley Press.

Ritchie, J. and Lewis, J. (eds) (2003) Qualitative Research Practice: A Guide for Social Science Students and Researchers. London: Sage.

Robson, C. (2002) Real World Research: A Resource for Social Scientists and Practitioner Researchers. London: Wiley.

Roper, J, Ganesh, S. and Inkson, K. (2010) 'Neoliberalism and knowledge interests in boundaryless careers discourse', Work, Employment and Society, 24 (4): 661-679.

Rosenfeld, R.A. (1979) 'Women’s Occupational Careers: Individual and Structural Explanations’, Work and Occupations, 6 (3): 283-311.

Rosso, B.D., Dekas, K.H and Wrzesniewski, A. (2010) 'On the meaning of work: a theoretical integration and review’, Research in Organizational Behaviour, 31: $91-127$.

Rovelli, C. (2014) Seven Brief Lessons on Physics. London: Penguin.

Rowlands, M. (2008) The Philosopher and the Wolf: Lessons from the Wild on Love, Death and Happiness. London: Granta Books.

Ryan, M., and Deci, E.(2000) ' Intrinsic and Extrinsic Motivations: classical definitions and new directions', Contemporary Education Psychology, (25): 54-67.

Safina, C. (2015) Beyond Words: What Animals Think and Feel. NY: Henry Holt and Company, LLC.

Safran Foer, J. (2009) Eating Animals. London: Penguin Books.

Sanders, C.R. (2010) 'Working Out Back: The Veterinary Technician and ''Dirty Work”, Journal of Contemporary Ethnography, 39 (3): 243-272.

Sanders, C.R. (2006) 'The Dog You Deserve: Ambivalence in the K-9 Officer/Patrol Dog Relationship', Journal of Contemporary Ethnography, 35 (2): 148-172. 
Sanders, C.R. (2003) 'Actions Speak Louder Than Words: Close Relationships between Humans and Nonhuman Animals', Symbolic Interaction, 26: 405426.

Sanders, C.R. (1995) 'Killing with Kindness: Veterinary Euthanasia and the Social Construction of Personhood', Sociological Forum, 10 (2): 195-214.

Sanders, C. and Arluke, A. (1993) 'If lions could speak: Investigating the animalhuman relationship and the perspectives of nonhuman others', The Sociological Quarterly, 34 (3): 377-390.

Sanders, C. (1993) 'Understanding dogs: Caretakers; attributions of mindedness in canine-human relationships', Journal of Contemporary Ethnography, 22 (2): 205-226.

Savickas, M. (2007) Occupational Choice. In: Handbook of Career Studies. Gunz, H.L. and Peiperi, M. (eds):79-97.

Sayer, A. (2004) Moral Economy. Published by the Department of Sociology, Lancaster University. Available at: http://www.comp.lancs.ac.uk/sociology/papers/sayer-moral-economy.pdf

Sayer, A. (2007) Moral economy and employment. In: Bolton and Houlihan (eds Searching for the Human in Human Resource Management: Theory, Practice and Workplace Contexts. London: Palgrave, 21-40.

Sayer, A. (2011) Why Things Matter to People: Social Science, Values and Ethical Life. Cambridge: Cambridge University Press.

Scheper-Hughes, N. (1992) Death Without Weeping: The Violence of Everyday Life in Brazil. Berkeley: University of California Press.

Schöberl, I. Wedl, M., Bauer, B., Day, J. Möstl, E., Kotrschal, K. (2012) 'Effects of Owner-Dog Relationship and Owner Personality on Cortisol Modulation in Human-Dog Dyads', Anthrozoös, 25 (2): 199-214.

Schwehn, M.R. and Bass, D.C (2006) Leading Lives That Matter: What We Should Do and Who We Should Be. Michigan: William B. Eerdmans Publishing Company.

Scully, M. (2002) Dominion: the Power of Man, the Suffering of Animals and the Call to Mercy. St. Martin's Press.

Seale, C., Gobo, G., Gubrium, J.F. and Silverman D. (eds) (2007) Qualitative Research Practice. London: Sage. 
Sealey, A. and Charles, N. (2013)' What Do Animals Mean to You?: Naming and Relating to Nonhuman Animals', Anthrozoös, 26 (4): 485-503.

Serpell, J. (1996) In The Company of Animals: A Study of Human-Animal Relationships. Cambridge, UK: Cambridge University Press.

Sewell, A. (2007) Black Beauty. Penguin Popular Classics.

Shamir, B. (1991) 'Meaning, Self and Motivation in Organizations', Organization Studies,12 (3): 405-424.

Shapiro, K. and De Mello, M. (2010) 'The State of Human-Animal Studies', Society and Animals, 18: 307-318.

Shields, C.M. (2007) Bakhtin. New York: Peter Lang.

Signal, T.D. and Taylor, N. (2006) 'Attitudes to Animals: Demographics Within a Community Sample’, Society and Animals, 14 (2): 147-274.

Singer, P. (1995) Animal Liberation. London: Pimlico Press.

Skeggs, B. (1997) Formations of Class and Gender: Becoming Respectable. London: Sage Publications.

Staats, S., Wallace, H., and Anderson, T. (2008) 'Reasons for Companion Animal Guardianship from Two Populations’, Society and Animals, 16: 279-291.

Steger, M.F, Kashdan, T.B. and Oishi, S. (2008) 'Being good by doing good: eudaimonic activity and well-being', Journal of Research in Personality, 42(1): 22-42.

Stern, D. and Eichorn, D. (eds) (1989) Adolescence and Work: Influences of Social Structure, Labor Markets and Culture. New Jersey: Routledge.

Stevens, P. (2012) 'Towards an Ecosociology’, Sociology, 46 (4): 579-595.

Stibbe, A. (2011) 'Language, Power and the Social Construction of Animals', Society and Animals, 9 (2): 145-161.

Stinchcombe, A.L. (2000). 'Liberalism and Collective Investments in Repertoires, The Journal of Political Philosophy, 8 (1): 1-26.

Sugawara, A., Masud, M.M., Yokoyama, A., Mizutani, W., Watanuki, S., Yanai, K., Itoh, M., and Tashiro, M. (2012). 'Effects of a Presence of a Familiar Pet Dog on Regional Cerebral Activity in Healthy Volunteers: A Positron Emission Tomography Study’, Anthrozoös, 25 (1): 25-34.

Super, D.E. (1980) 'A life-span, life-space approach to career development', Journal of Vocational Behaviour, 16 (3): 282-298. 
Taylor, N. (2010) ' Animal Shelter Emotion Management: A Case of in situ Hegemonic Resistance?', Sociology, 44 (1): 85-101.

Taylor, N. (2007) ' Never an It': Intersubjectivity and the creation of animal personhood in animal shelters', Qualitative Sociology Review, 3 (1): 59-73.

Taylor, N. (2004) 'In it for the Non-human Animals: Animal Welfare, Moral Certainty, and Disagreements', Society and Animals, 12 (4): 317-339.

Terkel, S. (1972) Working. New York: Pantheon Press.

Thompson, E.P.(1971) 'The Moral Economy of the English Crowd in the Eighteenth Century', Past and Present, 50: 76-136.

Tippet, J.and Kluvers, R.,(2009) 'Employee rewards and motivation in non profit organisations: case study from Australia', Journal of Business and Management, 4 (3): 7-14.

Tovey, H. (2003) 'Theorising Nature and Sociology: The Invisibility of Animals', Sociologia Ruralis, 43 (3): 196-215.

Tracey, M. (2015) 'ISPCA boss gives reasons for withdrawing from dog pound', The Nationalist, $10^{\text {th }}$ February: 2.

The Guardian (2015) Available at: www.the.guardian/environment. 'Cecil the Lion'. (Accessed December 24 $4^{\text {th }}, 2015$ ).

Tuan, Y. F. (1984) Dominance and Affection: The Making of Pets. New Haven: Yale University Press.

Turner, T. and McMahon, J. (2011) 'Women's Occupational Trends in the Irish Economy: Moving towards High-skilled Occupations or Evidence of Deskilling?', Gender, Work and Organization, 18 (81): 222-240.

Ulrich, D. and Ulrich, W. (2010) 'Getting beyond engagement to creating meaning at work’: Blog. Available at: http://blogs.hbr.org (Accessed 1st December, 2011)

Van Maanen, J., Sorenson, J.B. and Mitchell, T.R. (2007) 'The Interplay between Theory and Method', Academy of Management Review, 32 (4): 1145-54.

Voorhoeve, A. (2009) Conversations on Ethics. Oxford: Oxford University Press.

Vroom, V.H. (1964) Work and Motivation. New York: Wiley.

Walsh, N. (2016)) 'Celebrities take stand against puppy farmer'. The Irish Mail on Sunday, August 28 ${ }^{\text {th }}$, 2016: 30.

Warr, P. (2002) Psychology at work. London: Penguin, 5e. 
Waterman A.S. (2005) 'When Effort is Enjoyed: Two Studies of Intrinsic Motivation for Personally Salient Activities’, Motivation and Emotion, 29 (3): 165-188.

Weber, M. (2009) 'Science as a Vocation'. In: Gerth., H.H and Wright Mills, C. From Max Weber: Essays in Sociology. London: Routledge Press.

Weber, M. (2009) 'Politics as a Vocation'. In: Gerth., H.H and Wright Mills, C. From Max Weber: Essays in Sociology. London: Routledge Press.

Weber, M. (2009) 'The Protestant Sects and the Spirit of Capitalism'. In: Geerth., H.H and Wright Mills, C. From Max Weber: Essays in Sociology. Routledge Press.

Weber, M. (1992). The Protestant Ethic and the Spirit of Capitalism. London: Routledge.

Weber, M. (1947) The Theory of Social and Economic Organization. New York: Free Press.

Weiss, R.M. (2000) 'Taking Science out of Organization Science: How Would Postmodernism Reconstruct the Analysis of Organizations?', Organization Science, 11 (6): 709-731.

Wels, H. (2015) “Animals like us”: revisiting organizational ethnography and research', Journal of Organizational Ethnography, 4 (3): 242-259.

West, C.W. and Zimmerman, D.H. (1987) 'Doing Gender', Gender and Society, 1(2): 125-151.

Wilde, L. (2000) 'The Creatures too, must become free: Marx and the Animal/Human Distinction', Capital and Class, 24 (3): 37-53.

Wilkie,R. (2015) 'Multispecies Scholarship and Encounters: Changing Assumptions at the Human-Animal Nexus', Sociology, 49 (2): 323-339.

Wilkie, R. (2013) 'Academic“dirty work”. Mapping scholarly labor in a tainted mixed species field', Society and Animals, 23 (3): 211-230.

Wilkie, R. and McKinnon, A. (2013) 'George Herbert Mead on Humans and Other Animals: Social Relations After Human-Animal Studies', Sociological Research Online, 18 (4) 19 http://www.socresonline.org.uk/18/4/19.html)

Wilkie, R. (2010) Livestock/Deadstock: Working with Farm Animals from Birth to Slaughter. Philadelphia: Temple University Press.

Wilson, C.C. and Nettling, F.E. (2012) 'The status of instrument development in the Human-Animal-Interaction field’, Anthrozoös, Supplement, 25: S11-S55. 
Wolcott, H.F. (1994) Transforming Qualitative Data: Description, Analysis, and Interpretation. CA: Sage Publications.

Wood, L.J., Giles-Corti, B., Bulsara, M.K. and Bosch, D.A. (2007) 'More Than a Furry Companion: The Ripple Effect of Companion Animals on Neighbourhood Interactions and Sense of Community', Society and Animals, 15: 43-56.

Woodham-Smith, C. (1962) The Great Hunger: 1845-1849. Penguin Books.

Wrzesniewski, A. and Dutton, J.E. (2001) 'Crafting a job: revisioning employees as active crafters of their work', Academy of Management Review, 26 (2): 179201.

Wrzesniewski, A. (2002) 'It's not just a job: shifting meanings at work in the wake of 9/11', Journal of Management Inquiry, 11: 230-234.

Wrzesniewski, A., McCauley, C. et al (1997) 'Jobs, Careers and Callings: People’s Relations to Their Work', Journal of Research in Personality, 31:21-33.

Wuthnow, R. (2006) in: Schwehn, M.R. and Bass, D.C (2006) Leading Lives That Matter: What We Should Do and Who We Should Be. Michigan: William B. Eerdmans Publishing Company.

Yanow, D. (2012) 'Organizational Ethnography: Between Toolkit and WorldMaking’, Organizational Ethnography, 1 (1): 31-42.

Zelizer, V.A. (2012) 'How I Became a Relational Economic Sociologist and What Does That Mean, Politics and Society, 40 (2): 145-174.

Zuboff, S. (1988) In the Age of the Smart Machine: The Future of Work and Power. Basic Books. 